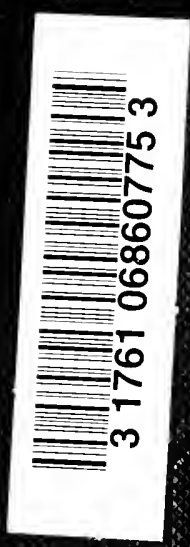





\section{Digitized by the Internet Archive in 2007 with funding from Microsoft Corporation}





\section{PAIN, PLEASURE, AND ESTHETICS}




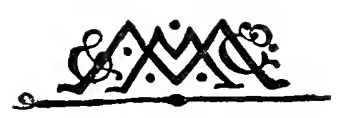


M368p

\title{
PAIN, PLEASURE, AND
}

\section{ÆSTHETICS}

\author{
AN ESSAY
}

CONCERANG THE PSTCHOLOGY OF PAIN

ANI) PLEASTRE, WITH SPECTAL

REFERENCE TO ASTHETICS

HENRY RUTGERS MARSHALL, M.A.

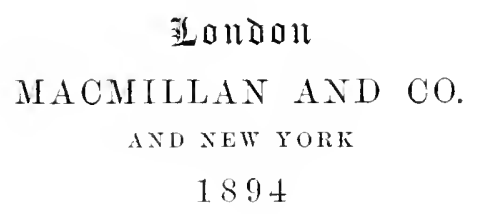

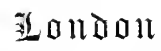
MACMILLAN AND CO. AND NEW YORK 1894

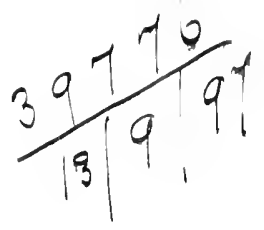





\section{PREFACE}

WHEN first I undertook the study of the theory of Art, many years ago, I was impressed by the emphasis of pleasure attaimment in all descriptions of art works, and by the emphatic pleasurableness of my own mental state during the contemplation of artistic productions.

My thought being thus turned to the consideration of the relation of resthetics to hedonics, I was led to make a careful study of the psychology of pleasure and of its correlate pain: the results of this study I here lay before those who may be interested.

This book has been long in preparation. It camnot in any sense be said to be a compilation, although I have alrealy published in Mind the outline of certain portions of the arguments here presented, with the hope thus of obtaining criticism and an interchange of views with others. I count it one of the rewards of my labour that I was thus led to feel the inspiriting influence of the late Professor Croom Robertson's personality. His death has been felt by me as a personal loss, as it has been by all psychologists, even where, as in my own case, circumstances necessarily limited 
personal acquaintance and intercourse. To his kindly encomragement I owe much; more indeed than to any other, except to that closest friend of my life, no longer with us, without whose sympathetic interest this book conld not have been written.

To express my obligations to the many masters from whom I have learned would be impossible. I feel impelled, however, to acknowledge the especial service rendered to me by Mr. Sully's thorough reviews of resthetic history, and his clear treatment of the problems involved.

The field I attempt to cover sadly needs illumination, as is evidenced by the acknowledged omission of all discussion of resthetics and of pleasure-pain theory in Professor James's large and valuable work on psychology, recently published.

The difficulty of stating a theory, in any degree new, without the coining of words is always great, and especially is this so in psychology, which is much hampered by its limited and indeterminate terminology. I have restrained myself, however, from the temptation to invent terms except

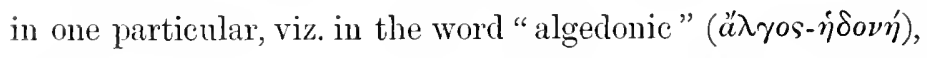
which I use adjectively to describe any phase of painpleasure experience; see p. 9 . I hope this daring will be pardoned in consideration of the evident value of the word for my purpose.

I have been compelled to deprive myself of the use of certain words merely because of the indefiniteness of their comnotations, or because of special, and from my standpoint incorrect, meanings attached to them by authorities. 
Feeling is such a word. It should be and is commonly used in a wide sense, but has been lately limited by some authorities to relate solely to pain and pleasmre phenomena. The restrictions implied in the aroidance of such words compel circumlocutions at times which I must beg the reader to overlook.

I trust that I have not given false emphasis to any argument that favours the positions I defend, where controversial treatment of others' views has seemed necessary; and that my work, however it may fail, will be recognised as aiming to bring us nearer to a true comprehension of the mental phenomena under discussion.

New Yonk, June 1893. 



\section{CONTENTS}

\section{INTRODUCTION}

Art axd Science . . . . . . . . P xi

\section{CHAPTER I}

The Psychological Classification of Pleasure and PAIN

CHAPTER II

Instincts And Emotions-The Art Impulse and the

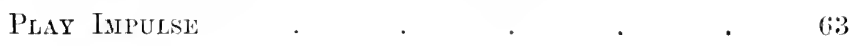

\section{CHAPTER III}

The Fiedd of Esthetics $\quad$. . . . . 106

\section{CHAPTER IV}

The Physical Basis of Pleascre hnd Pain-I. . 167 


\section{CHAP'TER V}

The Physical Basis of Pleasure and Pain--II. . 217

APPENDIX 1.-Pains OF Restriction . 272

APPENDIX II.-Detalls of ENIDENCE . . 283

\section{CHAPTER VI}

Algedonic Esthetics . $\quad . \quad$. $\quad . \quad 2 \quad . \quad 299$

\section{CHAPTER VII}

Gexernl Sumdary and Results . . . . . 346 


\title{
IN'TRODUCTION
}

\author{
ART ANU SCIENCE
}

A GLANCE at the table of contents of this volume will make it evident to the reader that it deals principally with problems of Psychology. A book that contains on its titlepage the word "Asthetics" will, however, be expected to appeal in some manner to the artist. The psychologist needs no other incentive than the scientist's curiosity to lead him to look through the pages which follow, provided he finds indications that his science is aided in any manner. But the artist, at the mere mention of psychology, will be apt to lay the book aside; and as I have some faint hope that I may help him or the eanse which he has most at heart, I must beg him, even if he go no farther, to give a hearing to this introduction, in which I shall try to state as briefly as possible my notion of the relation that exists between art and science. This statement will indicate the point of view taken in the work to follow, and will bring into emplasis some facts which seem to me to be valuable to both artist and scientist.

That a sentiment of antagonism exists between the average artist and the average seientist I think must be taken for granted, and I shall ask why it exists, and whether it is reasonable. Is there not some misunderstanding be- 
tween the two classes of men which may be cleared away? May it not be possible thus to bring about an increasect harmony and effectiveness in the work of both scientist and artist?

First, then, let us ask, What is the basis of the antagonism?

I think it will be agreed at the start that the mental attitudes of the scientist and of the artist are themselves diverse in character.

The scientist is pre-eminently a searcher: he is aggressive; the artist is distinctly a listener and a follower of the commands of an inner voice.

Scientists, as we well know, are liable to exaggerate the importance of their work: few indeed are those great souls among them who see beyond the details of investigation, and realise the great importance of the problems which transcend their powers. The average votary of science is filled with self-confidence, aronsed less by any notion that he knows all things himself than by a firm belief that he is on the path which leads to fulness of knowledge and power, and that he is the representative of a mistress omniscient and ommipotent. This self-confidence of the scientist is repulsive to the artist-the listener and follower-who has long and wearily striven to express the leadings of the inner voice, and who appreciates how he has failed, with all his effort, to picture worthily his inspiration. The claim that we could reason art products into existence, were we clever enough, seems to him preposterous, and so far as he can see such is the claim an resthetic science wonld make.

On the other hand, the active, energetic scientist who is treating of facts given to him in nature is liable to look with some little contempt upon the artists, whom he thinks of as dreamers, and whose waywardness he altogether deprecates.

That this difference of mental attitude, however, does not 
justify the existence of the hostility under consideration becomes evident if we look a little deeper. In the first place, it is apparent that the attitude of the listener and expresser of the commands of the imner voice, which is marked in the artist, is, in fact, shared to some extent by every man of talent in every walk of life. So far as a man is in any degree a genius, it is because an inner voice, which he cannot account for, and which is not heard by others, has guided him in new, untrodden paths. The strictest scientist reaches but a little way so long as he merely accumulates facts: his triumphs come when, by some "inspiration," a vision of relations between these facts is revealed to him.

Science, surely, can bear no grudge against the imagination; on the contrary, her main dependence is upon the imagination, to which she looks for those hypotheses which serve as the incentive to experiment, without which there were no scientific advance. As Tyndall" says, "Nourished by knowledge patiently won, bounded and conditioned by co-operant reason, Imagination becomes the mightiest instrument of the physical discoverer."

But beyond this, the scientist is deeply indebted to artistic genius: like all other men, he gains the joys of life in regions which are distinctly asthetic in the wide sense in which we shall find we must use the word, and clearly shonld not underestimate the value of what is so important a part of his life.

In similar manner we find the artist's development dependent upon the very qualities which are in more emphatic degree distinctive of the scientist; and furthermore we find him at every turn making use of the results of the

${ }^{1}$ The Scientific Usc of the Imagination, 1. 6. Cf. also James Sully, The Human Mind, i. p. $374 \mathrm{f}$. 
scientist's labours in the past, and often in an unsystematic way adopting his methods of technical discovery.

This second point need not detain us, and therefore may best be illustrated at once. I may mention as a typical example the use of perspective, without which the pictorial artist of to-day camnot do his work; but perspective is evidently a purely mathematical science in its origin, and although certain short cuts are used commonly which are not reasoned out, perspective itself cannot be used effectively apart from a clear knowledge of the principles involved. One has but to compare the drawing of Diirer's day and of Tadema's to see how much this special science has affected art. It is interesting to note in this connection that among the Frenchmen who have taken to themselves the name "impressionists" [a term which really should have a fuller application], the "pointillists," Dubois-Pillet and Seurat, are found studying as they work, the one from Rood's theory of colours, the other from Chevrenl's writings on simultaneous contrast. It is not necessary to multiply examples in this direction, and we may well turn back to consider the dependence of art upon those qualities which seem to be distinctively scientific.

Science, in its essence, is but the orderly arrangement of human experience; and surely the experience of our ancestors is made use of daily in art method and practice. No age has given more study to ancient art than ours is giving. At no time have artists turned more attention to the old masters than in our own day. It is apparent, therefore, that resthetic method is in reality developing in line with the body of science, although the crudeness of its form prevents the general recognition of its relation to what we call science. A further view makes this clearer.

As we look back at the great epochs of art, at the styles they produced, the schools they founded, we see the outcome 
of development and of accumulated racial experience which has lasted through generations. The youth of one generation found its art environment of those art products which had been sifted out as the best by the generations that had preceded its own. He stepped from this educational standpoint to victories made possible because his vigour was not used up in treading again the laborions path, filled with failures, which his ancestors had taken. And if the use of crudely recorded experience through unconscious means has gained such triumphs, what might not be the gain under systematic arrangement of experience, especially needful in these times when stability of conditions is so rare that racial transfer of experience is less to be relied upon?

The artist, however, often takes a stronger attitude of hostility than that which we have been discussing. He feels science to be an open enemy. He clains that the scientific spirit never goes with artistic production : that attention to the scientific aspect of things prevents artistic productivity and appreciation, and he is likely to bring confessions like Darwin's to witness in his favour.

It is true that extreme effort in any one direction implies a curtailment of effort in all others, and that a man or an age given pre-eminently to activities which are not artistic will not give the world great art products; but this gives no more logical gromul for contention against scientific than agrainst any other extreme activity-socialistic or political, for instance. Notable examples of art-masters who were eminent as widely versed in the knowledge of their times, the Leonardo da Vincis, the Goethes, rise to disprove the position that scientific attainment per se incapacitates a man from being a producer in art.

It is true, also, that eonstant and exelusive eoncentration of thought in one special direction will lead to curtailment of 
capacity, and of pleasure-getting, in those directions not especially connected with the chosen path. But this implies a shifting of resthetic field, as we shall see later, rather than its loss. It is the price an ardent specialist like Darwin must pay for the success he wins. It is a loss of joy in the inpressions that give resthetic delight to the average highly educated man among his companions-a joy that he himself, perhaps, used to reach in sympathy with them: his mental life and capacities, and his æesthetic field, have shifted to regions in which but few of his fellows can follow him.

The hostile attitude not infrequently voices itself in objection to the intellectual, critical treatment of æsthetic subjects in general, on the ground that such treatment is likely to curtail art production of high grade.

It is rather remarkable, we may note in passing, that such a notion should exist among artists when we consider how many theorists of the highest position among those who speak our tongue (and still more so is it among the Germans), have based their resthetic theories upon fundamentals which are entirely intellectual : where clear vision seems lacking, the very best of them (Kant, for instance) have adopted, with little hesitaney, the theories of subconscious intellectual action as satisfactory to account for æesthetic values.

The study of art history, it must be confessed, has tended to substantiate this notion of the inverse relation of art production to intellectual consideration of asthetic matters; for as it shows ages which are unproductive of art work of high value, it seems also to show that the age of non-production has often been one of devotion to pure critical for'malism.

It seems to me that it might better be claimed that the studious age has been the parent of the productive one; but the facts are in all probability acconnted for not by any lack 
of eritical spirit during the ages of great art outcome, but by the emphasis of eritical work which the absence of notable art production brings into prominence.

Guyau, judging the lack of art product to be due to the approaching death of a social age, looked upon it as a sign of loss of the excessive vigour which is necessary to the appearance of genius. This last explanation is doubtless true, whether the loss be found to be due, as he thinks, to social disease, or even if it be traceable to over-emphasis of scientific or any other concentrative activity. For, as we have already seen, any exclusive work will curtail effective activities in other directions. This, however, is apparently little more than a statement of the limits of capacity-an acknowledgment, in fact, of relative incapacity. Surely we should not let these facts lead us to a position which would leave incapacity in control, and which would by discouragement of intellectual treatment of art subjects virtually deprive skill of its best tools; for it is certainly elear that to science and scientific method of analysis, systematic or unsystematic, the artist owes much in the past, and from them we may hope to gain much in the future.

This cursoly view of the sitnation evidently indicates that the antagonism between artist and scientist is not fundamental. If this be so, there is ground for hope that the two may be brought together if the basis of the misunderstanding between them is made clear.

The scientist displays less of the antipathetic spirit; but for all that is, in my view, more at fault in this disagreement. As we have alrearly said, science tends to be arrogant: she claims to rule, and has a way of looking down upon those who do not follow her ways, as though she had grasped the full meaning of the universe. But this the artist does not acknowledge for a moment; and rightly does 
he protest. He holds that he hears voices and has visions which tell of realms in which science can have no power, and concerning which she can teach him nothing. In this he is certainly correct; and what is more, the widest-minded scientists appreciate the truth of the artist's claim. Perhaps the artist exaggerates the self-complacency of science, but it seems to me clear that humility is the lesson for science to learn in this particular. She must be willing in this regard to take second place: she must be content to deal principally with logical arrangements of what is and has been, and to teach such lessons as she can deduce therefrom. Her work for art must always be to a great extent negative. If she teach us what have been the principles which advancing art has shown, it is to enable the artist to avoid carelessly putting out effort in directions opposed to these principles which have guided in the past. If she show us some necessary relation of the phenomena with which the artist deals, it is that he may learn not to waste effort in vain encleavour to treat his subjects in a mamner contrary to these necessities. The anatomist teaches the artist what the relations of bone and muscle and tendon are in the physical framework, so that with help from this source of knowledge he may create his ideal form without the dissatisfactions which go with the presentation of false anatomical relations. The mathematician teaches perspective that the artist may naturally avoid disturbing anti-perspective errors, into which he might fall in his enthusiastic concentration upon the expression of his ideal. Science must always follow where creative genius leads, in whatever direction it is developed.

The province of science (apart from the work of scientific genius) is to bring the productions of genius into such relation with our life that we may ourselves in some measure use the fire she kindles to lighten our path. If 
science will but learn her lesson of humility as regards resthetic genius, more than half the battle is won.

But art must also acknowledge more fully her indebtedness to Science in the past, and must make evident more fully her desire to be a learner to-day and always. Width of perception beyond the immediate sphere of his work, and yet through the deeper senses which his special work has cultivated, is an essential characteristic of the genius in every line of effort. If the artist camot look to science as his leader, he can trust her as a valued adviser, who shall warn away from pitfalls in which others have been lost, and shall teach him how to work and how to learn most easily, so that the maximum of his force may be available for the expression of his ideal. It is for the artist as for all other men: the wider his knowledge and experience of the world, the more effective will be his chosen work, provided he does not allow his study to break up his habit of concentrated impulsive energising in his art expression.

All men must learn to take as well as to give. We camnot continually be students; if we are to study to the best advantage, we must alternate with this study the activities it makes possible: and similarly we cannot always be expressing ourselves artistically; we need to absorb constantly and in all directions from the highest movement of the world in which we live, if we wish to be masters in any line whatever. We onght not to encourage any erlucational habit which would lead the art student to any cxclusive, absorbing attention to matters apart from his special work, whether this complete attention be given to the scientific or to any other aspect of things; for as we lave seen above, attention in one direction necessarily curtails all other activities : but the encouragement among artists of the study of resthetics as a science does not imply this error. A man whose genins is artistic will never be led away by 
scientific concentration. If a student is led away from artistic concentration by this study, then surely it is evident that his talent is scientific and not artistic; and as surely the world will be a gainer in the sequel. Artists of very mediocre talent abound and multiply; it certainly were well if some of them were brought to see that they can do more effective service for the world and for art by devoting their energies to artistic investigation than to artistic production.

If I have gained the attention of my artist reader by this explanation of my standpoint, I would say to him another word. In what follows there will be found a great deal of technical psychology which I think he will scarcely care to follow, even if he has found time to acquaint himself with the rapid movements of the science of mind sufficiently to enable him to do so. Certain of the conchusions which I reach will perhaps be interesting to him, however, as preliminary to the chapters which especially relate to his subject; and in order to aid in following the drift of the argnment, I have opened each chapter with a summary, in which I endeavour to express myself in non-technical language.

A science does little for practical life unless it can be brought within the comprehension of people of intelligence who are not able to follow the steps of an argument dependent upon knowledge attained only through special study. As a clever friend has said to me: "Psychology in our day is in such condition that it camnot be read by the ordinary man without a glossary, and the glossary has not yet been published." I trust that the ordinary intelligent reader who is interested in psychology may find these statements clear: if he so desire he may refer for the detailed argument to the more technical position defined in the second part of each chater. The psychologist himself may find these introduc- 
tions not altogether useless, for I hope by page references to save him the labour of reading through some arguments which I find it necessary to state in full, for the sake of contimuity, but which the individual reader nay not need to study in order to convince himself of the correctness of the points maintained. 



\section{CHAPTER 1}

THE PSYCHOLOGICAI. CLASSIFICATION OF PLEASURE AND PAIN

\section{Introductory Summary}

Pleasure and Pain are states so distinct and so familiar to all of us that it is unnecessary to make any explanation concerning the subject-matter of this volume; but, as happens often when terms are appropriated from common speech for scientific purposes, the words pleasure and pain themselves are used so loosely in ordinary conversation that some difficulty arises when we attempt to employ them with accuracy. That this is no fault of our English usage is shown by the fact that French and German writers find as much trouble in this respect as we do (p. $7 \mathrm{ff}$.). The most obvious means of avoiding this difficulty would be to adopt some one word to cover the subject of this discussion. The Germans have very generally adapted the word Gefuihl to this use; and an attempt is being made in the same direction by some of our best psychologists who wish to nse "Feeling" in the same limited sense. I do not think such usage will win acceptance; for "feeling" has too broad a meaning in everyday conversation to be useful for such specific scientific purpose. At all events, if it were used thus in this connection, misunderstanding might arise as to my own view, and I 
am therefore compelled to adopt the compound word pleasurepain for my purpose, this having the convenience of being clear in its intention, even if a little cumbersome in form.

Pleasure and Pain being original mental states are, strictly speaking, undefinable; but, as is the case with all such original states, they may be explained and described by making clear their relations to other mental states.

All of us who feel sharp sense pains, and a small number of us, viz. neurologists and physicians, who are experimenting with sense organs, or are dealing with mental states involving sense pains, are wont to speak of all pains as sensations-a term which is properly employed to designate mental states connected with action from without upon our well-recognised sense organs, the eye, the ear, the nose, the skin, etc. That a classification of pleasure-pain with sensation will not hold is apparent upon consideration (p. $15 \mathrm{ff}$.), and indeed is not generally thought to hold with relation to pleasures, which are more often classed with cmotions.

If we attempt to classify pleasmre and pain with the emotions (p. $32 \mathrm{ff}$.), however, we are compelled to claim that pleasures and pains are themselves emotions, and thus defend a more complete separation of pleasure-pain from sensation than will be acknowledged ; or else we must practically identify emotions and pleasure-pain, adopting the theory that emotions are mere complexes of pleasures and pains, as has not infrequently been done. This latter hypothesis, however, is one which I think is without warrant. The impossibility of this classification of pleasure-pain with emotion, which becomes apparent when we consider their marked difference of quality, is emphasised especially when we take note of the very diverse manner of their rise into consciousness. There is no typical emotion which fades into another, as pleasure does into pain, without other marked changes in the mental states involved; nor is there any which is aroused both by such simple states 
as mere sensations and by the most complex of states as well.

For all this, it must be agreed that the connection between sensation and pleasure-pain, and between emotion and pleasure-pain, is very close, and this fact might lead us to look for a special bond between the three, were it not generally agreed that there is a comnection of no weak nature between pleasure-pain and our intellectual states also.

Such being the case, there seem to be three possible methods of classification, any one of which may prove to be proper.

We may surmise, first, that pleasure-pain modes are the fundamental elements from which all mental life develops (p. 36 ff:), a hypothesis which, apart from other oppositions, is negatived by the fact that our mental life is not developed on two distinctive lines, viz. of pleasure and of pain.

$\mathrm{Or}$, second, we may incline to the notion that in pleasure-pain we have a special mode of mental activity, a series suigeneris, unlike and standing apart from any other mental state in character and means of genesis, which, however, is connected with all other mentality in some subtle way.

But there seems little warrant for this hypothesis when it is examined critically (p. $38 \mathrm{ff}$.).

A third possible hypothesis seems more reasonable, viz. that pleasures and pains may be differential qualities of all mental states, of such nature that one of them must and either of them may, under their proper conditions, belong to any element of consciousness.

This third hypothesis is not fraught with objections as are the other two (p. $4 . \mathrm{fi}$.). On the other hand, it is corroborated in many ways, notably by the common-sense usage which applies the terms pleasure and pain to narrow states and to wide complexes alike, and by the aid it gives us in bringing the phenomena of pleasure-pain into mity with all the rest 
of our conscions life, by classing them with those general qualities of which intensity is an example. It makes it easy for us to understand how pleasure-pain fields may differ in people of diverse constitution, and also makes it possible to account for the pleasurable and painful complexes which we all experience.

It teaches that revival of an element which was pleasurable or painful may also be pleasurable or may be painful, hut (p. 53 fi.) that the pain or the pleasure cannot be revived apart from some comected elements any more than a definite intensity can ; there must be some state of mind which is intense; there must be some element which is painful or pleasant. It teaches that indifference is no state of neutralisation of pleasure by pain or vice versâ (p. 56), but that it may be conceived to exist as a purely neutral state when both the conditions of pain and those of pleasure are wanting.

Verification of this hypothesis ought to be possible through a study of the laws of pleasure and pain in the relatively simple region of sensation, and, after these have been formulated, by looking for their corroboration in other mental regions. Before further progress can be had, however, it will be necessary to make, in Chap. II., some explanation of the nature of the emotions with which pleasure and pain are so closely connected as to have given rise to much confusion; after that we shall take up certain resultants of that examination important to our consideration; and later shall examine the knowledge we have as to the physical basis of pleasure and pain, to see how far it corroborates the psychological view here maintained. 


\section{Technical Treutment}

$\S 1$. The study of psychology in general uight properly and advantageously be approached by treating, in the first place, those qualities which are necessary to the very existence of a developed consciousness, presented as an increment to the mentality of the ego,- such qualities, for instance, as continuity, complexity, attention, which must appear with any developed conscious state.

These qualities having been described and their relations determined, a second step to be taken would be the consideration of certain qualities, some of which must and any of which may (given the proper conditions) belong to any specific psyehosis,-for instance, futureness, presentness, or pastness.

It would be proper, again, to consider certain qualities which are determined by exclusive differentiation, and which, if we are to judge from sensational evidence, seem to be determined by exclusive differentiation within the physical organism which is coincidently active. Under this division we should find treated sensation, emotion, impulse, ideation products, fixed percepts and concepts. These psychoses of limitation I shall speak of at times in what follows as eontents. Strictly speaking, the word content should perhaps have a wider application, but the signification which I give to it is that which is attached to it most frequently, and I think it better to use this term with explanation than to employ the cumbrous phrase "psychosis of limitation," or to coin a word to convey my meaning.

We should find it necessary then to consider certain qualities, one of which must and (given the proper conditions) any one of which may belong to any psychic clement. It 
is under this last category that I would place pleasureindifference-pain. My reasons for so doing will appear in the present chapter, and will, I think, be corroborated by the steps taken in the chapters which follow.

$\S 2$. The subject-matter of our discussion is fortunately perfectly clear. All know what we mean when we speak of pleasure and of pain. And at this point I may as well say that I draw no distinctions other than those of degree or breadth between pain and disagreeableness or between pleasure and agreeableness.

There is great difficulty, however, attendant upon the proper treatment of our subject, occasioned by the uncertainty of psychological terminology as applicable to the field before us. The usage in the case of the word "feeling" may be taken as a typical example of English uncertainty. Certain psychologists of the highest rank-Dr. James Ward, for instance-would lave us indicate by this word the field of pleasure and pain, ${ }^{1}$ and naught else. Dr. Ward, of course, acknowledges that the word "feeling" has very different meanings for the ordinary man, and even for the psychologist. In ordinary speech it is at one time used as equivalent to touch, at another as descriptive of such organic sensations as hunger and thirst, and again as the proper designation of the typical emotions, e.g. anger, fear, etc. On the other hand, we find it used by psychological anthorities to indicate the fundamental effect in all experience. Thus we find Mr. Spencer in his Psychology saying: "A relation proves to be itself a kind of fecting - the momentary fecling accompanying the transition from one conspicuous feeling to another." 2

1 Ency. Brit., art. "Psychology."

2 Principles of Psy., \$ 65. Mr. Spencer's free use of "feeling," by the way, not unnaturally worries his German readers, who generally translate the word as Gefühl (Cp. Stumpf, Tonpsychologie, vol. i. p. 9). 
Professor James also uses the word in this wide sense. In an article published in $1884^{1}$ we find him saying: "We ought to say a feeling of and, a feeling of if, a feeling of but, and a feeling of by, quite as readily as we say a feeling of $b l u c, "$ ete. So also, as I understand him, Mr. Shadworth Hodgson ${ }^{2}$ would use the word, and John Mill's usage was not very different. $^{3}$ Again, it is a very common thing to find the word "feeling" used to cover not only the field of definite emotions, but also the wider field of indefinite sentiment, especially among the artists. It is to be noted, further, that while "feeling" does not to all mean merely pleasure and pain, on the other hand pleasure and pain are themselves, as we shall presently see, elassed very frequently away from anything which is ordinarily understood as "feeling"-notably with sensation.

The German psychologists, as a rule, use the term Gefiihl as exclusively equivalent to pleasure and pain; but it is not infrequent to find here also as great indefiniteness as among the English. Wundt, in a late article, ${ }^{4}$ shows how uncertain is the meaning of terms in this regard, for within a century the usage of Empfindung and Gefiihl has been entirely reversed, the former having had formerly the subjective connotation which is now ascribed to the latter: as he says; if a green light be pleasant, according to the original usage, "wir fiuhlen es griin und wir empfinden es angenehm;" nowadays we say, "wir empfinden es grün und wir fühlen es angenehm." He also in his Physiologisehe Psychologie gives a section to "Empfindungen des Gefiuhlssinnes," meaning sensations of pressure, temperature, etc., and within a few pages gives us a chapter on "Gefühlston der Emp-

1 Mind, ix. 5.

${ }^{2}$ Cp. Mind, xiii. 165.

3 Cf. also "Seripture," Am. J. of Psy., iv. 4, p. 584.

4 Phil. Stulien, VI. Heft iii. pp. 337, 338. Cf. also his Vorlesungen ü. d. Mensehen und Thierseele, 1st edition, ii. \$ 30 ; and Volkmann, Lehrbueh d. Psych., p. 302, ete. ; also Waitz, Lehrbuch d. Psych., \$ 40. 
findung," "in which he treats of pleasure and pain. The plural Gefiuhle, also, has many connotations which lead to confusion.

If we turn to France we find a similar uncertainty. Dumont calls his study of pleasure and pain Théorie scientifique de la Sensizilité, while Professor Delbouf gives us a general theory of all consciousness under an almost ideutical title, viz. Théorie générale de la Sensibilité. If any reader wish to convince himself of the indeterminateness of French terminology, let him read chap. i. of Bonillier's Dn Plaisir et de la Douleur.

It is clearly advisable from the outset to avoid the use of terms which may create misapprehension. A word is sorely needed to cover the whole ground of pleasure and pain, and one which does not carry with it hidden assumptions in directions open to question. The word "feeling," which Mr. Ward would have us use thus, will not, in my opinion, serve this purpose. It is impossible practically to limit the meaning of the word to cover the pleasure-and-pain modes only. It is too serviceable a word in its wider use to be replaced easily, and its verb "to feel," with a very broad significance, has become quite indispensable to the average English speaker.

In practice, indeed, there appears to be no special value in the usage which Dr. Ward adopts, unless we are able to make "feeling" cover the ground of the "emotions," on the hypothesis that "emotions" are summations of representations of pleasure and pain-a hypothesis which we shall presently see to be untenable. What is more, I am convinced that the advocates of this usage would find many difficulties with their arguments if they substituted "pleasure-indifference-pain" for "feeling" in their writings.

\footnotetext{
${ }^{1}$ Wundt, in Phil. Studien, VI. Heft iii. p. 364, argues that this use of words is proper, beeause in the case of sensation the Gefuill is bound most intimately to the immediate impression, which is not the case with the "higher moral and resthetie feelings.."
} 
"Feeling," then, having very different meanings for different people, if it be used in the narrow sense to cover pleasure-pain only, some reader is almost certain to read into the writer's thought his own broader usage of the term instead of that intended.

Let us here use the term "pleasure-pain" to cover the ground, ${ }^{1}$ as I have done in a number of articles already published, avoiding as far as possible the use of the word "feeling," but where its employment seems necessary giving it the wider significance above noted as according with the usage of Professor Tames.

It would be well if English usage authorised the

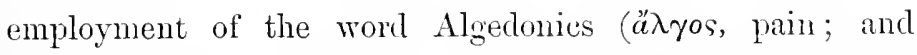

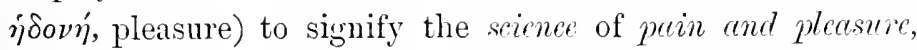
as Hedonics is already used to signify the science of pleasure. I shall occasionally venture to use the word "algedonic" as an adjective to cover the ground of pain and pleasure, in correspondence with the usage of the word "hedonic."

\$. In order to clear our path a little, it will be well at the start to inquire what classifications of pleasure and pain are made naturally by thinkers working in diverse paths, without special reference to algedonic theory; perhaps we may thus obtain some guide. For this purpose we must needs take some general classification which is supposed to cover the whole ground of psychic experience. As English speakers, we may in this preliminary view make use of Professor Bain's classification-Sensation, Intellect, Emotion, Will-without adverse criticism."

1 There is a difficulty in this use of "pleasure-pain" as identical with Mr. Ward's "feeling," and the ordinary German psychologieal use of Gefüht, in that it may be understood to assume the non-existence of indifference as a state allied to pleasure and pain. No such assumption is intenderl. The discussion of iudifference must be deferred for the present.

21 do not wish to indicate a belief in any such prartial and distinct 
First as to sensation. The direction in which the psychology of our day has made its most striking advances is that of the development of psycho-physics. A very large proportion of the complex and absorbing investigations undertaken by those who devote themselves to this relatively new science deal with phenomena of sensation, and therefore we should not be umprepared to find, as we clearly do find, those who become absorbed in this and kindred studies emphasising the function of sensation, and to some extent exaggerating its importance in the mental field. This tendency is often manifest in the writings of scientific men who are not psychologists, but who deal directly or indirectly with neural anatomy and pathology, in which writings it is common to find casual statements which imply a classification of pain with sensation, although one finds no similar classification of pleasure. Mr. Ward has said, "Most psychologists before Kant, and our English psychologists even to the present day, speak of pleasure and pain as sensations;" and this remark can only be called too sweeping if it be made to imply a deliberate classification. Perhaps a few instances may be worth citing. M. Taine says that "in the nerves of muscle and skin there are three and only three kinds of sensation: those of contact, those of heat and cold, those of pleasure and pain." " Professor Delbœuf ${ }^{2}$ says he considers that "la fatigue et la sensation sont des phénomènes de même nature et comparables." Fechner's method in the extension of the principle of Schwelle to the region of

psychie action as may be inferred from the use of this division, i.e. a belief that these classes of psychic facts are so elearly separated as to be found quite apart without overlapping in character and without coincidence in time of presentation. But even if one avoid such a view, it is certainly true that our states of conscionsuess have at times such emphatic and comparatively listinct elements, that it is legitimate to let these emphatic elements give the name to the whole states.

1 On Intelligence (Trans., 1871), p. 137.

¿ Eléments de Psychophysique, 1. 46. 
Gefiuhl seems to me to imply this classification, indicating a mode of thinking which transfers the laws discovered in some sensations to others of the same grouping. Our English scientific writers who are not psychologists habitually use the term sensation to cover pleasure-pain, more especially when speaking of pain. Among psychologists, Lewes speaks of the "sensations of hunger, thirst, giddiness, ... pain, etc." "2 Even so careful an analyst as Professor James uses the expression "sensatious of hearing, touch, sight, and pain " 3 in one of his later writings. Mr. Spencer's words would clearly indicate a similar identification with sensation; where he says, "Presentative feelings, ordinarily called sensations, are those mental states in which, instead of regarding a corporeal impression as of this or that kind, or as located here or there, we eontemplate it in itself as pleasure or pain." ${ }_{4}$ Mr. Spencer here, however, seems to take out of the word sensation all of its ordinary meaning_certainly all the meaning implied in the Sensation of Professor Bain's classification which we are using. But on the other hand Professor Bain ${ }^{5}$ agrees to follow Mr. Spencer in a view which he attributes to him, making "feeling the generic term of which sensation and emotion are the two species." This does not appear to me to be consistent with the words of either anthor in other connections, but if it be accepted as intended to be the more exact statement of their view, we should be led to say that they identify pleasure-pain with sensation and emotion. Thus they form a link with those who would class pleasure and pain altogether as emotions. In fact, the theory held by both Professor Bain and Mr. Spencer, that emotions are representative sensations, leads

${ }^{1}$ Cp. Vorschule der Asthetik.

2 Problems of Life and Miml, 3rd series, chap. iv. and elsewhere.

3 Mind, No. 45.

4 Essceys, T. 310.

5 Senser and Intelleet, 3rd edition, 1. 668. 
them both to use the word "emotional" as equivalent to pleasure-pain with great frequency (see Chap. II. § 7). Still they mean by emotion in general what I mean, viz. those states which are typified in love, fear, anger, etc. Professor Bain especially emphasises the emotional connection by treating pleasure and pain under the heading Emotions in his Emotions and Will. On the other hand, it is to be noted that in his criticism of my discussions of this subject in Mind (April 1892) he lays great stress upon the sensational view.

Other writers who use the word "emotional" exactly as Professor Bain does are less wide in the placing of the pleasure-pain limits. Dumont, ${ }^{1}$ for instance, argues for the classing of pleasure and pain with emotions, and Paulhan ${ }^{2}$ uses them as interchangeable terms.

Among the Germans Frend is commonly coupled with Schmer: The Freneh use aimer as much to indicate delight or pleasure, as love. Similarly in English it is common to find the word "pleasure" or the word "pain" replaced by the designation of some pleasant or painful emotion. Hume, for instance, says, "Pity is an uneasiness, malice is a joy;" the word "joy" being evidently equivalent to "pleasure." Professor Cattell " translates "Gefiiliston d. Empfindung" into "emotional tone of sensation"; and Kirschmamn ${ }^{4}$ speaks of the emotional tone in eontrast, referring to pleasure-pain quality solely. In ordinary colloquial English, love is used often to express mere pleasure, and even among careful linguists we find this lack of distinction. As an instance I would cite the well-known verse from St. Matthew's Gospel, "Thou shalt love the Lord thy God with all thy heart, with all thy soul, and with all thy mind," which has remained

\footnotetext{
1 Thérie stientifique de la Scrusibilite, p. 24.

¿ Pliénomenes affectifs, 1p. 22, 95. "Mind, 51.

4 Am. J. of Psy. iv. 4, 1. 553 .
} 
unaltered in the Revised Version of the New Testament, notwithstanding that loving with the mind carries with it, in strictness, no meaning, unless it be taken as equivalent to taking plecesure with the mind-a distinction which the more acute Greeks apparently did apprehend, for we find the original to read $\dot{a} \gamma a \pi a ́ \omega$, and not $\phi \iota \lambda \epsilon ́ \omega$.

Turning from Sensation and Emotion to Intellect and Will, we find no similar tendency to class pleasure and pain with either member of the latter pair ; no indication that they are looked upon naturally as of Intellect or of Will. But, on the other hand, we find no difference between the ordinary expressions for the relation between intellect and pleasurepain, and those for the relation between sensation and emotion, and pleasure-pain. People speak almost as commonly of intellectnal as of emotional or sensational pleasure and pain. The pleasures of judgment stand on the same footing as do many pleasures which are called purely emotional. The pains of physical fatigue evidently bear the closest relation to the weariness of constrained attention upon intellectual problems. The pleasures of the imagination are so important an element in some minds as to have been made by certain theorists the exclusive basis of resthetics. Passing to Will; apart from the theoretical connection in antecedence and in result, there is evidently a close bond between pleasure-pain and the will-act itself as expressed in discussions concerning the fixity of attention, the feeling of effort, and similar topics. Still it is not a bond which to the ordinary man will appear strong.

The confusion here indicated is not lessened when one turns more closely to the consideration of definite pleasurepain theory. One constantly finds difficulty in comparison of statements, because it seems apparent that the opposed theorists are really writing of different things-perhaps of different parts of one subject, but without distinction of 
word. Contradiction of one honest thinker by another necessarily means that experience in the two differs, or that words bear different meanings for the two. Under this condition of affairs it is evidently important to reach a clearer agreement.

What has been thus far gathered may be roughly stated as follows: Whaterer be the nature of pleasure and pain, they are in one way or another connected with all the states of consciousness, which we have for our purposes considered under the divisions Sensation and Emotion--Intellect and Will; and the connection is closer with the former pair than with the latter; so much closer, in fact, that there is a natural tendency to class pleasure-pain now with one and now with the other of the former pair.

Apart from any theory which might make Sensation and Emotion developments of pleasure-pain, to which we recur later, it will be well, therefore, first to ask whether there be any strong ground for the classification with Sensation; whether any for the classification with Emotion.

One point of importance may well be presented here, though it be so commonplace that it ordinarily passes unnoticed, viz. that pleasure and pain are almost invariably classed together. They are at times called opposites-related as heat is to cold. Now, pain is looked upon as normal and pleasure as its mere absence; and, again, pleasure is normal and pain its mere negation; but the bond between the two is rarely questioned. It is the judgment of common sense: pleasure and pain are two states which are too disparate to be commonly known by any one word, but so inseparably connected that they must be mentioned in one breath. This community of character should seemingly lead us to hold that where we class the one we must class the other also. Ve cannot with reason say, for instance, that pain is to be 
classed with sensations, and then that pleasure is an emotion, still holding sensation and emotion to be diverse in character. This, however, is just what one is very likely to do. It seems to me clear from common speech that the ordinary man naturally thinks of pain as a sensation and of pleasure as an emotion. This fact needs explanation, which I attempt below ; but just here it serves to cast doubt upon any view which would class pleasure and pain exclusively with sensation, as it also does upon one which would class them exchsively with emotion. Let us consider this more in detail.

$\S 4$. First let us ask whether there is sufficient ground for the classification of pleasure-pain with Sensation in a scientific arrangement of psychical phenomena.

We have already seen that this classification is implicitly stated in the writings of many physiologists and psychologists. These are, however, for the most part incidental statements which it is difficult to treat seriously. Psychologists owe acknowledgment, therefore, to Dr. Herbert Nichols for having brought into the field of argument, in clear form, the definite theory that pleasure and pain are Sensations, as he has done in two articles published in the July and September numbers of the Philosophical Reviow for 1892.

Before dealing with objections, let us examine the arguments presented in favour of the hypothesis that pleasures and pains are to be classified with sensations.

1. It is held that pain is just as distinct, just as "disparate," as any of those mental states which we all agree to call sensations. This fact, if granted, is of course suggestive of the position maintained, but that it furnishes an argument of negative rather than positive force is apparent when one notes, first, that it is not claimed to relate to pleasure at all, but only to pain, 
and furthermore, that it can be asserted of only a very limited proportion of our pains. ${ }^{1}$

I think it will be granted that the great mass of our pains are not of this distinct and "disparate" nature: "floating pains," as they are sometimes called, are certainly not distinct. ${ }^{2}$ What is more, those which are markedly "disparate" are, in my observation, not pains pure and simple. There is always a something else than the pain by which we are likely to describe it. It is a cutting pain, or a pricking pain, or a crushing pain. One can always discern some differential where the pain is distinct, although the pain itself appears to me to be the same in all cases. Certain pains which are extreme are apparently without locus; in other words, do not seem evidently attached to any content, e.g. the pain one feels when thinking of a dear friend who lies dangerously ill far away. Such pains, however, are clearly repressive, and being systemic in origin, as I note elsewhere, they are naturally not localised in special bodily parts. They are severe because of the deeply ingrained habits of mental life that are thwarted.

But even granting to pains this occasional "disparateness"this distinctness which enables them at times to usurp conscionsness,- this fact seems to argue little for a sensational classification; for there are other states which appear to me to be

1 Wundt, in a late stuly (Phil. Stud., Bd. VI. Heft iii. p. 359), states the relation thus: "Ein Unterschied freilich bleibt zwischen Gefühl und Empfindung, der auf wesentlich andere Bedingungen des ersteren hinweist. Die Empfindung ist nicht nur selbst ein einfaches, nnzerlegbares Element unseres Bewusstseins, sondern auch ibre Entstehungsbedingungen sind relativ einfache, berubend auf bestimmten psychophysischen Organisationsverhältnissen, die bei den verschiedenen Empfindungen als wesentlich übereinstimmende erscheinen. Ganz anders das Gefühl. Von dem sinnlichen Gefühl an, welches unter ähnlich einfachen Bedingungen zu stehen scheint wie die Empfindung, bis zu den höheren intellectuellen Gefühlen bietet sich hier eine Stufenreilie höchst mannigfaltiger und immer verwickelter sich gestaltender psychologischer Entstehungsbedingungen."

$\because$ It cannot be granted, as Dr. Nichols puts it (op. cit. p. 405), that we are unable to attach a floating pain "to some other sensation as a quale"; for the very fact that these pains appear to shift is evidence that they are compected with other 1sychic elements, which, however, we are not accustomed to discriminate. Shifting either implies distinct localisations, which we clearly have not in such cases, or else an uncertainty of judgment in reference to obscure localisations; localisations we have in any case, and these imply attachments to sensations or else definite local signs in the pains themselves, neitler of which suppositions ean be made nse of by Dr. Nichols without logical weakness. 
equally distinct, and which in moments of intensity equally usurp sway over the whole mental field, which, however, we should never think of classifying thus: e.\% the psychic phase which fixes our conviction that an object of revival is real and not a pure imagination, - that which makes the difference between a memory or an expectation, and a mere revival; which latter may have very clear time relations without being thought real in that time. It is to be noted also that the argument which we here examine is of little value unless we agree to relegate to the vagne region of "representation" a large proportion of our pains and almost all of our pleasures, - a proceeding to which there are many objections which I shall touch upon later.

2. In the experiments which are commonly made in the laboratory, it is found that electrical and direct mechanical stimulations of nerve trunks, or of their terminals in certain spots, give pain, but that no sort of manipulation of these stimulations which has been tried has brought pleasure. From this it is argued that, as pleasure cannot be obtained by the activities of the nerves in question, and as pain can be, there must be specific nerves for pain. But it seems to me that we may argne from the facts to a quite different conclusion, viz. that the nature of the electrical or mechanical stimulus applied is such that it is always productive of the conditions of pain, and that therefore pleasure cannot be reached through the activity of these particular nerve trunks or terminals unless they be stimulated by other less abnormal methods than those thus far adopted by thr ordinary experimenter: This view is strengthened by evidence which we have that certain nerves have a very limited capacity for action under the conditions which make pleasure-production possible. In certain directions we must have a summation of gentle stimulations if pleasure is to be noticed. The delicious softness of down and the agreeable smoothuess of satin cannot be appreciated unless broad surfaces are affected at one time. It is even possible, indeed, that certain sensational nerves may be practically incapable of reacting under the conditions which pleasure implies. Surely from these facts we gain no convincing argument in favour of specific pain nerves.

Under the view that I have above suggested there is no difficulty in accounting for the fact that the inner organs, e.g. the intestines, of which we are nearly or entirely unconscious in normal health, are productive of pain under the abnormal conditions of disease or under the artificial stimulations of the 
investigator; and the argument ${ }^{1}$ from these facts also loses its force.

3. It is held that certain nerve trunks, when excessively stimulated by the methods open to the experinienter, do not give pain. This, it is claimed, shows that there is no capacity to produce pain in the organs which have been stimulated. The claim is too wide, however; for, granting the facts, all that is really shown is that nerves which wonld give pain under the experimental conditions are separate from the trunks which the stimulation reaches. It is not clear, however, that the facts are to be conceded. Evidence cannot be felt to be decisive by the advocates of the view which it is supposed to corroborate, if they think it is necessary to state it as doubtfully as Dr. Nichols does in his articles. ${ }^{2}$ I think the argument cannot, on any ground, be considered a very satisfactory one when we consider the great difficulties attending the production of the artificial and delicate stimulations relied upon, and the greater difficulty of obtaining these results in subjects whose tale of absence of pain can be considered scientifically conclusive.

4. It is shown that where one operation brings both touch (e.g.) and pain, in many cases the pain arises distinctly after the touch, etc. This lateness of perception is probably' exaggerated by the tendency ingrained in us to consider with promptness those elements in our experience which enter into the make-up of objects; pleasure and pain are notably not of this nature. But so far as the statement is true for normal subjects, the facts certainly here argue that separate sets of organs have been stimnlated successively. The possibility is not precluded, however, of there being in such cases a certain sensation other than the pain, to which this pain belongs, which sensation follows the sensation of touch, etc. In other words, it is quite possible to argue from the observed facts that touch is followed by sensation $X$ in a painful phase.

As Lehmimn says in his valuable work on this subject, ${ }^{3}$ it appears "dass ein Gefühlston, dieser sei mun Lust oder Unlust, nie von einer wenn noch so schwachen Empfindung isoliert vorkommt, und dass man in allen solchen Fällen, wo man eine Sonderung beobachtet zu haben meint, das Empfindungselement nur iibersehen hat." p. 341 .

${ }^{1}$ Cf. Goldscheider, Archiv f. Anatomic u. Physiologie (Physio. Ab.), 1885,

2 Cf., for instance, Nichols, Origin of Pleasure and Pain, op. cit. 1. 407,

l. $17,1.23$; p. $41 \%, 1.21$.

${ }^{3}$ Der Hauptgesetze 1. menschlichen Gefühlsleben, p. 33. 
What has seemed to be the clearest piece of evidence of separateness in this connection loses its force under closer study. It has been often noted that a person tonching a very hot body, listinctly feels the touch first, and afterwards feels the pain produced by the burning. Lehmann, ${ }^{1}$ however, has shown that the reaction time for warmth is much longer than that for pressure, and that therefore we should expect that a person touching a very hot body would feel the painless touch before the painful burning.

When one presses a needle into the skin, the touch sensation may precede the pricking pain ; but this may result from the fact that certain other nerve elements than those of tonch are affected after the needle has pierced the skin, namely, those which bring about the pricking sensation. I am perfectly willing to believe, indeed, that a set of nerves and nerve terminals other than those affected by action upon the surface organs of pressure, heat, and cold, may be discovered, and that we shall find them to be brought into action by rupture of the surface, by laceration, by eutting, by piercing; and I think it will be allowed as possible that the action of these nerves under the conditions involved in the usual experiment must always be painful; but there is here surely no crucial argument to show that specific pain nerves have been discovered. In those morbid cases where several seconds elapse after the sensations of touch and cold are felt before the pricking pain arises, we may surmise that some disturbance has occurred which has delayed the action of the nerves affected by the laceration or cutting or pricking of painful degree. Such restrictions of activities we find in the other recognised sensations. The facts of anulyesia which have been held to tell in favour of the existence of special pain nerves may also be found to be explicable in some similar manner. We may interpret the observed results to mean that the capacity to experience one form of sensation (e.g. cutting, pricking) in a certain part of the body may be cut off, together with the capacity for pain-giving which goes with it, without cutting off in the same parts the capacity to experience other sensations (e.\%. those of pressure, heat, cold) with their capacity for pain-giving.

The most startling cases of anclgesia are those connected with hypnotic influences, and Mr. Myers, who has made a special

1 op. cit. pp. 44, 45. Lehmann's whole argument in this comnection is well worth reading, and is, in my opinion, conclusive.

I think it desirable to state here that this book was completed before Lehmann's work appeared. 
study of such cases from an entirely different standpoint, corroborates my view. In his article on "Subliminal Consciousness" 1 we read, p. 331 : "I am concerned to show that some intelligence is involved in a suppression (of pain) thus achievedachieved not as narcotics achieve it, by a wholesale deadening of consciousness of all kinds, but by the selection and inhibition from among all the percipient's possible sensations of precisely those which will be in any way disagreeable to him. It is not the mere anesthetisation of some particular segment of the body or particular group of nerve-endings-such as cocaine, for instance, might produce - but a removal also of a number of concomitant feelings of nausea, exhaustion, anxiety, not always directly dependent on the principal pain, but needing, one would say, to be first subjectively distinguished as disagreeable before they are picked out for inhibition.". . . p. 333: "I have already pointed out that the inhibition of all the pain consequent on an operation is in reality a complicated associative process, and involves the singling out and fitting together of a great number of sensations which have only the subjective bond of being disagreeable to the subject, - with a view of then inhibiting this whole complex of sensations, and leaving the supraliminal consciousness in perfect ease."

5. Schiff and his followers have been led to argue for special pain paths in the spinal cord, by the observation that under certain morbid pathological conditions or by the use of anæsthetics all the generally-recognised senses may be lost to the lower extremities, whilst the pains produced by pricking or cutting remain. But, as in the case preceding this, it certainly is possible to argue from these observations that the other sensations are cut off, leaving only the sensation of prickingentting, which is always stimulated painfully under the methods adopted by the experimenters. ${ }^{2}$

6. Finally we have the argument from the important experiments made by Goldscheider, in which it is claimed that he has isolated pain nerves and terminals. This argument rests thus

1 Procecdings, Society for Psy. Research, Feb. 1892, pp. 331, 333.

2 Wmult (Phy. Psy., 3rd edit. p. 114) has pointed ont that the facts as we lave them do not necessarily imply the existence of distinct transmissive fibres for pain, separate from those of the generally-reeognised sensations. Cf. also Theo. Lipps, Grund. d. Seclcnlcbens, 1p. 202, 205, 206. Mantegazza, in his Physiologic de la Doulcur (chap. x.), after carefully going over the disputed ground, finds it necessary to aeknowledge (notwithstanding a strong personal inclination to the contrary view) that science to-day does not admit the isolation of any special tibres for the transmission of pain. 
far upon the observation of one man; and in no field of science is it more likely than in that of nemal anatomy that subsequent observers will find ground for modification of a first investigator's results. Goldseheider's early experiments led him to the important discovery of pressure spots, cold spots, heat spots, in the skin surfaces, but did not lead him to believe that his observations told of pain spots; later — led doubtless by his interest in the theory of sperific enrigies-he eame to the conelusion that the evidenee did sjeak in favour of pain spots also. ${ }^{1}$ The article declaring for this latter position was published in 1885. Since then he has made many investigations, but principally in relation to the pressure, heat, and cold spots. His words have often implicitly denied the theory of specifie pain nerves; but this may he passer over. ${ }^{2}$ In the same year, 1885, Blix published in the Zeitschrift für Biologie a series of observations and a discussion eovering the same general ground, and his conclusion is that "there are three specifie kinds of nerve apparatus in the skin, one for heat, one for cold, and one for pressure. For the sense of pain there are no speeific organs proven in the skin" (vol. xxi. p. 160). It does not seem to me that there has ever been sufficient ground for holding that Goldscheider's results are conclusive. Windt, in rewriting his Physiologische P'sychologie for the third edition, has reeognised Goldscheider's discoveries in relation to the heat, cold, and pressure spots, but he does not agree that he has proven his ease with reference to pain. ${ }^{3}$ Professor Ladd, in his late Elements of Physiological Psychology, ${ }^{4}$ seems more inclined to take Goldseheider's word for it; but even he does not think the case proven. Lehmann's" argument is, in my opinion, a perfectly satisfactory reply to Goldscheider's elaims. Even if we accept, for the sake of argument, the correctness of the facts as stated l,y Goldscheider, it seems to me highly probable that it will be neessary to reinterpret them, perhaps in accordanee with the hypothesis I have above suggested in reference to argument 4, in terms of which they are, in my opinion, readily statable as follows: that the

${ }^{1}$ Cf. Archiv f. Anatomie u. Physiologic (Physio. Ab.), 1885, Sup. 1. Si.

2 Cf., for instance, op. cit. p. 345 ; also Sup. 1). 19, 88 ; also his later discussion in Dubois Reymond's Arehiv, 1891, p. 164.

3 Vol. i. pl. 395, 409.

4 P. 512. Cf. Lloyd Morgan, Animal Life and Intelligenee, p. 378; also Theo. Lipps, Grundthatsachen d. Sectentebens, p. 202 : also pp. 205, $206 \mathrm{ff}$., as in general upholding my contention.

${ }^{5}$ Op. cit. p. 37 ff. 
nerves in question and their terminal organs are those of the cutting-pricking sensation which always occurs in painful phase under the conditions involved in the methods adopted by experimenters.

So much for the direct favourable arguments. Dr. Nichols has brought forward two indirect arguments in favour of this view which must receive attention.

7. He shows that the sensational hypothesis enables us to understand the distribution of pains and pleasures by the additional hypothesis that there are few or no pain nerves where pleasure usually occurs and few or no pleasure nerves where pains are usual, this latter hypothesis being certainly warranted by our knowledge of the distribution of other nerve terminals. It is apparent, however, that this argument is not effective unless it can be shown that pleasure-pain distribution cannot be made comprehensible under any other hypothesis than the one he defends. That such is not the case I think I shall be able to show later. ${ }^{1}$

8 . The same objection may be made to the effectiveness of Dr. Nichols's argument from biology. He shows very cleverly that it is possible to sketch out a theory of biological development compatible with the sensational theory of pleasure and pain; but this does not establish his main thesis unless he can show that it is impossible to bring opposed pleasure-pain theories into line with our modern biological conceptions. I shall presently attempt to show that one counter-theory at least is compatible with our general notions of biological development. ${ }^{2}$

1 Cf. Chap. V., $\$ 17$.

2 With reference to Dr. Nichols's carefully elaborated theory I have little to say, except to note the danger of trusting overmuch to results obtained from such combinations of hypotheses as one must make use of in biologica] retrospect. The danger is illustrated in the fact that the very number of the review which contains the first part of Dr. Nichols's article contains also an argument by $\mathrm{hl}$. Stanley showing grounds for a position exactly opposite in one respect to that taken by the forner. Dr. Nichols holds ylcasure to have been the primal sense. Mr. Stanley, on the other hand, holds pain to have been the primal sense. There is a difficulty in reference to both of these theories, viz. that if pain and then pleasure, or pleasure and then pain, be supposed to be the originally differentiated sensations from which all others have been developed, we slionld certainly look for their disappearance in the process of development, or else for a distinct commonsense division of all sensational phenomena on lines of pleasure and pain; 
I have above presented all arguments of moment which to my knowledge have been brought forward to substantiate the view that Pleasure and Pain are to be classified with Sensation. It seems to me that any unbiassed observer must grant that the utmost that can be claimed for these arguments is that they furnish ground for the provisional acceptance of the view in question as a working hypothesis unless oljections to the acecptance of the hypothesis appear in other directions. But it seems to me that very formidable objections do appear as soon as the matter is taken into full consideration. Some of these I wish to lay before the reader.

9. As we have already seen, pleasure and pain have been treated in relation by masters of thought from the earliest times. It appears to me that this weight of anthority cannot properly be ignored: such a full expression of the observation of mental states by thoughtful men is clearly a datum of psychology which camnot be passed over by scientific psychologists. in their consideration of this subject. Sufficient ground for these statements of relation appears in the fact that pleasure and pain arise in conscionsness as disparate

and this we nowhere find. Dr. Nichols does not make clear to me what may be the mechanism by which the hypothetical pleasure nerves bring about "the nenral activities whose function is to continue certain beneficial processes," or that by which the pain nerves bring abont the "neural activities whose function is discontinuance." Apparently the contimunce and discontinuance must refer to the organ which is functioning in direct connection with the pain and pleasure activities, and as we must postulate, I presume, one brain centre for pain and one for pleasure to regulate this discontinuance and continuance in an indefinite number of directions, it would appear to be necessarily by means of some direct return motor (?) activity to the functioning organ; but how it is to act upon the organic function which is to be discontinued or continued, I do not muderstand. Can it be inhibitively in the case of pain and in manner to dnplicate the stimulus in the case of pleasure? 
CHAP,

parts of a continuum. One fides into the other, when there is no other observed change in the nature of the mental elements presented at the same time. Strong stimuli, if continnons, gradually fail in the production of pleasure and as gradually become pain-producers. One displaces the other. Apparently no element of conscionsness can be both pleasurable and painful at the same time; the one appears to exclude the other, althongh it seems equally certain that psychoses composed of diverse elements may have in their make-up coexistent elements both pleasurable and painful.

Since the sensations of heat and cold, which are held in relation, have been found to have specific nerves and corresponding terminals, the fact of the relation between pleasure and pain would be no objection to the sensational view were it not for the fact that while the discovery of pain nerves has been claimed, there is not the slightest indication of the existence of pleasure nerves. This failure casts further doubt upon the claim of Goldscheider as to pain nerves, the existence of which is already denied by other anthoritative observers; for surely if the pain nerves are isolated, we should expect to find some evidence of these related pleasure nerves. Dr. Nichols attempts to overcome this objection by the somewhat summary process of referring almost all pleasures to the region of representation, which he considers may have a coincident of organic activity, although the original pleasure sensations and their organic basis be no longer traceable. I think there is little warrant for this supposition. Pleasures are just as clear, just as "presentative," to me as pains are, in reference to the vast majority of my sensuons activities; and, furthermore, there are grave objections to the treatment of pleasure-pain representations in the manner above referred to: of this I speak below more at length. 
10. But the difficulty here presented becomes more marked when we consider the matter of brain locus. There is some ground for the notion that a locus has been found in the cortex for the pains of cutting-pricling-laceration, althongh this can scarcely be said to have been established. ${ }^{1}$ On the other hand, there is not the faintest indication, to my knowledge, of the existence of a pleasure centre in the brain. This, again, evidently casts much cloubt upon the claim that a pain centre has been discovered and seems to inclicate that the centre, if its existence be verified, will probably be found to be the centre for the sensations involved in cutting and pricking, which, under the experimenter's methods, have been stimulated in painful phase. Surely, if pleasure and pain are sensations, developed probably early, perhaps earlier than any others, in the history of our race, we ought to be able to identify in the cortex the centres of their coincident activities, as we have done those of many of the other senses; or else some adequate explanation should be forthcoming for their non-appearance. ${ }^{2}$

Pleasure and pain show characteristics which are not noticeable in the generally-recognised sensations.

11. Each of the typical sensations has a very special means of production by which it, and it only, is brought into consciousness. None of them has the characteristic which is observable in pleasure-pain, of being aroused by the widest range of psychic occurrences.

Sensations are pleasurable and painful. Pains, indeed, as we see, are so closely related to sensations that an attempt is made to bring them together in classification.

But emotions also are pre-eminently pleasure-pain

1 The evidenee, indeed, is so contradictory that it has appeared quite possible to hold, as has been done by $\mathrm{F}$. Courmont in his late work, Le Cereclet. et ses Fonctions, that the cerebellum is the seat of all pleasure and pain activities, and those connected with the emotions.

2 Cf. Lehmamn, op. cit. p. $159 \mathrm{H}$. 
coloured. Pleasure is, in common parlance, spoken of as an emotion; and emotions are usually treated by English psychologists together with pleasure and pain.

Intellectual pleasures and intellectual pains, again, are well known to all thoughtful people.

Certainly we have here phenomena very different from anything noticeable with the recognised sensations. We never, for instance, have a cold thought as we have a painful thought, or a sonorous emotion as we have a pleasurable emotion.

12. Under continuation of stimulative conditions, the typical sensations do not habitually change from one form to another. A definite stimulus does not habitually alter from a pressure into a sound, nor from a sound into a brightness. To be sure, water which feels hot when the hand is first plunged in, may soon seem none too warm, but it does not become cold unless there is a real change of the conditions of stimulation. But under continuation of stimulative conditions, pleasure habitually fades into pain, although there are some relatively few exceptions, probably traceable, as I elsewhere argue, to alterations in the system, which really bring about a change in what appear to be continuous stimulative conditions.

13. Again, in the case of ordinary sensations, within the limits of normal activity, increasing or diminishing intensity of physical stimulation brings corresponding alterations of psychic activity, although the relation is complex and not simple. But with pleasure-pain the case is quite different. An increase of intensity of stimulus often at first increases a pleasure, then decreases it, then produces an increasing painfulness,-a series of which we have no counterpart in sensational experience.

14. The differentiation of the typical sensations seems to be related to differences of environmental action upon us. The eye mediates ethereal vibrations. The ear tells of air 
waves. Heat and cold terminals react to molecular vibrations. Taste probably deals with chemical reactions. But pleasures and pains are not determined by any such special relations to our environment. Heat may be painful or pleasurable; so may cold, so may taste, so may touch, to go no further. This fact in itself surely renders the sensational classification improper on purely logical grounds.

15. The alterations of pleasure-pain phase which are observed in connection with identical stimuli at different times are apparently incompatible with the sensational hypothesis. Hypernormal activity in any special direction often produces pleasure at one moment and pain at another, the change occurring often within narrow time limits. Are we to suppose that under certain conditions the pain-sense organs are affected by a given stimulus and the pleasure organs not, while under some mysterious altered conditions with the same stimulus the pain organs become quiescent and those for pleasure become active? We surely are in a position to ask for some explanation of this mode of stimulation, so different from that found with other senses. Again, activities which are uniformly disagreeable when first experienced, if not too extreme or too long continued or too often stimulated, habitually become gradually less disagreeable and finally may be productive of pleasures. This process is commonly described as the "acquisition of tastes." The only explanation of these phenomena in terms of the sensational theory would seem to be that pain nerves become separated from activities or cease to act when the latter function, and that pleasure nerves begin to become comected with the same activities. But what has kept these pleasure nerves from atrophy during the long periods they have been inactive? And after the new connection of the activities with pleasure why do not the pain nerves suffer atrophy, as they certainly do not? For we find that a man who has learned to enjoy the taste 
of olives, at first disagreeable to him, may eat a few with his dinner every day for years and always with enjoyment; but if he double his allowance some day, he will find the last one disagreeable. The man who walks little may find the action of his muscles on a five-mile walk very painful, but if he persevere he may come to find that definite amount of action in those muscles enjoyable and regularly required for his comfort. If, some day, however, he use these muscles in a twenty-mile walk, he will find that his capacity for pain in them has not disappeared. The hypothetical pain nerves have not become in the least disabled by disuse. How does it happen that for year after year we live on with practically no consciousness whatever of the existence of our intestines, until some day an irritant gives us excruciating pain? Have these supposititions pain nerves been lying dormant for so long, and yet actually gaining capacity to act with vigour, instead of becoming atrophied as other organs do?

Cases like this and the one immediately preceding it have led to the suggestion that a certain width of stimulation may be necessary to bring the pain nerves into action. If we accept this notion, we are confronted with the further difficulty that those of our activities which occur after rest are most vivid and widely effective, and yet are our most pleasurable experiences. The very same conditions which are held to bring about the stimulation of pain nerves here seem to be productive of pleasure. How is it that the man who is well rested and vigorous in health finds it difficult to experience pain, although he is more active than the average man? How is it, on the other liand, that the gentlest stimulus is painful to one who is exhausted by illness or who is thoroughly weary?

So much for pain. What can be the special conditions which determine the stimulation of the supposititious pleasure nerves has not yet, I believe, been even suggested. 
16. It would seem that if pain nerves are so widely distributed as is implied by the sensational theory, there should be a more distinct localisation of pains than is experienced; this localisation, in general, however, is so very indistinct that the fact has been used to argue for that theory which makes pleasure and pain a special mode of conscious life distinctly removed from all other mental activity.

17. In bringing this list of objections to a close, I must mention one difficulty which relates to the special form of this sensational theory clefender by Dr. Nichols in the article above referred to. Dr. Nichols's theory, especially as it relates to pleasure, necessitates the existence of images of pleasure and of pain, similar to the images of sensations and objects which are grasped in revival. I think there is no ground in experience for supposing that pleasure and pain are "represented" in this way. It seems to me to be an error to hold that there are images of pain or of pleasure, as it wonld be an error to speak of there being imagres of intensity, for example. The intensity of an image of a sensation is not an image of the intensity of the sensation. The intensity in both cases is a psychosis of relation; and it seems to me that the case is similar with pleasure and pain. Sensations and their "images," indeed, however closely they may be bound together, are always markedly distinct. It seems probable to me that the "image" is present with the sensation, but swampel, as it were, by the force of the sensation, somewhat as represented by the symbols below.

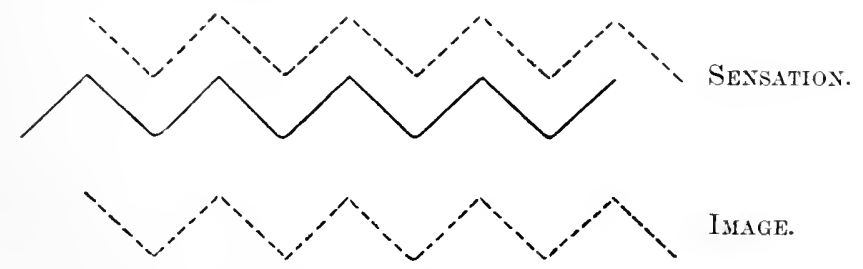

This "image" we learn to think of as a revival or if- 
presentation of a sensational presentation, because in sQ large a proportion of cases where it occurs it is emphatic after a presentation has disappeared, and is hence thought as a return of, instead of as a residum of, the presentation. Thus when the image arises it is grasped in its relations as familiar, but with a sense of the loss of its emphatic part.

Be this true or no, it is certain that sensational images are definitely distinct from their sensational presentations, and I cannot find any corresponding distinction in my experience of pleasure-pain. A pleasant sensation may be revived pleasurably (or at times painfully), a painful sensation may be revived painfully (or at times pleasurably), in manner similar to that by which relations of sensational intensity are revived. The word "pleasure" and the word "pain" are also revived with objective connotations in pleasurable and painful phases respectively; but I cannot bring myself to believe that I have images of pleasures or pains similar to the images I have of sensations, or that pleasures or pains can be revived apart from any content to which they are attached.

I have entered into this discussion with considerable fulness, as it seems to me important to bring conviction on this point to the body of physiologists who are now adding so much to our knowledge, and whose results are too likely to be expressed in terms of the sensational theory to the loss of their future value. In Chap. V., $\$ 17$, I refer to this matter again, and am able to show, I think, that the objections here raised do not apply to the theory I defend.

Before taking up our next section I feel constrained to say one word more.

Introspective psychology in our day cannot take any steps without inquiring whether they are in accord with the results reached by our new-born science of psycho-physics. On the other hand, if there be any force whatever in the 
argument for the thoroughgoing coincidence of psychic and neural phenomena, investigators in psycho-physics on their part must also take into account the records of introspective psychology. The mass of observations from introspection is large in comparison with what has been obtaineci from the studies on the physical side, and this should lead to an emphasis of the former, in our time at least; and it seems to me clear that the balance will be always in favour of introspection; that it is the final reference to which all psycho-physical result must be made now and always. The rapid development and the brilliant and valuable results obtained from this new science of psycho-physics have, however, led, if not to a disregard of introspective evidence, at least to an over-emphasis of the data from nemology. The sensational hypothesis as to pleasure and pain under discussion appears to me to be eminently a case in point. The evidence produced in favour of this hypothesis is almost altogether physiological and anatomical, and furthermore, in my opinion, is in itself not at all of such nature as should lead a truly scientific mind to adopt the hypothesis without reserve. It does not seem to me that it would have been possible for psychologists to have maintained it had they as scientists taken into full consideration the data from subjective psychology proper, which bear on the question.

It is as true to-day as it was when John Stuart Mill wrote the following words: The relations of the science of Mind " to the Science of Physiology must never be overlooked or unclervalued. It must by no means be forgotten that the laws of mind may be derivative laws resulting from laws of animal life, and that their truth, therefore, may ultimately depend on physical conditions; and the influence of physiological states or physiological changes in altering or counteracting the mental successions, is one of the most important departments of psychological study. But, on the other hand, 
to reject the resource of psychological analysis, and construct the theory of the mind solely on such data as physiology at present affords, seems to me as great an error in principle, and an even more serious one in practice. Imperfect as is the science of mind, I do not scruple to affirm that it is in a considerably more advanced state than the portion of physiology which corresponds to it; and to discard the former for the latter appears to me an infringement of the true canons of inductive philosophy, which must produce, and which does produce, erroneous conclusions in some very important departments of the science of human nature." 1

As we turn from this discussion we must note that while on the whole it seems clear that the essential characteristics of sensation are not traceable in pleasure-pain, yet this fact must not blind us to the evident closeness of connection between the two classes of phenomena.

$\S 5$. If Pleasure and Pain cannot properly be classed with Sensations, can they with any more propriety be classed with Emotions?

Here the comnection may seem to many even closer than with sensation. We constantly experience sensations which seem to be colourless as to pleasure and pain; but emotion seems to not a few to lose its full meaning apart from one or the other. Still there are the strongest reasons for separating the two. If we accept pleasure-pain as emotional, what are we to do with sensational pleasures and pains? We must hold in explanation of the facts that this doublefaced emotion is one which is capable of being brought out by any sensation, pure and simple, under favourable conditions. But what other emotion acts in such a way? Do

${ }^{3}$ Logfir, book VI. chap. iv., end of $\$ 2$. 
we find simple colours or pure sounds or tastes or touches each one by itself, and all alike, producing such emotions as fear or anger or love, as we know the sensations each and all prodnce pleasure-pain phases? In fact, do we find any of them drawing out any one such typical emotion apart from all associative objectification? Certainly such is not the teaching of experience. To be sure, certain sensations have a close connection with certain emotions-as red is the typical colour inclicative of the hostile attitude, and as minor chords have a tendency to produce sadness; but this fact is generally believed to be explicable as due to associative bonds with more or less definite objects which have in the past acted to bring forward the emotion. In fact, under normal conditions the typical enotions have as necessary antecedents the perception of objects. There is no fear proper without an object to fear; and, even in those abnormal cases where the emotion is artificially aroused without the antecedent thought of a real object, the one experiencing the emotion finds it very difficult and at times impossible not to imagine an object or objective condition acting upon lim. But pleasures and pains show no such characteristic.

Some of the objections nuged against the classification with sensation, with certain shiftings of point of view, hold here also. 'Typical emotions do not run into one another as do pleasures and pains, upon the variation of intensity or continuity of presentation. Changes of intensity of emotion and differences of individuality bring alterations and differentiations of pleasure-pain phase - emotion here acting exactly as does sensation.

If pleasure-pain be emotional, it is at all events certain that the emotion is of a peculiar variety: one which is brought into activity by the functioning of its companion emotions. But we know of no other emotion which is capable of acting as a stimulus to produce any one other emotion. 
When we say that "pity is akin to love," it is the fading away of one emotion and the arising of another which we describe, not the production of one by the other, nor the superposing of one upon another; pleasure-pain, however, in different forms is superposed upon the typical emotions, and alters in intensity and even in phase with their change of strength. Moreover, no emotion, if pleasure-pain be excluded, has the double yet single character which is here presented.

Bonillier, in his Du Plaisir et de la Douleur (see p. 87), presents an atomistic theory which would make pleasure and pain elements which in greater development become wellmarked special emotions. He would make pleasure and pain the simple forms of what in complexity or summation are the love of life and the fear of death respectively, the former of which he holds to be the greatest of all pleasures and the latter the greatest of all pains. That these two emotions are respectively the greatest of pleasures and pains cannot be held above question. Certainly pessimism and suicide argue against the universality of the love of life as the greatest pleasure, and it cannot be granted that the fear of death is universally an all-engrossing pain. ${ }^{1}$ In another

1 It is to be noted that Mantegazza (Physiologie de la Douleur, p. 78) thinks that the fear of death is of moment as a pain, but principally in old age. It may be that this fear is of greater weight among the Latins than among their neighbours in the north. In this comneetion the following note may be interesting: Sir Lyon Playfair, in a letter to Junius Henri Browne, anthor of a paper with the title "The Dread of Death," says: "Having represented a large constituency (the University of Edinburgh) for seventeen years as a nember of Parliament, I naturally cane in contact with the most eminent medical men in England. I have put the question to most of them, 'Did you, in your extensive practice, ever' know a latient who was afraid to die?' With two exceptions they answered, 'No.' One of these exceptions was Sir Benjamin Brodie, who said he had seen one case. The other was Sir Robert Christison, who had seen one case, that of a girl of bad character who had a sudden accident. I have known three friends who were partially devoured by wild beasts under apparently hopeless cireumstances of eseape. The first was Livingstone, the great African traveller, who was knoeked on 
direction insurmonntable difficulty arises if one attempt the explanation of other emotions than love and fear; or if this be escaped by disclaiming the necessity for such explanations, it beeomes equally difficult to deal with the generallyacknowledged comnection between love and fear and the other emotions, and with the relation of these other emotions to pleasure and pain. To this separation between pleasurepain and the emotions we shall return in Chap. 11.

Whatever objection there may be to the classitication of pleasure and pain with emotion, it is to be noted, nevertheless, that here, as with sensation, the connection between the two is intimate.

Pleasure-pain, then, is not Sensation, and yet is closely bound up with Sensation; it is not Emotion, but is closely bound up with Emotion also.

If, then, we could see no trace of it elsewhere, we might expect to be able to identify it as a bond to conneet these two great elasses of mental phenomena somewhat after Mr. Spencer's mamer. But, as we have already seen, traces in other mental fields are not wanting, for we find the best thinkers connecting intellectual states in the same general mamner with pleasure-pain. Intelleetual pleasures and pains are no meaningless terms; they are as full of actual

his back by a lion, which began to munch his arm. He assured me that he felt no fear or pain, and that his only feeling was one of intense curiosity as to which part of the body the lion would take next. The next was Rustem Pacha, now Turkish ambissador in London. A bear attacked him, and tore off part of his hand, and part of his arm and shoulder. He also assured ne that he had neither pain nor fear, but that he felt cxcessively angry because the bear grunted with so much satisfaction in munching him. The third case is that of Sir Edward Bradford, an Indian officer now occupying a high position in the Indian office. He was seized in a solitary place by a tiger, which held lim firmly behind the shonlders with one paw, and then deliberately devoured the whole of lis am, beginning at the hand and ending at the shoulder. He was positive that he had no sensation of fear, and thinks that he felt a little pain when the fangs went through his hand, but is certain that he felt none during the munching of his arnı." 
import as are the phrases sensational and emotional pleasures and pains. We, therefore, must give up looking for pleasurepain as of emotion and sensation, to the exclusion of intellect, and at the same time there would be no possible justification for its subsumption under intellect to the exclusion of sensation and emotion.

$\S 6$. If subsumption under any of these great classes of mental phenomena be impossible, and still the bond with all be close, three different hypotheses seem to be open to us for the explanation of the observer facts.

A. Pleasure-pain modes may be the fundamental-the original-elements, the basis of all psychic life, from which other forms arise by development or transformation.

B. Pleasure-pain modes may be psychic elements sui generis brought into consciousness indirectly by the efficiency of sensation, emotion and intellection.

C. Pleasure-pain modes may be quales, - which may arise with all psychic elements,-special qualities common to all mental phenomena.

$\S 7$. Hypothesis A is fascinating for one who by nature tends to look for monistic conceptions of the world of experience. In its widest form this view has found its most thoronghgoing defender in Horwicz, who in his Psychologische Analysen attempts to carry it ont to its results through all mental fields. But his work, though filled with interesting detail and fine psychological analysis, has not carried conviction in the direction of its main theme among the best thinkers who have followed him. It fails for lack of satisfactory evidence. Were there no other objections, it seems to me that the diversity between the two phases pleasure and pain presents an effective one. If pleasure-pain be the basis of all psychic life we ought to find it possible to 
trace two distinct lines of development or transformation, one corresponding with pleasure and the other eorresponding with pain. Such division of mental life, however, we nowhere find.

From one point of view Mr. Spencer may be called a defender of hypothesis $A$, considering his wide use of "feeling" and his apparent identification of "feeling" with "pleasur" and pain"; but lis use of the word "feeling" is so obscur" (ep. Psycholoyy, \$ 65, with his definition of "feelings" and then of "presentative feelings-ordinarily called sensations" in his essay on "Bain on Enotions and Will") that one can scarcely feel justified in calling him an advocate of this hypothesis.

According to other statements, Mr. Speneer might be said to hold to such position only in part (and here I'rofessor Bain might be held to follow him-see Senses and Intellect, 3ril edit. p. 668), making "feeling the generic term of which sensation and emotion are two species." It seems to me, however, that the same objection is effective against such a narrower generalisation which holds against the wider. If sueh a position were adopted, we shonld be led to look for a division of our sensations and also of our emotions on lines of development or transformation of pleasure and of pain, which Mr. Spencer makes no attempt to do, and which Professor Bain distinctly states to be impossible.

Dr. T. Ziegler, in his lately published book, Das Gefuihl, has adopted Horwicz's view; but I do not find that he presents any effective argument sustaining his position. There is, in my opinion, a confusion in his use of the term Gefith, by which apparently he usmally means to express "subjeetiveness." A large number of his arguments would evidently. fail if he substituted Lust und Shlomers for Gefuihl. The assumption he makes that pleasure and pain are phases of this subjectiveness (Gefuhl) is, in my opinion, mwarranted. 
$\S 8$. Let us turn to hypothesis $\mathrm{B}$, viz. that in pleasurepain we have a mental series sui generis. This view has been upheld explicitly or inplicitly by the highest anthorities in the past, and does not lack supporters in our own time. It may be stated as Wundt puts it: "Das Gefuihl ist der" Zustand, in welchen die Seele durch ihıre Empfindungen und Vorstellungen versetzt werde :" 1 " the subjective complement of objective idea." This view Wundt accepts with the note that even here we have an Erkenntnissact at the start; the primal fact being that wir empinden; the product of which in becoming objectified into ordinary Empfindungen involves a subjective aspect, which is Gefiill. ${ }^{2}$ This view, as I understand it, is founded upon the acceptance of pleasure-pain phases as psychic elements sui generis which are brought ont by the activity of all sorts of Empfindungen and Vorstellungen. The same general position seems to be implied in Mr. Ward's statement that each state of mind is irreducible beyond the three facts-attention, feeling, presentation. $^{3} \quad$ Professor Dewey, in his Psychology (p. 247), expresses the same notion in these words: "Feeling is unique and unsharable... cannot be defined . . . can only be felt." Both of these writers use "feeling" as the

1 Phys. Psych. (3rd edit.), i. 542 ; cp. 543.

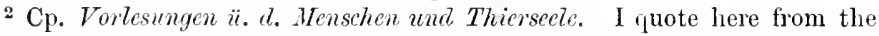
first edition of this work. Wundt's later statements are if anything more emphatic in this direction. I must eonfess that I am not able to reconeile his statements in this regard. His acknowledgment of the Erkenntnissact in Gefüh grasping, or anterior to it, would appear to place his view under hypothesis $C$, were he not so emphatic in the complete separation of Gefuihl and Vorstellungen. I note, however, with gratification that in the last revision of his Phys. Psych. there are indications of a change of view in the direetion of hypothesis $C$. Note the opening paragraph of the chapter on "Gefuhlston der Empfinchungen" (p. 508), where he has added to the text of his 2nd edition the words, "Beide [Lust n. Unlustgefiihle] sind qualitative Zustände." There are other indieations of the same character. The lack of clearness is donbtless due to the fact that he approaches the subject from another standpoint than the one here taken.

3 Ene . Brit., 9th elit., art. "Psychology." 
equivalent of "Pleasure and Pain." It would not be difficult, it seems to me, to show in Professor bain too a tendency at times to take this position B. Under " Emotions of Intellect" he treats of the operations of intellect as yiving occrsion to a certain select class of feelings; speaks of "the trains of contiguons association" as presenting "no special stimulant of the emotions." "The element of feeling, or pleasure and pain viewed as such," he elsewhere says, "enters into allirnce with the more intellectual states of mind," etc., as though it were a matter entirely apart from them and brought out in some way by their action.

The same position is implied in all theory (and here Professor Bain's stand is decidedly affirmative) which looks upon "feeling" modes as always present with or in all psychic elements, indifference being a third phase of "feeling" rather" than the absence of "feeling": a theory which seems to me to be the ontcome of an acceptance of hypothesis $B$, but otherwise nutenable. $^{1}$

Tt is of minor importance to show a thoroughgoing acceptance of this doctrine by any thinker: it is of great importance to inquire whether the doctrine is valid.

The threefold division of mental phenomena which is adopted by the advocates of this view has not been defended strongly until modern times. Is one of its upholders, Mr. James Sully, acknowledges, "The tripartite division is in a peculiar manner the ontcome of subjective analysis, unaided by objective (physiological) considerations." 2 These physiological considerations indeed present a very strong argu-

1 The view that there is no such thing as indifierence except as balance of pleasure and pain, where belanee means neutralisation of one by the other, does not at the first glance seem necessarily to imply this theory $\mathrm{B}$; but, as we shall see below, the theory of balance is not easily hronght into relation with hypothesis C.

a The Humen Hime, vol. i. 1. 73 . 
ment against the view. As Mr. Sully himself says a line or two above what I have just quoted: "It is thus evident that the physiological division of cerebral functions (sensory and motor) does not correspond with the psychological division of psychical functions" (i.e. the threefold division). "It would ronghly answer to the old bipartite division of mind into a cognitive and a conative factor."

Acceptance of this view B implies to some extent a clinging to the old crude "faculty psychology"; attractive because it enables one with a clear conscience to avoid the treatment of each particular mental phase with reference to other divisions of the psychic stream, or to the stream as a whole. It is so easy to refer to the vague region of "feeling" all that we find incomprehensible, or that we will not take the trouble to subject to analysis.

The defenders of this position should, in my opinion, at the outset be able to explain in some clear way how it is that we are able to bring the matter of pleasure and pain under intellectual analysis at all, if they are grasped by us in a manner so completely apart from knowing. I have never seen any lucid explanation of this point. Waiving this objection, however, let us see whether we can account psychologically for the general acceptance of this hypothesis B. It seems to me that our experiences of the pains of restriction and of the pleasures of rest account sufficiently for the setting up of this sui generis theory, although they do not establish its validity. For, as I shall show later, these pains and pleasures are systemic in origin and to a great extent apparently contentless; yet they fill up a large part of our life experience, and lead to the notion which gives, in my opinion, the principal ground for acceptance of this doctrine, viz. the supposed pre-eminent subjectivity of pleasure-pain, its lack of objectivity, "of local- 
isation, of elaboration into percepts or intuitions of the external."

Here I am unable to follow, although natmrally it is with diffidence that I raise objection against the high authorities who support this position.

There is no doubt that subjectivity is ordinarily easier to grasp in the region of pleasure and pain than in other mental regions, and this is a fact demanding explanation; but I think it is easy to show that it is impossible to draw any decided line in this respect between pleasure-pain and other mental states. Those who ponder much over psychological matters fail to find it difficult to think of sound or of light as subjective; in fact, to think it objective becomes difficult : and yet how hard a thing for the common mind to grasp! Lehmann, ${ }^{2}$ who accepts the view under discussion, is forced to acknowledge that Vorstellung and Gefühl are both subjective states, the difference being merely that the subjectivity of the latter has a higher potency. On the other hand, we are losing all the true meaning of objectification and localisation if we fail to consider that to be objective and localised which we plece in definite parts of our body, as we do constantly with pleasure-pain. But what if one distinctly places a pain clean outside of his body, as one does who thinks he feels pain in a limb which has been amputated?

This objectivity has been acknowledged by Theo. Lipps," who explains it as due to closeness of association with localisable presentations. It is to be noted also here that an objectiveness of the pleasure-phase is tacitly accepted by no less an anthority than Kant when he separates the

I J. Ward, Ency. Brit., 9th edit., art. "Psychology." Cp. Volkmanu, Lehrbuch d. Psych., ii. 300. Also Wundt, Vorlesmern, 1st edit., ii. 11, where he says: "So bald man einmal die Beziehumg anf einen suljectiven Zustand fallen lässt, so waltet kein Grund mehr, die dann woch ubrig heibenden Gemuithszustinde zn einer gemeinsamen Klasse zu vereinigen."

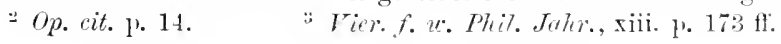


pleasure of the beantiful from the merely agreeable on the basis of the universality of the former. This universality is surely an objectification.

The argument for subjectivity as a mark of pleasure-pain looks something like this. The ordinarily-acknowledged "qualities" of presentation are found to make up the basis of objectifieations. Now on the generally-accepted theory there can be no separation of object without also a separation of subject, and, as the elements above mentioned become notably objective, one must look for the necessarily correspondent subjective elements; pleasure and pain being notably subjective, they are held to be special subjective elements.

It is evident that this argument is based upon a preconception, objectionable because it is a preconception ; viz. that there must be a special kind of activity for subjectiveness.

But supposing that this be true, and furthermore that the word "feeling" is appropriated to the description of this special aetivity of "subjectivity," no adequate proof has been presented, it appears to me, to lead us to identify this special activity with the realm of pleasure and pain. This point camnot be too strongly emphasised.

There stands against the theory the fact that there is an opposition between Empfindungen and pleasure-pain, an apparent tendency for one to exclude the other, which seems to me to be an unlooked-for fact, to say the least, under a theory which calls for a subjective mind-operation of disparate character to correspond with each objective mindoperation; and yet we find authorities speaking of the two points almost in one breath. ${ }^{1}$ The superior subjectivity,

${ }^{1} \mathrm{C}$. Wundt's Vorlesungen, 1st edit., ii. p. 6. Strange to say, Wundt explains the apparent exclusion exaetly as he does the exclusion of one Empfindung by another on the ground that we cam only grasp one idea at a time in an Erkenntnissact. 
"imerness," of pleasure-pain, even if granted, does not appen1" to me to be a sufficient ground upon which to base the acceptance of such a hypothesis as $B$.

Subjectivity, in fact, is not so much of the matter of what rises into conseionsness as it is of its reflective form.

Evidence of this, and at the same time an argument against the exclusive subjectivity of pleasure-pain, is seen in our ordinary argument for the physical basis of mind. What really happens is this. A certain complex psychosis arises of sufficiently definite and fixable nature to have a word correspondent which is "the present action of sense-nerve"; but this after all is still a mental complex and nothing more, so far as we are here concerned, but it is one which has the characteristic of objectivity. "Sensation"- - comparatively simple and isolated psychosis which also arises when the complex psychosis "present action of sense-nerve" ariseshas not this objective aspect, and hence we learn to look npon the action of nerve as the objective condition of sensation which is subjective. But it is to be noted that this subjective thing sensation may be, and as usually studied is, as far as possible, purely colourless as to pleasure and pain.

Opposed to this hypothesis B there stands the fact already noted that thinkers of high ability (to pass over ordinary men) do not find themselves naturally taking the view that pleasure-pain forms are mental modes sui generis, but on the other hand nuturally endeavour to relegate pleasure and pain to other classes of mental content; e.y. to sensation or to emotion.

Again, under such a theory as B we should, from the standpoint of the physiologist, naturally look for a very distinct form of nerve-organ, the action of which would be found concomitant with the presence of pleasure-pain. This not being found, we are forced into one of two positions. 
Either (1) we have here reached the point where the action is that of the whole soul, above all organs-a view which must be entirely unsatisfactory with our modern views of the relation of mentality to the physical basis, and which will be found objectionable also because it implies a break-a separation among mental modes of which there is elsewhere no evidence. Or (2) we must say that there is a concomitant in the action of a special kind of pleasure-pain organ, but that we have not yet been able to discover this organ; and then we meet with other equally serious objections. In the first place, such a position seems incompatible with the acknowledged primitive nature of pleasure-pain. Surely its special organ onght to stand ont emphatically. Put waiving this objection, we are met by another. If there be an organ stimulated by the action of the organs of other psychic modes, what shall we say of the relations of pleasure-pain to intensity? It is not easy to understand why a certain degree of intensity in one sense-organ $a$, differing widely from the intensity in another sense-organ $b$, should nevertheless be able to produce the same sort of activity in the hypothetical pleasure-pain organ: a series of mental levers, so to speak, with varying lever-arms must be postulated to explain the facts; and of the existence of such quasi-levers we have no evidence whatever. When we pass ont of the region of pure sense into the wider emotional and intellectual fields, the objection appears, if anything, more formidable. The difficulty, to be sure, may be glossed over to some extent by the assumption of the indifference-phase, which, if it have no other value, has the advantage which always comes with the raising of a cloud of mist behind which the credulous may easily picture all manner of wonders. It enables one to surmise that in that field of pleasure-pain of which we know nothing, if we could but see it, we might find the explanations of the parts which we do see. But to one who discards 
the indifference-phase, and believes in it as merely a name attached to presentation where pleasure and pain are absent, or to one who believes it to be mere balance between pleasure and pain, there is no such comfort. Moreover, it is not easy to accept the hypothesis of a definite pleasure-pain organ without looking for special organs for pleasure and for pain, or even for the special varieties of pain, if we are unable to hing ourselves to class the umeasiness of cravings with the anguish of tissue-destruetion; and such specialisation should, it seems to me, have led to the discovery of some one of the organs, and this discovery again to the localisation of all. It is needless, however, to say that here too our evidence fails us. In fact, the lack of favourable evidence is the greatest obstacle standing in the way of the acceptance of either of the hypotheses thus far touched: preconceived theory has been responsible for their elaboration, and not an analysis of fact or evidence forced upon us from experiente. ${ }^{1}$

§. If, after the objections which appear, this lack of evidence is accepted as conclusive, it forces us to turn to hypothesis $\mathrm{C}$; in other words, to hold that pleasure-pain modes are quales of all mental states: qualities, one of which must, and any of which may, belong to any element of conscionsness.

It will be worth while here to explain more in detail the distinctions implied in this hypothesis which have been already outlined at the beginning of this chapter. Under

1 It is not unlikely that some one may ask, What becomes of the distinetion which common sense expresses as existing between "head and lieart," if we make no distinction of opposition between pleasmre-pain and the quales of presentation? This question itself implies the subsumption of pleasure and pain under emotion, which is what is really referred to when one uses thus the word "heart"; and this snbsumption we have abandoned. The distinction between "head and heart" is a true one ; it is a lhrase expressive of the opposition between intellect and impulse. What I would also call for is the separation of pleasure-pain from impulse, and its acknowledgment as a quale of impulse as well as of the purer intellectual operations. 
hypothesis C, pleasure and pain (and indifference, if it is allowed as other than a transition point between the two) are primitive quales which may appear with any mental element; simple primitive ideas in the Lockian sense, and therefore correctly classed by him $;^{1}$ simple primary differentiations of presentation which are grasped by us essentially after the same manner in which we know the mind to act in other directions, but in the most primal form of such action.

It is possible to look upon all mental states as we experience them, as differentiations of some original primal form of consciousness which in truth we can onlyspeak of theoretically because we must grasp it as presented in its differentiations ; our mental fields are too late a development to appear apart from all differentiations. Now, as has been noted in the third division suggested in the opening paragraph of this chapter, there are some differentiations which have become distinctly marked, and therefore classifiable, being thus distinct because they are determined by a limitation of the presentative field, by the action of the organ of presentation as a whole, if we may so speak, on limited and narrowed lines, o.g. light-presentations, sound-presentations, taste-presentations, fixed percepts and concepts. There may again be further differentiations of these specific queles, as colour under light, while the specific character always remains; blueness is always of light, never of sound. Hypothesis C would not place pleasure-pain as a special member of any such limited and definite differentiation of presentation, but as primary quales which affect all presentation, however wide, however narrow. Somewhat after the same manner we grasp the notion of intensity as being common to all presentation, and as being a quality which must have appeared had the "qualities of limitation" not arisen.

1 Essay, Book II. chap. xx. 
Any theory which would place pleasure-pain on a par with the narrowed differentiations leans in the direction of hypothesis B, which we have discarded.

It is perfectly true then, as Mr. Ward says, that "pleasure and pain are not simple ideas, as Locke called them, in the sense in which touches and tastes are"; but I would hohd that they are Lockian ideas for all that, although not "in the sense in which tonches and tastes are." The distinction is important becanse it really is little other than the distinction between hypotheses $\mathrm{B}$ and $\mathrm{C}$. If the view which Mr. Ward attributes to Locke be correctly attributed, he was an upholder of hypothesis B. But the quales of limitation, if we may so call them, are clearly connected with distinct differentiations of nerve-organ, which cannot be confounded on their physical or mental sides. Now, as we have ahready seen, no such organ has yet been found for pleasure-pain, and this fact would be enough of itself to lead to distinction between the two positions.

At the very beginning of our examination of hypothesis $\mathrm{C}$ we find encomragement in the fact that the objections which appeared against hypotheses A and B do not hold.

That psychic life is not divided on the lines of pleasure and of pain is no objection to a view which makes pleasure and pain quales of all presentations composing our psychic life as we know it; for the distinctly-marked-ofi psychic states are not supposed to be developments from the pleasure-pain modes, but states still subject to these qualifications.

As we have seen, hypotheses $A$ and $B$ are not naturally adopted, but, on the other hand, the common-sense connection between pleasure-pain and all phases of mental life points in the direction of the hypothesis now under examination.

No special nerve-organs, and no distinct differentiations of such organs, are to be looked for to account for quales 
which relate to the whole field of mental life, for their physical conditions, whatever they be, must be looked for in all that which we learn to look upon as the physical basis; i.e. in all of nerve necessary for mentality, whatever special parts are for any one moment called into activity. Each case of distinct presentation may thus be said to bring forward its own pleasure-pain organ, as it were, fitted to act under proper conditions.

The varying relation of intensity to the degree of pleasurepain aronsal in different organs loses its force as an objection as soon as we take this view and cease to look upon pleasurepain modes as produced in coincidence with action in a special organ or organs stimulated from withont. In the cases mentioned under the discussion of hypothesis B, our difficulty disappears with the realisation that we are dealing with a real difference of pleasure-pain organ, if we may so speak. Other difficnlties of the same general nature also here find explanation. A stimulus which now produces the same pleasure-pain phases (or a definite succession of phases) in two sets of presentations, as taste and smell, again on another occasion produces a very different phase or succession of phases in the two organs. Or again : a flow of thought brings change from pleasure to pain in rapid succession without any apparent orderliness. Such facts hypotheses A or B fail to render comprehensible. With the quale-hypothesis, however, the difficulty disappears; for we find in each case either a shifting of the field of presentation, which brings, as it were, new pleasure-pain organs into play, or else a lapse of time during which it is easy to conceive that there may be an alteration of the conditions upon which the pleasure-pain phase depends.

But beyond the fact that those objections do not hold against hypothesis $\mathrm{C}$, there is much corroborative evilence in its favour. The view is confirmed by the already 
everyday nse of terms, not only among those already referred to who have no scientific bias, but, what is of more moment, among thonghtful men in all spheres of effort. The indiscriminate application of pleasure-pain terms to all mental phenomena, whether elementary or complex, is most common. The study of the views of theorists shows similarly broad use of terms and great diversity of view. Such diversity of dogma at the first glance appears perplexing; but an examination must lead to the suspicion that we have here merely the effective influence of the thinker's "personal equation."

Themental fields in which pleasure and pain are experienced vary in different people; indeed, shift from year to year in the same person; and this naturally leads to the conjecture that the theoretical exclusion of certain psychic fields from participation in the pleasure-pain quales is dne to the actual lack of emphasis of the pleasure-pain quality within these fields in the theorist limself: Quite in accord with this position is the fact that a mental bent (which is implied in the stremuns holding to a theory) itself indicates a tendency to more than average mental activity in the direction covered by the theory. But it is hypernormal activity ordinarily which is emphatically pleasurable or painful. Finding his own pleasure-pain emphasised in one mental region, and nowhere else so emphasised as to be specially noticed, it is natural that our stremous theorist should be fortified in his support of his limited view.

Again, this hypothesis $C$ has the advantage that it serves to bring the phenomena of pleasure and pain into unity with all other mental phenomena. We no longer have the mind grasping pleasure-pain in a manner apart from its grasp of presentation; but we look upon these phenomena as differentiations of the presentation, mind functioning here not otherwise on general lines than it does with all differentiations.

This view is also corroborated by the aid it gives us in 
the conception of the nature of hedonic complexes, especially to an æsthetic result, for we here learn the important fact that any presentation may be pleasurable, and may go to make up, under proper conditions, a part of a hedonic totality. Of this I speak at length in Chaps. III. and VI.

Those who uphold hypothesis B, what we may call for simplicity the sui gencris theory, will certainly demand of us some explanation of the subjectivity of pleasure-pain, or, as I prefer to put it in terms of hypothesis $\mathrm{C}$, they will ask us to show why the algedonic quality of the subjective mental state is more emphatic than that of the objective mental state.

In the first place, we must note that those who emphasise the inferior objectivity of pleasure-pain are using the word objectivity in a narrow sense; in other words, they refer especially to that distinct objectivity which has to do with the gathering together and unifying of disparate elements; and plensure-pain modes do not present the conditions which would bring this distinct objectivity into prominence, while the contents to which they are attached do present those conditions.

Theo. Lipps, as we have seen above, endeavours to explain away what seem to be indications of objectiveness of pleasurepain states. He further ${ }^{1}$ appeals to the experience which appreciates the wideness of Gefühl above any special presentation, as evidence of subjectiveness. But if pleasure and pain are qualities of all presentations they will be felt to be beyond any special one, and would naturally give us the experience to which he appeals.

If one follow Mr. Shadworth Hodgson in attributing the specific character of "subjectivity" to "the passing of a content into a distinct perception" as opposed to " the distinct percept into which it has passed," he will find ready an explanation

1 Vier. f. $u . P s y . J a h r .$, xiii. p. $173 \mathrm{ff}$. 
of the greater Gefuihlness of subjectivity (to reverse the ordinary statement), for there can be no question as to the superior activity and vividness, and therefore superior pleasure-pain colour of the mental processes involved in the coming to a relatively-fixed mental position, over those involved in the relatively-fixed mental position which is reached.

The real basis of the recognised connection between pleasure-pain and subjectivity, however, will, I think, be found in another direction. The Ego is of the field of inattention, if, with Dr. Ward, we may be allowed this wide term usage; in other words, if, in any conscious state, we abstract the field of attention so called, the Ego is still left, and so is this field of inattention. This field of inattention is composed of elements which are apart from the blichpunkt under Wundt's terminology; do not belong to any "apperceptive system," as our neo-Herbartians would call it. They make up a complex which is "contentless" under ordinary usage of terms: a field in which differential contents are so equalised that no one is brought into emphasis above another, a state of balance which precludes the processes which bring about definiteness of objectivity. The elements of this complex, so dim in themselves, so delicately balanced as to attention, still under our theory, as will appear more fully later, must each have its pleasure-pain quality, or tone, weak indeed in intensity, but the whole field as a mass must by summation be felt to be full of pleasure-pain; the balance at one time moving in the direction of pleasure and at another in the direction of pain. Pleasure-pain, therefore, will naturally be closely connected, in our mental grouping, with this specially algedonic "field of inattention" with which, as we have seen, the Ego is intimately allied, if not identical. What wonder then that pleasure-pain has been claimed to be peculiarly subject- 
ive?-the more so that the other general mental qualities, attention, complexity, continuity, realness, themselves imply the presence of distinct elements which may be objectified in the narrower sense. On the other hand, it seems to me altogether unreasonable, on such meagre ground, to argue for a special mental action for pleasure-pain when we make no such demand in relation to other general qualities.

It may be argued against hypothesis $\mathrm{C}$ that if it be true we should not expect to find the distinction between pleasurepain and the narrow fields of which it is a quality. ${ }^{1}$ But it seems to me that the complete separation gives us no reason for surprise. Why should not a simple coloured field, for instance, and its pleasure-pain quality be distinctly thought separately? As well might we be surprised that the colour and its intensity can be considered separately. Because we do consider the intensity apart, we do not therefore think it necessary to postulate a separate mind activity for the grasp of intensity in general.

Now I myself feel convinced that many of the best thinkers of the past would have assented to this view had it presented itself to them in the form in which it comes to us in our line of thought ; they have approached the consideration of pleasure and pain from standpoints (mainly ethical) which have not called for an analysis on the lines here taken up.

Fechner, for instance, suggests the hypothesis that pleasure is dependent upon the agreement and pain upon the disagreement (incommensurability) of the nerve vibrations. Whilst this suggestion is acknowledged to be vague and unverifiable at present, it is certainly distinctly in line with the view I defend.

Lotze in his Microcosmus (Book V. chap. v.) says: "Pain 1 Cf. "Scripture," Phil. Studien, Bd. VI. Heft iv. p. 538. 
or pleasure can never occur in (this) formless and colourless generality, but must always have, or rather must always be, something definite in form or colour; as, in fact, we should say that movement is velocity which has some given direction, and not that it has velocity and direction."

Thinkers of to-day speak for themselves; and, judging from the drift of general writing on these subjects, I have some confidence, notwithstanding adverse statements on some sides and silence on others, that the answer of a good part of our modern psychologists would be favourable to the acceptance of this hypothesis of quale. ${ }^{1}$ Still, although I think it is often tacitly assented to, there are a number of its implications which are not generally noted and accepted. To some of these I have already called attention; and in closing I would note a few more points of the same character, which are important for our future consideration.

$\S 10$. Let us first consider what hypothesis $\mathrm{C}$ has to tell us of revival as applied to pleasure and pain.

The Law of Algedonic Representation.-Revival is determined by a return of original conditions. Under hypothesis $\mathrm{C}$, then, revival as applied to pleasure-pain strictly means merely the recurrence within the wide bounds of presentation of the conditions of the particular pleasurepain phase under consideration. But this is clearly not what the average writer means when he speaks of the representation of pleasure or pain. A revival of some definite presentation is thought of. As far as pleasure-pain revival is connected with such definite presentation, representation properly means a revival of the presentation under the same conditions relative to pleasure-pain production which held when the presentation was original. But it must be noted

1 Cf., for instance, Lipps, Grendthatsachen d. Seelenlebens, chap. ii. 
that the revival of the presentation (i.e. the representation) will not necessarily bring the same pleasure-pain phase which held when the original presentation was before the mind, if the conditions upon which pleasure-pain phase depends be altered when representation occurs. The original presentation may have been painful, while its revival may be neutral or pleasurable, if the proper conditions differ in the two cases. Or the presentation may have been pleasurable, while its revival may be neutral or even painful.

There is a case on record in a New York hospital of a patient who has feigned serious illness, and has gladly undergone three times in succession a critical and painful operation after having once experienced it, and this solely for the sake of being retained in the hospital, and thus gaining the (to her) attendant luxuries of care and comfort. In such cases the representation of the operation is certainly not anything like as painful as the presentation of the operation was: otherwise it could not be so completely mastered by the wide summation of slight pleasures comnected with representations of the kindness and careful nursing which followed the original pain. ${ }^{1}$

It seems to me clear that a presentation may appear in one algedonic phase and its representation in quite another. Most of the presentative contents that give us pleasure and pain are indifferent representatively, and this may be due to the fact that the psychic elements that were common to both presentation and representation were originally indifferent, or that the organ of the content is not drawn into strong enough action to bring noticeable pleasure or pain, for,

1 Lehmann (op. cit. p. 261 ff.) notes that algedonic phases cannot be reproduced without contents to which they are attached, but he makes the assumption that each element must be attached to a fixed algedonic phase, an assumption that is not warranted and that seriously affects the value of his argument in many directions: see my reference to his work in Chap. II. Compare Professor Dewey's Psychology, p. 86, where the same doctrine is tanght. 
as we shall presently see, hypernormal activity is the usual coincident of distinct pleasure or pain states.

As pains, as a rule, involve more excessive action than pleasures, we should expect the representation of painful contents in many cases to be non-painful, or even moderately pleasurable, where in the nature of the case the action is reduced in intensity; and it is notorious that we are able to look back with indifference, or even with a moderate pleasure, upon events which were of great painfulness when experienced.

Most people, howerer, speak of a revived pleasure or of a revived pain as if it were either a mental state sui generis, which is revived apart from any presentation, a view which we have already decided against; or else as if the pleasurepain phase were an inherent part of the presentation or necessarily connected with it, so that revival of the original presentation (its representation) could only occur in the same phase as that which coloured the presentation. But experience denies such a notion.

While it is generally held that representation of a content involves part of the elements of the presentation, it is not claimed that it involves all.

If the presentation is $A^{\prime} A^{\prime}$ and the representation $A^{\prime}$ merely, then it is clear that the algedonic tone of $A^{\prime}$ may differ from that of $A$, which latter may overwhelm that of $A^{\prime}$ when the two appear together in presentation.

Or it may be that the conditions of $A^{\prime}$ in $A A^{\prime}$ are altogether altered when A' appears long after the original presentation occurred.

In ordinary cases, where we think we remember particular pleasures or pains, we will find that we are really taking pleasure or pain out of the general remembrance of the wide circumstances which originally attended the pleasure or pain that we suppose we are now recalling.

When we actually do recall a pleasure or pain it is hy 
the revival in pleasurable or painful phase of the original presentation.

This becomes evident when we note (e.g.) how easy it is to recall a particular headache when we have a headache; and how difficult to recall it if we have no headache. I seem as I write to recall vividly a severe headache produced in boyhood by an accidental blow of a swift ball between my eyes, but find it impossible to recall the torturing pain of a torn tendon suffered only a few years since. What makes the difference? Why, merely this; my head and eyes are aching this morning from strain in witnessing an opera last evening, and as the image of the effects of that blow involve the same elements which have been overworked, the image-making itself is painful. Jut my leg is now in normal condition, and the image of the psychic elements produced there is not now in painful phase.

We ought, in fact, to speak of a pleasant representation, not of a representative pleasure ; of a painful representation, and not of a representative pain.

It is upon this unfounded position in regard to representation that any theory must rest which would make an emotion a complex of revived pleasure-pain states, a product of pleasurepain stummation, after the manner of James Mill and Mr. Spencer and their followers. For further discussion of this subject see Chap. II. $§ 7$.

$\S 11$. Indifference. - We find here also an interesting side-light cast upon the problem of indifference; for under this view it is impossible to hold a nentralisation of pleasure by pain as we could if we were to accept hypothesis B. Were pleasure and pain modes sui generis, we might imagine the two sets of mental lever arms, which seem to be demanded, under such theory, as acting in opposition to prevent the 
pleasure-pain organ from functioning, or might surmise that one stimulus counteracted another to the production of the neutral result. But muder the qualc theory each pleasure and each pain exists of itself in and with its own content. A pleasure and a pain may exist at the same time in conscionsness, or a complex of presentations which are pleasures and a complex which are pains, side by side, so to speak, at the same moment, as we often find it in experience; but it cannot be granted that fusion is possible, or neutralisation of a pain by a pleasure, or vice versa

That there is a state of neutrality between pleasure and pain is acknowledged in the mere statement of the problem of indifference.

To call this indifferent state a state of feeling seems, as I have said, to imply theory $\mathrm{B}$, explaining pleasure-pain as coincident with the functioning of an organ of "feeling" which must be active always in one way or another. It seems more consistent with hypothesis $\mathrm{C}$ to hold that presentation may exist without any pleasure-pain quality as a purely neutral state, the conditions (as yet undefined) of the rise of both pleasure quality and of pain quality being wanting. That all meutal states which lend themselves to the emphasis of reflection are algedonic, is beyond question; but if hypothesis $\mathrm{C}$ is to be held, we must think of presentation as the primal fact of which pleasure-pain modes are primal qualities, and this gives us ground for holding the primary and essential existence of presentation per se, apart from these quales.

This doctrine may be aceepted without it being necessary to decide whether this nentral field is more or less wide, or whether it is narrow and merely appears wide in some instances, beeause the pleasurable or painful qualities are brought out in too low a degree to be emphatic.

As will appear later, I favour the latter position, which is 
upheld by evidence to be presently brought forward. I am glad to find that my introspection in this regard accords with that of Mr. Sully.

If this view of the existence of nentral presentation apart from pleasure-pain quales be accepted, it will prevent the acceptance of any theory that makes either phase the essential one; the phase which seems to be its oppositc being a mere mark of the other's absence. Neither the theory of pessimism, which makes pain normal and pleasure its absence; nor the theory of optimism, which makes pain the abnormal and pleasure the normal state-neither theory can be held to be in accord with hypothesis C, which would lead us to make the difference between pleasure and pain dependent upon real difference of condition, and to name both as positive states. If the two are incompatible, this must mean merely that the conditions in the two cases are incompatible in the same organ at the same time.

$\$ 12$. In closing, I wish to present a few points which are apart from the argument itself, but which are of importance in connection with it.

In the first place, this theory in its widest form may be accepted by thinkers whose views differ materially in other particulars.

The Herbartian view, if it can be made to stand against its objectors (which I think impossible), ${ }^{1}$ will not be disturbed by hypothesis $\mathrm{C}$, which would merely make the application of the theory as wide as consciousness. Similarly, hypothesis C seems to me to present no opposition to theories which would explain pleasure as the mental side of efficiency and expansion, and pain as the mental side of lack of efficiency and contraction (Ward); nor to a theory that pleasure indicates equilibrium, and pain departure therefrom (Delbœuf, Spencer); nor to that which makes pleasure equivalent to a tendency to

1 To this I refer in Chap. IV. $\$ 4$. 
persistence, and pain to a tendency to change (L. Stephen, Bradley). Whatever is to be saic pro or con. may be argued quite within the lines of the quale hypothesis.

Let us now turn to a second point which is worthy of consideration. It may be well to inquire how it is that men make the ordinary classifications of pleasure-pain with sensation, emotion, intellection, which we noticed in the beginning of this chapter.

The word "feeling" and the word-complcx "pleasure and pain" carry with them necessarily mental contents; and these contents differ materially with different people.

When I ask myself what I mean by "feeling," the general field of the contents of representation to which "feeling" is attached in my experiences tends to arise and does arise more or less distinctly. When you ask yourself the same question, another field of contents than mine arises; and so it is with each individual. Again, the associative revived horizon connected with the rord "pleasure" is made up of all the more or less dim revivals of those mental states which are pleasurable for us. So the associative revived horizon connected with the rord "pain" is made up of all those more or less dim revivals of what are pains to us. In both cases the focus, so to speak, of this pain and of this pleasure horizon is made up of those mental states which are the most common sources of the most vivid pains and pleasures respectively. In the case of pain, these sources in general are, in my experience, without question the presentations of sensation, with emotions of the most active sort holding a second place. In the case of pleasure there is no such special line of vividness, although the emotional field holds an especially strong position. It is most natural, therefore, that when we raise the rords pleasure and pain together, their common associative horizon should be most distinctly marked, and that they should usually be classed as emotions. 
When we take them separately we should expect to find, as we do, that pain is commonly spoken of as a sensation, and pleasure as an emotion.

$\S 13$. Finally, I must turn again to the matter of terminology. It is evident that if the position which is here defended be the correct one-if pleasure and pain are distinct qualities, which may attach to any mental element, and do not involve any special mental mode-then we no longer have urgent need of a current word to cover the whole region of pleasure and pain and the hypothetical region of indifference. "Feeling," therefore, to the great relief of ordinary men, may properly be retained in its present wide use to cover any particular mental action in the sense in which it is used by Mr. S. Hodgson, Professor W. James, and Mr. H. Spencer. We must have some word to cover this broad ground, and if authorities force upon us the limited use of "feeling," they are surely called upon to supply a term to take the place of the word they appropriate.

Ordinarily, the use of the word "pleasure" and of the word "pain," or of the couplet "pleasure and pain," will be satisfactory in place of the word "feeling," as Mr. Ward would have us use it.

A word is perhaps needed to designate certain states which are ordinarily and roughly called emotional, and which would be called pleasure-pain states or algedonic states under the terminology which I have used in what has gone before: states of mind in which the pleasure-pain quality is the only thing we can grasp; in which the balance of attention is so perfect that no special "contents" appear in the mental field, the pleasure and pain qualities being emphasised by their continuance and by what may be described without misconception as a process of sunmation.

It is not unnatural that the word "emotional" should be 
roughly used to cover this ground, for so large a part of our emotional life is made up of this vague pleasure-pain field without any emphatic content. The tendency in the future, however, will be, I believe, to limit the use of the word "emotional" to the description of those well-recognised states (love, fear, hate, etc. etc.) which seem to be to a great extent fixable by their emphatic content of muscular and other sensations, and it is not desirable, therefore, to attempt to use the word to indicate the vague region above described, the emotions proper being themselves more definite states.

$\S 14$. It seems to me that in the argument which I have above made, psychological evidence has been presented which makes it reasonable to accept as a working hypothesis the notion that pleasure and pain are qualities of a most general nature, either one of which may, and one of which must, belong to each psychic element which is differentiable. It seems worth while to examine this hypothesis in fuller letail.

I think it fairly clear that if the hypothesis be accepted we may hold that the laws of pleasure and pain which we are able to trace in one special class of mental states should be discernible in all. If, therefore, we make our examination in the region of sensations, which are relatively simple, and fixable to such a degree that the shifting of pleasure-pain field during the examination is avoidable, then we may properly look for the application or modification of the laws there discovered in other regions of mind which are less clearly defined. Before we undertake this task, however, it will be desirable to secure a somewhat clearer nnderstanding as to the psychological nature of certain "qualities of limitation," as I have called them at the opening of this chapter. There is no difficulty to be apprehended in relation to Sensation itself, but with Emotion the 
case is different. We have seen that many people hold emotions to be complexes of pleasure-pain in representation : or to be special kinds of pleasures and pains or reactions upon such. All these views we have seen reason to oppose. The question remains, What are these emotions? I think it is worth while, before proceeding further in our examination of pleasure-pain laws, to attempt an answer to this question, which I do in Chap. II., and to develop further (as I do in Chap. III.) one point which becomes prominent in the course of Chap. II. After these matters have been treated, the next important step to take in the process of verification of the hypothesis will be to ask whether it accords with what we know concerning the physical basis of pleasure-pain, with the hope that the examination may help us to gain some knowledge of this physical basis which, under this theory, we should expect to find in some conditions or modes of activity relating to the whole of the nervetissue, whose action apparently forms the basis of all mental life. This discussion will be undertaken in Chaps. IV. and $\mathrm{V}$. 


\section{CHAPTER II}

\section{INSTINCTS AND EMOTIONS}

\section{Introductory Summery}

Tre reader of the preceding chapter will remember that we there found evidence of close relationship between emotional and pleasure-pain states. We concluded, however, that it was impossible to look upon pleasures and pains as special emotions, and equally impossible to define the emotions as complexes of pleasures and pains. We shall find it interesting and instructive to determine the relation which does exist between these two sets of phenomena, and with that end in view it will be desirable to consider the proper meaning to be attached to the word "emotion."

The typical emotions, such as joy, fear, love, anger, etc., are evidently related to instinctive activities (p. $67 \mathrm{ff}$.). They arise without intention on our part, and even contrary to our will, and they evidently relate to the advantage and disadvantage of ourselves or of our race.

Instinct, strictly speaking, is a term to be applied to tendencies observed objectively in ourselves and others, and not to the mental states which are co-ordinate with these tendencies. The compound word instinct-fcelings I shall use to indicate the mental states that correslond to instinctive 
activities. Emotions then may not improbably be found to be complex co-ordinated "instinct-feelings."

If we ask ourselves what co-ordinated instinct-feelings are to be looked for under developmental laws as we understand them, we find that we shonld expect to discover (p. $70 \mathrm{ff}$.$) -$

A, a psychosis, or complex state of mind, connected with the approach of the advantageous to us; which we have in the emotion of Joy.

$\mathrm{B}$, a psychosis connected with the approach of the disadvantageous to us; which we have in the emotion of Dread.

C, a psychosis connected with the departure of the advantageous; which we have in the emotion of Sorrow.

$D$, a psychosis commected with the departure of the disadvantageous; which we have in the emotion of Relief.

Also when we pass from the conditions of passivity in the organism to those of inherent activity, we should look for-

$\mathrm{E}$, a psychosis connected with the tendency to go out towards an advantageous object; which we have in the emotion of Love.

F, a psychosis connected with the tendency to flee from a disadvantageous object; which we have in the emotion of Fear.

G, a psychosis comnected with a tendency to drive away a disadvantageous object; which we have in the emotion of Anger.

$\mathrm{H}$, a psychosis connected with the tendency to act to attract advantageous objects to us; to this we find no corresponding cmotion. Further-

I, a psychosis comnected with concentration of effective attention upon strange objects; which we have in the emotion of Surprise.

$K$, a psychosis connected with tendencies to imitate the action of other individuals; to this we find no corresponding cmotion. 
Leaving out of consideration for the monent the cases $H$ and $K$, it seens proper therefore to define emotions as (relatively) fixed psychoses corresponding to fired co-ordinutions of instinetive activities which wise "pron the apperence of definite objects.

If this definition be correct, it at once appears that pleasure and pain camot properly be counted among the unotions, for the former" are not in any sense "relatively fixed psychoses," nor can they be shown. to "correspond to fixed co-ordinations of instinctive activities," nor to arise always upon the presentation of definite objects. This consideration, however, seems to show us that the true relation between the emotions and pleasme-pain is this (p. $90 \mathrm{ff}$.): that emotions are states of mind composed of elements which to a great extent are usually highly pleasurable or painful, which fact accomts for the elose relationship already spoken of. If we return now to the cases $\mathrm{H}$ and $\mathrm{K}$ (spoken of at p. $98 \mathrm{fi}$.), we perceive that we onght not to expect to find definite emotional names attacher to these instinctive activities, becanse, in the nature of the cases, the psychoses wonld not be fixed and the same, in suceessive instances. But if we should not expect emotional names connecter with these mental states, we should be able to recognise the instincts to which our argument points, and to name their corresponding impulses. We do find well recognised the impulse corresponding to $K$, namely the "imitation impulse" (Nachahmung-tricb). The impulse corresponding to $H$, i.e. the tendency to act to attract to us, I think we have in the impulse to prodnce art work, what we may for brevity call the "Art Impulse." This "art impulse" would thus appear to be a common heritage, as much as are the imprulses to love, to fear, and to hate (p. 101); a fact which should be well considered by those who are tempted to make artistic work a means of subsistence. 
From this last argument it wonld appear that the production of results which shall give pleasure to others must be fundamental for Esthetics. This is a view that may not be acceptable at the first glance, but which I think will be found to be corroborated by a psychological examination of the mental fields that are important in Esthetics. This examination will be attempted in the next chapter.

\section{Technical Treatment}

$\S 1$. In the preceding chapter we noted that the emotions have often been held to be identifiable with pleasure-pain states. We saw reason then to reject this identification, and later in this chapter I shall present further argument defending this rejection. But we have seen also that the bond between the emotions and pleasure-pain phenomena is exceedingly close; it is important for us to determine what the relation between the two is, and I therefore wish to consider here what meaning should properly be attached to the term Emotion.

It is apparent, in the first place, that emotions are what I have spoken of in Chap. I. as psychoses of limitation. They are not as stable in content as are the sensations, but still are recognisable as in the main fixable. If to-day we experience a definite enotion, Fear for instance, we appreciate that we are experiencing a psychosis composed on the whole of the same general elements that arose in conscionsness yesterday when we feared.

It is equally apparent that the typical emotions are intimately related to, if not to be identified with, complex co-ordinated reflexs. They are initiated normally by the rise in conscionsness of percepts, and when these percepts are once given, their appearance is detemined. Only with 
difficulty ean we restrain the activities involved, if the percept arises in consciousness; and only indirectly and after long contest can we break down the tendency to the reaction. This becomes clear when we consider specific instances. No argument showing the unworthiness of her lover will prevent. the rise of the maiden's love, if the loved one appear in reality or in memory. Equally impossible is it to prevent the rise of fear upon the appearance of certain objects which we know well to be harmless. But it is perhaps worth noting here, as we shall see later, that such love for the worthless and fear of the harmless may often be connected with advantages and dangers which must have been real in the past history of the race, though we ourselves cannot have known them. Without looking at other similar examples, which will readily occur to the reader, it will be apparent that we are here carried back to the region of Instinct, to which we may well turn our thought.

When we consider the nature of Instinct, we are brought face to face with one of those difficulties of terminology by which psychological studies are so frequently hampered; for it is not at all clear what meaning is to be attached to the word "instinct." Darwin, in treating of this subject in his Origin of Species, ${ }^{1}$ does not stop to define the term, because he thinks the recognition presents no difficulties; instead he gives a number of examples, all of an oljertie kind. One of the latest and best attempts at precision in this direction is found in the definition by P'rofessor Lloyd Morgan in his Animal Lifr and Intelligence." "Instinctive activities," says he, "are those organised trains or sequences of co-ordinated activities which are performed by the individual in common with all the members of the same more or less restricted group in adaptation to certain circumstances oft recurring or essential to the continuance of the species." Here "agin we

$$
1 \text { P. } 205 . \quad=1.4 \% \text {. }
$$


have a distinctly objective definition relating to the actions as viewed by an observer, and not relating to the consciousness of the active individual. This, which is the commonsense view, and the one to which Darwin appealed, is, in $\mathrm{my}$ opinion, to be followed; for we clearly need a special term to describe these "organised trains of sequences of co-ordinated activities" which shall not necessarily involve any recognition of their psychic side, and common speech does attach the word "instinct" to objectively viewed activities in gradation all the way from those which the actor knows not at all (pure reflexes) to those most complicated coordinations which the actor thinks of as the product of his own will.

Here, as everywhere else in psyehology, we find lack of exactness and distinct difference of nsage. Romanes, ${ }^{1}$ for instance, says, "Instinct is reflex action into which there is imported the element of conscionsness." This takes into account the psychic coineident of the activities, althongh the objective standpoint is not abandoned. Similarly Volkmann ${ }^{2}$ speaks of instinet as "that organic preformation as a result of which a definite impulse (Trieb) acts in a constant manner withont the intermediation of a clear idea." Höffding goes a little further from the nsage I adopt, for we read in his P'sychology, ${ }^{3}$ "Impulse proper and desire are distinguished from mere instinct in possessing always an idea of the end thongh not always of the means; while instinet leads to means being applied to an unconscions end. Instinct is a manifestation of impulse in so far as the actions and movements leading to the end become the object of ideation and of interest."

If we are to use the word "instinct" in the way I suggest to describe purely objective quasi-mechanical facts, we certainly require as broad a word to describe the psychic elements of varying complexity which correspond to these "co-ordinated activities" of varying complexity. For this purpose I shall use the compound word "instinct-feeling." 4 The word "impulse" is often used with very nearly this

1 Mental Evolution of Animals, p. 159.

L Lehruch, ii. p. 439.

" Translation, p. 323. Italics mine.

4 The word "feeling" is here used with the wide signification referred to in Chap. I., end of $\$ 2$. 
significance, but as we shall see in the Appendix I. to Chap. I., this word should more properly be applied to indicate a state of mind determined by instinctive tendencien, but involving an element of repression of their instinctive activities; being therefore anterior to the "instinct-feelings" propes, which are coincident with the appearance of the instinctive activities.

Under my terminology then "instinct" describes the oljective aspect; "instinct-feeling" describes the mental state. As the instincts become more and more rapid in their reactions, or as they involve less and less of action in the complex centres of the brain, they come closer and closer to what we call reflexes; i.e. they lose those qualities which enable us to revicw their psychic coincidents reflectively in the consciousness which is coincident with brain activity. Where instincts involve complication of co-ordinations which arise upon the perception of differentiated objects, their psychic coincidents are retained as part of consciousness.

When these co-ordinated activities become in the main relatively fixed, i.e. wher they remain practirally the same in sucessive eases, we should cxpect to find correspondingly fixed 1'sychoses with definite neme attachments. When, on the other hand, these co-ordinated activities are not relatively fixed we should not erpect to find theti conscious side of a fixed neture, nor should we look: for a definite name attechment.

\$2. Let us now turn to developmental considerations. It is not too much to hold that in a developing race, through the emphasis produced by elimination and survivil, or perhaps through inheritance, there would probably arise a tendency to general co-ordinated increase of activities, and, on the other hand, a tendency to a corresponding grneral coordinated decrease of activities, upon the presentation of distinct objective conditions. These opposed tendencies 
would evidently become connected through elimination with the approach of, and departure of, advantageons and disadvantageons objects, as follows :-

$A$, general increase of activity above the norm, arising upon the Approach of the Adrantageous ; a general expansion, a condition of activity favourable to receptiveness.

$\mathrm{B}$, general decrease of activity below the norm, arising upon the Aproach of the Disadiantayeous; a forced quiescence, a shrinkage of the whole active body.

As a direct resultant from these perturbations we should expect to find-

C, general decrease of activity from the hypernormal towards quiescence, upon the Departure of the Advantageous.

$D$, general increase of activity from the subnormal, from forced quiescence, upon the Departure of the Disadvantageous.

Now it is apparent that if these very wide general coordinations remain effective until the race has become as complicated in development as is ours, then they ought to affect our conscionsness in a broad way, and we should look for relatively definite states of consciousness corresponding with these general co-ordinations. As a matter of fact we do find the following states:-

A. JoY, which is comnected with the Approach of the Advantageous.

B. DrEAD, which is connected with the Approach of the Disadvantageous.

C. Sorrow, which is connected with the Departure of the Advantageous.

D. ReLief, which is connected with the Departure of the l)isadvantageous.

All of these states are felt to be very wide in effect, to be reactions of the whole system. It further appears that there is reason to connect these states with general increase and general decrease of activities as noted above; i.e.- 
. Toy with general increase above the norm.

Dread with general decrease below the norm.

Sorrow with general decrease towards quiescence.

lielief with general increase from the subnormal.

Jor.-Darwin in his Eamession of the Emotions ${ }^{1}$ says: Under a transport of joy "there is a strong tendency to various purposeless movements, and to the utterance of various somds. We sce this in our young children, in their lond laughter, clapping of hands, and jumping for joy ; in the bomding and barking of a dog when going out to walk with his master ; and in the frisking of a horse when turned ont into an open field. Joy quickens the circulation, and this stimulates the brain, which again reacts on the whole body."

Darwin (op. cit. p. 212) again says of joy, which he liere describes as high spirits, cheerfulness: "A man in high spirits, though he may not actnally smile, commonly exlibits some tendency to the retraction of the corners of his month. From the excitement of pleasure, the circulation becomes more rapid: the eyes are bright, and the colonr of the face rises. The brain, heing stimmlated by the increased flow of blood, reacts on the mental powers; lively ideas juss still more rapidly through the mind, and the affections are warmed. I heard a cliild, a little under four years old, when asked what was meant by being in good spirits, answer, 'It is langhing, talking, and kissing.' It wonld be difficult to give a truer and more practical definition. A man in this state holds his body erect, his head upright, and his eyes open. There is no drooping of the features, and no contraction of the eyebrows. On the contrary, the frontal muscle, as Morean observes, tends to contract slightly; and this smooths the brow, removes every trace of a frown, arches the eyebrows a little, and raises the eyelids. Hence the Latin phrase, Exporrigere frontem-to muminkle the brow - means, to be cheerful or merry." Lange, in his book Ueber Gemüthsbeveyungen, 1" 19, sass: "With joy there results a heightening of the functioning in the volnntary muscles, together with an expansion of the smaller and most minnte blool conduits. As a result of this increased functioning of the voluntary muscles and nerves the (Fröhliche) joyons person feels himself uplifted, as in the case with every one whose muscles are strong and not wearied. . . The general opening up of the fine blood-vessels brings ahout its invariable result in increased blood supply to the head," which accounts for the brightening of eye, of flushing of face, of "watering of mouth," etc. "Joy makes one young again." "Intellectual functioning is increased ; there is a flow of thought, of ideas, of fancy." This intellectual

${ }^{1}$ P. 76. Darwin here conples "vivin pleasure" with joy; to this we refer helow. 
functioning is marked in those cases where the state is spoken of as "calm joy." The physician notes that joy improves the digestion, which is merely another form of the statement that general hypernormal activity means more effective functioning in the alimentary canal as well as elsewhere.

It seems to me that I need present no further evidence that joy is always accompanied with hypernormal general activity. That joy cannot be experienced without this same general activity is indicated by the fact which I shall bring forward later that certain emotions imply the opposite conditions, viz. sorrow and dread ; and these, as we should expect under the hypothesis, we find are looked upon as opposites of joy, joy indeed being impossible of realisation so long as these emotions are existent.

General good health, with its consequent vigorous action, always gives a joyful tone to our lives; and the general joyousness of healthy children may be explained as the result of large nourishment (which srowth implies) with relatively few channels for activity to waste it. If we wish to produce artificially in ourselves a joyous frame of mind, we have learned that we must change the scene to one where direct stimulation will call for active attention and must take up vigorous: activities, before there is the least chance of experiencing the full width of the emotion sought.

Sornow.-The first knowledge of a great loss oftentimes leads to frantic and ill-clirected efforts to flee from (fear) or to do something to ward off (anger) the evil, determined by the form in which the loss is conceived. But when the loss is felt to be irreparable, then real sorrow comes upon us; then "the circulation becomes languid; the face pale; the muscles flaccid; the eyelids droop; the head hangs on the contracted chest; the lips, cheeks, and lower jaw all sink downwards from their own weight. Hence all the features are lengthened; and the face of a person who hears bad news is saic to fall.

"The breathing becomes slow and feeble, and is often interrupted by deep sighs. As Gratiolet remarks, whenever our attention is long concentrated on any subject, we forget to breathe, and then relieve ourselves by a leep inspiration; but the sighs of a sorrowful person, owing to his slow respiration and languid circulation, are eminently characteristic. As the grief of a person in this state occasionally recurs and increases into a paroxysm, spasms affect the respiratory muscles, and he feels as if something, the so-called globus hystericus. was rising in his throat. These spasmodic movements are clearly allied to the sobbing of children, and are remmants of those severer. spasms which occur when a person is said to choke from excessive grief." I If the reader will refer to Professor James's Psychology, vol. ii.

1 Darwin, op. cit. 11. 178. On Mp. 192-195 ff. Darwin explains the expression of eyebrow and month as due to uncontrollable actions in chamnels which have been much nsed protectively in the early history of race and individual. 
p. $443 \mathrm{tf}$, he will find a fuller description of sadness conclitions. It does not seen worth while to print more here, for it is clear from what we have seen that there is always a general reduction of activity where sadness occurs. The fact that colours which approach to whit (characteristic of daylight impressions) Jring abont psychises tonding to joy, and that colours approathing black (characteristic of night impressions) induce psychoses tending to sorrow, scems to ne to argue that increased and lecreased activity respectively, in the lirections most important for our intellectual life, may, other things being equal, be determinate of those corresponding general states which make up joy and sorrow.

That joy is incompatible with sorrow is a necessary cleduction from our hypothesis, if joy implies general hypenormal activity. Reductions of vitality through old age, or illness, or debauclery, or at the close of a priod of action, as at evening, bring with them sadness. Men whose intellectual activities, professional or of business, are brought to a standstill because they are dependent upon actions of others which fitil, are nnreasonably depressed. The professional man whose clients do not cone forwarl as of rore, the husiness man whose buyers fail him, fall rapidly into the ilepressim of melaneholy.

A practical suggestion may, perhaps, he here allowed. Depression of general activity may be overeone hy any means which incluces an increase of general activity. Sorrow may be turned into joy by effort of will in the mamner snggester so foreibly by Professor James.? Melancholy caused by failures of stimulus to activity, such as have just heen mentioned, mar be overcome, in a degree, if the business or professional man will undertake some ideal work of the seneral kind to which he is accustomed, thes practically supplying himself with the stimulus which is lacking. But it is apparent that if the depression be due to natural debility aused ly temporary or more permanent conditions, the "enforcerl giaty," withont change of processes of absorption of energy within, must, otler things being equal, be a severe strain upon the system; this, mnless halancel by some means, must result in deeper depression after the eftort to the cheerful has spent its force. This is a fact to which the experience of every man who has been through deep sarlness will attest. If we undertake to eliminate salness by any such artificial method, therefore, we should, lest we do further injury, look to it that we supply dinectly, or inlirectly, this energy which is to be drawn out. Our doctors ordinarily trust to the beneficial effect which the increased general activity will have upon the digestion, which then absorbs, perhaps, more than enongh to balance the waste. But it is ly no means quite certain that this good effect will always occur to orler. The safer method is to limit your perivils of "enforced gaiety," not to let them go too far, and to let them be follower by as full rest as is possible. Haply is the man 
who, when borne down by sorrow, can sleep. Surely it is better physiologically and practically, and on general ethical grounds, for a man under such conditions to be an element in the world of conseionsness for less hours per day than his fellows, provided his lessened hours of conscions life ean be relatively cheerful. Often have I been relieved of sorrow pains by complete stillness-lying on my back-even when I could not sleep; but sleep is the great remedy. "Weeping may endure for the night, but joy cometl in the morning."

From sorrow we must tum to the elosely-allied state of Dread. Dread, muler my teminology, covers what will, by some, be called inactive fear. Fear proper I think implies activity in flight. At least fear is the term usually applied in speaking of the emotion connected with flight. Dread is indeed elosely allied to fear proper and is often connected with it, but I think it separable as being a state following or preceding active fear-one which may exist apart from it and which is notably distinct from it. Anxiety is a state forkering on active fear when there is doubt concerning flight from danger's really present or only ideally represented, or when the mind is still turmed to the effort of discovering some means of arerting a disaster. I think my definition is upheld by the fact that dreat is especially connected with dangers which are not elearly understoon, and where, therefore, actions to avert or flee flon them, would be uncertain of effectiveness. What I mean then hy dread is that cowering down under a certain danger which we camnot avert; in which there seems to be a tendeney to contract ourselves into smaller compass; to use our powers inhibitively. Darwin ${ }^{1}$ says of what I call dread : It "is the most depressing of all the emotions; and it soon indnces utter helpless prostration, as if in consequence of, or in association with, thè most violent and prolonged attempts to escape from the danger, though no such attempts have actually been made;" and again : ${ }^{2}$ "The frightened man at first stands like a statue, motionless and breathless, or erouches lown as if instinctively to escape observation. The heart beats quickly and violently, so that it palpitates or knocks against the ribs; but it is rery dountful whether it then works more effieiently than usual, so as to send a greater supply of blood to all parts of the body ; for the skin instantly beeomes pale, as during incipient faintness. This paleness of the surface, however, is probably in large part, or exclusively, due to the vaso-motor centre being affected in such a mamer as to eause the contraction of the small arteries of the skin. That the skin is moch affected under the sense of great fear (dread) we see in the marvellous and inexplicable mamer in whicl perspiration immediately exules from it. This exudation is all the more remarkable as the surface is then cold, and hence the term 'a cold sweat'; whereas the sudorifie glands are properly excited into action when the surface is heated. The hairs

1 or. cit. 1. 81 .

2 op. cit. pp. 290, 291. 
also on the skin stand erect, and the superficial museles shiver. In connection with the disturbed action of the heart, the breathing is hurried. The salivily glands act imperfectly; the mouth becomes dry, and is often opened and shut."

What may le called the danger shock is closely allied to dreal, the latter being comnected in our mind with effects of longer duration. I sive below Lange's I description of the conditions of what his German translator calls Schreck and which I translate "Dread." "Dread," he says, "is closely related to grief,--we find as its accompaniment the same weakening (Liihmung) of the voluntary muscles, the same convulsive condition of the muscles contracting the blood-vessels, both, however; appearing in higher degree and sudienly. There enters here, however, a new element, namely a couvulsive contraction of the other organic museles, similas to that which, in the sorrowful, is confined to the muscles of the blood-ressels. The essential physiological difterence between sorrow and dread (Schreck) lies in this, that the convulsive condition of the involuntary nuscles in the dreating person spreads over all these museles, so far as one can judge ; in the grief-stricken, on the other hand, over one sroup only. . . Through his solrow one is burdened, oppressed, bent down; but crippled through dread (Furcht); one is immediately turnerl to stone through dreal (schrech), is by it chained to the earth. The erippling of the muscular apparatus of the speech-organs makes it difficult or impossible to utter words: one is dumb with dread. . . While dread, if one takes into account only its attributes thus far mentioned, is to he considerel merely a more intense or acute form of sorrow; there is . . . in fact a wide elass of phenomena which show us that dread has its own independent physiognomy, which differentiates it decidedly from sorrow; these are the symptoms, which arise, alprarently, because all involuntary organic muscles which stand withont any kind of control of will, movements, contractions, called forth in the inner organs, take part in the convulsive condition, while with the sorrowful they are narrowed to the hlood-vessel muscles." Darwin has tanght us that what is called "feigning death," which oceurs on the presence of a danger, does not really take up the forms of death, but is a form of paralysis. It is elosely allied to the trembling which supervenes when active fear is extreme. Both seem to be due to the breaking down of co-ordination through the great force of the stimuli which reach the several muscles.

As Mosso " says, "Under the impetuosity of a powerful emotion the government of the unseles by the will is suspended." Under such ronditions doubtless, flight being impossible, the condition of enforeed inhibition in dread supervenes, until death real or feinned results. The value to survival of this trembling and paralysis probably lies in the fact that it results in a withrlrawal from the enemy of the stimulus

1 Ueber Gemüthsbovegungen, 1,. 21 fi:

2 Lir Peur, 1. 149. 
to hostility. For we do not find ourselves impelled to attack a being which shows no symptoms of fighting. We tend impulsively to avoid the object, and not to strike it. If we know by experience that it is dangerous although cowardly, we strike by an effort of will, and not from the impulse connected with defence.

That conditions of very extreme depression caused by illness bring lread in its extreme form is well known. Dread, moreover, is incompatible with joy, which we have seen to be determined by the conditions opposite to those here hypothetically connected with dreail. A further argument in favour of the general position is seen in the fact that the return of activity from the extreme subnormality produced loy inhibitory effort (dread), and the beginnings of the rise of activity from the general subnormality connected with mere passiveness: (sorrow), have a common psychosis which we call relief, to which we now turn.

RELIEF is certainly a psychosis of general nature, of width and fulness, which implies general activities. The relief from dread where normal activities have been actually inhibited is naturally more noticeable than the relief from passive sorrow. Each, however, has the same characteristics. The first rising activity which can no longer be suppressed flows off in the lirection of least resistance. The lungs are at last inflated and we have the "sigh of relief"; in sorrow especially the first form of relief is connected with weeping and sobbing; all of which are apparently determinerl by the overflow of the newly arising energies into the channels which have been most often called into activity in the past. ${ }^{1}$

\section{$\$ 3$. Thus far we have had under consideration the activities} of organisms of a passive, uninitiative kind. Later, in the levelopment of the race, as spontaneity became markerl, there may be supposed to have arisen, npon the presentation of objects-

E, certain co-ordinated activities leading to approach towards the object presented.

$\mathrm{F}$, certain co-ordinated activities leading to departure from the object presented.

Later on, as prevision became more marked-

$G$, certain co-ordinated activities tending to the driving away of the object presented.

${ }^{1}$ Cf. James's Ps\%, 1. 445. Note also Darwin, op. cit. chap. vii. for a fuller treatment of this sulject than seems necessary here. 
$\mathrm{H}$, certain co-ordinated activities tending to hring abont attraction of other individuals.

Evidently the co-ordinations above discussed would, under the laws of survival, become connected with advantageous and disadvantageous objects, so that approach and activities tending to attract would become connected with advantageous objects, and departure and repulsive activities with disadvantageous objects. Whilst this comection was becoming established, we might expect also the rise of certain

I, co-ordinations of activities tending to effectiveness of attention and certain

$K$, co-ordinations of activities relative to the imitation of individuals, which will result alvantageonsly for those who follow such companions as have learned to avoid evils anrl gain goods.

In the cases $\mathrm{H}$ and $\mathrm{K}$ where the activities would be of a very varied nature, we should not look for coincident, relatively definite, conditions of conscionsness which would be relatively fixed.

To these we return later.

In the cases E, F, G, I, however, such relative fixity should be looked for.

As a matter of fact we do have the following mental states:--

E. Love arising with tendencies to approach an object, which, in the long rm, has been racially advantageous.

F. FEAR arising with tendencies to depart from an object, which, in the long rum, has been racially disudvantergeous.

G. AxGEr arising with tendencies to drive away an object, which, in the long rum, has been racially disulvantageous.

I. Surprise arising with tendencies to effective attention.

The word Love, under my terminology, is evidently used in a broad sense. If it be correct, then much of what goes by the name of love is so called becanse of indirect combination or comnection with the 
psychoses here described; the connection, and cause of identity of name, however, being assignable in all cases I have examined. Sexual love is a particular form of this feeling differentiated by the presence of the tendency to act with sexual reference. Professor Bain ha: referred the love psychosis to the pleasures of touch, particularly in reference to the embrace. A summary of his statement of the case, with Professor James's criticisns, I recommend to the reader as being more interesting than anything I could write. ${ }^{1}$

Darwin's statement of the relation of love to contact appears to me more accurate than Professor Bain's.2 As Darwin "says, "The feeling. which are called tender are difficult to analyse; they seem to be compounded of affection, joy, and especially of sympathy."

When we consider to what a wide range the word "love" is applied it becomes very rvident that any limitation of it to sexual reference in impossible. We love our fool, our sports, our homes, our country, our parents, our male friends, and in none of these cases is there any embrace element apparent. Sexual love is indeed the most vivid and jowerful form of love, but surely with the examples above noted it is apparent that there must be some general basic state common to all these special forms of lore, and to which are superadded the farreaching effects which we realise when the olject loved is of the opposite sex. The common ground, I think, is this impulsive tendeney to subordinate all activities to those necessary to bring about our approach to the loved object. ${ }^{4}$ At all events, it seems clear to me that all love does contain this, and therefore it is perfectly legitimate to use the word to intieate the general "instinct-feeling" which I here describe. When I love, I find always a tendency to nove out of $\mathrm{my}$ immediate environment towards its object; this mental state has distinct elements localisable in the muscles I would use in leaving my chair and walking forward, and I must acknowledge muscular sensations in arms and chest which are not unlike what would go with the embrace; but of course these elements are not all; the love is the total vibration of the system which, if carried out to its full conclusion, would make us arise and go to the loved one as did the prodigal to his father. Horwicz ${ }^{5}$ tells us that there are three signs showing the true content of love. 1st, The seeking to approach the loved one or the striving to unite. 2nd, The willingness to sacrifice oneself. 3rd, Feeling $(G e f i i h l)$, sympatlyy. It seems to me that 2 and 3 are rather resultants, than of the essence of love. The willingness to sacrifice oneself pobably arises from the fact that love is indirectly induced by actions which give pleasure to others; while sympathy in

1 .Tames's Psy., vol. ii. l'p. 551, 5.52.

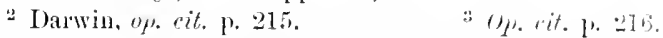

4 Cf. Martineau, Thpes of Ethieml Theor", ii. 1\% 12:3.

5 thrlysen, vol. iii. 1'. 452. 
a condition of love's continuance: withont it, inharmonions relations soon arise to break the bond.

As we have already seen, the activities of fear under this theory are directly opposed to those of love, and we have noted that the two states are acknowledged to be incompatille. When an animal or child fears us we overcome the fear, that is, leplace it with love, by berging it to come to us, not by approaehing it; anl when we wish to bring ourselves to love other's we volnntarily go towards and keep with them. Similar relations will be found with the equally incompatible state of anger, which we disellss later.

Fear is closely allied to dread above treated, but is differentiated from it by intense impulses to move away from the object presented. ${ }^{1}$ The word "panie" may be alplied to that state of fear in which there is attually active moving away from, but fear, as usually experienced. has the impulses to turn and rum, in part restrained. Thus fear involves at the same time the conditions of rlead : and it is as though Nature had taken the forces accumulated by the original inhibitury effects following the presence of danger, and had made them of use by forcing them through certain ehamels in which they might be most effective in taking the individual from the danger. There is the "sinking of the heart" and the psychosis of general contraction noticed also in dread when the clanger is not definitely localised; but, with this, intense involuntary impulses to turn and flee which ean be overcome only by great voluntary effort. The intensity of the tendencies to flight indeer very often prorluce, as we have already seen in discussing dread, an overthrow of co-orlination which results in trembling and leath-like paralysis.

Movements in the direction of the object presented break down lear. Face your enemy and advance upon him, and he no longer appears the formidable antagonist he seemed a moment ago. Alproach the lions, as did Christian in the P'ilyrim's Progress, and you find them chained. Courage comes with this action, as fear comes with the turning and moving from the ohject, even when this action is taken voluntarily, as I have alrealy noted. Love which learls one to go out to its object "casteth out fear." Anger, which is the impulse to attack, may alternate with, hut cannot be simultaneons with, fear.

The complete ontcome of AxGer is recognivelly in actions to drive away or destroy the olject presented. There are sudden derangements of the general circulatory action - perturbations in the sympathetic nervous system; as in the ease of jor, "there is an expansion of the blood-ressels, an increase of innervation in the voluntary museles; but in anger the phenomena are more intense, so that often the limits of the co-ordinations of voluntary movements and of

${ }^{1}$ Cf. Leslie Stephen's Science of Ethice, 11. 51; alio Mitrtinean, op. cit. ii. 1. 129. 
their strength, under the power of anger, are overstepper so that the movenents become forceless and insufficient." 1 The likeness to joy is seen rather in the mood of the warrior going out to battle than in that of the man suddenly impelled to action by the unlooked-for appearance of an enemy.

But beyoud these general effects there can be no question that typical anger has necessarily connected with it hostile attitudes and actions. As Aristotle ${ }^{2}$ put it, "Let anger be defined as an emotion accompanied by pain, impelling us to inflict open punishment for any appinent eontempt towards ourselves or those belonging to us." I shall quote from Ditrwin "again : "Rage" (which he considers to be anger of narked degree) "exhibits itself in the most diversified manner. The beart and eireulation are always affected ; the face reddens or becomes purple, with the veins on the foreheat and neck distented. . . On the other hand, the action of the heart is sometimes so much impeded by great rage, that the countenance becomes pallid or livid, and not a few men with heart disease have dropped lown deat under this powerful enotion. The respiration is likewise affected; the chest heares, ant the dilated nostrils quiver: As Tennyson writes-

Sharp breaths of anger puffed her fairy nostrils out.

Hence we have such explessions as 'breathing out vengeance, and 'fuming with anger.' The excited brain gives strength to the muscles, and at the sane time energy to the will. The body is commonly held erect ready for instant action, but sometimes it is bent forwards towards the offending person, with the limbs more or less rigid. The month is senerally closed with firmness, showing fixer determination, and the teeth are clenched or ground together. Snch gestures as the raising of the arms, with the fists clenched, as if to strike the oflender, are common. Few men in a great passion, and telling some one to begone, can resist acting as if they intender to strike or push the man violently away. The desire, indeerl, to strike often becomes so intolerably strong, that inanimate objects are struck or dashed to the ground; but the gestures frequently become altogether purposeless or frantic. .. The lips are sometimes protruded thring rage in a manner the meaning of which I do not understind, unless it depends upon on descent from some ape-like animal. . . The lips, however, are much more commonly retracted, the grinning or clenchel teeth being thus exposed. This has heen noticed by almost every one who has written on expression. The appearance is as if the teeth were uncovered, ready for seizing or traring an enemy, though there may be no intention of acting in this manner."

${ }^{1}$ Lange, op. cit. 1. 32. My translation is free. The whole chapter is interesting.
2 Rhetoric, Book Il. chap. ii.
: op. cit. ]. $240 \mathrm{nr}$. 
That anger camot be fully experienced withont these activities of hostility will, I think, become evident to any one who will try to feel anger while avoiding any of its characteristic expressions, e.y. while stroking the head of a child, with a smile on one's face, with the teeth apart, with the hands unclenched.

That Surprise is always accompaniel by activities looking to the perfection of attention is, I think, shown in the following quotation from Darwin ${ }^{1}$ : "Attention, if sudden and close, graduates into surprise, and this into astonishment, and this into stupefied amazement. The latter frame of mind is closely akin to terrol: Attention is shown by the eyebrows being slightly raised; and as this state increases into surprise, they are raised to a much greater extent, with the eyes and mouth widely open. The raising of the eyebrows is necessary in order that the eyes should he opened quickly and widely, and this movement produces transverse wrinkles across the foreheat. The degree to which the eyebrows and mouth are opened corresponds with the degree of surprise felt; but these movements must be coordinated, for a widely-opened month with eyebrows only slightly raised results in a meaningless grimace, as Dr. Duchenne has shown in one of his photographs. On the other hand, a person may often be seen to pretend surprise by merely raising his eyebrows. . . The eyes and month being widely open is an expression universally recognised as one of surprise or astonishment. Thus Shakespeare says, 'I saw a smith stand with open month swallowing a tailor's news' (King John, Act IV. Seene ii.). And again, 'They seemed almost, with staring on one another, to tear the cases of their eyes; there was speech in their dumbness, language in their very gesture; they looked as if they harl heard of a world destroyed' (IVinter's Tale, Act $V$. Scene ii.) . . That the eyebrows are raised by an imnate or instinctive impulse may be inferred from the fact that Laura Bridgman invariably acts thus when astonished, as I have been assured by the latly who has lately had charge of her. As surprise is excited by something mexpecterl or unknown, we naturally desile, when startled, to perceive the cause as quickly as possible; and we consequently open our eyes fully, so that the field of vision may be increased, and the eyeballs moved easily in any direction. But this liardly accounts for the eyebrows being so greatly raised as is the case, and for the wild staring of the open eyes. The explanation lies, I believe, in the impossibility of opening the eyes with great rapidity by merely raising the upper licls. To effect this the eyebrows must be lifted energetically. Any one who will try to open his eyes as quickly as possible before a mirror will find that he acts thus; and the energetic lifting $u^{\prime}$ of the eyebrows opens the eyes so widely that they stare, the white being exposed all around the iris. Moreover, the elevation of the eyebrows is an adrantage in looking upwards; 
for as long as they are lowered they impede our vision in this direction. The cause of the mouth being opened when astonishment is felt is a much more complex affair; and several causes apparently concur in leading to this movement. It has often been supposed that the sense of hearing is thus rendered more acute; but I lave watched persons listening intently to a slight noise, the nature and source of which they knew perfectly, and they did not open their months. . . Every sudden emotion, including astonishment, quickens the action of the heart, and with it the respiration. Now we can breathe, as Gratiolet remarks, and as appears to me to be the case, mucl more quietly through the open mouth than through the nostrils. Therefore when we wish to listen intently to any sound, we either stop breathing, or breathe as quietly as possible, by opening our months, at the same time keeping our bodies motionless. . . When the attention is concentrated for a length of time with fixed earnestness on any object or subject, all the organs of the borly are forgotten and neglected, and as the nervous energy of each individual is limited in amount, little is transmitted to any part of the system, excepting that which is at the time brought into energetic action. Therefore many of the museles tend to become relaxed, and the jaw drops from its own weight. This will accomnt for the dropping of the jaw and open month of a man stupefied with amazement, and perhaps when less strongly affected. I have noticed this appearance, as I find recorded in my notes, in very young children when they were only morlerately surprised.

"There is still another and highly effective cause leading to the mouth being opened when we are astonished, and more especially when we are sudkenly startled. We can draw a full and deep inspiration much more easily through the widely-open mouth than through the nostrils. Now when we start at any sudden sound or sight, almost all the muscles of the body are involuntarily and momentarily thrown into strong action, for the sake of guarding ourselves against or jumping away from the danger, which we habitually associate with anything unexpected. But we always unconscionsly prepare ourselves for any great exertion, as formerly explained, by first taking a deep and full inspiration, and we consequently open our mouths. If no exertion follows, and we still remain astonished, we cease for a time to breathe, or breathe as quietly as possible, in order that every sound may be distinctly heard. Or again, if our attention continues long and earnestly absorbed, all our muscles become relaxed, and the jaw, which was at first suddenly opened, remains dropped. Thus several canses concur towards this same movement, whenever surprise, astonishment, or amazement is felt."

The conscious side of the sudden turning towards the unknown object is an element of surprise which deserves further emphasis than Mr. Darwin grives to it. The action looks to more perfect adjustment of the organs by which knowledge is reached. We have become so 
accustomed to this action that we make a figure of speech from it, and talk of being terned from a train of thought by some surprising relation. Any one may convince himself that surprise is dependent upon the activities above described, and cannot be experienced if they be eliminated, if he will make the attempt to be surprised mon imagining a sudden noise back of him and remain without turning, holting his teeth clenched and keeping his eyes closed.

$\S 4$. Now it is to be noted that all of the definite mental states thus far mentioned-.Joy, Dread, Sorrow, Relief, Love, Fear, Anger, Surprise-are typical emotions; and this leads us to the hypothesis that motions are the relatively fired psyrhoses (instinet-feelings) coineident with correspondingly fixed co-ordinations of instinetive activitics arising "pon the jursentation of determinate objective conditions.

It is apparent that in what has preceded this we have been treating of the widest distinctions only. Under the theory defended no two emotions are likely to be identical in different men, or even in the same man at different moments, for it is lighly improbable that there will ever be an exact recurrence of a certain combination of components in an impulsive reaction. As Paulhan ${ }^{1}$ says, "Il n'y a pas deux émotions semblables; l'amour, chez Stuart Mill, n'est pas le même que l'amour chez Casanova. De même, le même homme n'est generalement pas amoureux ou ambitienx, ou orgueilleux à quarante ans, exactement de la même manière qu'il l'a été à dix-huit ans." It is evident, under such circumstances, that, as has already been suggested, there is great danger of being misunderstood in any description of what is the content of any named emotion. But this danger must be braved.

The name given to a state must be determined by its most prominent, ever-present, and generally-recognised differential mental components. When one runs impulsively

1 Phenomènes Affectifs, p. 15\%. See also p. 158 for development of this same notion. 
from a danger towards a protector, the psychic side of the activities of ruming are common to both the state of love with which he looks forward, and to the state of fear with which he looks back; but these psychic coincidents of running being relatively unimportant, are scarcely considered. What are considered are the complex reactive psychoses which always appear in consciousuess when he loves, and those diverse ones which appear when he fears. We are to consider, therefore, in each case that constant mental complex which is always experienced whenever we designate our state of mind by the name of one of the emotions, paying especial attention to characteristic differential elements.

Still the psychic side of the muscular reactions which make up the visible expression with which we have principally been dealing, must be important, if the hypothesis be correct. The muscular sensations, in truth, attract most attention in the introspective study of emotional states. I think it evident that these sensations are, in all cases where expression is marked and disparate, exceedingly important elements, and are those which are most easily fixable, and by which, therefore, we for the most part differentiate the several states $^{1}$ in other worls, the muscular elements mainly determine our broader classification and naming of the emotions; but it is apparent, I think, that they cannot make up the total of what we speak of as an emotional state of mind.

Nor do I think it is at all possible to limit the physical activities involved with the emotions, to such effects of voluntary innervation or alteration of size of blood-vessels or spasm of organic muscle as Lange seems to think determine them ; nor to increase and decrease of muscle power as Féré's results might suggest; nor to such changes, in relation of

1 Cf. Professor James's article in Mind, 34, and my discussion of the same in 36 . 
size of capillaries, in voluntary immervation, in respiratory and heart functioning as Lehmann ${ }^{1}$ has observed.

The fact is that we are still very much in the dark as to the physical coincidents of the emotional psychoses, and in my judgment we always shall be. For these emotions seem to me to be coincidents of reactions of the whole organism tending to eertain results. The superficial changes involved we may to some extent discover, but until we reach a stage of omniscience we camnot hope to understand and describe all the activities and their relations that are involved. We may, however, with propriety roughly classify our emotional states by broad distinctions of physic content as comnected with certain ends that we see attained by the reactions; as I have done above: but we must acknowledge that each individual idiosyncrasy and each temporary change of individual activity should alter in small ways the psychic complex, and this, as we have seen, accords with experience.

To go further with this developmental consideration would perhaps be possible, but the value of such argument, doubtful, some will say, even as far as we have gone, becomes more so the further we proceed, because of the uncertainty as to the history of our racial development. I think it worth while, however, to say a few words in reference to the psychological hypothesis to which this cursory developmental view leads us.

$\$ 5$. The definition of emotion above given is opposed to the ordinary notion that emotions are mental states which cause certain expressions. We should speak not of the expression of the emotions, nor of emotions as caused by the expressive activities, but of the emotions as the psychic side of these expressions, using this last term broadly. This is the position involved in the definition of emotion adopted by

${ }^{1}$ Cf. Lehmann, op. cit. pp. 64 ff., $112 \mathrm{ff}$. 
Professor James in his Pyychology, ${ }^{1}$ where he says: "The bodily changes follow directly the perception of the existing fact, and our feeling of the same as they oceur is the emotion;" but the definition I give does not involve the doubtful contention which Professor James makes, viz. that the emotion is causcl by the expression. Whether this contention be verified or no, the definition I give seems to me to hold true. Professor James's own acute arguments seem to me to afford us full reason for accepting the view that emotions are not psychoses which cause the expression, but are the psychic coincidents of the expression, and of what goes with it.

That all typical emotions are determined by the appearance of percepts, and are instinct-feclings, ${ }^{2}$ will, I think, not be denied. Although in our complicated life we have come to realise the end to which our vivid emotions lead us, they are in no sense dependent upon that knowledge for their power. Where an emotion appears to grow upon us, it is because the object of it gains gradually its place in its group. The casual acquaintance becomes one whom we love, not as the result of the appreciation of advantage to be gained by his co-operation, but as soon as his general action towards us has placed him in the category of those who are in sympathy with us; the emotion is changed in character and force, but is immediate at each step; the love once gained is not easily overthrown by evidences of perfidy. To take another instance, the boxer strikes at first with calculated precision, but presently, when "he warms to his work," he becomes angry, the

1 Vol. ii. 1. 489.

2 The weakening effect of a suddenly arising emotion, as noted by Wundt in his Psy. Phy., 3rd edit. vol. ii. p. 406, is due, doubtless, to this instinctive nature of emotion, and to the fact that its power is dependent upon the immediacy of the reaction; it works suddenly, to the equally sudden loss of power and activity in the parts not necessarily acting in the direction of the object of the emotion. The psychosis of this weakening forms, of course, in certain directions, an important element in the complex which we call the emotion. 
blows follow one another withont the intermediation of thought. He then becomes a true fighter.

If, then, the emotions are determined by the instinctive activities, each marked difference of activity should be accompanied by a difference of emotional quality. The psychosis, when one cowers before an approaching danger, is clearly not the same as that when one is actively fleeing from danger, although there is so much in common between the two states that both are carelessly called ferers. Rage similarly, with its active demonstrations, is certainly apart from hatred, with its quieter calculations. The love which involves the wide excitement, the intense glandular secretive activities which arise when the loved object is of the opposite sex, and one with whom sexual relations are possible, must be a very different total complex from the love towards a brother, from which the excitements above mentioned are entirely eliminated.

Under such a view it is evident that the incompatibility of the activities involved in the two cases should lead us to expect to find that "perfect love casteth out fear," as we read in the Scriptures. Aristotle noted the same and lindred facts. "No one loves a person whom he fears," says he ${ }^{1}$ and again," "It is impossible to feel anger and fear at the same time." In like manner, for instance, we should be prepared to find it impossible, as it is in my own case at least, to experience anything like definite surprise with clenched teeth and half-closed eyes; open eyes and mouth being characteristic surprise expressions. Inifferences between the mental hahit of individuals should also be expected to lead to such differences of conception of the content of the several emotions, as we find. Actions brought about by will or by accident should in a wide way be accompanied by psychoses similar to what wonld be experienced were the acts such as 
"express the emotions." Let one in the dark, hearing footsteps behind one, start suddenly to walk faster. If he pay close attention, he will note the "sinking of the heart" and other psychic effects which go a great way to make up fear proper. Other instances of importance are given by Professor James. ${ }^{1} \quad$ His argument by exclusion, ${ }^{2}$ too, is suggestive for us here. That the cutting off of the important muscular or other components of a complex emotional state, one by one, should reduce the emotion by great steps correspondingly, is to be expected under our hypothesis.

$\S 6$. A few points may well be brought forward which give indirect corroboration in reference to the emotions above described.

Joy, sorrow, dread, and relief may be grouped together. In view of the relations to general activities above described, joy and relief, on the one hand, should be expected to show close bonds: sorrow and dread on the other; and thus we find them. Of the more active emotions fear should be found closely allied to dread, and because it must have its canse in the actions of others, should be somewhat less emphatic in our experience than love and hate, which, on the other hand, imply spontaneity, an emphasis of our individuality, a going out towards others. No wonder is it that Empedocles held love and anger to be the determinants of all phenomena. As Mr. Bain says, they "stand out boldly as giants of the group."

The relation to safety in the presence of danger which is common to both hate and fear should make the transition

1 Psychology, vol. ii. p. 462 ff. Lehmann (op. cit. p. 114) justly holds that it is impossible to claim an identity between these "artificial emotions" and the emotions as normally initiated, for if they were the same we would be unable to note the difference between them. All that can be claimed, of course, is that a large proportion of the psychie elements are the same in the two cases, and this is all that is needful for our argment.

2 llikl. 1. 463. 
from one to the other very easy. This is a matter of experience. The animal driven to bay loses fright, and fights with a fierceness which is proverbial. Those dangerons objects which are pre-eminently too powerful for us to withstand, excite fear, and those which are notably weaker than we are excite anger or disdain. The lion, even when caged, is fecivd, not hated. We detest snapping lap-dogs, and spiders and mosquitoes.

Seven of the emotions above discussed are held to be determined by relations to advantageons or disadvantageons objects; but it is apparent that (1) there are cases where the emotion arises while the relation claimed can be shown not to exist; and (2) there are cases in which the relation cin be shown to exist where the looked-for emotion does not appear. These exceptions are explicable on developmental lines.

The second point above mentioned needs little discussion, for it is evident that if there be many recognisable dangers from which we do not instinctively recoil, and many recognisable gains which we do not instinctively reach ont towards, this is to be expected where conditions are relatively new to the race. The first point is covered by the supposition that the inherited tendencies have in the past history of our race been connected with the advantages or disadvantages which we now fail to realise; and enongh instances can be brought forward, in which we are able to see that the looked-for relation has existed in the past, to warrant us in accepting the supposition as probable. The joy and sadness connected respectively with the thonght of the coming of Spring and the departure of Summer are not commensurate respectively with the advantage and disadvantage to us in these days. For us the fluctuations of season bring little practical change; the previsions and precautions of modern life have broken the force of the dangers and have taken away from 
the importance of the gains; but among our ancestry there must have been a very direct relation between Spring and ease of living, and between Winter and hardship. The same may be said with less force about the joy connected with sumrise, and the sadness with evening; for us, who turn night to day, the commection with changes of general activity must be greatly lessened. Both of these cases, especially the latter, are complicated by real increase or decrease of general activity in the manner already touched upon.

Many dread every approaching thunderstorm, and feel relief at its departure; the dangers connected with lightning effects, so slight for us, must have been very considerable for our quasisimian ancestors. Real fear is experienced by timid people upon seeing the beasts of prey in a menagerie. Their fierce cries and ferocious aspect and appearance of power must carry $n s$ back to the times when they were a real canse for alarm; for, encaged, well fed, and closely guarded, they are as nearly harmless as anything in our enviromment can be. Malevolence, too, is shown towards insects and smaller reptiles which do not harm us, but which we can imagine may, in certain species, have been exceedingly dangerous to our forefathers. The love felt by mány people for dogs seems inconmensurate with their advantage to us. Under om system of living, they are indeed often real nuisances; but as protectors and helpers our ancestors must have found their companionship of great value.

$\S 7$. The principal point of interest for us, in comnection with this hypothesis, lies in the fact that if the theory maintained be correct, the separation of pleasure and pain from the emotions is evidently a psychological necessity; for it is manifestly impossible to hold that pleasures and pains are "relatively fixed psychoses," or that they "correspond to 
fixed co-ordinations of instinctive activities," or "arise upon the presentation of determinate objective conditions." Or, to use I'rofessor James's terms, it is clearly impossible to think of pleasures and pains as "our feelings of the bodily changes which follow directly the perception of existing facts."

IIoreover, pleasures and pains are not determined by percepts, as emotions are; they are part and parcel of the elements which go to make up these percepts, as well as of the simpler' states which we call sensations, to go no farther. Again, pleasure-pain modes do not differ radically with the differences of content to which they are attached, as emotions do. The pains of sorrow and the pains of fear are not essentially diverse, nor are the pleasures of love and those of trimmph opposed in any way, notwithstanding the great distinction between the states to which they are attached. Again, pleasure-pain modes cannot, with the least degree of certainty, be brought about by will or by accident, through the stimnlation of the activities which have before brought them to us. The objects,-the sensations which one day give us pleasure produce pain on another day. Finally (to adopt from Professor James the method of exclusion), it is clear that we do not lose all of our emotion if we think ont of it all of its pleasure-pain; there is much else left which is recognisable as emotional still. On the other hand, we are able to eliminate the pleasure or pain only if we at the same time effect the gradual obliteration or radical alteration of the elements to which they have been attached. It appears to me, therefore, that the position taken in Chap. I. as to the separation in classification of emotion and pleasure-pain is amply justified.

It may be urged, however, that we have passed over one notable reason why the two groups of phenomena should be classed together. It may be held that there are definite expressions for pleasure and for pain, and that this fact forces us, under the above theory of the emotions, to place pleasure 
and pain under the emotional category. I think it will appear clear, however, to any one who studies the subject, that "expression" is quite a different matter in the two cases. Emotional expression is called out by and relates to objects. Pleasure-pain expression is called out by and relates to distinctly subjective states. Darwin, althongh his thought is obscured by the prevailing uncertainty of terminology and by his failure to consider the distinctions between pleasurepain and emotion, nevertheless brings out clearly in his book on the subject that the expression of pleasure is little else than the result of an overflow of surplus energy into channels which are otherwise in frequent use (which, as we shall see later, is a fact we should look for under our theory), but with no discernible end. The activities which pain brings about are very wide, involving the whole nervous system. ${ }^{1} \mathrm{Mr}$. Darwin has shown us that the more evident external expressions of pain involve activities which tend to relieve the pain by alteration of attention, ${ }^{2}$ or by efforts to remove the paingiving object or to attract what may aid, or by actions tending to protect delicate parts of the organic system during the violent actions which these efforts imply. ${ }^{3}$

Inasmuch as it is perfectly possible in many cases by an effort of will to inhibit the expressions of pain without in the least reducing, but rather with the likelihood of increasing, the pain itself; and, on the other hand, to inhibit the expressions of pleasure without reducing the pleasure except so far as it was

${ }^{1}$ Cf. Mantegazza, La Physiologie d. l. Douleur, 1. 60. He lias attempted to show that the obscurer activities in part tend to "prodnce carbonic intoxication, which alleviates the painful sensation."

2 Cf. Mantegazza, op. eit. p. 219, for a variety of examples.

3 Lehmann (op.eit. p. 75 ft.) has lately attempted to define special effects of pain and of pleasure upon heart action and respiration and capillary volmme. His results do not convince me that he has found any expressive effects for simple pleasures or pains, or that he has defined the whole of the effects examined. Nor do they slow, in my opinion, that there is any special action for pleasure or for pain apart from influences of the contents to which they are attached. 
distinctly part and parcel of the muscular contractions involved in the pleasure state thus narrowed, it seems evident that the expression in these cases is a different thing from emotional expression proper, which, as we have seen, cammot be cut off without distinctly limiting the emotional state.

It seems to me that it may be held that pleasure and pain bring rbout true emotional states which are the psychoses of the activities involved in and with their so-called expressions. This position is corroborated by the fact that so soon as the expressions become separated from pure subjective reference and relate to oljective conditions, then they tend to become identified with well-recognised emotions. Heasme expressions, when extreme, tend to bring about general activities, and the pleasure is identified with joy. Pain expressions bring us sorrow or dread, or the violent activities with which anger is commected. When pleasure leads us to an object we find ourselves loving it. But the pleasure would be there even if we made no motion, actual or ideal, towards it. When pain leads us to strike the mosquito we feel anger, but the pain would have been there had we made no attempt to kill.

It is apparent that the facts here emphasised enable us to account for the common classification together of emotions and pleasure-pain, above referred to, in a mamer more satisfactory than was possible in Chap. I., where a partial explanation was given of the lack of distinction. We shall find, indeed, further ground for this ordinary lack of discrimination which we were umprepared to discuss at that time, but which is appropriate here. The two sets of phenomena are allied in that both are primitive; in both cases we are able to trace their genesis back to the earliest developments of consciousness; both guide towards the advantageous or away from the disadvantageous, the development of sensational discrimination not showing this character- 
istic. In the case of pleasure-pain, as we shall presently see, we need to postulate only so much mental power as will make possible the discrimination between the psychic phases which are the coincidents of nerve states, healthful or unhealthful, to the nerve organ. In the case of the emotions, we need to postulate a broad step in the development of intelligence, viz. the capacity to recognise objects.

It will perhaps be well here to consider a little more closely the theory which attempts to show that the emotions are complexes of pleasme and pain in representation.

The early associationists, attracted by the strong algedonic quality appearing in the emotions, and not unnaturally tending to carry to extremes their thought as to association, suggested the hypothesis that there is nothing in the emotions except revivals of pleasures and pains which have been experienced directly, or which are transferred (from means to end, for example), and which cause the bodily actions called their expressions. The theory was not carefully thought out, and has shown no little weakness under the examination of the associationists themselves. A serious flaw in the theory is brought forward by Professor Bain (James Mill's Analysis; note to chap. xxi. sec. ii.) when he says, "Anything that looks solely to the circumstance of pleasure and pain (important as that is) fails to grapple with all the facts. For example, there is no account rendered of the very familiar emotion of wonder." Mr. J. S. Mill (in the note to same chap. and sec.) presents a still more notable objection to the theory in the following words. He takes fear as an example of the psychoses in question and says, "The idea of a pain, ${ }^{1}$ if it acts on the bodily functions at all, has an action of the same kind (though much less in degree) as the pain itself would have. But the passion of fear has a totally different action.

${ }^{1}$ I should say the painful reviral of a pain. 
Suppose the fear to be that of a flogging. The flogging itself, if it produced any physieal demonstration, would produce cries, shrinkings, possibly muscular struggles, and might by its remoter effects disturb the action of the brain or of the circulation; and if the fear of the flogging produced these same effects in a mitigated degree the power of fear might be merely the power of the idea of the pain. But none of these are at all like the characteristic symptoms of fear; while those characteristic symptoms are much the same whatever be the particular pain apprehended, and whether it be a bodily or a purely mental pain, provided it be sufficiently intense and sufficiently proximate. No one lats ever accounted for this remarkable differenee." Another objection ocenrs to me which may be mentioned here. If the so-called emotions are merely representative pleasures and pains, then the representation to ourselves of the pleasures and pains coming to us should produce in us the "emotions." Any one who will experiment in this particular will, I believe, decide that no such rise of "emotion" takes place under such cireumstances, $e \%$. no amount of representation to a hungry man of the pleasures of eating or of gratitude to a possible benefactor can bring about joy such as would follow upon the appearance of some one bearing food.

Later on Darwin and other evolntionists ealled attention to the usefulness of the expressions to the individual and the race, and this seemed to strengthen the associationist position, although in reality the valuable results obtained from evolutionary inquiry served to mask the weakness of the fundamental notion.

Höfding in his Psychologic has lately taken up the original doetrine, and has stated it in most attractive form, but he brings no new or effective argument to prove the position. 
Lehmann ${ }^{1}$ still more lately has defended the hypothesis, and, in my opinion, has for the first time stated it in a form that makes it worthy of serious consideration. It may be put thus :-

(A) Each intellectual element has attached to it a definite pleasure or pain phase which is not alterable ${ }^{2}$ without a practical change of individuality; hence, when this element is revived, its fixed pleasure or pain phase is revived also. Pleasures and pains cause motor activities (or expressions) which differ with the intellectual elements to which they are attached. $^{3}$

Emotions are strong complex pleasure or complex pain states, largely representative (B), which cause complex motor activities, which latter add their pleasure-pain qualities to the totality.

This is apparently a rational hypothesis, but it is founded, in the first place, upon a dogmatic assumption (B), which cannot in any way be proven, and which is not a necessary one.

In the second place, it is untenable, because the evidence all points to a denial of the notion (A) that unalterable algedonic phases are attached to each intellectual element (Vorstellung). ${ }^{4}$

In the third place, it fails, because, as I shall presently show (Chap. V. Appendix II.), emotions which have a practically fixed content (Voistelleng) are experienced by an individual, within narrow time limits, in variable algedonic phases, which would be impossible if the hypotheses were correct.

The theory, indeed, is entirely without force unless the

1 op. cit. p. $56 \mathrm{ff}$.

P. 165 ff.

3 P. 278.

${ }_{4}$ Note the cases in opposition to his view which Lehmann himself gives (op. cit. p. 162 ff.), and explains lamely as due probably to the fact that new intellectual elements here enter with different algedonic phases. See Chap. V. Aplendix 1I. of this book for further evidence in opposition to Lehmam. 
emotion, which is a psychosis of comparative fixedness, is made up of elements which have a similar fixed character.

It is hard to see how so complex a thing as an emotion could be formed by summation of such simple mental elements as pleasure and pain are usually held to be. The most we should expect from such summation would be an increase or decrease of pleasure or pain; for, as Aristotle says, "pleasure is a certain whole," the form of which cannot be perfected by any time-process, nor by any process of summation of elements, and the same may equally well be said of pain.

If we examine the facts apart from the assumption that the expressions are caused by states of pleasure or of pain, we find that certain general systemic reactions (inclusive of muscular ones), with their algedonic tones, have become connected with the perception of objects which have brought in the past not necessarily pleasure or pain to the individual, but racial advantage or disadvantage.

That pleasures and pains produce reactions, and that these reactions may have been co-ordinated by inheritance to ward off the particular pain and retain the particular pleasure, is true; but it is apparent that the pleasure or pain, if of presentation, or even if the phase of a representation of an idea, would bring action connected with that presentation or idea only, and that no summation of such pleasures and pains would result in a fixed state like an emotion with elements relative to racial result, apart altogether from the pleasure or pain of the individual.

It is conceivable, however, that complex perceptions of objective conditions bearing certain relations would produce certain complex reactions, which would be turned to account racially, as suggested above; and as these reactions would be powerful, they would be highly pleasurable or painful ; hence 
it seems more rational to adopt the hypothesis that the emotions are the psychoses of these reactions.

It becomes apparent now that the true relation between pleasure-pain and the emotions is this. The emotions are complicated psychoses which almost invariably involve either repressions or hypernormal activities, either of which, as we shall presently see, are determinants of pleasure or pain. The emotions as a class, therefore, must be notably algedonic, as we find them; but this gives us no logical ground, it appears to me, for the treatment of the emotions as a subclass under pleasure and pain, as is done so often. ${ }^{1}$ It is quite as inproper as would be the treatment of the sensations as a sub-class under pleasure and pain, because of the pleasure-pain quality bound up with the sensation.

$\S 8$. Let us now return to the consideration of the two sets of co-ordinated activities which we above reserved for later discussion, viz. $(\mathrm{H})$ the co-ordinated activities tending to bring about attraction of other individuals; and those $(\mathrm{K})$ relative to the imitation of individuals. In these cases, as already noted, as the activities called forth must vary markedly in different individuals, under our hypothesis we onght not to expect to find their conscious coincidents ot fixed nature for the race, and therefore we should not expect to find fixed name attachments commected with them. In

${ }^{1}$ Professor James Sully still clings to this illogical arrangement. His examination leads him to the conclusion (Human Mind, ii. 1. 57) "that emotion is in general describable as a mass or aggregate of sensuous and representative material, having a strongly marked and predominant concomitant of feeling or affective tone." Why this should lead one to treat the emotions under the "feelings," whieh he says (p. 46) "are constituted by elements of pleasure and pain," I cannot see, unless one treat the intellect also under the same heading. 
other words, we have here co-ordinated "instinct-feelings" coincidents of co-ordinated instinctive activities, which we should not expect to be designated as special emotions; but, on the other hand, we ought to be able to recognise the instincts themselves, and their "instinct feelings" we ought to be able to describe even if they are not fixed enough to be known as emotions.

The instinctive tendency to act-to-imitate is well recognised, and, on the psychic side, this tendency is named the "imitation inpulse" (Nachahmung-tricb) ; the "instinct feelings," however, as we should expect, have no named emotional state connected with them. Discussion of this particular impulse need not detain us.

The tendcney to act to attract other's requires more study. Pleasure being evanescent, under a given stimulus, the simplest means of retaining the pleasure consists in the increase of the stimulus in proportion as the pleasure tends to decrease; approach to the object stimulating involves this increase so far as the important direct stimulation through eye and ear is concermed, and in this way we may have the beginnings of the attractiveness of pleasure. However that may be, the attractiveness of pleasure-giving activities is unquestioned. It seems probable, therefore, that the first activities to become instinctive in this direction would be such as would lead impulsively and blindly to the production of movements by the actor, looking to the production of pleasure in those whose attraction is advantageous. The tendencies in this direction are seen among all the higher animals, being especially marked in competitive efforts to fascinate desirable mates. From these recognised attempts to attract, it is no abrupt step to the activities of the savage, bringing about the same result; nor is it difficult to recognise amongst ourselves the same tendency to act to compel attention. The instinctive activities in this direction are so 
varied that it is not surprising to us, from our point of view, when we find no very well-defined emotional name attached to these actions. They have enough in common, however, in the concentration of attention upon ourselves, which characterises all of them, to lead us to expect such emotional recognition as we find in the psychoses of what we call "selfconsciousness," which are their invariable accompaniment, blindly impulsive though they be.

It seems not improbable, under our hypothesis, that with a later development there would arise more complicated methods tending to bring about attraction: first, tendencies to the production of objects or objective conditions which shall please; and second, and still more complex in their nature, tendencies to actions or to the production of objects or conditions which shall be useful. Under our hypothesis we certainly should have no reason here to expect to find fixed and named emotional states corresponding even approximately to such varied activities; on the other hand, we ought to find these tendencies recognised as impulses. The second group we find no difficulty in identifying with the benevolent impulses. How is it with the first group? Is there any blind impulse in man leading him to produce objects or objective conditions which shall attract by pleasing? I think we have it in the widely-distributed impulse to artistic production.

The "art impulse" is a blind impulse which leads men to create with little or no notion of the end they have in view. ${ }^{1}$ That this art impulse in one form or another is a common heritage for all members of our race is, I think, true without

1 As Richard Wagner has stated it, "in the artist the presenting force is in its very nature uncouscious, instinctive; and even where he requires thought in order to form the outline of his intuition, by the aid of the technical ability with which he is endowed, into an objective work of art, it is not exactly reflection that decides for him the choice of his means of expression, but rather an instinctive impulse, which constitutes indeed the character of his peculiar talent." 
doubt. What child, what savage, does not show some tendency to use his surplus vigour in crude attempts to produce works which in their developed form give us our best art products? Almost every adult feels some tendency to write verses or to compose melodies, or to dabble with the brush and palette, or to represent his thought with the draughtsman's pencil.

But, strange to say, there is a prevalent notion that the existence of an art impulse of any noticeable strength is a sure indication that the one who feels the impulse is especially "called" to devote his life to the production of art works. To use a comparison suggested by Mr. Rudyard Kipling; who would think, because he found his boy pugnacious with his companions, that he must make him a soldier, with a large chance that he would develop into a Napoleon?

The fact is that certain impulses develop in childhood which disappear entirely in after life; this, as far as we can judge, being the result of our growth by steps through forms which have belonged to our ancestors in the dim past. Capacities which appear to give promise in childhood may therefore be lost before the adult age; and this adult age, with its experience, must be reached before the man can become so especially skilful that he will stand apart from his race as one of talent or genius. This is true in all directions of development, in all vocations of life. There are geniuses in the world of finance and in the field of battle, as there are geniuses who work with sculptor's tool and painter's brush; but there are many men who work unknown in finance, many common soldiers; and likewise there are many who must feel the tendencies to artistic production who never can come to the front, because their capacity is not great enough to enable them to do work of high quality.

Those with moderate talent may earn their daily bread by turning their strength to the prociuction of what is useful for their fellow-man. Artistic work is essentially luxurious; it 
is demanded after the needs of man are satisfied, and therefore only that which highly attracts those who pay can be expected to win rewards. The man who has not high endowments as an artist cannot therefore hope to succeed in making a living out of art work, and, if my position be correct, should not feel that he is in any way called upon to devote his life to the production of inferior work in æsthetic directions merely because he feels the "art impulse "; far better were it for him to turn his energies in directions in which his efforts may lead to greater usefulness to the world at large, and in which at the same time there would be less of pain for himself and less of pain for the sympathetic public, who dislike to see the poor artist starve as much as he dislikes the process himself. Were these facts given their full weight many a man would hesitate, as he does not now, before undertaking art work as a vocation. In art, as in every walk in life, it is only those of talent or genius who succeed, while the many who are without talent must fail to produce marked effects; but in art the best work only is worth doing. In other lines inferior talent may find valuable work to do, even if it be not notable in quality.

That the art impulse leads to the production of objective conditions which attract by pleasing cannot be denied. That this result in pleasure-giving is fundamental in æsthetics will perhaps be called in question by some of my readers on the spur of the moment, but I think when they have examined the subject with me in what follows, from the psychological standpoint, they will see that the position is corroborated by that view. The chief value of this discussion here is that it shows not only that the theory I shall maintain from the standpoint of psychological introspection is compatible with the developmental theories of impulse genesis, but that these latter theories, based upon so 
diverse a view, lead us to look for the very result which I claim introspection forces upon us.

\$ 9. Before turning to the psychological consideration let me say a few words in reference to the "play impulse," from which, since Schiller's day, there has been a tendency to derive the impulse which leads the creative artist. Schiller's view was derived from Kant, and the notion, indeed, was practically a revival of Stoic thought. But both Kant and Schiller felt the "play impulse" to be wider than the "art impulse," and were led to derive the latter: from the former, because both arise without definite ends, with no evident human interests at stake.

By play we mean those activities, usually thought of as "spontaneous," which appear to have no objective reference and no function other than the using up of accumulated energy.

It is clear that the direction in which this energy will accumulate will be determined in our complex life by the co-ordinations of activities which have been or are to be turned to useful purpose, a point which has been emphasised by Mr. Herbert Spencer. ${ }^{1}$ But this fact may be properly overlooked in the consideration of the primitive "playimpulse"; for it is apparent that from these simple actions, tending to use up accumulated energy, must have been derived all those co-ordinations of activities which, in our complicated life, appear to subserve valuable ends; for without these simple, so to speak, fortuitous actions there would be no basis for the emphasis of co-ordinations by elimination or contest, survival or heredity,-if, indeed, after the discussions of today, hereditary influence in this particular direction shall be shown to be of moment. If this point be well made, we must

I Principles of Psychology, vol. ii., last ehapiter; see also his essay on "Use and Beauty." 
derive from the simple impulse to use accumulated energy, not only the "art impulse," i.e. the tendency to do blindly what shall attract by pleasing, but also all those impulses which involve more than reflex answers to stimuli, and with which we are able, after the act, to connect determinate objective ends. Love, anger, the imitation impulse, not to speak of the impulses to do what will prove of use; none of these can be conceived to arise in an organism which has no power to go out into activities beyond such as are the direct answer to stimulations. Nor ean we with Kant and Schiller hold that the "art impulse" is especially connected with the "play impulse " through lack of end, ${ }^{1}$ if I am right that an end for art work is discernible in attraction through the pleasing of others. Unconsciousness of the end conld, of course, not be claimed as a bond between the art and play impulses, becanse consciousness of end is as unnecessary with love and fear and anger, and the emotions in general, as with the "art impulse." The "art impulse" and the "play impulse" are, indeed, emphatically spontaneous-that is, they seem to go out in search of the object of their activity; but the same may be said, although apparently in a less degree, of the benevolent impulse, and, under certain conditions, of love and the fighting impulses.

We have thus far been speaking of simple conditions. If, when we speak of the "play impulse," we mean the impulse to undertake those complicated sets of activities which appear in our developed life when there is a surplus of energy that can no longer be held quiescent, then it appears to me that there is still less ground for the derivative connections between art and play activities.

I think I have above shown that it is possible dimly to

1 Mr. Herbert Spencer puts the thought in this language: "The activities we call play are united with the resthetic activities by the trait that neither subserve in any direct way the processes conducive to life." 
discern the useful end to which the art impulse leads, viz. the attraction of others by pleasing; this view will be strongly corroborated if, first, it can be shown that there is no other basis than that of hedonics upon which psychological resthetics can rest, and, second, that the artist does blindly work always to the production of objects or objective conditions which shall produce relatively permanent pleasures. The first point /I shall examine in the next chapter; the second in Chap. VI. 


\section{CHAPTER III}

THE FIELD OF \&STHETICS

\section{Introductory Summary}

A GREAT deal of attention has been given by thinkers in the past to the subject of Asthetics, but for all that we find ourselves to-day without any Science of Esthetics, and without any Philosophy of Art which is comprehensive and widely acknowledged as valid. This is probably due principally to the fact that thinkers of importance have found themselves called upon to deal primarily with theories of knowledge and of activity in relation to their fellows; and have turned to the discussion of Esthetics with preconceived notions and settled formula, to which they have subordinated the facts forced upon them from the realm of art.

Attempts have been made by many writers, who have taken example from Aristotle, to discover some special qualities in beautiful objects which determine their beauty (p. 115 ff.). These efforts have invariably failed. The same objective tendency is observed in the many efforts made by the best of thinkers to describe and account for certain absolutes or universals of beauty to which our individual experiences relate (p. 116 ff.). No agreement between thinkers in this direction has been reached, however, and we must acknowledge that no satisfactory resting-place for art theory has thus been attained. 
Better results seem to be within the reach of those who study the subject from the subjective side, examining the mental state of the observer of the beautiful in nature and art procluct; looking within for some principles of unity upon which to base a philosophic treatment of the subject.

The usual sensational initiative of resthetic psychoses (p. 119 ff.) has attracted attention to the sensational aspect, but it has been found impossible to discover any seusation, or group of sensations, to which the rsthetic is limited, nor do we find that the resthetic is determined solely by sensational experience.

Emotional states seem to be very closely allied to the resthetic; but we find upon consideration that we cannot limit the resthetic to emotional psychoses without counting sensation of no effect (p. 120 ff.).

The field of intellectual activity has also been presented as the special field of resthetics (p. 121). But this view would exclude the prominent sensational and emotional elements,-a proceeding which is indefensible. We find no distinctly intellectual product without which an æsthetic state of mind becomes impossible, nor does an examination of the intellectual processes themselves bring us any more satisfactory result. We find no special movement of thought, nor any distinct formal arrangement of thought elements, with which we can identify the rsthetic state of mind.

One bond of unity we do find (p. 122) in the hedonic quality of the rsthetic state. Whatever else they are, however much they may differ in other respects, æsthetic psychoses are always pleasurable. But it camot be claimed that all pleasures are resthetic, therefore it is quite proper to consider whether any special class of pleasures can be eliminated from the resthetic field.

We find upon examination (p. 12\%) that it is impossible to cut off the sense pleasures or, on the other hand, to limit 
iesthetics to them. In like mamer we find it impossible to limit resthetic pleasures to either emotional or intellectual fields, and equally impossible to cut off either pleasure field from effectiveness for asthetic result. An attempt has been made by Kant (p. 132 ff.) and others to limit æsthetic delights to elements of disinterestedness, but this position is opposed by other thinkers, and seems to be controverted by the importance allowed by the highest authorities to the principle of usefulness. Others have emphasised the passive pleasures (p. 135), holding them to be alone asthetic; but this view appears unsatisfactory when we consider, first, that all receptivity in the system involves reaction, and, secondly, that many so-called passive pleasures are not judged to be rsthetic, e.g. the cooling effect of a breeze on a hot day.

It has been claimed that the esthetic pleasures are different in quality, are "higher" in grade, than the non-rsthetic pleasures (p. 137 ff.); bnt this seems to be merely the statement of an identical proposition, for it camnot be shown that there is any other criterion for the valuation of pleasure qua pleasure than that of intensity. No two men agree in their grading of pleasures, and the differences of grading which we find seem to be determined by differences of that mental field in which pleasure is strongest or most permanently strong. Immediacy of pleasure getting (p. 140) and width of pleasure getting have been suggested as possible æsthetic criteria, but neither of the suggestions has brought conviction to many thinkers.

The Separation of Asthetics from Hedonics (p. 148 ff.)

We have thus far found no basis of unification amongst all resthetic states of mind other than their pleasure quality. There appears no difficulty in conceiving that the complex 
and varied rsthetic psychoses may be determined in some manner by pleasure, provided we look upon pleasure as a general quality which may, under the proper conditions, belong to any mental element; and this is the view which has been forced upon us by the considerations presented in Chap. I.

Our study thus far seems to show clearly that the connection between rsthetics and hedonics is too close to be superficial - a fact that is emphasised by the observation that iesthetic fields vary from race to race and from individual to individual, and that they differ as the mental habits vary in different races and individuals. Inasmuch as mental habits determine our pleasure fields, it is easy to see that divergence of standard is compatible with the resthetic-hedonic theory, and this point is made more emphatic when we note that rsthetic theorists have evidently been influenced in their views by their individual mental tendencies. But notwithstanding this evidence of closeness of connection between esthetics and hedonics, we are confronted by a great difficulty in the fact already noted, that while all asthetic states of mind are pleasurable, not all states that we call pleasurable are called æsthetic; and that notwithstanding the study which has been given to this subject, no agreement has been reached as to the grounds for the separation of the rsthetic and pleasure fields. Until the rationale of this separation can be explained it will not be thoroughly satisfactory to treat resthetics as a branch of hedonics.

One point has become clear in what has preceded this (p. 149), viz. that very many powerful thinkers have looked upon beauty as a fixity; an Absolute or a Universal. If pleasure is the basis of resthetics, then there must be a quality of fixity, of permanence, about it, unless these careful thinkers have read their experience incorrectly.

But pleasures are notably evanescent; and it cannot be 
claimed that there is a class of pleasures, which are permanent in themselves, that make up the rsthetic field. There are states of mind, however, which may remain pleasant for long periods in consequence of shifting of the field of interest; other cases where an effect of permanency is produced by the fact that the mental state is always pleasant when it is presented and disappears before it becomes painful. The varieties of effect produced in us by beautiful objects, and the capacities that we have in comnection with all art works of shifting attention before we tire, seem to point to a possibility that this seeming permanence, this relative fixity, may be the basis of the separation of resthetic from non-æsthetic pleasures. This leads (p. 152) to the adoption of the following hypothesis: That object is to be considered beautiful which produees a psychosis that is permanently pleasurable in revival. Each pleasure may form an element of impression in an cesthetic complex; but only those pleasures are judged to be asthetic which (relatively speaking) are permanently pleasurable in memory: the non-æsthetic, so-called, pleasures of memory being merely pleasures in name, psychoses nonpleasurable in themselves in revival, but to which, for one reason or another, the word "pleasure" still clings. We are led also to the further conclusion that that object is to be considered ugly which produces a psychosis that is permanently disagreeable in revival.

If this hypothesis be true we should expect the rsthetic field to vary from race to race and from individual to individual, and in the same individual from year to year, as we find that it does (p. 153 ff.); for these variations involve differences and changes of the mental elements of consciousness such as are natural to man.

Under this hypothesis (p. 154), besides (A) the wide field of resthetic impression, above spoken of, which admits all pleasures, we should look for (B) a field of individual 
judgment of the moment, determined by the momentary effect upon us of an art work or of a beautiful natural object; (C) a relatively stable field of rsthetic individual judgment, determined by the elements which persist pleasurably more than momentarily, this field marking our individual taste; (D) a still more fixed and objective field, viz. that of the highly-cultivated man as we conceive him, this field determining our judgment when we take the attitude of the philosophic critic.

This view does not exclude the ideal resthetic field (F), which must vary from individual to individual; which is not the vision of an Absolute, as usually conceived, towards the attainment of which we weakly aim, but a field which differs from the average field, and which each of us feels the world ought to adopt.

This view thus enables us (p. $158 \mathrm{ff}$.) to explain on a basis of relativity the facts of resthetic judgment as we find them. It enables us, furthermore, to account for the differences of theory to which we have above referred, as due to differences of individual mental constitution in the theorists themselves.

It appears, then, that the theory above discussed indicates that it may not be impossible to explain the only serious difficulty which presented itself to the acceptance of the hedonic-resthetic view.

No longer discouraged by this obstacle, we shall in Chap. VI. consider the laws of resthetics as based upon the laws of hedonics. Before undertaking this task, however, we shall find it advantageous to examine the laws of pleasure and pain as related to their physical basis ; to which we turn in Chaps. IV. and V. 


\section{Technical Treatment}

$\S 1$. I have already stated my belief that Esthetics may be properly looked upon as a special branch of the broader science of pleasure and pain, and must be so viewed, it appears to me, if we are to make satisfactory progress in the psychological treatment of its problems.

I think it can be shown that the essential characteristic of a beautiful object in nature or art is to be found in the algedonic effect which it produces: and just here it may well be noted that much obscurity in discussions upon this subject has been caused by a failure to clearly separate this effect upon the observer from the problems connected with the impulse to art production; and I must beg my reader to observe that I am about to discuss the state of consciousness arising in a man when he perceives a beautiful object.

In what follows I shall use the words "art" and "rsthetics" in a very wide sense. I shall apply the word "æsthetic" to any impression, whether produced by stimuli received from nature or by any device of man, provided it serve to make any one think the source of this impression beautiful.

Any device of man which serves to produce in any one an aesthetic thrill I shall not hesitate to call a work of art. When a man is experiencing or has experienced an resthetic feeling must be judged by his statement which cannot be questioned, or, in not a few cases, by some less distinct expression. We must allow that that object has wrought an rsthetic effect which has produced on general lines the same individual or racial expression that we accept as evidence of resthetic enjoyment in ourselves and in our own friends, with whom we sympathise fully. I think this wide use of terms will be justified in what follows. 
§ 2. Comparatively few people in our day, even among those who claim wide cultivation, realise how much of human thought has been given in the past to the philosophic consideration of esthetics, althongh the special student of art theory soon becomes impressed with this fact; for, turn whither he will, he finds his way blocked by the ruins of systems which obstruct and obscure his path. That we have reached very little satisfactory result is indeed true, and this fact, no doubt, explains the existing inappreciation of the importance of asthetic philosophy itself, and accounts for the small general interest which is taken in the work of the past in this direction.

However tedions the labour be, the student of to-day who hopes to advance must necessarily endeavour to gain a comprehensive view of what has already been done in his special field. Our relatively modern methols of written record have given to the thought of the past few centuries a retentiveness which makes it for ns a didactic entity, and the historical method therefore has in these days become of primary importance. The student of resthetic theory finds his work long and laborious, and after it all must admit, I think, on the whole, that asthetic psychology has gained little of fundamental importance from the discussions by philosophers in the past. This by no means shows that resthetic problems have been left unconsidered by the best thinkers; it indicates rather that they have looked upon them for the most part as secondary issues; issues of moment, truly, but subordinate to systemisation which from other points of view had become of predominant importance.

It is because of this subordination that we find on every side presentations of eminently partial views. In some cases these are held to be valid, and are made the basis of unsatisfactory dogmatism. In other cases we find the discussion carried forward on lines so narrow that the student becomes 
doubtful how far the writer has intended to claim his principles to be fundamental. Note, for instance, the Cartesian treatment of beanty, which limits its range to elements of sight pleasure; and the notion of Aristotle as to the relation of imitation to art, to which we refer below : views of masters these are incleed, but views which we, nowadays, are unable to take seriously.

It happens thus that our study brings the masters of thought before us in most cases as "prophets," in the old scriptural sense, rather than as scientific teachers. They furnish us with inspiration for our work and with data of value drawn from their own experience; of more value indeed, for the most part, than the theories which they propound. On the other hand, we find in many cases men of less importance in the world of thought touching special problems of psychologic æesthetics in more satisfactory manner than the well-recognised masters.

The asthetic hedonist does not need to look far for the psychologic explanation of this fact, for it is well recognised that the psychosis of thought is not strong in pleasure-pain elements; men whose lives are given to thought and who write of thought must expect to lose in themselves all predominance of pleasure and pain in direct connection with the subject-matter of their writing; and if pleasure be of the essence of resthetics, it is but natural that asthetic problems should be given a secondary place by such writers.

It seems to me clear that non-hedonistic resthetic theories have, from a psychological point of view, resulted in failure.

In the section which follows this I attempt to show the lines on which these non-hedonistic theories have developed and the directions in which they fail.

This section may be passed over without break in the argument by any reader who will allow the points contained in the paragraphs with which the fourth section opens. 
\$3. A.-The earliest definite thought centres about olyjects which attract attention; nor is this objective reference exchusively a characteristic of crude thinking; it is natural for any one whose point of view is cosmological rather than psychological. We shonld expect, therefore, to find early writers, and in later times men for whom the work of objects is specially important, examining the beautiful ohject itself for some quality or qualities which must be present if it is to appear beantiful; qualities which will account for the effect produced by its contemplation.

Aristotle's resthetic theory had evidently a strong objective bent. Although he held that one of the ends for which the artist worked was the giving of pleasure, this pleasmre was to be given by the imitation of beantiful objects, and in these he thonght he had fornd certain distinctly objective qualities upon which beanty depended;-such as order, symmetry, a certain magnitude. Only fragments of his art theory, however, seem to have come down to us, and what we have is so evidently incomplete that it can only be referred to illustratively. His principle of imitation, for instance, casts out of the resthetic field most of music and practically all of architecture, and his demand for symmetry excludes much which all the world nowadays agrees to call rsthetic.

Tendencies to objectivism appear in the asthetic discussions of many later writers of the highest anthority, e.g. Herbart and his followers, and in that of men of less weight as psychologists. Edmund Burke, who has written a work on the sublime which is valuable in many directions, shows this tendency. He gives us a set of objective qualities as necessary to beauty, which are manifestly inadequate to cover the ground. ${ }^{1}$ The thought of Hogarth as an active art

1 Smallness of size-smoothness-grarlnal rariation of outline-delicacy -brightness-purity and softness of colonr. 
worker in a certain line is worthy of consideration as expressing a natural, although superficial, solution of the rsthetic problem. His six elements of beauty, ${ }^{1}$ very different from Burke's, are equally incomprehensive.

This special method of procedure has not often been seriously carried out, however, and doubtless because the difficulties which appear soon became overwhelming. The indefinite variety of those objects which are looked upon as beautiful makes hopeless the task of enumerating any small number of objective qualities which shall cover all the ground.

Plato's "ideas" were emphatically objective, and, notwithstanding assertions to the contrary, modern idealism itself has never been able to shake off this objectiveness, so far as resthetics is concerned. In presenting to us ideals, universals, absolutes, as fixed rsthetic standards, it has in this very fact taken an objective attitude. ${ }^{2}$ The value of modern Idealism in its bearing upon philosophic questions being granted, we must admit, I think, that psychologic æsthetics gains very little from it. So far as its tenets are not covered in what we shall presently discuss, it gives us little in this direction which is not psychologic mysticism. It has had much to say concerning resthetics, but principally to force it into line with some preconceived metaphysical system or to make it fill some gap which otherwise would leave the thought sequence incomplete. As an instance of this we may note Kant's treatment under quantity, quality, relativity, modality.

The relation of the Universal to the Particular, of the Idea to its objective realisation, of the Absolute to the

1 Fitness to some design-variety-uniformity—regularity or symmetry -simplicity-intricacy-quantity.

${ }^{2}$ Even those who turn away from an objective search would be likely to say that the æsthetic psychosis implied an objective content, but not even here are thinkers agreed; Schleiermacher seems to hold the productive faculty alone to be essential in æsthetics. 
Finite, has been made to account for iesthetic effects in many different ways, but without leaving us any help in deciding why objects are beautiful or which of divergent standards must be accepted.

This last question presents the great stumbling-block to the acceptance of any form of universal idealism or absolutism, so far as westhetic standard is concerned; for if there be an absolute ideal beauty, a universal beauty, why should any one differ radically from me as to whether an object before us is resthetic or not? Or again, why should my own change of mental attitude make me think that beautiful now which some years ago I thought worthless? Perhaps my reader will say, with Lotze, that development of capacity for the apprehension of this ideal is necessary; that if he think the object before us is beautiful and I do not, it shows that my capacity to grasp the ideal is more limited than his own. But suppose before us an object which you call resthetic, and which is not merely negatively indifferent to me, but positively ugly-disagreeable to me, although I may perhaps be able to look back to a time when it was resthetic for me also. It is not that I find it mæsthetic, but utterly the reverse of rsthetic-that is, it is quite opposed to my standard, while it is in accord with yours; the standards, therefore, camnot differ by mere limitation, but are radically contradictory. Bergman ${ }^{1}$ suggests the ingenious hypothesis that the difference lies in actual difference of object grasped; that you and I think we grasp the same thing, but really do not. That the ideals do not differ, but that we are incorrectly comparing different ideals. If this position be accepted, we must, so far as I can see, acknowledge all taste as equally authoritative in the positing of a standard, and this takes away the very basis of the idealistic position here discussed. Perhaps it might be maintained that, notwith-

1 Bergman, Ueber das Schöne, I. $168 \mathrm{fr}$. 
standing this diversity of the appreciation of beanty, the criterion of universality is valid, by claiming that that is called beantiful which we think of as universal, however far that universality may be from being a fact. Such argument, however, will not hold, for in most cases we are aware fully of the existence of diverse views as to the object which is beantiful for us, and notwithstanding this, our psychosis is distinct and clear, and is not in its essence changed by any consideration of the fact that others differ from us in their judgment.

Mr. Begg, who approaches the subject from an intuitionist's standpoint, takes a listinct objective position, and acutely suggests that diversity of standard does not argue against the objectiveness of beanty, but in favour of its universal distribution. Different people differ in their capacity to perceive the beanty in some special object, but it is there for all that, if one single person sees it. He who considers the object ugly is so constituted that he is affected by other qualities in the object than its beanty, and these latter draw his thought away to special ugliness. Such a position, however, if I understand it, can be maintained only by one who has not yet seen the force of the modern criticism of "faculty psychology."

The argument in favour of beanty as a manifestation of an objective universality is weakened by the lack of any clear separation of the character of universality from the non-æsthetic. I, for my part, cannot agree that the merely agreeable is not often recognised as non-individual. What others eall pleasure, people as a rule are very ready to class as agreeable, while they are not at all ready to allow an objective impression to be beantiful unless they delight in it themselves. On the other hand, I cannot feel that the

1 W. Proulfoot Begg, The Development of Taste and other Studies in Esthetics, chap. viii. 
iesthetic thrill is any less egoistic than the most purely individual sense gratification. Truly the work of art is realised as giving pleasure to others as well as ourselves, ancl this knowledge of sympathy adds keenly to onr enjoyment, but mere universality does not raise a pleasure into the resthetic field, for were this so, many of those pleasures which we call the very lowest would be of the very highest resthetic value, and much that we hold to be best would be cut ont of the field by the smallness of the number who rejoice with us. It is patent to all that the world of the artist who is in advance is small, and yet we camnot on any acceptation of terms say that his work is on that accomnt mesthetic.

If we gain little else from the study of these systems, one fact is brought to our notice which is of considerable psychologic importance, and to which we shall return, namely, that these thinkers find their asthetic field not only wide but relatively permanent; were it not so, introspection would so clearly deny the conceptions of universality and absolutism that they could not be defended.

B. Let us now turn to the subjective view of the rsthetic field.

Could we go back to the days of the crude "faculty psychology" our task were simple, for then we, with Shaftesbury and Hutcheson, might satisfy ourselves by the assumption of a special internal sense for the perception of beauty ; modern psychology, however, compels us to discard this and all kindred views.

(a) Earlier thought of an introspective character, whatever be its direction, tends to lay especial stress upon sensualism. We see this to-day in the careful work of our painstaking psycho-physicists and in the thought of those whom they influence; in fact, we all find it difficult to avoid over-emphasis of the importance of sense-organ pro- 
ducts. The study of the beautiful from its introspective side has not infrequently shown this same over-emphasis. ${ }^{1}$ The very term æsthetics in its derivation has a sense counotation; Baumgarten first used it because he looked upon the beantiful as the perfection of sensuous knowledge, and Kant's "Transcendental Esthetie" treats of the a priori principles of sense. Perhaps the most thoroughgoing statement of the strictly sensualistic position is given in our own time by $\mathrm{Mr}$. Grant Allen in his Physiological Astheties; but he himself has apparently lost faith in his own work in this special direction, ${ }^{2}$ and it need not therefore be considered at length. Although the sense-impressions give the normal initiative in a vast majority of our resthetic psychoses, it is impossible in the field of sense to obtain any satisfactory solution of asthetic problems, and men will not accept a view so narrow; they recognise at once that the effect produced upon them by a beautiful object is wider and fuller than sense-impression.

(b) If the use of terms can be taken as a basis for classification, a good deal of the theory of the past may be classed as emotional, and this is true, especially among English thinkers, of whom we may mention Alison and James Mill. But "emotion" is a word of very indefinite meaning when it is made to describe the resthetic field. It is either employed with little departure from the usage of the question-waiving "faculty psychologists," or else it represents little more than complexity of pleasure or pain. Emotionalism under the first signification merely restates the questions of resthetics, and under the second throws us back upon hedonism, which we shall presently consider.

(e) The most emphatic drift of thought in the direction

1 Burke is quoted by Von Hartmann as a representative sensualist, but I think it more jroper to class him as an emotionalist. He defines beauty as a "quality by which an object eauses love or some passion similar to it."

2 See Hind, No. 45. 
of the content is, and for a long time has been, towards intellectualism, and naturally so. When critical examination fails to show any special intellectual product which, in width and in nature, corresponds with resthetic effect, there is a natural diversion of attention to the examination of the intellectual processes themselves, which leads in its extreme develoyment to $(d)$ bald rationalism.

"Harmony" of mental action (and cruder notions as to objective harmony are seldom altogether eliminated) and the process of "unification of the manifold" are now and again brought forward as all-sufficient to account for westhetic result; but it is easy to show that we live in an atmosphere of harmonies, and are constantly dealing with unities in manifoldness which not only have no marked resthetic character, but ordinarily are devoid of all westhetic character whatever: the same argument holds against other similar principles.

Rationalism takes a strong hold upon men's minds, and maintains its ground, especially among German thinkers, although often too covertly held and vaguely stated. It is easy to see, however, that no amount of argument, however conclusive its form may be, can change our notion of what is, or what is not, beautiful unless it induce an actual change in the matter which is presented to thought.

No better position is gained by referring the process to sub-consciousuess, - by arguing that the effect is due to recognition of relations too delicate to rise above the "threshold," but grasped, for all that, in the resthetic state of mind. This cowardly means of covering defeat one finds, with no little surprise, willingly accepted by thinkers of the highest rank, to this day, and with the best of authorities in the past to give weight to such method; for it must be remembered that as Leibnitz considered music to be "count- 
ing performed by the mind without knowing that it is counting," so Kant was only willing to give music a position among the arts of beanty becanse of the fine mathematical relation between harmonious tones which from other investigations have been found to exist, and which he supposed to be sub-consciously grasped in the resthetic effects produced.

The vaguer statements of simpler intellectnalism, which one finds so frequently, merely go to emphasise the fact that reflective thonght is of the greatest importance in the iesthetic psychosis. The best work of later writers, as we shall see in what follows, tends to give value not only to the sensual and the emotional, but also to the intellectnal, as all involved in the resthetie state, as we know it, and this is the position to which we should be led by our synthetic line of thought, if no other evidence appeared.

I do not find that the contentions of the Formalist, except so far as they are hedonistic, go far to help us pyschologically. Concrete formalism fails to give us any massailable criterion of the asthetic, and abstract formalism gives us nothing more valuable, from our point of view, than a mere restatement of the fact that we must look elsewhere than to sensualism, or to the matter of the content, for the essence of the resthetic. But so far as formalism is hedonistic, it points, it seems to me, in the right direction. This hedonistic view will receive full treatment in what follows.

$\S 4$. Although the discussions which we have above reviewed bring the student to no satisfactory result, they cannot fail to draw his attention to the fact that the field of iesthetics is always hedonic; and this is, indeed, a fact of great psychological importance. Whatever else may be said of the resthetic mental state, its pleasurableness cannot be questioned. It is not necessary, therefore, to prove the 
hedonic commection, and, on the other hand, I do not see how it is possible for any one to pass it over lightly. Thinkers of all grades and of all schools, from Aristotle downwards, acknowledge the necessary connection with pleasure, whatever position they take as to the value or importance of this fact.

It is not difficult indeel to find authorities, from Epicurus to Hume, whose statements may be interpreted as decisive expressions of the view for which I argue; and some few -Fechner, for example-who distinetly base asthetics upon hedonics. The average man, however, does not think of pleasurableness as a charccteristic feature of the resthetic unless his attention is called to it, and there is a good deal of popular disinclination to the treatment of pleasure as an element of any special importance in the asthetic psychosis. Certain men of penetration also raise the most violent opposition to any such treatment.

The popular opposition is not difficult to understand, for the ordinary man does not learn of himself to catch the close relation between a thoughtful phase of psychic life (which in fact is seldom pleasurable to him) and the pleasure quality which may go with it; he habitually thinks of the two not only as separate but as in opposition, and when led to consider anything so complex as the identification of hedonic phase and iesthetic phenomena, he is mable to catch any relation between the laborious thonght involved in the consideration, and the revivals which come to him in connection with the word "pleasure." He is led astray, however, principally by his inability to think clearly. When he thinks of resthetics he always occupies his mind with some content of art, and thus it not infrequently happens that it is difficult even to persuade him that pleasure is an ever-present result obtained from the consideration of art forms. 
With the theoretic opposition it is not so easy to have patience. Von Hartmann ${ }^{1}$ goes so far as to deny us the right to consider the hedonic quality in cesthetics as more than an accident unrelated to the essence of the beautiful. He grounds his position upon the unimportance of the objective real thing; if this be unimportant, he holds, then so also is the hedonic aspect, for, says he, we have as little right to look for the essence of the resthetic in the effect (Gefiihle) as in the cause (the object) (Asthetil, p. 40). In passing one may note that there seems here to be a hidden shifting of ground. The "cause" of which he speaks is an objective thing, that which he calls "effect" is something which psychologically has no objective significance, and which hence is not an "effect" in the same sense in which the object is the "cause"; the objective universality of resthetic pleasure, which Kant upheld, not concerning us in an analysis of the psychologic state under discussion. But apart from this point, I for one cannot with Von Hartmann see any theoretical objection to looking to the object for our criterion, a procedure which he considers altogether reprehensible; to the object in fact we have been looking in the past, and the trouble is not that the search in this direction is illegitimate, but that our search has brought no result. We find nothing in the object which is always there if the iesthetic quality is to present itself to the observer. TVe therefore turn our attention away from this object to that much of the subjective state which is not part of this object, and there we do find something which is always present where asthetic effect is produced, viz. pleasure.

The psychologist cannot allow himself to be deterred from research in this direction by any objections determined by theoretical preconceptions, although the strong opposition deserves consideration and explanation. Hedonic the cesthetic

${ }^{1}$ Cf. LEs. seit Kant, p. 354. 
psychosis certainly is. Whether this hedonic quality be of great moment is a question to be determined.

The Associationists in psychology have seemed in a way to identify beauty with pleasmrableness by claiming it to be the result of the association with objects of agreeable and interesting ideas. Their doctrine in this regard is difficult to treat specifically because of their failure to differentiate pleasure from the emotions, and because of their treatment of pleasure as though it were representable, in the same sense that a sensation is, rather than as being a quality which may attach to a presented content without belonging to its revival at all. See my remarks on this point in Chap. I.

That associations which are pleasurable are important elements in an resthetic effect I agree, as will appear later. If the doctrine be held to mean, however, that resthetic effect is determined altogether by pleasure revivals I cannot follow, for we shall presently see how much presentative pleasures have to do with the effects of beanty.

If, on the other hand, the doctrine be meant to signify an identity between hedonic phenomena and resthetic phenomena, we are at once met by the objection that while all resthetic states of mind appear to be pleasurable, not all pleasurable states are allowed to pass as resthetic. The problem which is thus brought forward is an important one, which we must consider somewhat at length.

$\S 5$. Our problem may be stated in the form of the question, What are the bounds of the asthetic within the hedonic ficld? No skill in introspective analysis is required to grasp the fact that there is a sepurction between the hedonic and the iesthetic: the careless thinker is the one most ready to take it for granted, and high authorities also make much of it. Sully, for instance, thinks Kant's elucidation of the separa- 
tion of the beantiful from the good and the agreeable, one of his important achievements for resthetics. ${ }^{1}$

But it appears to me that altogether too much is made of this separation. Thinkers who are our teachers have overemphasised the separateness by drawing attention away from the conncction between the two fields, and it is important, I think, to take a position opposed to the usual one; i.c. to emphasise the lack of separateness between hedonics and resthetics.

If one examine the literary work of art critics and the more or less philosophic and scientific writings which deal with the facts of resthetics rather than its theory, one will find little more than descriptions of pleasure-getting, coupled with more or less thorough attempts to arrange this pleasuregetting in a logical way. If, on the other hand, one examine the writings of those who have expressly studied the psychology of pleasure, one finds asthetic phenomena treated altogether as the best-recognised data of hedonics, used to corroborate theory and to justify classification, exactly as the simplest sense-pleasures are used. ${ }^{2}$

A suggestive although not a final argument in favour of this close connection between the two fields is found when we take another point of view. If we take into consideration any average complex asthetic object, we find it a very wide one with certain elements which are emphatically pleasurable. Eliminate in thought the pleasurable elements one by one, and we find that while in the main the object does not change the mass of its content, its resthetic quality gradually disappears. We may acknowledge still that it has a right to be named resthetic because of the opinions of others and

${ }^{1}$ Article " Esthetics," Ency. Brit. Cf. also Blencke, Die Trennuny d. Schönen v. Augenehm, p. 3.

2 Cf. $e . g$. Mr. B. I. Gilman's article on Pleasure and Pain in the American Jonernal of Psychology, vi. 1. 
beeause of our own judgments in the past, but for ourselves at the time it has lost all that makes it worthy of being called by so hononrable a name. Te are all familiar with the fact that an object which but a moment ago was resthetic for us may become uniesthetic by a degradation to "indifferenee" or painfulness of the special content which was giving us pleasure. The suggestion of a ridiculous or painful association with some essential element in an art-complex will for all time reduce for us the isthetie value of the whole work. The average art eritic indeed very often makes and ummakes resthetic objects for the masses in this way.

Certainly these facts indicate a very close commection between the hedonic and asthetic fields, and one which psychologically would seem to be essential. Of course the separation so eommonly made inust also be acknowledged, and it is worth our while, I think, to consider the main results which have been reached by those who have attempted to mark the lines of separation with distinctness.

$\S 6$. If the field of asthetics be a portion of the hedonic field, it eertainly ought not to be a difficult task, one would say, to mark off in some rough way that part of the hedonie field which is resthetie from that which is not: to differentiate the one from the other by a process of limitation of the pleasure field. This, however, cloes not appear at all an easy matter when one comes to attempt it.

The average intelligent observer who has not given the matter especial study will be likely to say, offhand, that the sense-pleasures at all events are excluded when we refer to the resthetic. In the exposition of theories from a non-hedonistie point of view this position has been often taken either explicitly, or less directly by the limitation of the field to non-sensorial states. Kant's separation of the agreeable from the beautiful indeed turns largely upon his notion that the sense-pleasures, 
which are essential to the former, are wanting in the latter. That resthetic pleasure is wider than sense is not open to question, but it must be granted that we obtain well-marked resthetic results which cannot be separated from sensation, such as we find, e.g., in the impression produced by a rich colouring, and in the fulness of simple tones. We find indeed when we go to the root of the matter that it is only the so-called "lower sense" pleasures which it is desired to exclude. The inclusion of sense effects through eye and ear does not create opposition. But it seems to me that if it be admitted that one set of senses can produce resthetic effect, the whole contention fails; and a close examination shows clearly, I think, that the rest of the senses may act in the same manner in the make-up of resthetic complexes. Among the intelligent men whom the readers of this book commonly meet it would probably be difficult to find any who would not exclude the gross sexual pleasures from the region of the resthetic. Sut I think it must be granted that for many perfectly moral people the revival of these pleasures is not altogether without effect in their appreciation of art work; and if we take the race as a whole it is certain that we cannot exclude this sense region from rsthetic significance: for surely no person pictures his heaven apart from his conception of what is beautiful; yet the heaven of the Eastern races would surely be incomplete were not purely sexnal delights an important element of its joy.

That sense-pleasures cannot be excluded from the field of iesthetic impression a large majority of the more capable thinkers find it necessary to acknowledge, for they do not hesitate to take the pleasures of the sense impression into account. Nobody can complain that Lotze had leanings towards sensualism. But he says clearly in this connection ${ }^{1}$ that the first condition of a work of art is its power to please

1 Outlines of .Estheties, $\$ 23$. 
the senses. "If we step into the shadow of the wood at height of noon," says Bergman, "the agreeable refreshment is bound up with the ilea of the grandeur of the forest; the refreshing coolness belongs to that which we feel to be the beauty of the wood ;" and this comes from one who lays the basis of esthetics in contemplative thought. For my own part, I feel that the pleasurable impression of any sense may become a rich component part of an wsthetic delight.

If one follow Alison or James Mill and his school, ${ }^{2}$ he will refer all resthetic enjoyment to emotional association. So far as this theory is separable from pure hedonism it is doubtless based upon introspective examination, which for certain people (and to this class I belong) shows powerful elements of emotion in many resthetic complexes. For me, love, fear, sorrow, joy, etc., appear to be part and parcel of many an iesthetic effect. I think it clear therefore that pleasures of the typical emotions are of great moment in resthetics, but at the same time it is equally true that they do not stand alone as the basis of iesthetic effect. "Association" by itself can of course give no account of distinctively iesthetic effect. It is a principle of important consideration in asthetics as in all phases of mental life. It shows us to some extent the movement by which we reach the beautiful, but certainly not the exchsive qualities which prodnce the distinctive effect.

1 The objection of the German idealists to the consideration of sensepleasures as of asthetic worth is based npon theory, but it cannot be supposed that they wonld uphold views which contradict their experience, and we must seek later to account for so strong an opposition. There is serions objection to the limitation of the use of the word " all but the Silcingfühle as Yon Hartmann does, in the fact that the word now covers very generally the whole ground of the beautiful, and objective evilence shows that people generally do not accept such a limitation.

2J. S. Mill thought that his father hal an unconscious follower in John Ruskin. (See his edition of J. Mill's Analysis, vol. ii. 1. 253.) 
The historically related opponents of Mill, viz. Reid, Hamilton, and Stewart, all upheld a view which asserts the non-importance of emotion in claiming overmuch for intellect; they, however, show more or less willingness to admit the worth of other factors. Other writers go much farther (e.g. Hemsterhuis, Diderot) in their restriction of the rsthetic to the intellectual activities. Kant excludes sense and depends upon reflection.

Both emotional and intellectnal theories are weakened by failure to accept the sense-element as valuable; but apart from this, such opposed theories, although upheld by thinkers of power, are mutually destructive as arguments looking to the fixing of resthetic differentia, on accomnt of this very opposition. It is incredible that emotional association can be all of resthetic enjoyment, when the experience of such men as Reid and Hamilton and Stewart could lead them to hold it unimportant; or that intellectual activity can be allimportant, when the associationists were able practically to ignore it.

It may be well perhaps to note some late examples of the intellectual emphasis. Professor G. T. Ladd, who does not by any means ignore the sensuous basis, holds (Elements of Physiological Psyehology, p. 521) that "even most elementary rsthetic feelings caunot be considered as on a par with the sensuous feelings or as mere aggregates of such feelings. The tone of feeling which characterises the sensations furnishes a material for genninely asthetic feeling, but the latter always implies also the working of certain intellectual laws and a union of simple feelings of sensation under timeform and space-form." But where shall we find the spaceform or time-form in the iesthetic effect produced by mere rich colouring or by the luscious tones of the human voice apart from any movement? If we follow Professor Ladd we are compelled to deny the resthetic quality in 
such cases altogether. We refer to this theory again below.

Bergman's view as to contemplation has been noted. He attempts to cover the ground of sense and emotion by bringing them into intellectual categories. Sense-beanty, form-beanty, stimmung-beauty; but contemplation is the basis. On the other hand, we have no less pretentious a thinker than Von Hartmann ${ }^{1}$ (lenying that distinetly intellectnal operations are even pleasuralle, and stating that for himself relations of two ideas seem absolntely indifferent up to the line where the intensity of the Vorstellungen becomes so strong that pain ensues. It is interesting to note that this contention is not merely modern. It goes back to Greek speculation ; Chrysippus, it will be remembered, held, as an argument against Aristotle, that pure speculation is a kind of amusement.

Many other theories have been brought forward which involve limitations, for the most part, far less narrow than in those cases just considered, and more often implied by overemphasis in some special direction than upheld by specific claims : some of these deserve examination.

Reid himself finds that action of intellect is not alone in giving resthetic quality, but is bound up with the functioning of our "moral faculty" in producing the effect reached; while Hamilton, on the other hand, lays stress upon the oceupation of the imagination and understanding in a full, free, and consequently agreeable activity.

Reid shows the step (logical rather than historical) to the emphasis of the play of "spiritual" feeling which we find in Cousin and Lévêque, in Shaftesbury and in John Tiuskin, although Ruskin's asthetic field may, perhaps, be better described as that of religious ecstasy. Hamilton, on the

$$
1 \text {. Ess. seit Kant, p. } 289 .
$$


other hand, shows the step to the extreme emphasis of imagination which we find in Addison. We may note also in this connection the trend of thought of which Bergman's position, already referred to, is an emphatic instance, viz. that the resthetic basis is to be found in the pleasures of contemplation.

But no one who takes a wider view than that of personal introspection can limit the field of asthetics to moral or to imaginative effects, and I doubt whether any one can thus narrow his own field. He must see isthetic effects which are non-moral, he must see others which seem to be entirely separable from the imagination; any theory which limits esthetics to imaginative effects orerlooks the importance of sense and emotional elenents, which are acknowledged nowarlays to be of great moment.

We cannot go farther in this examination of the effort to separate the agreeable from the beantiful without considering Kant's well-known contention in this regard. We must not overlook, at the start, the fact that the matter of Kant's consideration was by no means identical with that before us at this moment. We inquire whether in the field of asthetic impression any special hedonic element must be cast out. Kant was concerned with the a priori character of his theoretical pure judgment; and, strictly spealing, therefore, did not deal with om problen. We may, however, with profit examine his argument to see whether the psychological positions involved throw any light upon our closely-allied inyuiry. Kant's main contention was that the judgment as to beauty had universal validity, while that concerning the agreeable was individualistic, ${ }^{2}$ and this was a contention into

1 The attempt to separate Schcingefühle from reale Gefühle (Von Hartmann's .Es., p. 46 ff.), although arising from metaphysical theory, probably is psychologically based upon the same personal bias which led to Addison's extreme view, and which produces the reference to contemplation.

a Blencke (Trennung d. Sehönen $v$. Angenchm, 1. 39) remarks that the evidence of the psychologic soundness of Kant's position is seen in the fact that 
which he was led from theoretical rather than empirieal considerations. It involved for him, in the first place, the position that sense-pleasures must be excluded from the iesthetie. For pleasure and pain spring from (1) sense-impression, or (2) from the processes involved in the binding together of ideas: only the latter of whieh can be general; therefore the field of sense-impression must be indiridual. We, dealing with the region of asthetic impression, have, I think, already seen convincing evidence that sense-pleasures eamot rightly be exeluded; and it seems to me that even if it were conclusively shown that they were strictly individual, i.e. incommunieable, this faet would not prove them to be valueless ats elements of asthetic impression. But to return to Kant's argument; his theory in this regard led him further to hold that all interest must be lacking in the beautiful. The sublime he allowed to have a moral interest-for moral interests are the only ones which are miversal-but becuty in his view has no direet relation to morality, and, as all other than moral interests are individual, beauty to remain universal must exelude interest. This is evidently a position reached from a purely theoretical basis, but apparently it must

we are content to be pleased ourselves, while, on the other hand, we try to communicate our judgment as to beauty to others, and suelı a result hant's prineiples would require. But it seems to me that Bleneke here goes too far. In the case of pleasures involved in the action of our own peculiar organs, we recognise the pleasures as our own to be sure, but are very ready to endeavour to bring about the same experience in our companions, by urging them to taste or touch, or listen or act as we are doing; and we only feel content that they cannot experienee them when we know that they have male the trial. It is merely an extension of this sympathetic altmism which leads us to endeavour to bring out for others by explanation or deseription the elements of a work of art which give us full pleasure; elements which are not apparent always upon the surface, and, perhaps, dependent upon the sounding of some ehord which may be struck directly or associatively by discussion aud deseription. Here, too, when we find disenssion and description failing to make the object beantiful for a companion, we come to see that we experience something which he cannot grasp. There seems to be no separation between the course of thought in the two eases. 
have had its corroboration in his own psychologic experience. Sympathetic pleasures play an important part in all art work of higher grade. Moreover, there is probably little doubt that for Kant and a large number of men of his general mental type the most valued pleasures were and are obtained in fields of disinterested effort; that for them purely egoistic pleasure-getting always carries with it an ethical reproof which leans towards the side of pain, and that for such men disinterestedness must therefore be an essential characteristic of the subjective resthetic field. But it seems to me quite clear that this is a matter of individual mental bias. The ordinary man who is not naturally disinterested in his action does not, I am convinced, find the presence of self-interested elements a bar to resthetic enjoyment. The pleasurable pride of ownership surely forms an element in the resthetic delight of many an art collector. Personal interest enters for all of us into our judgment concerning the beanty of those whom we love, and ownership has the same effect upon the judgment of many men concerning the beauty of their possessions. To return again to Kant's position. The recognition of usefulness implies self-interestedness, directly or indirectly, and Kant therefore found it necessary to hold that the taste judgment was based upon an unpurposive purpose, an aimless usefulness ${ }^{1}$ (Zucekmëssigkeit ohne Zucck)-that is, a usefulness of such nature that it is unrecognised as useful, and hence not followed because of the interest involved. As an element in the resthetic impression, however, I do not think that even recogniscble usefulness can be overlooked. It is commonly supposed to be an essential to architectural beauty, at all events, and the relation to other branches of the resthetic is also commonly supposed to be intimate. Kant stands opposed to so great a thinker as Aristotle in this respect, and

1 Von Hartmann, Ess. scit Kant, 1. 23, says even this comes down to objective fitness. 
later observers, such as Adam Smith, Dugald Stewart, Kames and Hogarth, and notably Fechmer, make usefulness of great importance asthetically. ${ }^{1} \quad$ Usefulness per se in my opinion is not of so high importance as is the absence of non-usefulness, as is indeed all avoidance of shocks; but it seems to me evident that it is an æesthetic clement for most of us, and when we find it considered of importance by such an acute observer as Fechner we are compelled to regard its exclusion as impossible. Ruskin never preached a more fallacions or mischievous doctrine than when he developed the thonght ${ }^{2}$ that it is the emphasis of the useless things in structure which makes architecture out of building.

Schiller restates the Kantian notion by his emphasis of the "play impulse" in reference to resthetics; the modern evolutionary school as represented by Mr. Spencer takes the same position, Professor Bain following closely. This leads Mr. Spencer to the exclusion of "life-serving functions" from the asthetic; but what becomes of Mr. Spencer's system if any functions, especially pleasurable ones, are thought of as nonlife-serving, directly or indirectly, I do not clearly see. Even if some functions of the so-called "higher" kind are classifiable as non-life-serving; to exclude from sesthetics all which do so serve would surely cut off a large part of our asthetic field.

As modern physiology draws a clear distinction between receptive and motor nerve, not unnaturally do we find a corresponding psychical distinction looked for in all directions, and Grant Allen in his Physiological Esthetics has attempted to identify the resthetic with the passive, receptive pleasures. Some such view is also found implied in the theories of not a few metaphysicians, and Fechner ${ }^{3}$ takes a

${ }^{1}$ Cf. in opposition to Kant, Theo. Liplys's Gmathatsedhen d. Sectenlevens, p. 599.
$\because$ "Lamp of Sacrifice.
: Tors. a. Fisthetili, rol. i. 1. 54. 
strong position in this particular; Mr. Allen may therefore claim the best of company. On the other hand, however, others-Schleiermacher, for example-take quite an opposite position in claiming all for the productive side of mentality. Guyau's clear criticism ${ }^{1}$ has given the theory of passivity so powerful a blow that no more than reference seems needful. It is well enough to emphasise the general passive nature of the pleasure involved in asthetic appreciation as opposed to the active pleasures obtained in the creation of an art work, but this gives us no reason for the exclusion of all pleasures of action from resthetic compounds. Our psychic life is so bound up with the active side that it is impossible to cut off the active element in any psychosis. Our emotions, our desires, all relate to action, and beyond that what is added to the pleasures of an asthetic psychosis by the elements of sympathetic activity is far from small. ${ }^{2}$

This seems to be the most appropriate place to refer to the definition of beanty which has lately been brought into prominence by Mr. Bosanquet in his History of Aisthetic. "The beautiful," says he (p. 5), "is that which has characteristic or individual expressiveness for sense perception, or imagination, subject to the conditions of general or abstract expressiveness in the same medium." But surely there is much of expressiveness of one kind or another in nature and art which is not only not beautiful but practically ugly. I cannot help feeling that Mr. Bosanquet has failed to keep clear before him the mental state determined by the activities necessary in the production of a work of art to which I have just referred, in which state this expressiveness is emphasised as it is not in the states necessary to asthetic appreciation. ${ }^{3}$

1 Problemes de l'esthétique contemporaine.

2 Horwicz holds that the resthetic effect produced by the representation of power is due to an aronsed idea (Vorstellung) of agreeable muscular action (I'syehologische Analysen, Th. II. Heft ii. p. 166).

"Cf. also Véron's theory as disenssed in his isthetics. He goes further 
But even so, surely "expressiveness" covers creative activity, which has no relation to the asthetic at all. Is it not the "expressiveness" of the characteristics of genins which draws our attention to and excites our wonder at the achievements of the inventor or the skilled general or diplomat?

Mr. Bosanquet's "approximate psychological definition of asthetic enjoyment" (p. 7), "Plecesure in the nature of a fecling or presentation, as distinct from pleasure in its momentary or expected stimulation of the oryenism," is stated in terms which are so vagne and so variously connected with diverse connotations that I am unable to grasp its intention, and I therefore do not feel able to criticise it.

It is not uninteresting to note here a late idealistic view which apparently makes activity all-important. Professor Ladd in his Introduction to Philosophy (p. 343) marks the differentia of asthetics thus: "Nothing that is apprehended as incaprable of change of motion in time or space, anch so of the successive realisation of different movements of physical or psychical being, appears beautiful to the human mind. But not all movement of physical or psychical being is beantiful; the movement which is beautiful must have two characteristics. It must have spontaneity, or a certain semblance of freedom; and it must use this spontaneity, as it were, in self-limitation of an idea." It is evident, however, from the very definition, that spontaneity, pure and simple, does not approve itself to Professor Ladd as fundamental; nor can it be held, I think, that we find the phenomena of beauty in all cases where we have "spontaneous movement which uses its spontaneity in self-limitation of an idea."

An attempt is not uncommonly made to distinguish between "higher" and "lower" pleasures, and this supposed in this direction, making expression of the personality of the artist ithe essential charaeteristic of art work. 
distinction is by some writers and by many talkers made determinant of the difference between the resthetic and the non-rsthetic. In Kames we find a good example of this doctrine.

There is something illnsory, however, about the very notion of such a distinction. J. S. Mill is doubtless right in holding ${ }^{1}$ that so long as people declare that pleasures differ in kind we must accept the lifference as a fact. But I think that all evidence goes to show that the real difference is always reducible to intensity, either in impression or through relative permanency in revival, beyond which I do not find any criterion for pleasure qui pleasure.

As Bentham tells us, "Quantity of pleasure being equal, push-pin is as good as poetry"; but the fact is that for the intelligent man in estimating cesthetic valnes "push-pin" is not as productive of pleasure as poetry is. ${ }^{2}$

Our gratifications are normally taken in the lines of our natural development. The direction of growth or of deterioration determines the field of pleasure-getting, and while there is the strongest ground for belief in a constant increase in pleasure-getting capacity, pari fussu with our mental growth, still it cannot be shown that the lelights reached by the man of high moral culture bring a better quality of pleasure to him than the gratifications of the barbarian bring to the savage mind; nor ean it be shown that the pleasure which we get when we reach a "higher" moral position is any better per se than that which we experienced before we reached it. The fact is that when we speak of the "higher pleasures" we are merely restating our problem in new terms. Those pleasures which are iesthetic are the ones we call "higher,"

1 Utiliterianisin, p. 314.

2 Cf. also Dr. James Ward in Ency. Erit., 9th edit., Art. "Psychology," for a careful statement of the facts. Compare Fechner (Vor. a. Es., vol. i. p. 26), who explains what is called "higher" pleasures as characterised nnerely by being themselves the source of new delights. 
but until we can give some definite meaning to the word "higher" in this comnection we gain nothing. In most cases those who discuss the matter from this standpoint are really dealing with ethical data. It is the man who has grown to be cipable of appreciating newer ethical standards, and who has lost his pleasure in the old, whose attention is directed most strongly to the distinction between pleasures of "higher" and "lower" grade. In manner to be presently described, what he has east off as unworthy no longer gives him pleasure in contemplation and is no longer judged to be iesthetic. This is not, however, because the resthetic has an essential ethical dependence, but because resthetics is founded upon hedonics; for the man has gained new fields of pleasure-getting as his character has developed: what he casts out as non-rsthetic because it is a "lower pleasure" is a pleasure merely in name, is in reality so bound up with painfuhess as to be necessarily uniesthetic. This by no means shows that what was pleasurable in his undeveloped or incultivated state was not resthetic for him at that time, nor does it prove that the pleasures of the savage are not asthetic for him in his barbarous state.

I would not have my reader think that I consider that ethical standards are unimportant in resthetics. Apart from the resthetic delight, which we gain from what Aristotle calls moral beauty, i.e. from the recognition of nobility of aim and strength of purpose, the appreciation of "rsthetic aspects of character," of "the beauty of holiness," the influence of our ethical standard upon our rsthetic field is most important; for, in the end, most thoughtful people will make their mature judgments turn upon them negatively, because what is for them immoral, is painful and non-resthetic. As we have noted above, however, the majority of our pleasures have no ethical bearings; the mass of rsthetic effects are made up of elements entirely ummoral. 
CHAP.

It is not denied that a work of art may offer other than pleasurable gifts, that the one who studies and appreciates a work of art may find it yielding other fruitage than mere enjoyment. There may be perfectly legitimate ethical aims in the artist's mind, and his ethical notions may be embodied effectively in his work, but of such aims and effects resthetics qua resthetics does not rightly treat, except so far as the characters presented, themselves become objects of pleasurable interest. ${ }^{1}$

As Schiller puts it in a special direction (Pathetisehe, p. 78), "Der Dichter, auch wenn er die vollkommensten sittlichen Muster vor unsre Augen stellt, hat keinen andern Zweck und darf heinen andern haben, als uns durch Betrachtung derselben zu ergötzen."

The attempts to determine the bounds of the resthetic field by a process of limitation of the hedonic appear to me to bring no satisfactory result; nor does it appear that the field can be determined by the characteristic manner of presentation of the pleasures which make up the total effect. Fechner ${ }^{2}$ suggested a criterion in the immediacy of the pleasuregetting. Von Hartmann, on the other hand, thinks Fechner's position is altogether withont foundation; holding that however immediate the pleasure connected with an object may be, it does not thus become resthetic. ${ }^{3}$ Such conflict of opinion makes this criterion unsatisfactory.

Horwicz ${ }^{4}$ seems to hold that sensational pleasure and resthetic pleasure differ not in substance but in that the wsthetic shows a broadening of the field. Cuyau ${ }^{5}$ follows in the same line, snggesting that the broadening of the agree-

1 Cf. Sully's Essay X., "Esthetic Aspects of Character," in Sensution and Intuition.

2 Vorschule d. Es., vol. i. 1. 15.

${ }^{4}$ Psy. Analysen, vol. ii. p. 168.

3 Es. seit Kant, p. 354 .

5 Troblems, 1. $75 \mathrm{fr}$. 
able horizon, the growth in extension of the pleasure field, is what we experience when an object appears to us to be asthetic. This implies, as he distinctly states, that intense and unextended pleasures in their very nature are unesthetic. This does not accord with my own experience; still I shall not deny that for him a widespread thrill alone produced what he called iesthetic feeling, as may well have been the case with a man to whom sympathy was so important an element of life as it was with the writer of Lart ue point de ve saciologique. In truth, all of our notable sesthetic psychoses are summational hedonic complexes; but this fact does not show, as it is made to argue implicitly, that the pleasurable elements which make up the same are not in themselves asthetic. I do not wish to understate the value of this width of effect in asthetics, for I think it of very great importance, as will appear in Chap. VI. The prominent place which Fechner gives to the associational principle shows the importance in which he held it. All notable works of art show it, and all persistent types of art subject. But, on the other hand, it cannot be held that this summation $p e r$ se, this width of field, this extensiveness, in itself is the all in all in iesthetics. To make it so forces upon us the impossible task of deciding where extension begins; compels us to look for some degree of extension on one side of which all is unesthetic, while on the other all is asthetic. Such a line of division, however, cannot be drawn.

$\$ 7$. The reader who has followed the above argument will grant, I think, that the search for a basis of separation between the sesthetic and hedonic fields has given us no satisfactory psychological result.

This fact evidently serves to emplasise the connection 
between the rsthetic and hedonic fields rather than their separation.

If this review has been unsatisfactory in result on the whole, it at least has brought into clear relief a remarkable conflict of authorities which deserves attention. Contradiction of dogma is so marked that one might believe rsthetics to mean something quite different for the opposed dogmatists. But although in some cases attempt is made on theoretical grounds to use the term resthetics in a limited and unusual sense, it is apparent that the opposed theorists are dealing with the same psychological data. However diverse the mental fields which they consider may be, they overlap in many directions, and the ground which is common gives assurance that practically the same matter is under discussion by all.

This conflict of authorities itself argues, it seems to me, that the hedonic quality is the bond between these diverse fields. It argues once again that the connction between the hedonic and resthetic fields is more worthy of emphasis than their separation. For if this view be the true one, we are led naturally by this conflict to hold that all fields of pleasure-getting are within the scope of the resthetic.

Whatever difficulties may appear to the acceptance of so wide a view for one who holds the current pleasure-pain theories, no especial difficulty in this direction, it seems to me, occurs to one who will accept the theory I defend. For one who thinks of pleasure as being a sensation or an emotion, or a psychic state of kindred nature; or for one who considers pleasure as a mental fact sui generis, a special kind of feeling $(G e f u i k l)$; for either one, I can see how difficult it might be to accept this, or, in fact, any hedonistic explanation of æsthetics.

The rsthetic psychosis is so complex and so variable in its elements that it cannot be looked upon as an activity of a fixed nature brought into existence by, or in the process 
of, other activities as under such views must be the case with pleasure, and what is determined by pleasure.

But if pleasure be, as I hold, a special quality which, under proper conditions, may belong to any mental element, then complexity and variability present no obstacles whatever. For coexistent varied and varying mental elements may well be pleasurable, and by the process which we may legitimately call summation may aid each other in producing pleasurable complexes which shall be resthetic. Summation of pleasure is nothing more than the co-presentation of varied elements which happen at the time to be pleasurable.

Granting, then, that all pleasure fields are to be considered, we see that if the esthetic field is determined by hedonic quality we should expeet to find the former varying with the character of the one who describes his field, for the hedonic field is known to vary from individual to individual. This variation has certainly been exemplified in what has gone before.

Furthermore, upon making a survey of the theories which have been reviewed, one can trace, it seems to me, the influence of individual "personal equation," shown by the several theorists. It is the man whose mind is impressed strongly by the presentations of sense whom we should expect to find emphasising the sensual elements in art work, and in our own times, in which scientific investigation has brought the sensational elements into undue prominence in many ways, we should look to find the most thoroughgoing exponents of such a position. Mr. Grant Allen, in his Pliysiologieral Esthetics, goes as far perhaps in this direction as any other writer. This book is the work of a man whose effort up to the time of its writing had been turned largely in the direction of naturalistic research. German scientific workers, like Helmholtz, give us also good examples of this sensational over-emphasis. 
Burke, though making "touch" the basis of many of his asthetic qualities, gave on the whole the greatest prominence to the importance of the "love" element in art, and Burke's life was one of philanthropic statesmanship; he had a strong predisposition to benevolence. Guyau takes similar ground, ${ }^{1}$ and he comes of a race among whom the amatory passion is proverbially predominant. Kant's miversality may be mentioned here, apart from the theoretical position which it implied for him, as probably showing his own region of cesthetic pleasure-getting.

We find again that the emphasis of the intellectual elements is presented by those whose minds are bent towards intellectual inquiry, and the fact that for most thinkers the centre of interest lies in their mental work accomts for the multiplication of theory in this direction. Hegel, making the resthetic the immediate presentation of the absolute to sensuous intuition; Baumgarten, looking to the field of obscure perception; Schelling, to the perception of concord-all show their mental bias. To pass to another field, it is the religious Consin who makes resthetics dependent upon the existence of a special internal spiritual sense, and Ruskin, the theistic devotee, who tells us that the representation of Divine Types is all-important.

Now it is evident that the mere pleasure field varies in much the same way in relation to each man's "personal equation," and in this we have the explanation of the divergence of view which we find, and a help towards the answer to our inquiry. Our field of pleasure-getting is determined by our capacities; as they vary, so must our enjoyments vary. Examination will show that in the main there is a correspondence between the resthetic field and the general pleasure field, which capacity determines. The barbarian loves brilliancy of colour and strength of contrast, and his

1 Problimes do l'esthétique contemporaine. 
crude art works show the qualities which give him his tullest pleasure. His greatest interest, the chase, war, and the coarser passions, form the subject of his art, as exemplified in the dance and in the earlier forms of representative effort. As his interests change, his art, the mark of his resthetic field, correspondingly alters; the more delicate beauties of form become predominant when perfection of physical skill, having shown its advantage over mere bigness or strength, las become the interesting feature for the race.

The impulse which leads to the propitiation of gods, and makes their supposed satisfaction the deepest interest of life, leads in early times to a glory of architectural art which accords with the power and might that men take the greatest pleasure in picturing. The intense religious impulse of a higher kind, the satisfaction of which makes the interest of the middle ages, finds its correspondence in the subject of its art.

Later times show a constantly growing delicacy of perception and emphasis of what may be ronghly called the more intellectual interests of life, and art shows a corresponding change.

The general correspondence between individual and racial life would lead us to look for a similar change of itsthetic field with our own individual development, and this is clearly seen. The child rejoices in objects not very dissimilar from those that delight the savage; the youth shows more fully the appreciation of the nobler emotional pleasures of art; the man must be full grown, however, to find his rsthetic field in the region near that of a Lessing.

Those who have taken especial note of dreams tell us $^{1}$ that we often admire in dreamland the beanty of objects which appear to us in waking life exceedingly ngly-that is, the waking ego rejects the standards of the sleep conscions-

${ }^{1}$ Cf. Am. J. of Psy., vol. v. p. 339. 
ness which may be supposed to be of an earlier, less developed type.

Thus we find in this riew an explanation of the existence of strong opposing positions taken in different ages, e.g. the Socratic emphasis of Usefulness, as opposed to the modem exclusion of Zncekmässigkit. We are thus enabled also to explain the fact that men of different qualities of mind differ so strongly in opinion in this regard; for it appears clear to us now, to use the words of the younger Mill, that "the sources of the feelings of beauty ... must be to a material extent different in different individuals."

Thus does it appear clear why some men who are intensely affected by and delicately appreciative of resthetic effects in some one direction, may at the same time be dullards in appreciation of a diverse art. It is not in the least uncommon to find an enthusiastic devotee of literary resthetics who cares nought for music, or a skilled musician who cares nothing for painting, or a talented plastic artist who gains little from music or literature. The extreme cultivation of one set of capacities indeed must in itself tend to prevent such high degree of cultivation in another diverse direction as is necessary for full appreciation of art works dependent upon the latter.

Thus also we find explanation of diversity of view in the same individual as he expresses the different moods in which his mind works from day to day; note, for example, Ruskin's emphasis of the useless in architecture in "Lamp of Sacrifice" as opposed to his principle of "vital beauty" in the appearance of the fulfilment of function in living beings. Thus we find explanation of the difference of view expressed by thoughtful men as their mental attitude changes with their development: note Matthew Arnold's strong emphasis of broad mystic effects in poetry in his "Maurice de Guérin," where he says, "Poetry can awaken it (a full sense of things) in us, and to awaken it is one of 
the highest powers of poetry:" and then his emphasis of concreteness in poetry in his later work as he grew to feel more strongly the influence of this keen scientific age: in his essay on Emerson we read, "He is not plain and concrete enough; in other words, not poet enough." The Arnold in this latter position was another man from the Arnold of the former. In the latter case his mental attitude approached Lotze's, and he, possibly unwittingly, expressed somewhat Lotze's view. In the former case he spoke as a poet, and expressed the importance of the indefinite mystic element in the asthetics of poetry.

Thus again we see that increasing years going hand in hand with changes of mental capacity, or limitations of capacity dne to intensity of application in certain special directions, must inevitably bring a man to a point where he can no longer gain delight in the fields to which the most cultivated men in their prime attach the greatest asthetic value, and which to him at some time may have seemed of deepest interest. If he allow the name resthetic to cling to that which the world calls resthetic rather than to the characteristic subjective mental attitude involved, he must find himself with Darwin mourning the loss of capacity for resthetic enjoyment. But surely Darwin was wrong. Concentration of effort, advancing years, do not cut us off entirely from resthetic delight, althongh they do change the mental region in which the resthetic impressions are gained, and, what is of more moment, do render our resthetic states less prominent because they limit directions in which mental activity is vigorous, and in which, therefore, pleasure-getting is full even if possible.

One more point must be mentioned here, viz. that this hedonic theory enables us to understand the logic of the common-sense view which groups together under the term "resthetic" states so diverse in form and content as the Sublime, the Ludicrous, and the Beautiful. 


\section{The Differextiation of Esthetics from Hedonics}

$\S 8$. We conclude, then, that there is no kind or description of pleasure which is not, for one person or another, part of what makes up the resthetic psychosis; that there is no pleasure or class of pleasures which we are able to say must be excluded from the rsthetic field in its widest sense, as it is shown to exist in the experience of the race. On the other hand, there seem to be for each individual certain pleasures which he individually does exchnde from his own æsthetic field. So far as I can judge from an examination of my own conscionsness, I can say that no pleasure-for-me at any moment fails to become a component part of the resthetic complex of that moment. There is no particular pleasure which I was experiencing a moment ago that I can say stood apart from the pleasures which during that moment thrilled me in what I recognised as an rsthetic state of mind. Common speech upholds this view, for we find the word "beautiful" applied to all sorts and linds of objects which give us the most ephemeral of pleasures. ${ }^{1}$ The Germans use schön in the same way, and the French their more varied phrases in similar manner. On the other hand, however, I clearly do with others call certain states pleasant which are excluded from the resthetic field, and this resthetic field therefore I do separate in thought from the hedonic field. Why or how this separation is made is a question which must be answered before hedonistic resthetics can be felt to be satisfactory or tenable.

1 Professor Ladd, from whom we should searce expect it (Introduction to Philosophy, 1. 331), "yields the right to the pathologist, from his professional point of view, to call 'beautiful' a preparation of cancerous tissue or of an organ filled with destructive microbes." 
We must note at the start that in undertaking this inquiry we change our standpoint in no small respect. No longer do we consider the make-up of the psychosis of iesthetic impression, but we are dealing with the matter of resthetic judgment and the standards which judgment implies. The question before us, then, appears in this shape. If any species of pleasure whatever may be an element of an asthetic psychosis, how does it happen that we come to judge any pleasure to be non-resthetic ?

In the course of examination of other's thought which has preceded this, I have already referred to one characteristic of the asthetic field, viz. that of permanency. This characteristic is worthy of note because it is directly opposed to the nature of the hedonic field as it is generally conceived. The ephemeral nature of pleasure is the theme of the pessimist; is recognised by the optimist as a fact to be accounted for. The asthetic field, on the other hand, is felt to be opposed to the pleasure field on this very ground, as is evidenced by the great number of theorists who uphold universality, absoluteness, almost Platonic idealism, as the basis of resthetics; how could they do so did not their experience give them knowledge of something permanent in the psychoses which they discuss? The asthetic hedonist then is confronted with the question whether there be any such thing as non-ephemeral pleasure; whether there be a permanent pleasure field which is the asthetic field, and to which is opposed the ordinarily recognised field of pleasure.

It seems to me clear that there is no such thing as a permanent pleasure. Pleasure, as elsewhere slrown, is a quality which may attach to any element of consciousness; but not permanently. It is a quality which always fades away under unchanged relations of activity and eapacity in the organ involved; the more vivid is the pleasure, other things being equal, the more rapid the fading; the outcome 
of the fading being either what is called "indifference" or" pain. On the other hand, it seems to me equally clear that complexes of mental elements may in arising so arrange themselves by a shifting of the field of contents as to yield new pleasures to take the place of those which fade away, so that a relative permanence may be reached. This permanence, however, will still be only apparent, not real, close examination showing the impossibility of retaining the enjoyment connected with such a complex indefinitely. This kind of pleasure permanence, I think it will be agreed, is in some degree possessed by all important resthetic objects.

But there is another manner in which an effect of pleasure permanency may be produced, and one of very great importance to this consideration. There are likely to occur cases where a content is pleasurably presented whenever it is presented at all ; and where the revival is pleasurable at the moment of its appearanee, and does not at any time beeome painful. Not that it might not be indifferent or painful under the proper conditions, but that in fact it never is, but is withdrawn from conscionsness whenever painful and for the most part even when indifferent. Such appearance of stability may readily obtain if the source of stimulus be within our control, so that we may avoid the stimulation as soon as it brings other than pleasure to us; this condition obtains in all fields of art, and pre-eminently so with the arts dependent upon the organ of sight, which thus have an advantage over the arts comnected with the ear, where stimulation cannot be controlled by covering the organ (as with the eyelid) or by simply turning the head, but only by much more complex and less automatic moments.

It seems not unlikely that we have here the basis of the distinction which is made between the resthetic and the hedonic. This distinction is noted in reflection and is due to 
comparison of revivals. It may be that those pleasures in revival which are permanent (relatively speaking) are temed iesthetic; and that those pleasures that are not thus relatively permanent are termed non-esthetic. When we ask ourselves the question, "Is this resthetic or is it not?" we clearly are dealing with comparison within the fields of revival; the lately presented is compared with a standard, and included with or excluded from its class, as the case may be. If this view be correct, it is what we call " the lately presented pleasmre" which is compared, and that with which it is compared is a field which relatively is permanently pleasurable in revival.

But if the "lately presented pleasure" is in any case excluded from this field of pleasurable revival, it must be because it is in reality no longer a pleasure. How comes it then that we call it a pleasure? P'leasures obtained by direct stimulation are not necessarily pleasures in revival. ${ }^{1}$ This change, however, is not always comnected with a corresponding dislocation of the word "pleasure," which may, and often does, continue to cling to much that no longer brings pleasure for us in revival. Nuch that is brought up in revival spontaneously when we think of "pleasure," or when we make recognition of the enjoyments of others, is no longer a pleasant revival for ourselves. These revivals to which the name "pleasure" still clings, but which are not pleasant in themselves, it appears to me are what we cast out as non-resthetic.

For me apparently the process is this: 1st, I class all that as resthetic which is pleasurable in revival, with no

1 It must be noted here, as I have argued above, that a revival is not necessarily pleasurable, because the impression of which it is a revival was pleasurable; nor was the original impression neeessarily pleasurable beeause the revival is so; the pleasurableness of any mental element depends upon conditions whieh may alter from time to time, so that recurrence of a content does not necessarify imply the recmrence of the pleasure-pain quality which held with any one impression of that content. 
painful and little indifferent tendency; in other words, the reqlatively permanent field of pleasure in revival is that which I call my resthetic field; all else is non-æsthetic. What is indifferent in revival I tolerate only as an adjunct; what is painful in revival I cast out of my resthetic field entirely; I do not always judge a work non-æsthetic because of a painful element in its revival, but I exclude that element as non-resthetic. 2nd, Those revivals I call hedonic and not resthetic to which the name "pleasure" clings in any way (either because I remember the original to have been pleasant or because of the recognition of the enjoyment which they bring to others), but which for me in revival are not pleasant but indifferent or positively painful.

Now all this refers to and describes the field of resthetic judgment, but, as already noted, is, strictly speaking, apart from the field of actual asthetic presentation. Every argument, in my opinion, goes to show that in the latter field any pleasure which is a pleasure at the time for the one to whom the rsthetic object is presented, does have to do with the make-up of the essential nature of the rsthetic effect. The difficulty which we have been considering would, therefore, appear to arise from a failure to distinguish the field of resthetic impression from the field of resthetic judgment. From the former no pleasure that occurs for an individual at a given moment can be excluded. From the latter all that is not pleasurable in revival is to be excluded, and this cuts off much to which the name "pleasure" persistently clings: the pleasures of the so-called "lower senses," for instance.

The relative permanency of the iesthetic field, as opposed to the ephemeral nature of ordinary pleasure thus explained, gives us then apparently a solution of the difficulty which remained in the defence of hedonic resthetics, and we are led to the general statement: For each person the asthetic 
field to which he refers in making judgments as to becuty is his relatively permanent pleasure-field of revivel. ${ }^{1}$

I say relatively permanent, because it is very evident from the nature of pleasure that true permanence here is impossible of realisation. If each individual pleasure is ephemeral, so must the pleasures of revival be ephemeral per se; there will, however, always be revivals which are pleasant for the time, and objects which are judged to be asthetic will be those which in reflection are pleasurable at the time of their revival. It will be apparent, therefore, that this rsthetic field, if I have described it correctly, must be constantly changeable as we have found it to be. It must alter with those conditions that render variable the nature of the revivals we are to find pleasurable. The racial changes from age to age which development implies, with the necessarily connected alterations of mode of life and habit of thought; the differences of national life, of education, of occupation, between tribes and families; the differences of environment, of habitat, of wealth; the differences of individual life, and, in that life, of years-all should show us differences of standard as to what is asthetic ; for each will show differences in the character of the mental revivals, which will be pleasurable. Who can deny that just such alterations of the resthetic standard are to be found varying in relation to the differences of life and thought thus sketched out? For each man there is indeed, for the time during which he is engaged in an examination of his mental life, a semi-permanent field of contents which remain pleasurable in revival, and which are revived when he questions himself as to what is his resthetic field. But even this field

1 The reader will bear with me if I again remind him that this is not the same as the field of the revival of pleasures as often understood, i.e. of contents once pleasurable, but which in revival may not be pleasurable at all. 
of the time, when reviewed in retrospect, shows its alteration in comparison with what he can remember to have made up the content of his resthetic field of the past: to the fact of this real non-permanency, it seems to me, is due the difficulty which is found in defining the field, so that in reality its description is usually indirect by the statement that one object is, and another is not, within its bounds.

$\S 9$. This matter of esthetic standards we must consider more at length. As we have already seen, under this view, the field of asthetic impression is a very different thing from the field of resthetic judgment. From the ficld of cesthetic impression (A) we are able to exclude no pleasure, whatever be its character, unless it bring in with it at the time an overbalance of pain. Any pleasure which can in any way be brought into comnection with the pleasurable complex, so that it forms part of the co-presentation or follows in its associative train, by this fact becomes part of the field of iesthetic impression. The field will be wider and more vivid than that of resthetic judgment. It will be notably "presentative," as this word is commonly understood in opposition to "representative."' The pleasmres of sense will enter notably into its complexes, as they are the most vivid of pleasures; but, on the other hand, the pleasures of revival will not be excluded from the field. Many impressions which are pleasant in themselves but not pleasurable in revival, and which, therefore, will be excluded from the field of resthetic judgment, will be included in the field of resthetic impression as part and parcel of the totality.

The field of resthetic impression is of far less interest, however, than the field of resthetic judgment; the ephemeral nature of pleasure, and the variation which this implies in the character of the revivals from which we are able to gain pleasure, would lead us to look for a ficld of individual 
csthetic jutgment of the moment (B), covering any complex, wide or marrow, which for the individual gives a pleasant revival at any special time. This must in its nature be very variable; it is the field of revival made use of when we make ofthand judgments in asthetic matters. But this field will be recognised as abnormal so far as it differs from the relatively stable asthetie ficld of the individnal (C), which is the basis of the judgments we make after reflection, and which rletermines our personal taste. From this field will naturally be cast out all that reflection shows us to be painful in any well-recognised case, or indifferent in all but unusual cases. To this field we look in the careful comparison which goes with the analysis of a work of art, while the resthetic field of the moment is the basis of our casual everyday judgments.

It must be noted that we are still dealing with a field which is only relatively permanent, which is liable to change from year to year, and in a lesser degree from day to day. Few of us ever realise this variability of individual taste, but as soon as we do we refuse to be satisfied; we ask for something more certain and stable. We do not care so much what a person's individual judgment is, as what it ought to be. It is here that the opponents of hedonism make their most vigorous attack. Hedonism, say they, shows us no difference between taste as it is and taste as it should be; if pleasure be your criterion you must give us a guide as to what ought to please; otherwise you sweep away all difference between what gratifies you and the true and noble beauty. I am perfectly willing to grant that this objection is well made against any astletic hedonism which would at the same time defend absoluteness of asthetic standard; but the weight of the objection bears against abso?utism in asthetics and not against resthetic hedonism. I grant

1 Cf. Von Hartmann, Es. seit Kant, p. 354. 
that if one is to be a hedonist in cesthetics then he is compelled to abandon absolutism psychologically, whatever position he may take from a metaphysical standpoint. But the hedonist in resthetics is not at a loss for a standard. His standard, to be sure, is more liberal, is less dogmatic than that which the absolutist aims to describe, but it has an existence of very decided vitality; it has an objective stability at any special moment which gives it worth, and I find it not less, but more valuable, than the absolutist finds the hypothetical quasi-platonic ideals which he aims to approach. To reach this resthetic "ought" of the hedonist is no very simple matter. The average man never reaches it. $\mathrm{He}$ is unwittingly the most ardent of absolutists. His own personal taste he believes to be a reflection of this certain fixecl absolute, and if others differ from him it is, in his view, because they are thoughtless or are led by other than resthetic influences, or are not sufficiently cultivated to appreciate what is good. What we have just here described he is content to do always, viz. to deal entirely with his own subjective standard; when he would have something more stable than individual taste, he canonises his own taste and makes that the standard. The logical hedonist, when he feels the need of a more stable criterion than his own taste, turns from his own field to an objective field; the field of the highly cultivated man as he conceives him (D); the field which every philosophic critic must acknowledge apart from his own individual taste if he is to treat art subjects with any breadth. The individual peculiarities of his own field, whilst none the less effective for himself, must be treated as individual rather than general; and his criticism be determined by reference to a broarler field which contains all that is common to those for whom he speaks. It must be noted, however, that it is not often that he himself recognises the non-personal nature of this standard.

This standard, it will be seen, is still changeable, un- 
stable; but it is relatively unchangeable and stable. It must vary with width of experience, of education, of refinement. It changes as a person limits his notions of life and of the universe, or as his views become broader and more sympathetic. It alters with his change of conception as to what is worthy in the world surrounding him, and as to the sincerity and value of other people's beliefs, and in the end it will be found to be largely determined by his ethical conceptions. As Wundt says, "Effectiveness of higher esthetic representations depends always upon the arousal of moral or religious ideas." 1 It is thus that Taine, though no hedonist, would have us measure a work of art by its importance and beneficence-that is, its power to develop and preserve the individual and the group in which he is comprehended. ${ }^{2}$ It is thus that Fechner would have us make our own final standard of rsthetic valuation dependent upon our conception of what on the whole has the best outcome for the well-being of mankind for time and eternity.

In emphasising the value of the recognition of others' standards, however, we must not overlook the fact that individuality of field is none the less important, for upon it is dependent the ideal asthetic field (E). This ideal field, from our standpoint, must be a variable one, differing for each individual; no absolute as usually conceived; no fixed objective Platonic ideal towards which we weakly strain, but the field which in some direction differs from the normal field; and in this direction the individual feels that the world ought to agree with him. Each one of us, however prosaic, has some sort of an ideal field of this kind; nonagreement with it in others looks like resthetic error. So firmly rooted is this belief in one's own ideal that intolerance is proverbial among artists and comoisseurs; intolerance

1 Elements of Phy. Psy., ii. p. 221. 2 "Ideal in Art."

${ }^{3}$ Cf. Vors. d. Est., end of vol. i. 
which is often amusing to one who looks at the subject from a student's standpoint. Once in a while an individual ideal when expressed enlightens the world of art. The artistic genius is the prophet who shows to others an ideal field which they recognise as effective for themselves, and which but for him would have been unknown to them. To express his own ideal must the artist work. He must indeed produce effective results in the field of presentative rsthetic enjoyment (A), but if his work is to be of importance it must go beyond the momentary effect; it must compel recognition as part and parcel of the stable field of pleasurable revival (C), and must not stand opposed to the objective standard which is given by recognition of the value of the opinion of others whose cultivation entitles them to speak with authority (D); if, however, the work of an artist is to be recognised as that of a master it must express an ideal (E) which the common mortal, however highly cultivated, does not and cannot reach of himseif, but which he will recognise when it is reached by another as an enlightenment of his own duller conceptions.

$\S 10$. In what has preceded it has already appeared that, if the hedonistic view be adopted, we must look for diversity of opinion, for descriptions of the resthetic field widely separated and even contradictory, because the rsthetic field is really a very different thing for different individuals. It will be well to note how far this theory aids us in accounting for the existence of the theories which we have already examined while looking for an asthetic basis.

Bald sensualism need not detain us; although it is worthy of mention as an indication of revolt against those theories which would exclude the sensational field entirely from the xsthetic, and as implying a conviction that the sensational pleasures really make an important part of the asthetic 
psychosis of presentation. Those theories which, by overemphasis of the function of the sense organ, appear to savour of sensualism are in most cases really rationalistic rather than sensational.

'The opposition to sensationalism, however, on the other' hand, is important. The casting ont of sensational pleasures from the esthetic field by anthoritative thinkers cannot be ignored; it must have a basis in psychologic experience. In terms of our theory it indicates that many well-marked sensations which are pleasurable in presentation are not pleasurable in revival. It has been noter that the sensepleasures which are cast out are those of the so-called "lower senses." The pleasures of retinal or aural stimulation, or those closely connected therewith, are not the ones against which our anti-sensationalist raises his voice. His objection is to the inclusion of the sensations of taste and tonch, especially in their grosser modes, and he drags all the rest of sensations after these. This appears to me to explain the whole position. For the developed man of to-day the so-called "lower senses" do bring pleasure in presentation, and often in what we may call primary revival, i.e. a revival induced by the representation of objects which, if presented, would produce the presentative pleasure. In reflection, however, there are many associated psychic elements, largely ethical, which rise in painful opposition to any such cherishing of these revivals as continuance of the pleasure implies. The whole mental state can scarcely be a pleasant revival under ordinary conditions, but must generally appear painful; and as such will be cast out of the resthetie field of judgment.

The theory which would identify iesthetics with emotionalism is really a hedonic theory, for it is based upon that mistaken analysis of emotions which identifies them with, or treats them as, compounds of pleasures and pains. This faulty analysis leads to the use of the word "emotional" to describe 
roughly any complex of pleasure. The theorist hence naturally calls his pleasurable æsthetic complexes "emotional," and finding upon examination that certain of the typical emotions are distinctly important and relatively permanent in the make-up of his most notable rsthetic states, he takes this to be sufficient evidence to sustain his position.

The elaboration of any theory is dependent upon emphatic processes of reasoning. The writer and thinker on æsthetic theory must have a decided intellectual bent. Rationalism and intellectualism thus appear natural as far as the writer allows himself to be carried away by the influence of those mental phases which are most predominant for him. Further, the mental states known as intellectual are pre-eminently those states in which we deal with revivals, and thus one turning to introspection for corroboration of theory finds evidence that the resthetic field is intellectual, imaginative, contemplative, as he emphasises respectively the relational side of the contents of revival, the contents themselves, or the fact that his asthetic judgments are connected always with reflection.

Formalism, as already noted, seems to result from a grasp of the truth that the basis of resthetic effect cannot be in the "content," or in any special limitation of "content"; that it is based upon some quality which runs through all "contents."

The determination of resthetics by reference to ethical or spiritual types arises apparently from the personal bias of the theorist, for whom everything in life must conform to ethical theory, and from an unwillingness to believe that any field so wide, and which is judged so important by the mass of men, can have any other basis than that which is for him at the foundation of all things.

The claim that all usefuhess to the observer must be excluded if an object is to be rsthetic-the insistence upon disinterestedness as an element of the resthetic psychosis-is 
based upon the fact that pure egoism of all kinds for the serious thinker of to-day is painful in revival because it is obstructive to the sympathetic impulses which are so important to our modern social life.

The theory of passivity, so far as it is not explained by the width of unmarked attention which forms the broad background in the resthetic psychosis, is probably based upon the psychologic observation that the revivals of states in which we appreciate reaction upon the environment furnish too emphatic and narrow fields of attention, too much concentration, to permit of any appearance of permanent pleasurableness; in other words, the fields of relatively permanent pleasurable revival are so pre-eminently the fields of passive appreciation that ground is given for the hypothesis, which, however, as we have seen, will not bear close examination.

The theory of immediacy indicates an appreciation of the fact that the resthetic judgment is determined by no complex process of reasoning, is no remote result of intellectual action, but is grasped mentally as simply as the very widest quale of presentation, and such a wide quale pleasure is.

Where one makes the distinction between higher and lower pleasures, and bases upon the distinction his definition of resthetics, he appears, as already stated, to be merely renaming his terms and restating his problem. He calls those "higher pleasures" which in reflection appear worthy of contimnance because their pleasurableness is not painfully opposed by other associated revivals-in other words, those which are permanently pleasurable in revival; and in so doing he thus describes his asthetic field of judgment.

As above suggested, theorists who from metaphysical considerations have adopted general absolutism or universalism find it possible to make esthetics fit in with their formulas, with corroboration from their psychologic ex- 
perience, which tells them of the permaneney of the æsthetic field; the fact that this permanency is relative only-is apparent and not real-being lost sight of. Further colour is given to such a view by the fact that the art worker feels that he is aiming to grasp something which exists, of which he has suggestions and for which he makes search until he can lay hold upon it. He works out a veritable blind impulse to create, to produce an object; knowing not and caring not that the characteristic of this object is to be this,-that it shall bring permanent pleasure in revival to those whom it is to affect. He may and does gain pleasure in his work, but that he feels is not his aim. He eliminates himself and works to produce that which is to affect others. He thus feels that his effort is separated from the production of effects merely agreeable to himself ; that it is disinterested; that it represents some ideal common to the race of man; that his striving is to picture some Universal, some Absolute. This position is strengthened by the fact that the mere grasping of a so-called Universal through its particulars is felt to be of importance in resthetics, as is shown clearly in the prominence which is given by so many thinkers to the principle of the "unity of the manifold." The explanation of this prominence does not appear to be difficult but must be deferred; it will be treated in Chap. VI.

\$11. A most fruitful lesson is to be learned from this whole discussion, viz. a lesson of liberality. As we have seen, the resthetic field of chillhood is not that of the youth, nor that of youth the same as that of the man of mature years. Differences of cultivation and of point of view must be constantly taken into consideration. We must not expect that others will agree with us in our revival-pleasure-getting, except on broad lines. The failure to recognise this fact is often a serious loss. The belief 
that beauty is something absolute, which he has mastered, brings to a man fulness of enmui, and too often cynicism, when he finds what he has learned to consider pre-eminently valuable beginning to pall upon him. Such is the position which too many a critical mind reaches, and which would be aroided could the critic but look beyond the standard which he himself has set, and take coguisance of the manner in which his resthetic field alters and develops as he grows in constitution of mind and life.

We learn also (and this I. consider most important) the futility of attempting to foree standards upon others. TVe too often expect youth, or those of low mental ability, to appreciate beanties which can be grasped only by men of capacity, who have given their years to acquirements which make appreciation possible; and as a result we produce disgust, most seriously opposed to the deveiopment of a refined esthetic judgment; or else insincere pretence of appreciation, which is evidently immoral in effect.

Before we turn from this subject I think we may well consider one other point.

Hedonism in restletics is for many hard to accept, becanse it savours of what is ordinarily called Epicureanism.

If æstheticism merely teaches selfish pleasure-getting we surely cannot complain if om moral teachers renew attacks against all emphasis of asthetic culture.

If the artist merely works for the pleasure he is to give, and which he sees will pay him in one coin or another, truly this will take the glory ont of all art effort. So sordid a notion will be bound to extinguish the enthusiasm which is the very life of art.

But no such positions are involved in our theory; for the true artist, in so far as he is an artist, has no end in view except the working out of an impulse to produce.

So far as he learus to calculate and mould his work 
to bring nearer to him a preconceived benefit to himself, so far is he led by other than the true art impulse; so far does he crush down the inspiration, i.e. the inborn tendency to produce certain results, which indeed bring pleasure to his admirers, but which are undertaken without such pleasure-giving as a preconception.

This art impulse is blindly instinctive in its simplicity, with no end in view at all beyond the completion of its work. In proportion as ulterior determinate ends become more fixed the fire of genius is dimmed, although the nobility of the man's work may perchance be heightened by the intrinsic nobility of his aim, beyond the line of mere westheties.

When we take the place of the recipient, on the other hand, while it becomes still more evident that the end in view in giving attention to art works is the pleasure they can give us, it is easy to see that the force of the moralist's objection to this emphasis of rsthetics is broken by the forms in which art necessarily presents itself; the selfcentredness, which crude hedonism would teach, gives place to sympathetic width of view under the sway of the Muses; the cramping limitations of egoism break down in the wsthetic atmosphere. The average moral teacher who identifies pleasure with sensation not umnatmally objects to a theory which seems to him to put so strong an emphasis upon matters of pure sense, which he values lightly on ethical grounds.

But the true hedonic theory here explained does not emphasise the activities of sense; rather does it lead us to discard the "presentative" elements, and to emphasise the reflective and "representative" elements exactly as such moralists would wish. For sense-pleasures are pleasures of limited range, and, as we shall see, pleasures of limited range, however vivid, must soon fade: a shifting field of 
wider range, however, may not only give us a source of delight more lasting, but also a totality of pleasure much greater in amount than sense alone can give. In attaining this shifting wider field we cannot lean exclusively upon the presentations of sense which nature guides with slower alternation, but must turn to the flow of what are usually termed "representations," which association connects with our presentative field.

$\S 12$. In closing it will be well to say a word in retrospect. We saw at the beginning that non-hedonistic theories of iesthetics as thus far propounded had failed to deal satisfactorily with its problems. That pleasure is always present in all resthetic psychoses we found acknowledged, and by comparison of the views of thinkers it has appeared clear that no class of pleasures can be held to be essentially non-iesthetic.

That there exists not only a theoretic but a popular aversion to the treatment of resthetics as essentially hedonic is acknowledged.

I have tried to show that the theoretic objection disappears if we differentiate the hedonic field in general from the resthetic field upon the basis of pleasure-permanency in revival, which must belong to the latter and may not belong to the former. Incidentally it has appeared that the theoretic opposition to the hedonic treatment of resthetics has been increased, if not occasioned, by an incorrect and inadequate view as to the nature of pleasure-pain, held by asthetic theorists. I have also tried to show that if my position be correct we are enabled to account for the genesis of many theories which have been defended in the past.

The still more complete misunderstanding of hedonics by the "unthinking herd," to use Berkeley's term, is sufficient to explain the popular disinclination to the acceptance of an 
resthetics which is based upon pleasure. Holding pleasure to be a sensation, or looking upon it as an emotion exclusive of sensation, it is clearly impossible to identify with pleasure rsthetic effects which for the most part deal with what is recognisedly non-sensational, and with what must be classed apart among emotions, if it can be called emotional in any respect.

Having reached this position, the natural continuation of our argument seems to require us to show that resthetic practice conforms with pleasure-pain laws. These laws have been only partially considered. We shall turn in the succeeding chapters to their fuller discussion. 


\section{CHAPTER IV}

THE PHYSICAL BASIS OF I'LEASURE AND PAIN-I

\section{Introductory Suminary}

Ax examination of the theories which have been presented to account for pleasure-pain phenomena shows that it is possible to separate them into four groups. We have first-

A (p. $172 \mathrm{fl}$ ). The theories arising from consideration of pains of violence, according to which pain is looked upon in the first instance as due to an overstepping of the limits of normal activity, and from this the principle is extended to inchude the negative limit of subnormal activity, which apparently makes it possible also to accomnt for pains of obstruction. Pleasure is then conceived to be occasioned by restoration to normal and healthful conditions. Under this conception we are compelled to look upon pleasure as a process of replenishment, a view which Aristotle showed to be intrinsically weak. There appears, moreover; to be no manner in which we can account under this theory for those most vivid pleasures which are evikently due to activities more than ordinarily vigorous, viz. the pleasures of exercise.

B (p. 176 ft.). A second group of theories is evidently based upon observation of the pleasures of relief which 
follow violent activities, from which arise $(X)$ views closely allied to those discussed under A, pleasure being held to be due to equilibrium and pain to tension; and again ( $\mathrm{I}$ ) certain contrast theories, according to which pleasure is merely the mark of the absence of pain, or pain the state of absence of pleasure.

The theories indicated by the letter $\mathrm{X}$ fail, as did those of class $A$, because they leave the pleasures of exercise unaccounted for. The theories indicated by $\mathrm{Y}$ show their weakness as soon as we consider that many pleasures arise ont of states which involve no pain whatever (the pleasures, for instance, which the healthy man appreciates in any exercise after restful sleep), and that many pains arise ont of states which involve no pleasure.

$\mathrm{C}^{\circ}$ (p. $177 \mathrm{ff}$.). The pains of restriction with which life is filled have also formed the basis of certain elaborate theories which make opposition the basis of pain; these fail, however, in many respects, and especially in making clear the rationale of pleasure production.

D (p. $182 \mathrm{ff}$.). Consideration of the pleasures obtained from bodily exercise has given rise to a very large number of theories which in one form or. another connect pain with actions dangerous to the system and pleasures with actions healthful to the system. There are, however, so many exceptions to the rules laid down, so many pains that are wholesome to the system and so many pleasures that are hurtful, that these theories have never been felt to be satisfactory, those which appear to cover the ground most fully being found to be illogical in detail.

Our review of these theories emphasises certain facts which it is well to consider (p. $190 \mathrm{ff}$.). In the first place, we find it generally conceded that all pleasures are of the same nature, and that all pains are likewise of the same nature, and that pleasures and pains are closely related. 
We find, again, that all pleasures are either (") induced by active functioning, or $(b)$ are connected with the cessation of activities; and that all pains are comected either with $(\alpha)$ excess of functioning, or $(b)$ with failures to function. Furthermore, that there is a state of so-called indifference which to all intents and purposes is neither pleasurable nor painful.

The facts thus brought out must be related and accomted for by any satisfactory theory.

So large a proportion of theorists have upheld the theory of a commection between pain and pleasure on the one hand and bodily ill and welfare respectively on the other, that it seems desirable to consider this view critically (p. $192 \mathrm{ff}$.).

It appears that in the beginning it was founded upon the experience that a specific oryon acts efficiently when it is giving pleasmre and inefficiently when it is giving pain. Recalling onr contention in Chap. I. that pleasure and pain are general qualities which may, under proper conditions, belong to any element of consciousness, we are able to hold that the organic basis of pleasure and of pain is not fixed, but shifts, as does the element which appears in conscionsness and to which the pleasure or pain is attached. We may therefore adopt the following working hypothesis: The activity of the orgen of any content if effeient is pleasurable, if inefficient is painful (p. $19 \pm$ ff.).

This formula at the first view seems to fail in that it takes no account of the pleasures connected with cessation of activities and of the pains of restriction; but when we examine these special pleasures and pains with care it appears that they are systemic, and are not connected direetly with the mental element which brings the pleasure or pain ly its dis- 
appearance from consciousness. It may be, therefore, that these systemic pleasures and pains are themselves also directly determined by some activities, respectively effective or ineffective, other than those which are the basis of the elements which disappear through rest or restriction. At all events we may reserve consideration of them for a moment, and examine our hypothesis with reference to the pleasures and pains which are evidently directly comnected with activity.

Efficiency and inefficiency describe conditions in which the action of an organ is respectively greater or less than the reaction we expect from it when it is stimulated in a given manner (p. 197). The emphatic cases of inefficiency and of efficiency all seem to have reference to differences of relation between the amount of activity in some organ and the mutritive condition of that organ, and this leads us to the adoption of the following supplementary working hypothesis: All pleasure-pain phenomene are determined by the relation between the action in certain organs which is eoineident with the conseious state under consideration, and the mutritive conritions of these organs at the time of the action (p. 202). This would seem to account for the acknowledged close relationship of pleasures as a class and of pains as a class. As to the grounds of the difference between pain and pleasure, observation shows that if the conditions which bring pain persist the pain in general increases; but that if the conditions which bring pleasure persist the pleasure decreases. This points to something used up in the case of pleasure, and the fact that there is something to use ul points to storage.

The same conchusion is reached if we consider (p. 202 ff.) that pain is not, and pleasure is, directly comnected with rest of the organ which is active in producing the mental state in question; for rest implies storage of surplus energy in an organ which has been active, and which in being active has 
created a deniand upon the system for a supply of nutriment, this supply not being cut off promptly when the call for it ceases.

We therefore reach the further working hypothesis: Plectsure is experienced uhenever the physical activity coincident with the psychie stete to which the plectsure is attached involves the use of surplus stored force. P'ain is erperioneed whenever the physical action which determines the content is so related, to the supply of nutriment to its orgen, that the energy involved, in its reaction to the stimules is less in amount than the energy which the stimulus habitually calls forth (p. 204). In certain cases where the stimulus calls for no surplus stored force, nor yet calls for a greater reaction than the organ is capable of giving, we should expect to have a state devoid of pleasure or of pain-that is, a state of indifference. Theoretically this state would be seldom reached, but states little separated from it we should expect to experience often, so that the region of practical indifference should be wide as we find it.

Returning to the pleasures of rest and relief (p. $209 \mathrm{ff}$.) and the pains of obstruction, we see that it is probable that the rest-pleasure may be caused by the use of surplus stored force in the systemic organs which have been withheld from action during the excessive activity preceding the rest. We see also that it is possible that the obstruction pain may be caused by excessive activities in the systemic organs, which, so to speak, endeavour to break down the obstruction. Finding no evident inherent objections to the working hypothesis, we are now in a position to examine it in detail. To this we turn in Chap. V. 


\section{Technical Treatment}

$\S 1$. In Chap. I. I have endeavoured to gather together in brief the psychological evidence which indicates that pleasure and pain are primitive qualities which, under proper conditions, may appear with any psychosis, whatever be its content. In closing that chapter I drew attention to the fact that this psychological theory, if a true one, should be found to throw light upon the problems relating to the physical basis of pleasure and pain. I shall attempt here to examine this special view of the subject, and shall hope to show also that the position already reached psychologically is corroborated, if we accept the view to which we are led by our investigation as to the physical basis of pleasure-pain phenomena.

Where a working lyppothesis which seems to be not unreasonable is strongly and honestly defended, we usually find that it is based upon some emphatic experience, which the theorist grasps clearly, and to which he attempts to relate all other experience at all connected with it. With any complex phenomena, therefore, which have been long under consideration, we may usually get at the indisputable data of experience by examining the special facts which have formed starting-points for serious discussion of the subject.

It will be found, I think, that all the most notable pleasurepain theories may in the first instance be placed in four groups, determined by the emphasis of certain kinds of pleasure or of pain, which, therefore, we must accept as data of pleasure-pain experience.

$\S 2$. A. The most emphatic of these experiences are the 
pains which we are able to connect with tissue-destruction, and the earliest suggested hypothesis may not improbably have been determined by consideration from this standpoint. Plato's contention that violation of limit is the basis of pain, which was probably a notion current in his day, evidently arose from such consideration. The attempt to account for pleasure as an opposite of pain led him to the materialistic theory that pleasure is due to replenishment, this being the basis of the restoration of limit. This view showed its weakness under the rigid analysis of Aristotle, who argued that pleasure conld not be looked upon as a process. As he says, "It is a whole, and we cannot at any particular time receive pleasure, the species of which would be perfected if it lasted a longer time." 1 The strength of the Platonic view lies in the fact that it serves to correlate the sharpest of pains with the pleasure of relief from pain and of rest. Horwicz, in his Psychologische Analysen, has adopted this theory in a form to which reference is made below. So acute a thinker as Delbcenf has formulated his views as to pleasure-pain avowedly on the same lines; this last, as the most developed form of this theory, deserves examination.

"Sensation," says Delbœuf, "is accompanied with a sentiment of pain as the result of approach to the limits of total exhaustion or the departure from the position of natmral equilibrium. It is accompanied with a sentiment of pleasure as the result of departure from the limits of exhaustion or the approach to the position of natural equilibrium." " Now this theory of pain, as it stands, evidently fails to take account of the pains of restriction of normal activities; for reference to Delbceuf"s formula shows that for him "departure from the position of natural equilibrium " means in the direction of activity only; and it still more evidently fails in the fact

1 Ethic's, Book X. chap. iv.

- Eléments de Psychophysique, p. 182. I have rearrangùl in trunslating. 
that not even all these "departures from the position of natural equilibrium" can be shown to be painful, for a large proportion of our pleasures (those of exercise) are most evidently in the direction of exhaustion and involve a distinct departure from equilibrium. The pleasure-theory, which he directly refers back to Socrates's observation of relief from restriction, fails to take account of these same pleasures of exercise, which we shall presently see are of great importance. While the theory covers the ground of the pleasures following excessive, exhaustive action, it does so, I feel, on spurious grounds. For Aristotle's psychological objection above mentioned remains unanswered, and on psychophysical grounds it may well be held that the argument is much weakened by the fact that we have no evidence elsewhere that processes of replenishment or repair are directly, per se, brought into consciousness at all.

Mr. Herbert Spencer also treats of pain as due to violation of limit, pains of restriction as well as those of excess being held to be concomitants of departures from the normal. He fails, however, to make clear why pain should arise with nonaction, which no psychophysical theory would hold to involve consciousness at all. He recognises the difficulty, but does not face it. ${ }^{1}$ An equal failure of his theory lies in his discussion of pleasure. Since the judgment of most observers is against the view that pleasure is a concomitant of normal activities-as would naturally follow from the arguments which go to show pain to be a concomitant of abnormal activities-Mr. Spencer finds himself constrained to maintain the connection with "medium" activities. That intense pleasures involve hypernormal activity we have already noted; the connection with "medium" activity can, therefore, be maintained only on most general grounds, and definition of the word "medium" is demanded. Mr. Spencer

1 Prin. of Psych., i. chap. ix. $\$ 123$. 
acknowledges the difficulty here, and attempts to solve it by reference to evolutionary doctrine. On broad lines, it is evident that the extreme states of restriction and of excess with which pains occur are detrimental to the organism, and hence we have the inference that "medimm" activities which are productive of pleasure are beneficial; which in a general way seems to be upheld by observation. A most interesting fact this is certainly; but, as he goes on to show, one which merely amounts to this: that if we grant pleasure to be a "feeling which we seek to bring into consciousness and retain there," I that race must persist which takes pleasure in beneficial actions.

Now, to me this appears to be a clouding of the question, and not an elucidation of it. The problem, as he himself states it, still remains, viz. "What constitutes a medium activity?" He has told us: Pains are concomitants of excessive activities; pleasures are concomitants of medium activities. When we ask ourselves what is meant by "medium activities," we find merely an added reference to organic evolution, so that we are able to restate his propositions, adding the words in italics, thus: Pains are concomitants of excessive activities detrimental to the organism. Pleasures are concomitants of medium activities advantagcous to the orymism. But again we are brought to face the old question, How do we know non-excess, medium activity - except by its pleasurequality, which we are attempting to explain? If the hypernormal action is pleasant it is called "medium"; as soon as it becomes painful it is said to be "excessive."

1 As Mr. Edmund Gurney has noted in his I'oxer of Sound, it is more than donbtful whether the ingredient of impulse implied by this definition is to be found in all pleasure, and the same may be said of pain as it is defined by Mr. Spencer. As we shall presently see, pleasure implies a tendency to persistence, and pain a tendency to cessation, of the activity of the organ giving the plcasure or pain, but this is not at all what Mr. Spencer's definition means. 
$\S:$ B. Those notable pleasures of relief which come after the pains of hypernormal action have naturally led to theoretical consideration. The quiet time of rest turns one of contemplative habit to thought of the stream of conscionsness, and the presence in that stream of full pleasure with remembrance of the pain-writhings of a while ago must attract attention. In this emphasis of the pleasures of rest and the attempt to relate pains to these pleasures, we have the basis of certain modifications or inversions of the theories just discussed. Hence apparently the theory that pleasure is comnected with equilibrinm, and that pain is a state of tension, as upheld by Horwicz ${ }^{\top}$ and Mr. Leslie Stephen.' Some objections to this theory have already been touched upon. The pleasures of rest are made to depend upon restoration of equilibrium, and this position is open to the objection made above against Plato's position as to replenishment. On the other hand, the pleasures gained in exercise, as already noted in discussing Mr. Spencer's position, themselves require a departure from normal activity in the direction of excess -i.e. a loss of equilibrium. ${ }^{3}$

In this emphasis of rest-pleasures we apparently have also the starting-point of those contrast-theories which in one form or another appear from the days of early Greek philosophy up to our time. Plato gave answer to the Cyrenaic and pre-Socratic theorists of his own time, who contended that pleasure was mere alsence from pain, when he presented the notion above referred to, that pleasure is determined by replenishment. He opposed their position on the ground that there is a neutral state which is neither pleasure nor

1 Psych. Analysen, ii. 2, 1. 40.

2 Science of Ethics, p. 51.

3 While Horwicz acknowledges this fact, he escapes its difficulties by adopting the strained hypothesis that the pains attending excess are really there, but covered over by the pleasure of the restored state of eqnilibrium, which still fills consciousness. 
pain, ${ }^{1}$ which could not be the case if all not-pains were pleasures. Notwithstanding this opposition, the Epicureans clung to the Cyrenaic doctrine. In forms more or less extreme it appears in the thought of such men as Bruno, Leibnitz, Locke, Hume, and Schopenhauer. But contrast cannot give a satisfactory explanation of either pain or pleasure. Although the change from pleasure to pain, or vice verst, appears to bring the newer of the two states into effective prominence, ${ }^{2}$ it is patent that there are many pains which arise without antecedent noticeable pleasure, and many pleasures which arise out of states which involve no pain. It is a most common occurrence to be awakened from unconsciousness by pain, which is the first state to appear. It is equally ordinary to move from one pleasure to another of higher degree with no intermediate pain. The pleasures of life are such positive states to my mind, that I always look for the bias produced by a pessimistic view of life as a whole, and an unreserved rebellion against its pains, when I find such a theory upheld.

$\S 4$. C. This world is full of disappointments, of curtailments, of restrictions; and it is easy to understand why the bitter pain which they bring, none too seldom to the student and thinker, has appeared to theorists to be most fundamental, the state to which all other pains and all pleasures must be related. These pains form the basis of pessimistic doctrine, and the pessimist not unnaturally finds himself making pleasure merely secondary, as relief from the normal state of pain. That a large proportion of our pains are connected with unsatisfied needs does not cover the fact that excessive action in the direction which has given satisfaction of these cravings brings the sharpest of pains. That a large

Tepublic, Book IX.

2 See Chap. VI. p. 325 ff. 
proportion of our pleasure is determined by satisfaction of needs does not explain those pleasures directly connected with the very cessation from activity, which cessation, in the end, develops physical needs and their psychical cravings.

The pleasure-pain theory of Herbart and his school is almost certainly based upon the observation of restrictionpains. Beyond the difficulties just noted, however, there is an objection to Herbart's special position, in that consciousness itself, as we find it, must, by his theory, be always dependent upon mutual antagonism of presentations, and thus all consciousness ought to be, in some degree, painful. This difficulty is but imperfectly covered by Herbart's explanation that pain is determined by that form of arrest, which does not consciously modify the content. Volkmann avoids explanation, setting aside the difficulty in part by the summary process of supposing that, in all cases where there is no pain, the mental side of the process is below the threshold of consciousness. He endeavours to make the position clearer also ${ }^{1}$ by supposing mood (Stimmung), an expression of vital function, to have a unity of its own; an unyieldingness (Unnachgiebigkeit), which covers not the whole quantum, however, but a mean between two extremes. Where the contrast within the sphere of yieldingness is brought into consciousness it gives us disagreeableness and not pain proper. ${ }^{2}$ Pain is thus due, not to a mere increase of an indifferent stimulation, but to an opposition between stimulation (Reiz) and $\operatorname{mood}$ (Stimmung), the conscious side of vital function. On the other hand, Herbartians would deternine pleasure by the superfluity of the mutual support which presentations give one to another $;^{3}$ and this suggests the query, What support can be superfluous under the

1 Lehrbuch der Psychologie, i. 242-248.

2 This distinction between disagreeableness and pain seems to me to be not warranted by experience.

${ }^{3}$ Cl. Mind, xiii. 489. 
Herbartian view? This building up of theory, hypothesis upon hypothesis, ingenious and brilliant as it is, is not proper to psychology unless it overcomes the difficulties connected with the problems involved; which, in my opinion, this theory fails to do. As Wundt ${ }^{1}$ points out, the greatest difficulty with it is that it fails to explain the simplest sensual pleasures. What is accomplished is, after all, little more than a restatement of ignorance, with pretence of scientific form.

Perhaps it was the emphasis of discords in nature which led to Fechner's contribution to this subject, mentioned in Chap. I., end of $\$ 9$. At all events we may here mention his hypothesis, which, as he himself is very ready to grant, is little more than a suggestion which has as yet no corroboration. To him it seems possible that pleasure depends upon the agreement, pain upon the want of agreement (incommensurability) of the nerve vibrations. As complete ignorance prevents the verification of this hypothesis, so it prevents $1 \mathrm{~s}$ from raising very definite objection to it.

As this book goes to press there appears in the Amcrican Journal of Psycholory ${ }^{2}$ an important attempt by Mr. B. I. Gilman to correlate pleasure-pain with physiological habit; a theory which it is proper to discuss here, because of the prominence given under it to the "thwarting of habit" as the basis of pain.

Mr. Gilman holds that "any presentation correlated with a bodily process that tends to fix a habit (increases a trace), is pleasurable; while any presentation correlated with a bodily process that tends to loosen a habit (decreases a trace), is painful. The latter ease is exemplified in the occurrence of any process $a$-followed-by-other-than- $\beta$ in a bodly where the trace $a$-followed-by- $\beta$ exists."

${ }^{1}$ Phys. Psyck., i. 534(3te Auf1.).

2 Vol. vi. 1. 
The theory, under the limitations of the article of which it forms the close, is of necessity stated with little detail of evidence; but it must impress any student as being the ontcome of very careful thinking by one who holds the fullest grasp of the subject-matter to be treated, and it is to be hoped, therefore, that a fuller and more detailed discussion of the subject will soon follow from the author's pen.

It is not an agreeable task to raise objection before the full force of evidence is presented, but I think it necessary to call attention to an important direction in which the theory as thus far elucidated seems to me to fail-namely, in explaining the notable relations of Pleasure and Pain to Intensity.

1. First, as to pleasure. As I understand the writer, the stronger a trace $a \beta$ gets, the greater intensity of the repetition of $a \beta$ that is required to strengthen it in a given amount. This being so, under the theory, we should expect that, with a given content, a continuation without inerease of an intensity which at one moment is pleasurable would in the next moment cause an immediate loss of pleasure intensity; for in such cases there would be no reason to expect any equal "increase of a trace," unless we make the assumption that there is a powerful tendency to the immediate obliteration of traces, and that the continued unchanged intensity is constantly working to keep the trace open, cutting it anew, as it were, and thus continuing the same degree of pleasure. But surely this would be a bolder postulate than is warranted by our experience of the general phenomena of habit. Now the fact is that, under such circumstances of continuance of an unincreased intensity, there is often no immediate loss of pleasure at all, as the theory thus implies, but an apparent continuation for a considerable time of pleasure without loss. 
2. In cases where, with a given content, there is a sufficient increase of an intensity, which was pleasurable before the increase, we should expect to find a continuation of pleasure, and, so far as I can see, no lapse into pain ; for, under such circumstances, if I understand the theory, we should find repeated increases of the trace; but, in fact, while increased intensity often does for a time give continuance of pleasure, it is a matter of general experience that the pleasure eventually wanes (see Wundt's Law, Chap. V. § 9) under any possible increase of intensity, and does lapse into pain.

The loss of pleasure, if intensity be sufliciently increased, can be accounted for under the theory, so far as I can see, only by boldly postulating a great gain in the capacity to receive traces; but such a postulate runs counter to that necessitated under the previous case, where we were compelled to assume a strong tendency to obliterate traces.

If it be held that the rise of pain, under the increased intensity, is accounted for by the fact that this intensity would eventually interfere with the functioning of the rest of the organism, and thus bring pain, we are then evidently forced to assume that the pain, when it comes, is determined by other contents than those which were giving the pleasure. This assumption is opposed to experience, and is not permissible in this instance without opposition to the conditions of our problem.

3. The pleasures which come with normal activities of rested organs, notably in those cases of recurrent alternations of action and rest which give us the delights connected with rhythm (see below, Chap. V. $\S 5$ ), are apparently not accounted for unless we adopt again the forced hypothesis of an extreme tendency to the obliteration of traces.

4. Turning to pains: with a given content, persistent continuation of an intensity which is at the outset painful should 
apparently eventually bring us to a condition of indifference, and then to a state of pleasure; for, as I understand the theory, the sequence $a, \chi$ (other than $\beta$ ), if repeated, will go on being painful (that is, will leave no trace) until $a, \chi$ is equally familiar with $a, \beta$; its energy, if we may so speak, being used up in blotting out the trace $a, \beta$. So soon, however, as $a, \chi$ becomes more familiar than $a, \beta$, then we will have pleasure in connection with $a, \chi$.

But while, in a vast majority of cases, continuation of a painful content brings more pain for a time, and gradually reduction of pain towards indifference, parallel, however, with reduction of the intensity of the content itself, there is not ordinarily any change from pain to pleasure without an intervening period of rest, i.c. of discontinuance of presentation of the content.

$\S 5$. D. The pleasures obtainable from bodily exercise have with good reason attracted attention, and it is not unnatural that the earlier races whose lives were filled with physical action, with whom fame was determined by skill and strength in muscular performance, should have made this emphatic pleasure the beginning of consideration. This was the basis of Aristotle's theory of pleasure, which, doubtless, embodied the thought of many before him. His theory, unfortunately, has not come down to us in such clear-cut and complete form as we could wish. We may put it thus : "Pleasure is the accompaniment of the energising of a sense in perfection when to it is presented a suitable object of the most perfect kind." 1 Althongh the theory as stated is far'

1 In Ethics, Book X. chap. iv. he tells us (Browne's translation): "Pleasure perfects an energy. . . . The most perfect is the most pleasant; and the most perfect is the energy of that which is well disposed with reference to the best of all the objects which fall under it." And again, in chap. v.: "Pleasures 
from satisfactory, Aristotle's enormous influence has led to a special study of the pleasures of exercise, and to this study we may trace a large proportion of the best thought-out theories of the past. These theories, although open to serious objection, show persistent life, which argnes not the blind following of a leader, but conviction, which Aristotle himself must have felt, that in the pleasures of exercise we shall find the key to the psychological problem of pleasure and pain. The theory, therefore, deserves more than ordinary attention, and I shall retum to it later; here I merely wish to note its weakness, as pointed out by J. S. Mill in his Eacamination of Hamilton, who had alopted the Aristotelian view in a slightly modified form. Mill shows that the perfection of action, in a large proportion of instances, gives no sign except the pleasure itself which it is held to explain (and similarly, mutatis mutendis, of pain); hence, if the theory be stated in the form of propositions for pleasure and for pain, these propositions are not convertible.

The theory has been felt to be incomplete, but the pleasures of exercise which it emphasises have suggested other theoretical positions.

Leibnitz, following Hobbes, held that pleasure is due to the cognition of furthered vitality ; and pain to the cognition of depressed vitality. Butler expressed the same view. This theory has been especially suggestive to many later writers. Bain's "Law of Self-conservation" reads thus: "States of pleasure are connected with an increase, states of pain with a decrease, of some or all of the vital functions." " Höffding holds that "pleasure appears in any case as the expression of heightened life, pain as the expression of retrogression and as the forerumner of death." 2 Fonillée expresses his view in

contribute to imcrease the energy." Cp. also Hamilton's interpretation, Lects. on Mctaph. ii. 452.

1 Hind and Budy, chap. iv. 2 Psychologie, p. 2i2, translation. 
almost the same terms. ${ }^{1}$ Professor J. Mark Baldwin, in his late Psychology, clings to the same notion. "Sensuous pleasure," says he, "may be defined as the conscious effect of that which makes for the continuance of the bodily life or its advancement, and sensuous pain the conscious effect of that which makes for the decline of the bodily life or its limitation." 2

Bouillier's ${ }^{3}$ atomistic theory that "love of life is the basis of and the typical pleasure," and "fear of death the basis of and the typical pain," tells the same tale, and we find the same general notion in more casual expressions, such as that of Clifford, that "the sense of increased power is the basis of all higher pleasure."

Bain's law, as being the most known, may be taken for consideration. Pleasure, he says, is connected with an increase of some or all vital functions; pain, with a decrease of some or all vital functions. If we attempt to convert these propositions we find ourselves at once in difficulty. It surely is not true that all increase of vital function is connected with pleasure, for in the case of specific organs pain accrues when the action is increased until it has become excessive, as common speech has it. It is equally certain that not all decrease of vital function is connected with pain, for the lowering of the functioning of a spccific organ which has been bringing pain often yields us pleasure. In such cases it may indeed often be shown that the pain has been connected with a decrease of energy in the system as a whole, and the pleasure with a corresponding general increase of potentiality. Hence it appears that the law, to hold at all, must be referred to the organism as a whole, and not to the organ which is active.

1 Pop. Seience Monthly, xxxi. 818.

2 Feelings and Will, p. 126.

3 Du Plaisir et de la Douleur. 
This may perhaps be made clearer by taking one of I'rofessor Bain's instances. "The pleasures of healthy exercise and of rest after toil " are evidently both comnected with processes indirectly increasing the vitality of the organism; but if the application of the principle be attempted in reference to the active organ, vitality means two different things in the two cases. In the case of healthy exercise it means increased vital functioning, and in the case of rest it means capacity for increased vital functioning. It is the same with pain. Pains of restriction and of "excess" are both connected with processes indirectly decreasing the vitality of the organism. If, however, reference be made to the active organ, decreased vitality in the case of restriction means decrease of vital functioning; while in the case of "excess" it means decrease of the capacity to function in the near future.

But if, to avoid this difficulty, we give the law reference to the organism as a whole, it seems to me it is still open to very grave objection. Painful fatigue, for instance, which certainly is not directly connected with decreased vital functioning of the organism, is not even always indircctly connected with it in the long run; for, while the capacity to function decreases temporarily, it is not infrequent that painful fatigue, if not carried too far, is connected with the growth of powers, which, on the whole, add greatly to our vitality. It becomes necessary in such cases to shift back again and to refer the loss to the capacity of the specific organ. Again, certain specific pleasures bring general organic detriment, and we are forced here to refer the plcasure to the gain of activity in the special organ itself. This necessary shifting of gromnd is very unsatisfactory. ${ }^{1}$

That there is an important connection between pleasure and pain and heightened and lowered vitality respectively for the organism is apparent, but that the connection is

${ }^{1}$ Cp. Sidgwick's Method of Ethics, 4th edit. p. 185. 
indirect is evident also. This indirectness of connection indeed is acknowledged by Professor Bain himself in drawing attention to such startling exceptions as the painfulness of the cold bath which is advantageous, and in explaining the "painlessness of certain diseases" on the ground that "the connection of pleasure with vitality, and of pain with feebleness, does not apply to all organs alike." As Martineau says, "The formula which identifies 'pleasure giving' and 'health promoting' cannot be admitted as true ; for though there is a small central interval where the qualities are found together, they soon begin to vary inversely as each other. And this is in accordance with the common sense and observation of mankind. No people are regarded with more general distrust, or are more sharply scrutinised by the life assurance offices, than the pleasure-seekers; there are none, I should say, who have less chance of establishing a new species by happy variation; or who, in fact, are more continually dying ont and commencing their fossil existence."

Professor Bain, in his supplementary law of "Stimulation and Exercise," makes a step away from the general vitalitytheory in the direction of exchnsive reference to the organ whose action is involved in the mental content. When he tells us that "to stimulate or excite the nerves with due regard to their condition is pleasure, to pass the limit is pain," he turns our attention to the examination of the specific nerve-organ involved and not to the vitality of the whole system. ${ }^{2}$ In this direction we shall presently follow himn; but his theory, as stated, is not of great practical value, for what "dne regard to their condition" means is

1 Types of Ethical Theory, ii. p. 351.

2 It is to be noted, however, that Professor Bain (Senses and Intellect, p. 295) is not willing to allow that it is proper to rely exclusively upon the effect in the organ of the content. 
not evident, and so far as I can see we have no guide to show us when the nerve is acting with this "due regard" other than the pleasure itself which we are endeavouring to explain. Such a form of argmment in Hamilton has received the full force of J. S. Mill's cutting criticism, as above noted.

Professor Bain (Mind and Body, p. 62) holds that "the principle connecting pleasure with increase of vital power receives confirmation from outward displays under pleasure and pain." But I feel that if this prove anything it proves too much; for, as Fechner has noted (Vorsch. $r$. Aesthetil, ii. $265)$, the greatest pains stimulate us often in the strongest manner, and it is impossible to refuse to call this a leightening of life, if we are to explain thus the expressive action in cases of pleasure.

Mr. Herbert Spencer's theory of pleasure-pain, above touched upon, appears on its face to be a version of the vitality-theory; at all events, his words lead one to believe that he so considers it; ${ }^{1}$ but, as I have above shown, his argument relates rather to the present distribution of pleasures and pains in the race than to their essential nature. Like Bain's, it cannot claim to be more than a law of indirect application, and it is of less value than Bain's in one view, because founded so largely upon hypotheses which are not above suspicion.

The most noted supporters of evolutionary doctrine have on the whole done little for us, if we except the strong emphasis given by Mr. Spencer to the fact, long before noticed, that the theory which traced pain to restriction and that which traced it to excess of action may both be correct in part. Difficulty, however, arises in defining what is too little and what is too much; and, further, in defining the conditions of pleasure as apart from the wide region be-

1 Prin. of Psych., i. end of $\$ 123$. 
tween the two states of pain, which is ordinarily called indifferent. ${ }^{1}$

Dumont, in his Théorie Seientifique de la Sensibilité, after a very thorough review of the work of his psychological predecessors, has adopted what is essentially a restatement of the vitality-theory in a form which appears on its face more scientific, but which proves no more satisfactory. According to him (p. 67) pleasure is determined by an augmentation of the ensemble of forces which go to make up the ego, and pain by their diminution. This definition is open to all the objections which Mill raised against Hamilton - which Dumont, however, waves aside as unphilosophic-and in its application is open to many others, consideration of which would be out of place here. It may be mentioned in passing, however, that, under Dumont's theory, as under Bain's, it is possible to explain the facts which experience gives us only by a shifting of term-meanings. "Force," as he uses the term, in some cases means what is ordinarily called activity of nerve, and in other cases it means ability to act.

Paulhan ${ }^{2}$ has referred pleasure and pain respectively to increased and decreased nervous systemisation, which, I take it, is a modification of the vitality-theory, but not an advance.

Closely related to these theories, but separated from them as leaving physiology aside and being purely psychological, we have Dr. J. Ward's very notable restatement of the Aristotelian position. "There is pleasure," he holds, "in proportion as a maximum of attention is effectively exercised, and pain in proportion as such effective attention is frustrated by distractions, shocks, or incomplete and faulty adaptations, or fails of exercise, owing to the narrowness of the field of consciousness and the slowness and suddenness

1 It is to be noted that Dumont (op. cit.) objects to Spencer's classification together of pains of excess and of non-exertion; his argument does not seem to me to be effective.

2 Phénomènes Affectifs, p. 96. 
of its changes." 1 As this statement is not correlated to physiological conceptions, it is, strictly speaking, apart from our subject just here, but it may be appropriate to note that we do not find what is to tell us when the exercise of attention is effective except the pleasure, or when it is frustrated or fails of exereise exeept the pain.2 Nahlowsky's theory, that pleasure-pain is the immediate conscionsness of the moments of rising or lowering of its own psychic life-act, is evidently an outcome of the consideration of exercisephenomena, but it has stepped away from the effort to give a purely psychological explanation of pleasure-pain facts in the direction of such metaphysical statements as we find in Descartes, Spinoza, Kant, Lotze, and Wundt ${ }^{3}$ —all of which gain their inspiration from the conception of healthy exercise, and which may be summed up in the words of Horwicz: "All pleasure-pain (Gefuihl) is the direct expression of the impulse towards self-maintenance of the soul; which feels that pleasant which harmonises with the conditions of wellbeing, and the opposite unpleasant." ${ }^{4}$ This is not far from Lipps's theory, ${ }^{5}$ which relates pleasure and pain to intensity, which, in certain degrees, is favourable (günstig) to the soul

1 Ency. Brit., art. "Psychology."

= Note objections raised by Mr. F. H. Bradley, Mind, No. 49.

* This, so far as Wunlt is concerned at all events, is not to be looked upon as any knoutculye of advantage or disadvantage, whether conseious or sub-conscious; for lie objects to any Erkenntnisstheorie of this kind on the ground that it first seeks the objective canse of feeling (Grfühle) in orcier to transfer to itself the original essenee of feeling (Phys. Psych., i. 540). And so with Lotze, who holds that pleasure is felt when the soul grasps the fact that hypernormal stimulation carries with it an increase of restored capacity; pain, when it grasps the fact of a decrease (Mct. Psyeh., p. 286). He was too clear a thinker to identify this increase of restored carracity with direct increase of vitality, as we have seen some of our modern authorities have done. He feels it neeessary to place the soul, as that which grasps, between the "feeling" and what is to result from the action to the benefit of vitality.

4 P'syeh. Anal., i. 169.

5 Grundthatsachen des Sceleulebens, p. 206 ff. Cf, also Lehmann's (op. cit. p. 150) acceptance, without rigid examination, of the notion that all pain is due to strife and all pleasure to harmony. 
and then gives pleasure; when, on the other hand, it is an obstruction (Hemmung) it gives pain. The theory cannot be carried into detail without raising a demand for other conditions than mere intensity. Certain intensities which give me pleasure in a certain psychosis at one time will give me pain at another. Many other difficulties of a kindred nature appear upon a close consideration. From here the step is short to mystic self-deceptive positions, which give us under the form of explanations mere verbal elaborations of our ignorance. ${ }^{1}$

$\S 6$. Purely destructive criticism such as I have above indulged in is always unsatisfactory, for it seems to indicate lack of appreciation of the value of the thought which others have given to the subject reviewed. But here I can do no unore than state the grounds which lead me to discontent with the theories discussed. All theories which up to this time have been seriously defended, will be found, I thiuk, to be reducible, in whole or in part, to one of those mentioned. And, while this examination has given us little upon which to rest, we have at least pointed out some few cardinal facts which must be explained by any satisfactory theory, and which may well form the starting-point of our investigation here.

1. There is a general agreement, with but few dissenting voices, that all pleasure is fundamentally the same thing, and that all pain in its essence is a single psychological phenomenon. What is more, there is always found the same practical agreement that pleasures and pains are or should be unifiable; that we should be able to bring them into clear and intimate relation with one another.

1 Münsterberg's marked service to psycho-physies prevents ny passing over without mention his theory (Beiträge, ete., Heft iv.) which attempts to correlate pleasure and pain with reflexly excited extensions and flexions respectively. I do not diseuss it above, beeause, as thus far explained, it surely is no more than tentative : no thorough eomparison with experience having as yet been shown. It seems to me entirely inadequate: failing, indeed, to explain even simple algedonic phases in sensation. 
2. There are certain facts so marked in experience as to have become the basis of the majority of pleasure-pain theories, and these must be explained and related to each other, viz.-

(1) All pleasures which we can experience may be referred to one of two great classes :-

(a) Pleasures induced by active functioning.

(b) Pleasures connected with cessation of activities.

(2) There are states, which are usually called indifferent, in which we note no distinet pleasure or pain quality.

(3) All pains which we can experience may be referred to one of two great classes :-

(a) Pains connected with excesses of function.

(b) Pains connected with failures to function.

It must be our aim then, so far as it may be possible, $(a)$ to find a single basis for all pains and a single basis for all pleasures; $(\beta)$ to find a common ground for unification of pains and pleasures; $(\gamma)$ to sketeh a theory which shall explain the facts acknowledged in the experience of thinkers as indicated by their statements; and $(\delta)$ to discover the basis of truth in the notable expositions which have come down to us, and the relation of the old views to the theory to which we are led.

\section{II}

$\S 7$. The reader who has noted the wide inflnence upon theory, produced by the experience of pleasurable exercise, will not regret that my own consideration leads me to direet attention at the start to the theory which these experiences have developed. For surely the line of thought to which master-minds have again and again returned must be worthy 
of especial consideration, even if it has not given us the solution of our problem.

In these days of reading and writing and thinking, the pleasure of exercise suggests the wide field of intellectual activities, as well as those which are, in a way, judged less noble. But the pleasures of the exercise of definite bodily organs are so vivid and typical that to them we certainly should look at the outset.

Aristotle's definition makes reference to perfection in the object stimulating the active organ. Whatever he may have meant by this perfection, it is apparent that the condition of the organ which acts determines the pleasure-pain quality, for, with no change of object, or of the stimulus which it brings, there is very frequently a complete change from pleasure to pain quality, and this can only be accounted for by some change in the receptive organ.

Upon a superficial examination it seems natural to connect the pleasure of exercise in an organ with the efficiency of that organ, i.e. with its ability to function vigorously. Pain, as involved in exercise, on the other hand, appears as similarly connected with an inefficiency in the organ-an inability to function normally in relation to the stimulus received. It will presently appear also, I think, that this position, while requiring explanations and definition of terms to bring the different pleasure-pain facts into relation, on the whole loes not present any formidable difficulties so long as we understand it as the interpretation of pleasure and pain in conncetion with the action of the spceific organs which are giving us the content of consciousness. But the modern notion which leads us to look upon the "brain as the organ of mind" and treats all the rest of the nervous system as mere antenne, so to speak, for this living, assimilating psychic centre, has led thinkers not umnaturally to take for granted that pleasure and pain have each a special loeus in the brain, 
so that if the proper tracts are stimulated in one case we must experience pleasure, and in the other we must experience pain.

It is very natural that this step should be taken; the more so that so large a proportion of our pleasures and pains are not traceable to any special terminal organ-activity. That it is felt, however, that the pleasure-pain is really bound up as a quality of the content in the case of terminal organ action is indicated by the theoretical search for a special kind of pleasure-pain conduction in the nerve carrying the stimulus to the brain, or for special pleasure-pain fibres bound up with the sensory fibres carrying the stimulus to the special pleasure-pain organ in the brain. (Cp. Lipps's Grundthatsachen, pp. 196, 197 ; also Wundt, Phys. Psych., chap. iv.)

I think it has been shown in Chap. I. that there is little evidence in favour of the existence of these special brain localisations for pleasure and pain, and the view is fraught with especial difficulty as soon as we attempt to relate it to efficiency and non-efficiency. Our pleasure-pain experiences shift from one phase to the other with the greatest possible rapidity and variableness with change of mental content, and this is incompatible with a theory which relates pleasure-pain to the efficient or non-efficient action of a brain-organ; for there is no reason at all to believe that the conditions of efficiency can so rapidly change as would be necessary for an explanation of the facts.

This difficulty, perhaps but dimly felt, leads to reference of the efficiency away from any special organ to the organism as a whole (whence have arisen the vitality-theories with all their difficulties already referred to), and then by another step to a practical abandonment of the whole search, psychological and physico-psychological, in the theory that we have 
CHAP.

in pleasure-pain a separate kind of mental action-in fact, another mind than the knowing mind; two individualities, so to speak, on friendly terms with one another and walking hand in hand, but for all that separated by a great gulf of incompatibility which neither can overpass. And this, in its final outcome, must lead away from what is psychological to mysticism.

In Chap. I. it has appeared that psychological evidence would lead us to look upon pleasure and pain as qualities which, given the proper conditions, may belong to any mental content,-qualities bearing a general resemblance, for instance, to the quality of intensity, but with this evident difference that intensity in one shape or another must always be of the essence of each and every mental content. This leads us to take a broader view. If the position be well founded, the search for and localisation of organs of special mental contents need not detain us, because, wherever the organ of the content may be, there will be the centre of the pleasure-pain quality. I am convinced that if we hold this position as to the psychological nature of pleasure-pain, we find not only the true interpretation of the Aristotelian efficiency-theory, but also the clue to a solution of the problems before us.

$\S 8$. It was the observation of efficient or non-efficient action in organs which were clearly known that gave the Aristotelian theory its birth, and to these data of experience we return, but with a wider view of what an "organ" means in this connection. From this standpoint the theory may read thus: The activity of the organ of any content if efficient is pleasurable, if ineffieient is painful.

Two difficulties at once become apparent:-

(1) An explanation is necessary of the meaning of 
"efficient" and "inefficient." Discussion of this-the more important-difficulty I postpone for the moment.

(2) It seems apparent that two great classes of pleasurepain are not covered directly by the statement, viz. the pains involved in restriction of activity and the pleasures occurring when rest follows painful excessive activity.

Those theorists who referred efficiency to the whole organism rather than to the active organ, were able to overcome this second difficulty ; for restricted activity is detrimental, and rest after extreme action advantageous in the main, to the organism as a whole. But, as we have seen, this reference to the advantage or disadvantage of the organism is franght with difficulties when we take into account those often-noted instances where sweets mean death and pains mean future vigour.

The pains of restriction and the pleasures of rest in fact point to the very position to which we have been led by other argument, ${ }^{\prime}$ viz. that the inefficiency and efficiency of which pain and pleasure tell us are inefficiency or efficiency in the organ which is active in producing the content to which the pain or pleasure is attached. For when we consider these states from this standpoint, we at once note that painful restriction of the normal activity in an organ does not imply action, but rather non-action, in the organ restricted, nor does it imply incficicncy in the organ restricted. So restriction of the excessive activity of an organ in pleasurable resting evidently does not mean an efficient action in that organ. Restricted and reduced activities, in fact, really imply a shifting of psychoses, and per sc involve the notion that the pleasures or the pains in such cases are determined by the functioning of other organs than those restricted. In fact, the difficulty here disappears i. 230 .

1 Cp. Lotze, Med. Psych., p. $237 \mathrm{ff}$; and Tolkmann, Lehrb. der Psych., 
altogether, it seems to me, if we take the view that the pain in one case and the pleasure in the other are due to inefficient action and efficient action respectively in other organs than those involved in the content which is restricted or quiescent. For is it not clear, when we come to think of it, that the pains of restriction and the pleasures of rest are systemic in origin? They differ most markedly from those pains and pleasures of action which cling to distinct and definite contents. They have no marked locus, are connected with no developing mental object.

My own experience tells me that, when an organ which has been over-stimulated is rested, the pleasure obtained is not only wider than was the pain which went with the over-stimulation, but that the content to which the pleasure clings is apart from the content which went with the pain; that when a normal action is restricted the pain is equally wide, and has a content apart from that which would have gone with the normal action. In fact, the common occurrence and emphasis of this form of systemic and unlocalisable pleasure and pain enables us, in my opinion, in great measure to account for the existence of the notion that pleasures and pains are phases sui generis-unlocalisable, uncognitive, as has already been noted.

If, then, these particular pains and pleasures are connected with mental states which are barely in consciousness, and which are so widely distributed that no specific content can be attached to them in reflection, it may be that they are still due to activities which are respectively inefficient or efficient (whatever these terms may be found to mean). We may defer further consideration of these pleasures and pains, therefore, until we have looked more closely into the nature of those which involve distinct mental contents, and by implication, action in nerve-concomitants of the where- 
abouts of which we may reasonably claim to know something. ${ }^{1}$

$\S$ 9. Returning, then, to the pleasures and pains of organic activity, we must ask what we mean by inefficiency with which we relate pain, and by efficiency with which we relate pleasure.

We call an action inefficient when the outcome of a certain stimulus is less than the outcome we looked for as the result of our experience. As our experience varies, so will vary our notion of inefficiency; but, on the whole, we gain a fairly fixed notion of what we, in agreement with others like ourselves, may normally expect in the case of organs which are frequent in their action, and the variations of whose action in relation to varying stimuli have therefore become matters of full experience. The notion of inefficiency thus reached is an ill-defined one, to be sure, but it is fixed in our thought by the fact that with the failure to meet our expectation in this regard often springs up the special and notable quality which we call pain.

The emphatic cases which attract attention are those in which we find (1) an unusual increase in the frequency of recurrence of the stimulus. The leg-muscle, which is accustomed to contract at short intervals for an hour each day in a walk, begins to produce pain if the exercise be continued for two hours at the same rate, or if in the single hour the pace be forced, and we soon find that with this constantly-increasing pain goes a constantly-decreasing action of the muscle under a normal stimulus, or a demand for increased effort to induce the continued action.

In another set of cases (2) we find the rhythm of stimulation not abnormal, but the amount of the stimulus greatly

1 It should be noted here that Bouillier (op. cit. p. 94) explains the pleasures of rest as systemic (cp. also Bain, Senses and Intellect, p. 283). 
CHAP.

increased; and here, too, we find pain and reaction less than experience leads us to look for. The man who constantly uses his hand in writing or drawing some day attempts to fell a tree, and finds the muscles of his hand, which held the pen or pencil for hours together, failing him rapidly and painfully.

(3) Still another set of facts attracts attention. The writer or draughtsman is some day reduced to weakness by fever. He resumes his duties, but finds that normal work of writing or drawing soon brings pain and inefficient outcome.

The first set of cases leads us to look for some condition of the organ which is relatively constant in time, and which has been disturbed by the abnormal rhythm of the recurring stimulus.

The second set of cases leads us to look for some condition of the organ which is relatively constant in amount, and which has been disturbed by the abnormal amount of stimulus.

The third set of cases leads us to see that this condition, relatively constant in time and amount, is disturbed by systemic weakness.

The thought of one who is acquainted with but the rudiments of physiology at once turns to the nutritive conditions of the organs which are governed by nervous stimuli largely separate from the systems reactive to stimuli connected with the emergencies of life: conditions which are constant in time and amount relatively to the intermittent action of the nourished organ, and which, on the other hand, are likely to be disturbed by general derangements of the body which affect their practically separate nervous system.

Now, let us turn to the notion of organic efficiency as related to pleasure. Efficiency, like inefficiency, is an illdefined notion, and one relative to ou experience. We 
call an action efficient when the outcome of a certain stimulus is reater than the outcome looked for. Variable as is our experience, still we gain a fairly fixed notion of the action to be expected as the outcome of a given stimulus, and, when the outcome is greater, it becomes the centre of attention with the pleasure which accompanies it.

Here, as with pain, there are (1) notable cases where, compled with pleasure-getting, there is an unusual increase in the frequency of recurrence of the stimulus. The muscular contractions at the beginning of a vigorous walk are pleasurable.

(2) There are notable cases where the rhythm of stimulation is not abnormal, but the amount of stimulus is hypernormal. The commonplace observation, that both pleasant and painful states weary and exhanst the frame, finds its justification in this hypernormality common to the two states. ${ }^{1}$ It is to be especially remarked here, however, that hypernormal rhythm and amount of stimulus usually give pleasure only temporarily. Pleasure is evanescent, the quality quickly fades into "indifference" or changes to pain, and the pain of hypernormality, either of rhythm or amount, is very much more permanent. It is at the beginning of the increased rhythm of action or of the unusual degree of activity that the pleasure is obtained.

Again (3), there are many cases in which normal action brings pleasure after an unusually prolonged rest. The muscles which we use every moment of the day, and with indifference, are used with pleasure by the healthy man when he wakes after a good night's rest.

It has not seemed necessary to give fuller examples of the connection between pain and pleasure and the hypernormal rhythm of action, or hypernormal amount of action in the nerveorgan, nor of the relation of pain to normal action under con-

1 Cf. Lotze, Ledic. Psy., I. 286. 
ditions of debility; for such examples will instantly occur to the reader. I think instances will almost as readily appear in corroboration of the statement that normal action brings pleasure after an unusually prolonged rest.

After the quiet of the night-hours the bird-song, as we awake, is more than usually pleasurable; the rested eye sees beauty in all colours. The rubbing, at our morning bath, of the skin, which has not during the night felt the normal friction of our clothing; the flavour of some special food to which we have been accustomed, but which has not lately been tasted,-all are pleasurable. The burst of delighted admiration and love for a friend whom we have not seen for a while; the zest with which a student takes up his line of thought, after it has been broken off for days by some necessity,-point in the same direction. In fact, I would not think of cumbering this chapter with these examples, were it not that Helmholtz, in elucidating his famous theory of discord, makes statements which, at the first glance, seem to deny the fact. It is, to be sure, apart from his subject to describe the nature of pleasure or of pain, but in explaining the phenomenon of discord in terms of aural beats he places the essence of the phenomenon in its painfulness, and brings this painfulness of aural beats into direct relation with the painfulness occasioned in the eye by flickering light. He then states that this painfulness in the eye is occasioned by the frequent repetition of the case where a new stimulation affects an organ which is at rest, which action he states to be painful, basing this position on the fact that the eye finds it painful to pass from a dark room in which it has been for some time into a glare of sunlight-a painfulness which gradually fades away if one remain in the brighter light. It may be worth while to quote his words in this comnection. "Why," says he," "such intermittent stimulation is so very much more unpleasant than an equally strong or even stronger continuous one, is easy to understand from the analogy of the other nerves of the human body. Each strong stimulation of a nerve brings at first a deadening of its sensibility; so that as a result it will be less responsive than before to new stimulation. On the other hand, as soon as the stimulus ceases and the nerve is left to itself, it is placed, in its general relation to the living body, under the influence of arterial blood, which soon restores its capacity for activity." Having brought into prominence the case of one "who steps into daylight from a dark room and is

${ }^{1}$ Lehr. u. a. Tonempfindungen, Part II. chap. viii. p. 281. 
blinded," he goes on to say (p. 283) of the action under intermittent light: "During the pauses the sensibility in some measure is regained, and the new stimulus acts hence much more intensely than if it had acted continuously in the same strength. Thus scratching gives a greater mass of sensation than pressure. Scratching, rubbing, and tickling are all disagreeable because of the intermittent stimulus." These worls may perhaps be held to refer the pain to hypernormal activity caused in the brain organ, and, in fact, I have no objection to raise to his statement of fact, nor to the general interpretation which he seems to put upon it, namely, that the whole state of the eye has become accommodated to the low conditions of stimulation obtaining in the dark room ; so that the stepping into a glare of light would be, in my view, a case of hypernormal amount of stimulation. Beyond this I would say that the loss of pain is due to the extraordinarily rapid antomatic methods of accommodation which obtain in the action of the eye, which speedily rectify the conditions to enable the eye to act normally under the increased stimulus. It is to be noted, however, that this obtains only provided the stronger stimulus is one to which the eye has been accustomed to answer periodically. If it be more excessive, then, accommodation being impossible, the pain does not disappear by continuance of the stimulation.

There would seem, therefore, to be no reason, under my view, for objection to his explanation of the facts which he presents, were it not for the implication of the argument that the disagreeableness is determined by the action after rest; by the stimulus being applied to an organ well prepared for activity. ${ }^{1}$ The emphasis, in my opinion, should be laid upon the condition uhich, in the case in hand, this rest implies, namely, the rebalancing of the organ to fit it to answer to stimuli of low amplitude only, so that what are not unusually high degrees of stimulus are in fact relatively hypernormal in reference to the organ's condition. 'This brings his view into relation with the large number of facts upholding my general position that action of an organ after rest from activity of that organ is pleasurable.

If we return now to the three noticeable groups of facts in relation to pleasure above noted, we find that here, as in the case of pain, the first and the second groups lead us to look for some condition of the organ which is relatively con-

${ }^{1}$ Cf. Theo. Lipps, Grund. d. Seelentebens, chap. xi. p. 245. 
stant in time and amount, and the third group turns our attention again to systemic conditions. The three together, as in the case of pain, lead us to judge a priori that pleasures are involved with the nutritive conditions of the active organ.

We are able, therefore, to make an important preliminary step in laying down this principle :-

All pleasure-pain phenomena are determined by the action in the organs concomitant of the conscious state, as related to the nutritive conditions of the organs at the time of the action.

It appears to me that we have here what looks like a solution of the second of the problems to which, at the close of the first part of this chapter, I called attention, viz. we have apparently found the basis of that coupling together of all pleasures and pains which is so universal, although these states are acknowledged to be distinctly diverse.

$\S 10$. We must now turn to the consideration of the grounds of this diversity. It is apparent, upon observation, that if in any given case of pain the conditions as to action and as to nutrition remain unaltered, the pain in the main tends to increase. When we are in pain and wish to decrease it, our first impulse is to withdraw from or remove the stimulus which is producing the painful activity. If the state be one of pleasure, however, the stability of the same conditions brings about decrease of the pleasure. If pleasure wanes we find ourselves antomatically acting towards the increase of the stimulus which had been giving us the delight. These facts point to something used up in the case of pleasure, and the fact that there is something to use up points to storage. Turning to another point of view, we shall find that we reach the same result.

As we have already seen, both pleasures and pains are produced at times by action of unusual frequency, and again by action of unusual amount. Mere rest, however, in an 
organ which is often active will give to normal action a pleasure-quality which would not appear without this abnormal rest. It is also to be noted that it is the early stage of hypernormal rhythm or amount of stimulus which brings pleasure, and evidently antecedent rest is here also a condition of importance. The difference between the hypernormality of pain and of pleasure, therefore, seems to turn upon the fact that pleasure is obtained where the organ has been rested.

What does this rest imply?

The processes of nerve-nutrition are relatively constant. The regular rhythm of normal pulsation but serves to emphasise the relative constancy of the flow of blood through the mutritive channels. Apart from this rhythmic cadence indeed there are changes in the course of the flow which are very important, but they do not take from the general fact that, relatively to the activities of our expressive life, the nutritive action is constant. Where the action of a nourished nerve is equally constant, or where its rhythms of action are comparable with those of the blood-supply, it may be supposed the energy used will equal the energy supplied. Where an organ is used irregularly the constant flow continues to bring life to the organ, but there is no regular use of the power gained to correspond with this constancy of income. Under such conditions it will evidently be of the greatest possible advantage to the system to store up in some way this power ready for use when the irregularly coming stimulus calls for action. In an organism large in relation to the forces affecting its parts, with its nutritive powers normally engaged, a call for nutrition in any part, such as will be necessitated if the nerve substance is to do its work with any degree of correspondence to the impulse given, could not be answered at once by the system; could not be answered until there had been produced some additional stimulation in the parts supply- 
ing the nutriment, and until time had been allowed for this nutriment to be brought to the part from which the call came.

For the parts of the system to wait for such nutrition before acting would in most cases prove very detrimental to the system at large ; the action must be instantaneous as far as possible, and this alone can be attained by the existence of a store of force ready to be given up at once upon the application of the stimulus; the replenishment of which store will take place as soon as the parts supplying the nutriment can be so affected as to turn their restorative current in the necessary direction. That there exists such power to store up force, so to speak, to increase potentiality, during the intervals between action whilst the flow of power-giving nourishment remains constant, cannot be doubted. That a race like ours, which is adapted to answer to the most forcible and irregular of stimuli, could have come to exist without such power is hard to conceive. Given these facts, rest in an organ which is at times active means storage of surplus energy; and action after rest means the use of this surplus stored energy. But, according to our view, action of an organ after rest gives a psychic content which is pleasurable; hence we have the working hypothesis :-

(1) Pleasure is experienced whenever the physical activity coincident with the psychic state to which the pleasure is attached involves the use of surplus stored force-the resolution of surplus potential into actual energy; or, in other words, whenever the energy involved in the reaction to a stimulus is greater in amount than the energy which the stimulus habitually calls forth.

By a similar course of reasoning we reach a kindred hypothesis as to pain, thus: (2) Pain is experienced whenever the physical action which determincs the content is so 
ielated to the supply of nutriment to its organ that the energy involved in the reaction to the stimulus is less in amount than the cnergy which the stimulus habitually calls forth.

In general, also, we may say that

Pleasure and pain are primitive qualities of psyehic states which are determined by the relation between activity and capacity in the organs, the activities of which are concomitants of the psychoses involved.

These hypotheses may perhaps be made more clear by symbolic representation.
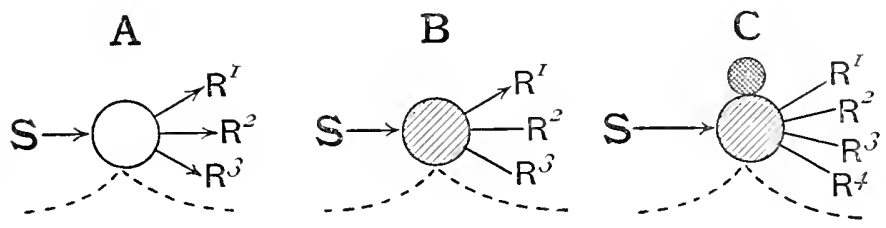

In these figures, $\mathrm{S}$ indicates the stimulus, $\mathrm{O}$ the organ stimulated, $R^{1}, R^{2}, R^{3}$, etc., the reaction to the stimulus. The dotted lines are supposed to represent the channels of nutritive supply. A represents the conditions immediately after the organ $O$ has reacted to its habitual stimulus (S). After the lapse of a certain time we shall have the condition $B$. The cross-lines represent the nourished condition of $\mathrm{O}$, which has absorbed enough energy from the nutritive supply to react normally to the stimulus if it appears. Under the conditions above discussed, where storage appears, we have the condition C, in which represents the surplus stored energy. Now we may suppose that $A$ and $B$ represent the normal habitual conditions, which may he stated thus: $S$ produces $R^{1}+R^{2}+R^{3}$, and is indifferent. If, however, under the case symbolised by figure $\mathrm{C}, \mathrm{S}$ produces $R^{1}+R^{2}+R^{3}+x$, we have pleasure. If, on the other hand, $S$ produces $R^{1}+R^{2}+R^{3}-\times$, we have pain.

The intensity of a psychosis is determined by the amount of activity within the conscious system, of certain elements relative to other activities; so, in somewhat similar manner, pleasure and pain under this theory are conceived to be determined by the amount of activity relative to the capacity of 
the organ involved. The likeness and, at the same time, the unlikeness between the quality intensity and the qualities pleasure-pain is thus made clear.

The Peripatetic doctrine seems, in a measure, to involve the position here defined, so far as pleasure is concerned, as an indirect resultant. The principle, however, so far as I know, has not been made fundamental by any psychologist, with perhaps one exception to be noted, although I think it may be held that it has been incidentally recognised by many thinkers.

For instance, Lotze (op. cit. 285) recognised that pleasure and pain both turned upon the using-up of capacity, but he referred the difference between the two to a recognition by the soul, whether the organ was or was not going to be able to gain after this over-use a heightened capacity for action, to the general organic advantage or disadvantage.

Horwicz (op. cit. iii. 40) recognises the fact that use of surplus force is involved in pleasure-getting, but deals with it as a restoration of equilibrium, which equilibrium is disturbed either above or below the normal where pain exists. Mr. Grant Allen (Phys. Aesthetics, 35) tells us that "all strong pleasures result from the escape of stored-up potential energy which has been hoarded for a considerable time"; but, for all that, he holds that "pleasure is the concomitant of a normal amount of function in sentient tissues." These statements seem to me to be in effect contradictory, and the latter to be in opposition to the principle as to the use of surplus stored force.

Professor Bain also tells us (Senses and Intellect, chap. iv. §18), "It is known that exercise is pleasurable only when we are expending surplus energy, and thereby making the blood to course through the system more rapidly" - that is, the use of stored force brings pleasure because it increases the vitality of 'the organism. Professor Bain's position is, on the whole, not clear to me. His principles of conservation and of stimulation, far from being complementary, are scarcely co-ordinate. The law of conservation is "teleological" (biologically speaking), deals with the present distribution of pleasures in the race, relates to the genesis of this distribution, but does not strike at the essential nature of pleasure. The law of stimulation, on the other hand, looks towards the essence of pleasure, but not satisfactorily, as we have seen, 
and Professor Bain himself holds that it is not in form to cover the whole ground (ibid. $\$ 23$ ).

Zöllner, however, has stated the position as to pleasure with distinctness (Kometenbuch, i. 325, 344, 378). His consicleration of the action of material points led him to belief in the universality of sentience (Empfindung), for him a much more fundamental fact of observation than is the capacity of matter for movement. From his mechanical consideration, he concluded that, in discussing the relative motion of two material points in relation to the work performed, two cases only are to be considered. Either the points move in the way determined by their resultant effective force, and their Spannkift or potential energy is transformed into living force or energy of motion; or, through the influence of a third body - an ontside influence-they move in the opposed sense of force, and then energy of motion is transformed into potential energy. In conscious life this intinence is exercised through two sentient (Empfindungs-) qualities-pleasure (Lust) and displeasture $(U n l u s t)$. And so, he goes on to say, all performance of work of natural beings is determined through pleasure and pain, and the motions so relate themselves as to reduce to a minimum the sum of pains. This theory, put in a few words, is this: Pleasure is the psychic side of the transformation of potential energy (I would suy surplus potentiul energy) into living force; pain is the psychic side of the transformation of energy of motion into potential energy. The formula as to pleasure is not far removed from that which I have here reached, but it is a mere bald statement of hypothesis without proof; and I may here state that my attention was not attracted to Zöllner's work until long after my views were complete in my notes. The formula as to pain is entirely unsatisfactory. What I call storage of force he would claim to be painful. But the fact that this condition is often very distinctly pleasurable led to the Platonic theory, which, we have seen, made replenishment the basis of pleasure. What is fatal to this part of the theory, however, is the fact that pain goes with destruction of tissue and loss of efficiency, which is not accounted for by his statement.

Alf. Lehmann in his lately published work (op. cit. p. 156) has called attention to the importance of the nutrition of the organ involved, but indefinitely describes pleasure as arising when the work of an organ uses no greater energy than its nutritive connection can supply (which overlooks the exhaustive effects of pleasure), and pain when there is a plus or minus misrelation (which goes back to the Spencerian position above criticised). 
CHAP.

$\S 11$. Before considering these hypotheses in detail there are some general considerations which may well be discussed. It will be evident upon the first glance (to refer back to our symbolism) that the conditions must be very rare in which $\mathrm{S}$ produces $R^{1}+R^{2}+R^{3}$, and neither more of an outcome nor less.

On the other hand, a very close approximation to this relation would be expected in all parts of our nerve-system which are subject to constant stimulus and reaction or to relative regularity of rhythm of stimulus and reaction, where the rhythm is so short that little opportunity for storage of nutrition can occur. These are the conditions which go with the great mass of our constant systemic nerve-actions; and a priori, therefore, we should expect to find a corresponding general phase of consciousness, roughly acknowledged as normal, which, however, under careful analysis, would appear of doubtful existence as a frequently recurring state. Now, just such a mental phase we do find in what is called indifference, which is acknowledged to be general enough to relate to all consciousness. That the mass of systemic psychoses-and, indeed, the greater part of our mental life of no very vivid form-is indifferent is what most men will consider a truism. It is only those who are accustomed to observe the very fine nuances of psychic life who find themselves unwilling to rest assured in this respect, and who are disposed to believe that almost if not all consciousness is in some degree coloured with either pleasure or pain, though often in degree too small for distinct recognition. ${ }^{1}$

Turning to the two phases of inequality in our symbolism, we see additional reason why the two corresponding phases of consciousness should be classed together as one pair of mental experiences, exclusive of all others; further, why,

${ }^{1}$ Cp. Sidgwick, Methods of Ethies, 4th edit. p. 125. 
notwithstanding this kinship, they should be exclusive of one another with one and the same mental content. This characteristic of pleasure and pain needs no more than mention.

$\S 12$. We have now reached a point where a return to the consideration of the pleasures of rest and relief and the pains of obstruction seems desirable.

In a highly organised system like man's we should naturally look for some such balancing of functioning as will insure capability in the organisation as a whole. If one distinct set of organs should become excessively active we should expect all imperfectly comnected functioning to be lessened in amount, for otherwise there would be a very constant risk of reduction of vitality to the danger-point. Such relation of the functioning in discomected regions is, indeed, a well-recognised physiological fact, in certain cases temporarily producing what approaches to paralysis in other regions than those of the excessive activity. The less marked cases are commonplaces. We have examples in the holding of our breath when our "attention" is strongly called for; in the general muscular quiet which prevails when we are mentally active. In fact, an over-activity must be isolated, as it were, to become noticeable; it is drawn into relief by the lack of activity of organs adjacent to it. What is more, this is evidently an advantageous tendency which would be conserved by survival. For the adjacent organs being quiescent will not call for much nutriment, and a larger amount than otherwise would be possible can be drawn from the available supply without endangering the system. The general mechanism of this balance is found in the relative constancy of amount of blood in the arterial and venous systems (cp. Mosso's celebrated experiments), so that excessive activity in one direction, calling for a larger amount of blood in that direction, withdraws the normal fulness of bloot from other 
courses, and stimuli will be thus rendered ineffective which would ordinarily produce activity; this failure to function acting as an obstruction to the diffusion of stimuli and of activity throughout regions which would normally be affected. It must be noted, however, that the reduction of the bloodsupply does not mean its cessation. There comes into play what may be called a species of nutritive momentum. If the blood-supply continue in its less full flow, normal activity being prevented by failure of diffused stimuli, then we have the condition which we have seen brings about storage of force. This storage of force will take place, be it noted, in those regions which are determined to activity by diffused stimuli which are in such cases cut off by the failure in functioning of some more distinct activity $\mathrm{X}$. The more excessive the initial activity, the more important will be the organ (X) which fails to react, and, therefore, the wider will be the region of inhibition through lack of normally conducted stimuli, and the wider will be the region of diffused storage of force. Now, suppose the excessive initial activity to cease ; then the inhibited stimulus $\mathrm{X}$ will again come into play; the diffused stimuli will act, and upon organs which are ready to deliver over stored energy. That is, in such conditions we shall have, in widely diffused systemic regions, activities involving the use of surplus stored force, and the width of this use of this stored force will be determined in a direct ratio by the relative intensity of the initial excessive activity. It follows also that, if activity which is normal be caused to cease artificially, every other connected organ which is active will receive a larger than normal blood-supply, and, therefore, will in some small degree show the condition in which surplus stored force is used.

This hypothetical process may be made clearer by symbolisation as follows:- In the figure following the dotted lines indicate as before the channels of nutritive supply; the solid lines indicate 
the lines of conduction of stimulative energy; the several $O$ represent the elementary organs, activity in which are the co incilents of the elements of the content.

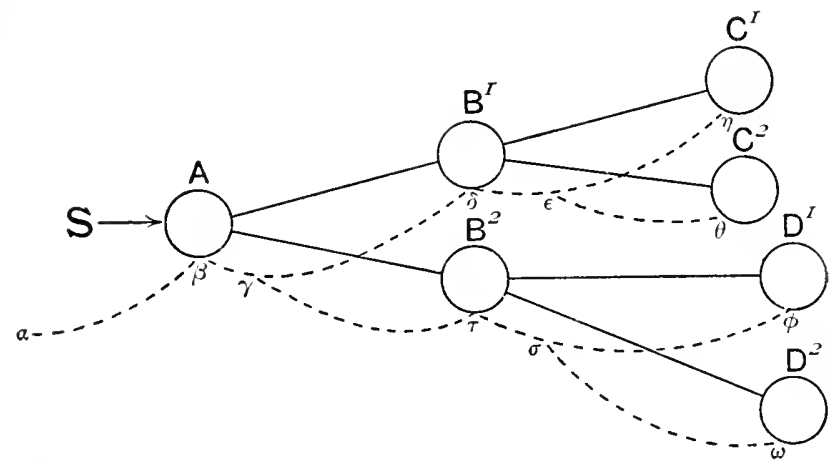

We may suppose the fignre above to represent the normal effect of the stimulation (S) of $\mathrm{O}^{\wedge}$. If, for any reason, $\mathrm{O}^{\mathrm{B} 1}$ becomes excessively active, then the action of $\mathrm{O}^{\mathrm{B}^{2}}$ may be supposed to decrease, or to cease altogether, in which latter case we shall have the condition shown in the diagram below.

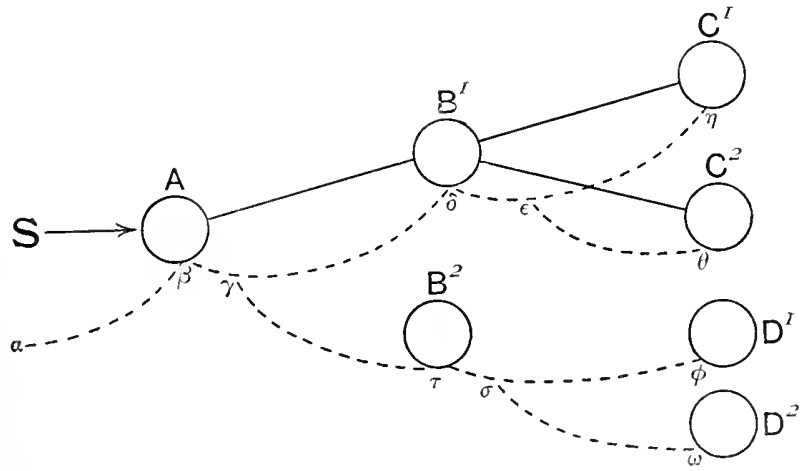

Here, it will be noted, that while the stimulus $\mathrm{AB}^{2}$, and hence $\mathrm{B}^{2} \mathrm{D}^{1}$ and $\mathrm{B}^{2} \mathrm{D}^{2}$, are lacking, the nutritive supply $\gamma \tau, \sigma \phi$, and $\sigma \omega$ is not correspondingly cut off. If then, after a time, the stimulus $\mathrm{AB}^{2}$ be re-established, $\mathrm{O}^{\mathrm{B}^{2}}, \mathrm{O}^{\mathrm{1}}$, and $\mathrm{O}^{\mathrm{D}^{2}}$ will act under conditions in which surplus stored force will be available, and the result in consciousness will be pleasurable. Let us endeavour to state this in psychological terms. 
Attention, whatever else it mean, surely involves loss of balance of psychic functioning. Excessive attention, whether voluntary or involuntary, whether caused from within or from without, means excessive psychic action in one direction and a consequent loss of activity in other directions. That is, it fulfils the psychic conditions which we have seen on the physiological side to involve action in a limited region, and the storage of surplus force in diffused regions. The cessation of this excessive attention, therefore, involves, as we have seen, action in diffused regions with use of surplus stored force. Now, here we have, it seems to me, dimly outlined what will probably be found to be an explanation of the pleasures of rest and of relief, in terms of pleasure as determined by activity with the use of surplus stored force. The reader needs but to be reminded of the diffused nature of the pleasure which, be it noted, always comes with rest from toil or from mental or physical strain; in other words, relief from attention voluntary or involuntary. The more pointed the attention-the more this attention tends to be painful-the wider and fuller is the feeling of delight at the relief from the excessive activity.

The action indicated in the paragraph preceding the symbolisation above, when interpreted psychologically, gives us what appears to be an adequate explanation of the pleasure connected with artificial rest; the delight comnected with the relief of muscular strain, which we feel when we throw ourselves into a supporting medium like water ; the pleasures of letting ourselves be led and guided in thought as in our physical enviromment.

As corroborative of this view, it may be noted that any hypernormal action which is widely spread over the whole system fails to give the pleasure of rest after its cessation. The painful conditions of hysteria and all other cases of general nervous activity, so-called "nervousness," give us general painfulness and exhaustion, an impossibility of rest, 
and no pleasure in the enforced quiet which exhaustion brings. ${ }^{I}$

$\S 13$. We have above brought the pleasures of rest under the laws of pleasurable activity with no great straining of our hypothesis. The pains of restriction, which have also the systemic quality characteristic of the rest-pleasures, will doubtless be found to be explicable in terms of the law of painful activity. In what follows I endeavour to indicate the lines on which I think this explanation will probably be found.

Returning to the plyysiological view, what happens when a normal activity is obstructed as the result of contradictory forces or failure of stimuli, but without radical change of nutritive supply? All the connected organs will, it would seem, take up into potential form all the energy they are able to store. But after that? If the blood-currents still persist without use of the material which they carry with them for the organ, they will fail to move on in their course with normal ease ; the nutritive channels will become gorged, their muscular coatings and their proper nerves forced to do abnormal work under conditions of excess and beyond the limits of storage. Moreover, the effect will not by any means be limited to the nutritive system. The whole make-up of the organism will react to open up the obstructed path; the directly disabled elements calling for aid in the shape of nerve force, and those thus called upon looking to still others for help; until, in some cases, the full width of the system is aroused to break down the obstruction. In the regions of fine capillary division amidst delicate tissue, as in the region of the brain, the very slightest obstruction may be expected to produce a relatively large effect in the direction of this

1 Oftentimes through the enjoyment of rest we may still feel the rhythmic throb of lessened pain from the part which has lately been doing such overservice, - a fact which goes to corroborate the view that the rest-pleasure is in different elements from those in which the active pain hacl appeared. 
diffused excessive work. When the obstruction is removed, however, the return to activity must involve work of organs which are well nourished, and must, therefore, result in the use of surplus stored force.

Now, these physiological considerations would lead us to look for exactly what we find, viz. pain of a diffused kind resulting from the obstruction of a normal activity or of any flow of activity: the well-known pain of obstruction, of hindered activity. They also lead us to look for pleasure of a widely-diffused kind in connection with removal of obstructions and a return to normal activity, and this we clearly do find. I shall not stop to illustrate this, for we shall find frequent occasion to recur to it from time to time in what follows. It is worth while, however, to note here that the wide regions of activity involved in these phases of pleasure in rest, and pain in obstruction, will render these states in general unlocalisable and disconnected from clear and distinct contents. It is this principally, it seems to me, which leads to the somewhat popular division of pleasures and pains into acute and massive; for the latter comes into prominence rather through the summation of a large number of elements of low degree than by any special acuteness in any direction.

This general discussion of these hypotheses as to the pleasures of rest and as to the pains of obstruction serves, at least, I think, to show it to be not improbable that these pleasures and pains will be found to be explicable in terms of active functioning, effective and ineffective; and if this be true it at once becomes evident why it is that we practically take cognisance of five phases as to pleasure and pain, althongh, in fact, the five are reducible to three. We have, as noted at the end of $\S 6:-$

(1a) The pleasures of activity involving the use of surplus stored force in the organ determining the content. 
(16) The pleasures of relief, of rest, which are reducible to (1a); but which depend upon activities apart from the content which had been emphatic before the relief or rest.

$(2)$ The state of indifference.

(3a) The pains of hypernormal activity.

(3b) The pains of obstruction, reducible to (3a), in a manner similar to that shown above for pleasures of rest and relief.

The principal point to be emphasised here is the fact that these pleasures of rest and pains of obstruction are systemic, i.e. are not eonnected with markedly fixed or localisable contents; so that while we may hope to find corroboration of the hypotheses as to these pleasures and pains in the course of our further examinations of the subject, on the other hand we may note that they need not enter into consideration when we attempt to deal with phases of fixed content.

$\S 14$. In what has preceded this we have examined the theories which have been defended relative to the states of pleasure and pain, and with espeeial care those which deal with their physical basis, but have found none satisfactory. We have noted, however, the faets upon which these theories have been based, and have found them all unifiable under a modified form of the Aristotelian theory, provided the efficiency in the case of pleasure and the inefficiency in the case of pain are conceived as relating to the organ which is active in producing the content of which the pleasure and pain are qualities. An examination of the notions of efficiency and ineffieiency has led us to see that pleasure-pain phenomena are determined by the relations between activity and nutrition in the organs which in functioning determine the content, and this leads us to the theory that pleasure implies use of surplus stored energy, while pain implies a subnormal reaction to a given 
stimulus. This has led to our statement of the hypothesis as above explained and symbolised. Examination of this hypothesis may be made in the main on two lines. 1st, We may examine mental states, to see whether they involve any special relation between nutrition and action on their physical side, and look for the pleasure-pain quality, which should be expected to appear with their rise into consciousness. 2nd, We may examine the laws of pleasure-pain in the case of fixed contents, where the organs which function may be supposed to be the same in all cases of the appearance of the content. In the chapter which follows this we shall take up this examination in detail.

I undertake this task knowing full well the danger which lies in the expression of theory which is not subjected to the test of refined experiment. No one can look over the ruins of complex theories, which in the past have been constructed to account for the physical basis of the operations of mental life, without feeling that our conceptions of the nervous basis of consciousness will be subject to radical change as time gives us more exact data. Whilst, therefore, I have above expressed, and am willing further to express, my notion of the basis of pleasure-pain in terms of the conceptions which our time holds with fair clearness, I do not feel certain that later on much of what I say may not appear as erroneous in form. I shall be altogether satisfied if I am able to bring my readers to believe that the physical coincidents of pleasure-pain phenomena are to be found in general qualities common to all processes which are at the basis of our conscious life; and that this is corroborated by introspective analysis of pleasures and pains. 


\section{CHAPTER V}

THE PHYSICAL BASIS OF PLEASURE AND PAIN-II

\section{Introductory Summary}

ACCordisg to the formula reached in Chap. IV., pleasure results from the use of surplus stored force in the organ whose activity determines the mental state or psychosis; and pain is cletermined by the reception of a stimulus to which the organ is incapable of reacting completely. The verification of this hypothesis necessitates very technical treatment, and I shall not ask the reader, who is not interested in the full argument, to follow its steps in any detail in this summary.

If we ask what laws of rise and failure of pleasure we should look for under our hypothesis, we find that we are led to adopt a formula which appears to be a correct psychological statement of the effect of habit in the deadening of pain and in the production of pleasure (p. $225 \mathrm{ff}$.).

We find a basis for the relation between rhythmic action and pleasure-pain phenomena (p. 231), and we are able to account for the evanescence of pleasure and for the relative persistence of pain (p. 232).

We find, further (p. $233 \mathrm{ff}$.), that many states of mind which would necessarily involve the conditions of pain or of pleasure under our theory, are found to be painful or pleasurable respectively as we should expect them to be. When we 
consider states of mind which involve fixity of mental elements we are able (p. $238 \mathrm{ff}$.) to trace the laws which we have found corroborated in the region of sensation, through all mental fields in which we are able to find alterations of relations of activity to effectiveness without change of the elements present before the mind.

If we proceed by another method (p. $257 \mathrm{ff}$.) we find corroboration of this view in the means adopted as the result of experience in order to produce and to reduce pleasure or pain.

We also (p. 260) find reason to believe that our formula is convertible; that we may properly say that all pleasure is the coincident of the use of surplus stored force, and that all pain is the coincident of organic conditions, which imply that the energy of reaction is less than that which should be expected to result from the stimulus reaching the organs, whose action determines the mental elements in each case.

Turning to pure psychology (p. 262), we find that our hypothesis compels a statement of the laws of pleasure and of pain in terms of attention which seem to be satisfactory.

We find, finally (p. 264), that an evolutionary view would lead us to expect what we find, viz. that if pleasure and pain tell of healthful and non-healthful activity in specific organs, they cannot be expected to tell accurately of health and of disease in the system as a whole; that the laws of survival and development, however, will in the long run bring about a general correspondence between the conditions of pleasure and individual advantage and the conditions of pain and individual disadvantage, but that with this general correspondence we must expect to find many exceptions, as we do find many of the sweets of life disadvantageous to us as individuals, and many of its bitter's advantageous. 
We shall find further corroboration of this theory by an examination of the results to which it would lead us in the field of resthetics, and to this we turn our attention in Chap. VI.

\section{Technical Treatment}

$\S 1$. In taking up this work of verification of the hyputheses reached in Chap. IV. we meet at the very start with difficulties and stumbling-blocks. The complexity of the laws in accord with which our lives are developed constantly renders indistinct onr special path of inquiry. Nature's tendency to antomatic regulation works in the individual against the continuance of extreme states, and tends to the obliteration of pains. In the race the emphasis of the advantageous and the tendency to the suppression of the disadvantageous complicate the evidence. The motion of habitual states towards inconsciousness renders the tracing of laws difficnlt.

Upon such points as this it is not worth while to dwell; but it seems desirable to emphasise one difficulty, for at the start we have to face in an aggravated form the special stumbling-block of physiological psychology, which looks for a physiological basis withont adequate means of applying physiological experiment. The difficulty is serions enough in ordinary cases where the functioning of special organs is examined. When we apply experiment in such cases, it is usually taken for granted that we know what organ is active in the special case under investigation. Writers upon psycho-physics are wont to give the inipression that they do know the organs which are active in the production of a given mental state, or that they might know them with proper investigation on well-established lines. But if we are 
candid we must confess that our ignorance in this respect is extreme. We note the impingement of a physical stimulus upon a bodily organ; we note certain changes in that organ; we postulate activity in the nervous filaments of the organ, although the nature of this activity cannot be described with definiteness. Our skilled neurologists tell us, however, that consciousness is not based upon this action, but upon another action produced thereby in the more complicated regions of the brain. They are now attempting by delicate experiments to fix special organs in the brain, and, we must acknowledge, have had remarkable success, considering the enormous difficulties of the task they have undertaken. But we are in no position to apply direct experiment to these brain organs in the human being. We may study the effects of related stimuli in a given terminal, but are in no position to claim that the same relations there traced follow in the brain. We are unable to assert, for instance, that the relations of activity which are traceable in the ear when we bring about a harmony of sound, or in the eye when we appreciate composite colours, hold in the brain organs, which are claimed to be the real physical seat of the activity which gives to us consciousness of these sounds and colours.

If the difficulty ordinarily is great where the functions of special organs are examined, it is peculiarly so in connection with our special investigation, for, as I have before noted, evidences of the very existence of special organs for pleasure and pain are entirely wanting; these states, so far as they can be said to have organs at all, seem to depend upon new activities with each change of content.

It is evident that we must not hope to bring forward evidence which an extreme criticism will allow to be crucial. But we may hope to accumulate less positive evidence in such mass as to produce conviction that we are moving in the right direction. 
$\S 2$. The thesis reached in Chap. IV. in its simplest form may be stated thus: Pleasure and pain are determined by the relation between the encrgy given out and the enrigy received at any given moment by the physical orgens which determine the eontent of that moment.

Pleusure is experienced whenever the physical rectivity coineident with the psychic state to which the pleusure is attached, involves the use of surplus stored force,-- the resolution of surplus potcntial into actual cnergy,-or, in other words, whenever the encrgy involved in the reaction to the stimulus is greater in amount then the chergy which the stimulus habitually calls forth.

Pain, on the other hund, is cxpcrienced whenerer the physical activity coincident with the psychic state to which the pein is attceched, is so related to the supply of nutriment to its organ that the eneryy involved in the reaction to the stimulus is less in amount than the energy which the stimulus habituelly ralls forth.

Plcasure thas results when the balance is on the side of the energy given out, and Pain when the balance is on the side of the energy received. ${ }^{1}$ Where the amounts received and given have equiralenee, then we have the state of Indifferenee.

A

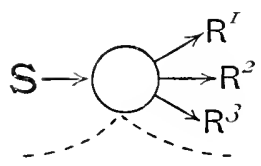

B

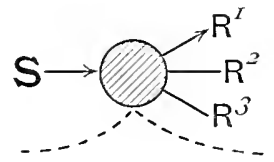

In the above diagram I represent a case of normal action. As in Chap. IV., $\S 10, S$ is intended to represent the stimulus, $O$ the organ stimulated, $R^{1}+R^{2}+R^{3}$ the "in-

1 Care must be taken not to make "energy" here the equivalent of " capaeity to energise," whiel would make the statement a false one. As we have seen above, this is no uncommon error. 
different" reaction to the stimulus S. Here, and in what follows, I speak of an equivalence between $S$ and $\mathrm{P}^{1}+\mathrm{R}^{2}+\mathrm{R}^{3}$.

An equality of energy in the physical sense I of course do not imply, for a very small amount of physical energy in $\mathrm{S}$ may produce a very large amount of physical energy in the group $\mathrm{R}^{1}+\mathrm{R}^{2}+\mathrm{R}^{3}$.

We may speak also of higher or lower potency in either the $\mathrm{S}$ or the $\mathrm{R}^{\mathrm{l}}+\mathrm{R}^{2}+\mathrm{R}^{3}$ groups, meaning thereby to indicate a disturbance of the relation of equivalence between the two groups, and at the same time to define the basis of this disturbance in one of the two groups.

$\S 3$. It is evident, I think, that the statement placed in italics in $\S 2$ is not in any strict sense capable of either psychological or physiological verification; we must turn, therefore, to the data which have led to the adoption of the formula.

Taking a step backward, we find that our thesis may be stated in these words: Pleasure is produced by the use of surplus stored force in the organ determining the content; and pain is determined by the reeeption of a stimulus to whieh the organ is incapable of reacting completely. Indifference occurs where the reaction is exactly equalised to the demand by the stimulus. This statement, however, is purely physiological, and, to be of practical value to us here, must be translated into psychological terms. In so doing it will be necessary to recur to physiological conceptions.

Each bodily organ has, as we know, a certain amount of elasticity, so to speak. The lungs contain a body of fixed air which is not changed in normal expiration and inspiration, but which may be partly changed upon systemic demand by increase of rapidity or depth of breathing. The muscles can all do more than their normal work for a short time without 
perceptible deterioration. Carrying out the general principle under consideration, we may hold it highly probable that the average nerve which is normally aetive at regular intervals will have a certain amount of surplus stored power which may be used if at any time the stimulus received is hypernormal for a short time; but ordinarily between the energy given out and that received there will be such an approximate balance that this surplus stored force will practically not be drawn upon. If, on the other hand, at any time the stimulus received be less than normal, the blood-supply to the nerve not being correspondingly diminished, there will result a storage of surplus power, varying in quantity with the capacity of the nerve, tending on the whole to be largest in those nerves which are at intervals called upon to react to extreme stimuli. We should expect, therefore, to find the following psychological conditions for pleasure :-

A content which appears nomally at relatively regular intervals will tend to be indifferent [e.g. breathing]. If it appear with hypernormal intensity or frequency suddenly in the course of the normal regularity, it will for a relatively short time appen as pleasurable, but this pleasurableness will soon fall away into indifference [e.g. spurts in muscular exercise]. A content which has appeared normally at relatively regular intervals, but the appearance of which has been suppressed for a time, will, when it appears, be distinctly pleasurable, and the intensity and duretion of this pleasurableness will be determined pertly by the length of time which has elapsed since the nomal appearanee in consciousness [e.g. the pleasure gained by the use of muscles which have been under restraint], and partly by the frequency with which it has in the past been liable to suppression [e.g. no great pleasure is obtained by changes in breathing, but much from the satisfaction of hunger or thirst], or to appearanee under conditions of cxceptional intensity [e.g. vividness in general].

Turning to pain.-Any stimulus of hypernormal frequency 
or amount reaching a nerve which has been often active, should, if our position be correct, first bring into use such surplus stored force as there is in the nerve until the amount of energy given out becomes in a way equivalent to the energy received from the stimulus. If the hypernormality of stimulus be continuous, this relation would exist for a relatively brief period only, and then the amount of energy given out would become less than the equivalent of the amount received, the balance in favour of stimulus increasing (if nutritive processes do not materially change) until deterioration of the nerve began to supervene, in which case the activity of the nerve would gradually decrease until it became incapable of functioning. In all cases the system is probably able, in consequence of the fuller action, to increase the nourishment supply, and if the over-action be not too extreme the extra supply of nourishment would be expected to bring about a condition of equality between the supply and the demand.

This, translated into psychological terms, would read thus :-

If a content which has already often appeared in conseionsness appear with unusual frequency or exceptional intensity, it will ordinarily be accompanied at first by pleasure, which usually will wane until the content appears indifferent. If the hypernormal stimulus continue (except as below deseribed) the content

1 That continuation of painful action beyond limits produces more or less permanent destruction of the parts involved seems to be shown by observation. The overworked muscle at length refuses to do its work. Excess of light blinds us more or less permanently, and continued excess of sound will deafen. Continnous over-feeding, besides its discom. forts, will produce destructive action in the digestive organs. Tastes are not often allowed to continue through great painfulness, but to both tastes and smells which are disagreeable we soon become callons-that is, we become unable to obtain conscious effects through the stimulation of the proper organs. The most painful emotional states due to excess of activity finally exhaust themselves and disappear in the exhaustion. The over-activity pains of intellect disappear in mental inactivity, in sleep. 
will berome painful, and this pein will increase in wmount, and having reached a maximum will decreass graduelly nntil it discuppeurs, but in such cases with it will ulso gradually dis"pinear the content itself, not to reappear in conseiousness for a considerable time, if at all. In some cases, hoverer, if the content be not ocer-intense, we may look for a gradual decrease of the puin folt at the beginning mutil a condition of indifferenee is receched. [We grow accustomed to pains.]

If our position be valid, therefore, the psychological conditions which I have placed in italies above should be traceable as laws wherever contents are fixable and are subject to variation in intensity or in rhythm of recurrence.

This tracing will be a serious task, and before we undertake it I think it will be well, for reasons presently to appear, to examine a few corollaries which seem to follow from the physiological view we have taken, and ask whether the psychic conditions which we should expect to correspond therewith are found in conscionsness.

4. The Algedonic Effects of Habit.-Let us first consider certain aspects of what in Chap. IV. I have called the principle of "nutritive momentum."

If hypernormal stimulus cause painful action, increasing even far enough to bring about the beginnings of deterioration in the nerve-tissue, the result may in the long run actually conduce to increase of the capacity for action. For this hypernormal stimulus will indirectly increase the blood-supply, and if the action be not carried too far, when rest comes there will supervene a condition of stored energy, so that upon a later application of the same stimulus the organ may be found not only ready to act, but ready to act under the conditions which involve pleasure. In fact this may happen in the course of hypernormal activity, if the latter be not too excessive. If the supply of mutriment increase rapidly the deterioration of 
the nerve substance may decrease and may finally cease altogether, and, as a result, the stimulus may no longer be excessive as related to the condition of the organ.

One more point. As our system tends to balance, it is to be expected that in the long run the supply of nutriment to an organ will come to be approximately equalised to the call which the organ habitually makes upon the system. Hence it will result that oft-repeated activities in definite organs will render storage of surplus force unusual and finally practically impossible, except under special conditions. Thus, organs which at the beginning of a series of stimulations have no capacity for this storage and are unable fully to react, and which perhaps have become capable of this storage and of the giving up of surplus stored force in answer to the stimulus, may be expected to lose the storage-hatit, as the stimulus becomes more usual and recurrent, although retaining for a time the storage-capacity, which itself may be expected practically to disappear so soon as regularity of stimulus recurrence has become fixed.

If we again translate into psychological terms we shall obtain the following :-

Pain does not necessarily tend to bring about obliteration of its content in future psychoses; but may, in fect, on the whole, conduce to its rigorous reeppecerence in pleasurable form. That is, a content which appars painfully at one time may, if recursent at a proper interrerl, be found slightly pleaserable, and if carived out to peinfulness at this second appecerance may be found still more pleasurable at a third appearanee at the same moper intervel. [Acquired tastes.]

In fret, it may even happen that an alinost continuously present content, if not too intense, may begin by beiny slightly sainful, but and in becoming num-painful, and cuen plectsurable, in e small degree, for a time. [We "grow accustomed to" pains.] In other words, decense of pain may appear before the maximum 
of pain is receched, and in that case the content will not disappear with the redued pein, provided the stimulus which indures its up-coming continu's, but will persist even if the pein disclpear into practieal indifferenee. If, in sueh eases, the content alisappear and reappear at no great intereal, at this reappearance it may be found to be acturlly pleasurable. There will, hourever, the "limit to all growth of pleasure-enpacity, variable in different eases, and, on the other hand, recurrence, with great regulerity, of the content will be aceompanied by gradual loss of pleasurableness. [Routine activities in general.] The eaporcity for pleusme-getting, however, will continuer so lony as variableness of reeuriener rusts, so that pain of wastruction may cusue if the reemenen be reeptionally prevented, and pleasure will result when there has ben fuilure of apperesenee in the normal whythm, and subsequent reappearanee [e.y.humger and its satisfaction].

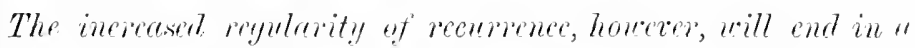
loss of the cery eapreity for pleasure, unless by a second morement through the seme comese as deseribul about.

Under the physiological view, growing callousness as to pleasure under continued stimulation is necessitated by the opening up of efferent channels implied in each reiteration of activity, this making the use of the surplus stored force ever more difficult. On the other hand, exercise of a strong form, it will be seen, is necessary for the building up of the basis of pleasure-getting.

The cravings would necessarily imply over-storage, and hence a preceding case of relative inaction; but we can conceive it possible that a certain time may be required for the accumulation of snfficient surplus to make the obstruction-pain evident, and in certain eases we may expect a sufficiently close accommodative action of the nourishing organs to prevent an over-charge of nourishment. Thus we may see ground for the fact that inaction (real or relative) does not always bring about the painful eravings. To which fact we refer again on 1). 234.

The paragraph printed above in italies expresses in psychological terms the ellect of habit in the deadening of pain and 
in the production of pleasure; and in the loss of pleasure through frequency of recurrence of the activities to which it was at one time attached. The deadening of pains through habitual activity is recognised in all regions of mental experience, and so is pleasure-acquisition. What are known as "acquired tastes" are more truly "acquired pleasure-gettings" in fields which have been painful or indifferent, and the course outlined in the beginning of the above statement is readily traceable in such cases.

Mr. Herbert Spencer gives an explanation of the acquired pleasure-gettings, which may be briefly stated thus: Activities which are resisted require to be excited by an extra quantity of "feeling" ("commonly the fear of pain that may result from nonperformance"). "But since the complex discharges through these complex channels render them gradually more permeable, the quantity of disagreeable representation of pain required to excite the actions decreases." This explanation upon indirect grounds seems laboured in itself. Moreover, it fails altogether, so far as I can see, to explain the evidently allied cases of acquired pleasures in sensation (the ordinary "acquired tastes").

One point which involves important results is especially worth illustrating. The reader will have noticed an implication that, apart from natural growth and the inherited capacity which that growth brings to light, increase of pleasure-getting in any special line comes only through hypernormal activity, which carries the mental state beyond its pleasurable phase and a certain way into the painful phase, which must follow with continuance of the hypernormal stimulus. The athlete must work beyond the lines of pleasure-getting into moderate weariness, if he is to gain growth of muscular capacity and the increase of the satisfaction which will be found in the stronger exercise. $\mathrm{He}$ who is learning to smoke or trying to acquire a taste for olives, for example, must go beyond indifference to the beginning of disagreeableness if he is to gain a future satis- 
faction in the use of tobacco or a liking for the bitterness of the olive. In similar manner, all mental endeavour which is to bring increased ease and increased satisfaction must be persevered in up to the time when the work itself wearies. All students have learned that to gain a thorough comprehension of a subject "hard study" is required.

So much for pleasure gains: the loss of pleasure through frequency of recurrence is also well recognised in all mental regions. To quote an example of Professor Bain's; upon the destruction of the Bastile many prisoners expressed no joy at their release. They had lost capacity for normal activities. What had been restraint was restraint no longer; but, on the other hand, the activities normal to them in former life, to the pleasure of which their friends would have brought them again, were found to be excessive and painful.

Professor Bain, ${ }^{1}$ in a criticism of my discussion of this subject, has furnished us with another most excellent example. "When General Wolseley disembarked in Egypt, with an expeditionary force, he found his operations retarded by the inability of the horses to gallop." In my reply ${ }^{2}$ I have given what seems to me to be the rationale of this case as follows :-

Constant practice is necessary for the most efficient action in any line, because it brings about the action of the organism as a unit more or less in subordination to the special action which is perfected. Let this practice be intermitted, and at once the other activities of the system which had been subordinated again arise, and some of them become the controlling ones; when the intermitted activity is renewed there will be pleasure connected with it (due to the nourishment through rest), but the subordination of the general system necessary for the greatest efficiency in the narrow line will not hold;

$$
1 \text { Mind, N. S. 2, P. } 184 . \quad 2 \text { Ibid., 5, p. } 89 .
$$


what is more, the intermission will have changed the nutritive habits, and as a result of the intermitted practice when the action is renewed, as in the case of General Wolseley's horses mentioned, although this action will be unusually pleasurable for a time at the outset, there will result a quick loss of ability, because of the failure of the nutrition, until the old nutritive habits have been reestablished. Introspection corroborates this general view, for I think it will be agreed that perfect efficiency is only obtained by a concentration, a narrowing of attention. This means an adjustment of higher centres, which will be easily put out of relation by lack of exereise. What is more, this kind of perfection on limited lines involving such constant practice does not leave room for any nutritive accumulution, and it is natural, therefore, to find that such perfection of skill after the first moments of exercise does not give great fulness of pleasure to the performer, in the psychic elements which are directly coincident with the skilful activity. The virtuoso in any line finds his constant effort laborious. $\mathrm{He}$ finds his greatest delights, indeed, in directions in which his special skill is not involved. As Professor Bain says, there is no law to connect taste and talent. All habitual exertion, whatever be its field, must become indifferent, and in all cases we must turn to paths not too commonly trodden if we are to obtain pleasure. Richelieu amused himself by writing bad tragedies; Darwin by reading crude novels. The principal delights the virtuoso gains in his work are indirect through the sense of power over others, and in comnection with their devotion to him. Let the skilled man be cut oft' from his laborious practice, however, and he soon begins to crave the intermitted activities as the organs involved become overprepared through "mutritive momentum"; when the opportunity for activity returns, he may have lost the balance implied in the perfection of adjustment he once displayed, but 
he will experience an intensity of enjoyment thit the full practice elid not give.

Another good example is one mentioned by Mr. E. IB. Delabarre, who calls attention to the fact that "the feeling. of fatigue located in the eyelid is not commensurate with the amount of work this organ has accomplishecl. It is sonetimes excessively strong in the morning after complete repose of the muscles involved." Under our theory this is evidently due to the change of nutritive habit, effected during the night.

These laws of habit, as related to pleasure and pain, have here been deduced from physiological conditions, which seem to be implied in the hypothesis of which we treat. so strong a corroboration encourages us to look a little further in the same direction before taking up again our more direct line of argument.

$\$ 5$. Rhythi.-Time is an essential factor in the process of organic repair. An organ, having the capacity to store surplus force, and which has been so stimulated that this stored force has been used, will not immediately recover its capacity to act with full vigour. For each organ there will be a certain time after action has ceased at which recurrent activity will be most effective. If stimuli are so applied that the action is male to recur at the exact interval of most efficient condition, and is not induced at intermediate times, we shall have for the organ involved the conditions productive of the most pleasure.

It seems highly probable that here we have the physical basis of the gratifications obtained through rhythms. There is a tendency to vibration for the whole system. Music of well-marked rhythm almost invariably canses us to move some bodily part "in time to the music." As Gumey says

1 Mind, N. S. 3, p. 383. 
(Power of Sound, p. 128): "We cannot doubt that the pleasure of rhythm is due greatly to the wide range of the nervous discharge, and also to the association of life and expansion, which especially collect around the sense of muscular movement." Thus it is that we are to account for the full pleasures of the dance with musical accompaniment -of mere watching the dance in the ballet_of marching to rigorous music, etc. The same principle may be traced through all art, so far as it is determined by successive rather than by simultaneous impression. The recurrence of definite elements in architectural work, of order and symmetry-the vibrating flow of the poet's verse-all point to the value of this principle, the application of which may indeed be carried far beyond the simple rhythms to account for pleasurable effects produced in many complex artistic productions. The recurrence of theme in music, for instance, which may be uninteresting if badly managed, gives the most intense pleasure if properly introduced. In such cases we have a feeling of readiness for the recurrence. Rhythmic consciousness, in fact, as thus viewed, appears as a specially marked and orderly species of what are called states of expectation when objectively viewed. To this I refer again in Chap. VI.

There is also a relation of rlythm to pain. The throbbing of acute pain is well known. So far as this is not directly triceable to pressures of blood-supply, it is probable that it is indirectly traceable to the rhythm of blood-supply, which determines some rhythmical hyperactivity, which in its tum is stimulative to the organ directly concerned in the painproduction. The intermediate moments of reduced stimulation will enable the pain-giving organ to recuperate slightly, so that rapid deterioration is prevented.

\$ 6. Algedonic Permanexcr.-. One more point. The 
conditions which are involved in the case of pleasure make it necessary that pleasure should ordinarily be evanescent, as it is generally acknowledged to be ; for the use of surplus stored force implics the reduction of potentiality, except under special conditions. On the other hand, with stability of content we should expect to find pain without such limit in time, provided the organ involved retained capacity to act at all, i.e. so long as the content which is painful continued to be present to consciousness. This, too, accords with general experience. Such exceptions to the general rule as appear, I think, are explicable with no great difficulty, as due to those alterations of nutritive condition in relation to action referred to above.

$\S 7$. Before we turn to the tracing of our formulated law in the region of fixed contents, it will be well to consider certain states which are determined by the special manner in which activities appear. If any of these states of mind seem to involve definite relations between activity and nutrition in the organs involved, we should be able to predict the pleasure-pain phase in which they must always appear. Some general search in this direction will be appropriate here.

\section{Pains of Restriction and their Satisfactions}

We have stated that the restriction of normal activities involves wide-spread systemic pain. Typical cases of such restriction are given when conscionsness is occupied with our hodily cravings;-clemand for exercise of muscle which has been unusually quiescent; hunger and thirst which arise when there is lack of normal food-supply; the artificial thirst which comes to the drunkard; those all-pervasive demands for tobacco and for opium which the habitual user feels when he tries to break up his habit. If these are typical 
cases of restriction, they are also typical cases of painfulness of a wide character.

The cravings are always preceded by an inaction or a low degree of action in the organ involved, but it is to be noted that inaction or low degree of action is not necessarily followed by these pains, presumably because the supply of nutrition which is necessary to the production of the rital condition which has its coincident in the pain, for one reason or another, is withheld; either through lack in the system or because of extreme calls in other directions. One does not feel himself "aching for a walk" after a ten-mile tramp. The itching of our skin does not occur at once after the skin has been rubbed to satisfaction. A craving for sweets or for a particular viand does not claim our attention immediately after we have partaken of sweets or the particular viand in quantity; we do not hunger immediately after eating heartily. We do not long for the odour of roses after spending an hour or so in a rose garden, nor do we crave light in mid-day, nor sounds in the intermissions of an orchestral concert.

In each case there must be a period of antecedent rest. The itching skin has not received its usual stimulation, or else its supply of nutriment has been abnormally large ; the craving for a particular taste arises after a lack of the viand which supplies it; hunger comes after fasting; the longing for a rose odour comes when we have had no flowers: we long for the light in the night, for sound in the desert quiet.

When, in considering the pains of restriction, we step beyond the simple cravings we are on more doubtful ground, and $I$ think it best, in order to avoid breaking into the continuity of our argument, to discuss the analysis of these more complicated states in Appendix I. to this chapter, in which $I$ think the reader will find corroboration of the view here expressed.

At the moment I must be content to mention briefly the most prominent examples.

Desire is a state which is acknowledged to involve repression of activities, and I think there is no doubt that it must also be acknowledged to be painful.

In Despair the permanency of the thwarting of our desires 
is emplasised, and here the pain appears in an extreme form. Joubt and Hesitaney ${ }^{-1}$ are also general states which imply restriction, and are notably painful; and so also Disappointment, which involves the thwirting of an ontgoing thonght in expectation.

Let us look for a moment at another sicle of the question.

In what has gone before we have seen that artificial restriction of an activity which woulel naturally occur involves a gained capacity for pleasme-getting in comnection with this activity when it does ocenr. All the states which involve the removal of the restrictive conditions above referred to onght, therefore, to be pleasant; and such we find them to be. The satisfaction of eravings, the attaimuent of desires, the fulfilment of expectations, are notably delightful. Give the ideal fulfilment of expectation instead of the obstruction of non-expectation adled to desire, and we remove the excessively painful state of despair, gaining anticipation, which is a very full pleasure.

Even where there is a vibration between expectation and non-expectation-i.e. when after despair we have Hope only-there will be a return of activity, which shonld involve considerable pleasure, inmediately followed by nonexpectation painfulness. We find Hope one of our most emphatic emotional states, as they are commonly called. This is clue, I think, not so much to its true emotional elements as to the large total effect of pleasure and pain involved in the state as above described. Why we always tend to call pleasure-pain qualities emotional, I have tried to show in a previous chapter. Where aversion is involved, pleasurable relief is ohtained by a loss of expectation. The attainment of an expectation after a temporary disappointment, even where the pain of disappointment has failed to come into notice; the settlement of belief after the conflict

\footnotetext{
${ }^{1} \mathrm{Cp}$. W. James, Psychology, ii. c. 26.
} 
of doubt; the will-act after the strain of hesitancy ; ${ }^{1}$-all have comnected with them such wide pleasure as we shoull, a priori, expect to find. The delights of liberty after restraint are proverbial.

\section{Pleasures and Pains of Hylernohimality}

We have been dealing above with the indirect pains caused by restriction and with the pleasures attained by normal action after unusual rest. If we turn to the pleasures and pains connected with hypernormal activity, we are able to take broader ground.

Attention, from our point of view, may be considered as determined by relative hypernormality of action in the organ involved in the production of the content attended to, the relation to the coexistent activities naking up the background of consciousness, out of which the content which is attended to arises. Such hypernormality of action under our theory implies pleasure or pain except at the time when pleasure passes into pain, and then it implies a condition of so-called neutral excitement. Attention is so frequently pleasurable or painful that Dr. James Ward, as we have seen above, has based his theory of pleasure-pain directly upon its effectiveness. It cannot be doubted, at all events, that many powerful states of pleasure-pain are states of marked attention, the more intense the former the stronger the latter. ${ }^{2}$

But it must be noted that we are here treating attention in a wide way; the delicate play of thought with which the term attention is usually associated in our minds in reflection

1 Cp. W. James, Psych., ii. 529, 580. i. 68 .

2 Cf. Sully, The Human Wind, i. 163; and Stumpf, Tonpsychologic, 
is notabiy close to the state which we eall indifferent, it being impossible to attend to fine distinctions of the diflerentiated qualities themselves where the special algedonic qualities are prominent, as we shall see below.

Question arises when we consider those cases of attention which are claimed to be neutral for long periods, and therefore apart from the momentary neutrality obtained at the moment of passage from pleasure to pain, referred to above. Considerable thought has been given to this subject of late. ${ }^{1}$ Professor Bain takes strong ground in favour of these neutral states of attention or "exeitement," as he calls them. Personal introspection leads me to agree with Mr. Sully that these states of attention are really widely, but dimly, pleasurepain toned. They often become suddenly markedly painful, and this implies that they were previously slightly painful, even though not so recognised. Where exeitement seems great and still not notably pleasurable or painful, I seem to note in the state a continuous shifting of ground-new contents in suecession, vivid in many cases but without stability of pleasure-pain phase. This shifting of content is indeed implied in the common-sense meaning of the word "excitement." Surprise, which may be called par excellence the emotion of effective attention, and which Professor Bain thinks a good example of indifferent excitement, appears to une to present, on the contrary, a distinet corroboration of the position here upheld. For certainly surprise gives a pleasurable element to the ludicrous, and the general delight in surprises is indicated by the crowds attracted to the pantomine and the cireus by the satisfaction they obtain in mere elownish novelties.

The mention of novelties turns our thought to another corroboration. Apart from the emotional surprise-component which is not always present, novelty in most cases implies a

1 Mind, Nos. 48, 49, 50, and 53. 
shifting of content to regions which have not lately been prominent, and therefore the activity of well-prepared organs, the use of surplus stored force. The pleasures of novelty indeed could have been looked for on a priori grounds if they were not forced upon us. ${ }^{1}$ Of this we speak again in Chap. VI.

Conpled with the pleasures of variety go those of unity. The emphasis of a common bond between two co-presented objects implies the action, upon one organ, of stimuli from two separate sources-that is, a hypernormal action in the organ determining the unity. If this organ has been well nourished we should expect the result to be pleasurable; and such we find it to be in a large body of cases. But in many cases of such conjunction of activities, of course, the amount of available force stored up must be small, and we ought to find, as we do, many unities which give us no noticeable pleasures. This point also is discussed further in Chap. VI.

General conditions of organic vigour imply conditions of storage, and hence pleasure in activity when it arises. This is recognisable as to general physical activity, and in the more delicate regions of consciousness covers those so-called cases of spontaneous activity (i.e. action produced by stimuli, so small in degree as to be unrecognised) which are always pleasurable.

$\S 8$. Let us turn now to consideration of states involving fixity of content.

1 It is to be noted that varieties may hecome non-pleasurable and even prainful. The exeessive action which they imply for the system at large should after a time bring general exhaustion and pain. We find ourselves "tired" of ever-reeurring newness, and longing for rest. That this general exhaustion is the eanse of the disagreeableness is eviclent from the fact that when we are very tired of variety we find any stimulation disagreeable. We seek repose from all stimulation. 
To make a thorongh examination in this direction it will be necessary to examine practically the whole mental field, and such examination in itself would break too much into our argument at this point. What is more, there are other obstacles to the complete discussion of this subject here. To the difficulty resulting from lack of common agreement as to the analysis of mental states, is to be added another equally formidable, and one that especially affects our consideration, viz. that the acceptance of the general pleasure-pain theory which I defend necessarily implies a considerable rearrangement of mental phenomena in classification, and such rearrangement, of course, cannot be attempted here. As debatable ground must be avoided, omissions which might otherwise be inexcusable may be pardoned.

As an example of this difticulty it may be noter that Professor' Bain treats of certain "emotions of intellect." These, except so far as they are reducible to emotions elsewhere discussed by him (e.t. surprise), turn out to be simply pleasurable or painful conditions. We find it impossihle to look upon an emotion as a mere complex of pleasures or pains, and therefore snch a classification requires revision from our standpoint. There may be diftienlty in deciding whether anger and pricle are pleasurable or painful, but their emotional character remains. Take away the pleasure and pain from the intellectual state, however, and the "emotions of intellect" disappear. This seems to me to argue conclusively against Professor Bain's classification in this particular.

We must content ourselves here with a mere sketch of method and a few marked examples, referring the reader to a fuller treatment of the subject in Appendix II.

In this connection the pleasures of rest and relief and the pains of restriction will require little attention. For although, as we have seen, they are only for convenience classed apart from pleasures and pains of activity, this special detachment arises from the very fact that the contents of which they are qualities are so shifting and indefinite that we are able to study them only on the wide lines of systemic function- 
ing. In all nental fields, whether sensational, emotional, or intellectual, rest after high degrees of tension is pleasurable, and restriction of functioning of which we are capable is painful, in the wide way already described. We shall restrict the discussion, therefore, to the pleasures and pains of active functioning.

$\S 9$. If conditions alter or are alterable so that withont change of content the relations between activity and nutrition vary, or may be made to vary, we should be able to note corresponding changes in pleasure-pain phase. Fixity of content on its physiological side implies the functioning of the same organs during the time of the continuance of the content. Increase of the intensity of a content therefore implies relatively increased activity of organic functioning, and this involves changed relations between the amount of action and the capacity of the organ for action. We may therefore rightly demand of our theory some information here.

The examination is greatly aided by one implication of the general theory, viz. that if we can discern laws relative to pleasure-pain phases by the study of some one region convenient for examination, we should be able to find traces of the same laws in other mental regions. Clearly, we must begin with Sensation, where as nowhere else we are able to alter at will the relations of activity to nutrition.

The study of sensational functioning undertaken with great fulness for other psychophysical purposes has led Professor Wundt to formulate a law as to the relation of pleasurepain to increasing intensity of sensational content. ${ }^{1}$ He finds that increasing intensity of sensation is accompanied by a rapid increase of pleasure up to a maximum, then by an even

1 See also corroboration by James Ward, Ency. Brit., art. "I'sychology"; Horwicz, Psych. Analysen, iii. 22. 
more rapid decrease to a point of indifference, and beyond that is accompanied by an increasing pain.

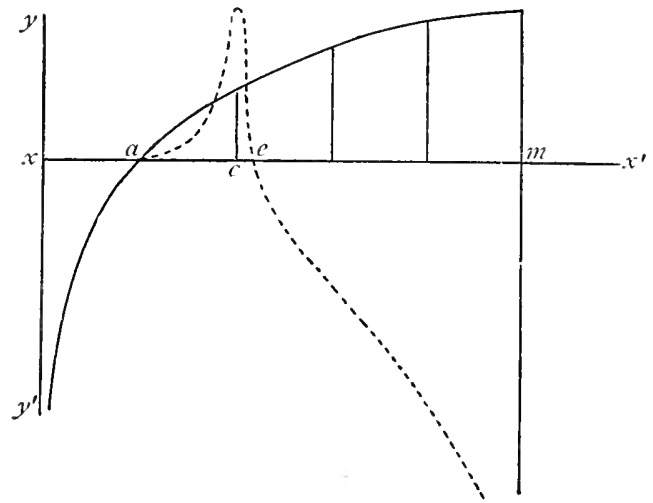

The diagram above, taken from his Physiologische Psychologie, i. p. 511 (3rd edition), explains the law graphically.

The horizontal line indicates the general "threshold" of" sensation and also of pleasure-pain. The solid-line curve indicates the rise of sensation according to what is known as "Weber's law." The rise of this curve above the horizontal indicates increase of intensity. The dotted-line curve indicates the alteration of pleasure and of pain intensity corresponding with increase of sensational intensity; all above the horizontal line indicating pleasure, all below indicating pain, and intensity being represented by distance from the horizontal.

This law certainly stands the test of general observation, but requires consideration because of its implicit denial in the assertion occasionally met with that some sensations are painful however low be their degree of intensity, and others pleasurable however ligh it be. ${ }^{1}$ To this we shall return after having considered certain other points.

${ }^{1} \mathrm{Cp}$., for instance, Spencer's Psych., i. $272 \mathrm{fr}$; also Gurney, Pouce of Sound, p. 4. 
CHAP.

$\S 10$. Let us now take again the standpoint occupied in the beginning of this chapter. Confer $\S 2$.

1. As we have already seen, an organ may theoretically have capacity to act which is exactly and only equalised to the demand involved in the stimulus that comes to it; and such may be held to be the case where the stimulation to activity is constant. This exact constancy, however, is probably seldom, if ever, reached. On the other hand, there will often be a near approach to this equivalence, and with organs habitually acting to what seem constant stimuli, or to those of regular and rapidly recurring rhythm, we should expect to find a wide region of activity very close to this theoretical equivalence and vibrating on either side of it.

2. The inconstancy of environmental conditions, however, makes it probable that for the great mass of organs, even where this approach to equivalence appears, there will be stifficient inconstancy of stimulus to bring about some capacity for storage of surplus force however small, and hence capacity for the use of such surplus stored force upon occasion, even though this use may be possible for a very short time only. This storage-capacity will vary in amount somewhat in proportion to the variability of the stimulus and to the importance of vigorous action whenever the stimulus occurs.

3. Whether this capacity for storage exists or not, there is no case in which it is impossible to conceive the conditions existing where the amount of energy demanded by the stimulus in reaction will be greater than the amount actually appearing in the reaction thereto.

4. All organs which have capacity to, and do store surplus force must do so by virtue of a regular or spasmodic supply of nutriment in excess of demand; hence, if the normal action of such organs be restricted, there will at first occur storage, and, when its limits are passed, then obstruction of the processes of nutritive absorption and consequent excess- 
ive action widely distributed in those organs producing the movement of nutritive eurrents. Inherited manner of growth may bring capacity for storage and increased nutrition to make storage possible, even before any distinet action has bronght about the call for untrition.

5. Aetion oceurring after such obstruction will bring about the liberation of more energy in reaction than is clemanded for equivalence with the stimulus, or, in other words, will use surplus stored force, and this usually in proportion to the amount of the previous restrietion of activity.

6. The use of surplus stored force will also oceur at the beginnings of hypernormal activity after normal conditions: the amount of stored foree, however, occurring without abnormal restriction will not be relatively large, henee in such cases will be soon used up.

7. Stimuli which involve more energy given than can be reacted to equivalently, if continued, will not be followed by a reverse condition, unless in abnormal cases there be a sudden inflow of nutriment. On the other hand, where with given stimuli the reaction shows more than equivalent potency, and when the stimuli are continued, the disproportion will decrease as the surplus stored force is used up, and then the relation of energies will be likely to be reversed, as we shall see below. Where the energy involved in the stimulation is of higher potency than that involved in the reaction, a reluction of intensity of stimulus may bring the two into equivalence, but, unless the stimulus is discontinned and rest supervenes, or a sudden inerease of nutriment to the active organ take place, there can obtain no condition where the energy of reaction is greater than that ealled for by the stimulation.

8. If an organ be aeting approximately in amount just up to its eapacity, increase of amount of stimulus will involve 
the use of such surplus stored force as it has (which may be practically nothing). After this has been used so far that the energies involved in both stimulus and reaction are equivalent, continuance of the hypernormal stimulus will involve conditions where the energy involved in the reaction will be less than equivalent to that called for by the stimulus; and as the hypernormal stimulus contimues or increases, the overproportion of energy involved in the stimulus will increase rapidly.

$\S 11$. Let us translate what has gone before into pyschological language, and at the same time look for correspondence with facts of experience :-

1. Indifference: a state which is neither pleasurable nor painful is theoretically possible, but, strictly speaking, will probably be seldom reached. On the other hand, a condition, carying so slightly either towards pain or towards pleasure as to be practically indifferent, will be very often reached, and, in fact, will be normal for those states of conscionsness, which are determined by systemie activities.

Of indifference in general enough has already been said. The fact of indifference is acknowledged in the mere statement of the problem. The real question at issue is whether indifference is a special state of mind of wide extent, and which excludes pleasure and pain; or whether it is a quality determined by those nicely balanced conditions which are intermediate between those productive of pleasure and those productive of pain. I do not see that experience denies this last statement to which our theory would force us. One thing, at least, is certain as regards the matter of indifference: the phase discoverable in sensation is traceable throughout all mental regions where there is fixity of content. There are emotions, as we have seen, which are so usually indifferent as to lead to the claim that they can never appear otherwise. 
Our normal life of thought is often apparently totally deroid of either pleasure or pain. In fact the more pleasures and pains obtrude themselves, the less there can be of empliasis of the contents to which the algedonic qualities are attached. It is only when practical indifference appears that the fine relations of psychic elements which thought implies can become prominent.

2. Apart from the theoretical indifferenee above refcred to, any content may bring pleasure under proper conditions, although the plcasure may be of very low degree and of very short duration. The capacity for pleasure-getting in connection with any special content will depend upon the variability of the appearance of the content in consciousness and "pon its importance in the life of the individual.

Any sensation may be felt pleasurably if the organ involved be well rested and the action be not too suddenly increased. If some sensations appear to be disagreeable even at their lowest intensity, it is because we cannot easily induce the action at a sufficiently low degree for experiment, attention being retained; or because the conditions of storage in the organs involved are inappreciable in consequence of the constancy of stimulus.

The smell of onions to most people is intensely disagreeable; but that it is pleasant in very slight degree is evident from the fact that if used in small quantities it gives an acknowledgedly fine flavour to certain food combinations, which flavour is dne entirely to odour, for it is well known that the onion has practically no decided taste.

The activities that are always known as painful and never as pleasurable, e.g. cutting, laceration, etc., are, as we have already seen, due to the conditions of experiment, which are such as to necessitate excessive activity in the organs involved. 
Neuralgic pains ${ }^{1}$ are so excessive that the contents to which they are attached lose all prominence, and we do not recognise the pleasurable phase of the same contents, if they occur, as related to our state of previous agony.

Fear is generally looked upon as a most painful state. It can, indeed, with difficulty, be separated from spasmodic painfulness. If, however, we pay close attention to the muscular components of fear, which are the special psychic elements which fix the state, I think it not impossible to trace it in a pleasurable phase. Let one walking in the darkness and hearing footsteps behind him deliberately quicken his pace, he will catch the beginnings of the marked components of fear, but not umpleasantly. There is a wellknown fascination which leads boys and men to go as near to dangerous things as they dare, and then flee from them. Fascination implies pleasure-getting out of the performances involved.

Most thinking, it appears to me, is mildly pleasant. Where it is indifferent or painful we divert our thoughtsthat is, we restrict the appearance of a given content, which has become too constant, so that when it arises naturally after a time of rest the pain is gone, and we grasp the thought as we do only when we are gainers of pleasure. Cp. Sidgwick, Methods of Ethies, p. 125, in corroboration. Von Hartmann, it must be noted, holds that the relation of two ideas seems to be absolutely indifferent up to the line where the intensity of the Vorstellungen becomes so strong that pain ensues (Fs. scit Kant, p. 289).

1 The etiology of neuralgia is not claimed to be determined, and naturally, therefore, the basis of these pains canmot be understood. It seems to me probable, however, that they may be caused somewhat as are the pains of inflammation referred to below, i.e. by some derangement that brings a strong excitation from one organ to bear on a nerve incapable of responding to so high a stimulus. A chance switching off, as it were, of a strong current to a line of great resistance. 
It may be well to consider here an apparent exception to the rule that activity in a well-nourished organ gives pleasure.

The pains connected with inflammation are resultant from stimulation, by pressure or otherwise, of parts which are exceptionally well supplied with blood, and must be supposed therefore to act efficiently; but the psychosis is certainly notably painful on the whole, although exceedingly delicate stimulation of an inflamed surface is pleasant.

A certain amount of the pain may be directly cansed by hypernormal action dne to the blood pressure, but it seems highly probable that the mass of the pain is caused by hyperstimulation of nervons tracts affected by the parts artificially nourished.

The hyperesthetic condition of the inflamed parts shows that exceedingly small stimuli serve to call forth enough energy to produce such powerful effects as under normal conditions could only be caused by very strong stimuli. An increase of the stimulation to any degree will therefore prodnce excessive activity brainward, and should give us extreme pain, as we experience it.

3. There will be no ease in which a content cannot appear in painful phase if the intensity of its presentation be suffieiently great.

I know of no sensational experience which, even if pleasurable normally, cannot be experienced disagreeably if intensity be increased or prolonged. What is more, there are many sensations very nearly indifferent as a rule, and scarcely traceable in pleasurable phase, which may appear painful in the extreme under serions over-exercise.

The conscious states connected with the intestinal activities are so far indifferent that they are out of attention until some time when subject to excessive stimulation they give excruciating pain. We gain here an explanation of those cases of disease which bring pain in regions in which 
we otherwise appear to be without sensation. In normal health these organs work in a reflex way with indifference, and so far as their coincidents come into consciousness at all, they do so merely as part of the background of our mental life. They have no power to store surplus force, so that under hypernormal stimulus they at once bring about a phase of pain. Mr. Spencer, as already noted, has taken the ground that there are certain sensations, such as sweetness, which can never be disagreeable, however intense they are. It may be that certain tastes which are usually pleasurable are so identified in name with the pleasurable quality that the observer will fail to use the same term in describing the painful phase of the same content. But Mr. Spencer's illustration is not a happy one. Sweetness, if intense, is exceedingly disagreeable to some people within my experience, and even $\mathrm{I}$, who am ordinarily fond of sweets, find no difficulty in obtaining disagreeableness from an excessive stimulus in this direction. Cp. on this general subject Mantegazza, Physiologic de la Douleur, pp. 109, 110.

Joy is looked upon as a typical state of pleasure-getting, and justly so. But for all this usual connection with pleasure, excess of joy brings an exhaustive pain from which. often the name joy may be altogether detached, although "a joy which is almost pain" is a recognised state. Looking beyond emotion, we see that any content of thought, if steadily presented with intensity, becomes painful. Thus Mrs. Browning in one of her somnets says-

\footnotetext{
Oh, entertain (cried Reason as she woke) Your best and gladdest thoughts but long enough And they will all prove sad enough to sting.
}

If we step beyond the normal we may instance the severe pain connected with those morbid cases of idée fixe which seem to present the typical disease of attention. In cases of 
excessive weakness caused by illuess, or in eases of depression of circulation, such as occurs with sadness, we should expect the organ whose action is involved in the thought to be in poorly nourished condition. Under just such circumstances we find it painful to think; we naturally allow the movement from image to image withont attention. Any thought which involves attention we find painful. So it is also when we have been for a long time mentally active. The tiredness is hard to define, difficult to isolate, but we find this certainly; that the painful tiredness comes with thought in the direction in which we have been active. Thus we find that change of direction of thought is ordinarily efficient to remove the pain. Still in cases where the activity has been long continued, where we may presume that the surplus energy has been in general exhausted, we find, as we should expect, pain in thinking in general, which ean only be relieved by total rest from thought. ${ }^{1}$

4. In proportion to the pleasure-giving capacity of a content there comes into existcnec a wide pain if this content's appcarenee in consciousness be abnormally restrieted. (a). Broadly painful. states which indicate capacity for special activities may arise at times before the special activity has been stimulated or experienced (b).

(a) The teaching here is, first, that any pleasure which has been experienced may be craved; and that in general the strength and pain of the craving is proportionate to the amount of pleasure which it is possible to gain in any special direction. ${ }^{2}$

In the regions of sensation this general law scarcely requires illustration; nor in emotional and intellectual activity,

1 It is commonly thought that change of direction is all-sufficient for healthy action. Mr. Lewes thought that almost all tiredness was preventable by ehange of activity, but investigation of late would lead us to believe that excess of activity in any region of mind will tire out the whole thinking being, and that total rest is a necessity for healthful action.

2 Evidently there are organs whose activities are ynactically never plea- 
if we acknowledge the essential bond between craving and desire. Even in cases where pleasure-getting is weak we experience cravings. Children and the less intellectual of men crave the experience of anger of a low degree, and hence probably the beginnings of the simulated anger of games among children and the contests of men, the represented delights of triumph being secondary. The craving to experience the stimulus of fear leads to the braving of dangers, where there is no incentive in imitation or applause. Surprise is craved notably by children. The thinker whose habit of attention to his thought-sequences is interrupted, finds himself experiencing very much the same indefinite uneasiness which the active man feels after prolonged muscular restraint.

(b) We learn, in the second place, that cravings may arise apart from their known object-indefinite longings for what one knows not, the outcome of restriction in nutritive courses which are urged to activity by stimuli connected with the natural processes of inherited growth, but too dim to be recognised. Notable instances are those vague feelings of physical uneasiness which are the common experience of both sexes when they reach the age of puberty.

Cravings, desires, imply capacity to act effectively ${ }^{1}$ and with pleasure, and this brings us to our next point.

5. All appearance of contents oceurring after such restriction, as has just been noted, will be pleasurable in some degree, and usually in proportion to the degree of the anterior cravings.

surable - that is, which never accumulate surplus stored energy, the supply being practically variable with the demand; in such cases there will be no experience of eraving pain in connection with the inactivity of the organ. The functioning of the kidneys gives us a case in point.

1 To cover such eases as desire for suceess, I wonld note that effectiveness may be relative only; desire implies effectiveness of the action for the individual who desires, not effectiveness of one action as against another. 
That is, all satisfactions of cravings and desires are in themselves pleasurable, and the vividness of the pleasure gained is in general proportionate to the strength of the craving or desire which has preceded. I think there will be no question raised as to the validity of this law in its widest range. [The common proverb says, "Hunger is the best sauce." The word desirable is often used as equivalent to "that which will give pleasure."]

6. All beginnings of vivid appearanees of eontents which have been before present in eonsciousness will be pleasurable in some degree (execpting the narrow region where pleasure-eapaeity is pratically lacking); though the pleasure will be of short duration unless there has been a previous time of non-appearance. This necessarily earries with it the implication that pleasure is not always determined by antecedent artificial restrietion of rise in conseiousness, but may be determined by simple inerease of intensity of eontent.

P'leasure is not always mere satisfaction of desire, as has been so often held. All use of surplus stored force will bring pleasure, even if the elements brought into action have not reached the limits of storage, and hence have not brought craving-pain. [Eating is pleasant, even if we have not felt the cravings of hunger.]

Our ordinary sensory field as it appears in consciousness has, it seems to me, the slight balance in favour of pleasure which comes with such beginnings of activity. Our senses are constantly changing the scope of their activity in small ways, and with the change comes slight pleasure. Apart from our sensations, which are determined directly by environmental stimuli, the great mass of our conscious states seems to me to have this slightly pleasurable tone where the flow is easy and not forced through habits of attention. ${ }^{1} \quad$ Spontaneity (so called) under this theory implies

${ }^{1}$ Cp. again Sidgwick, Mcthods of Ethie's, 1' 125. 
pleasure; and I think common observation bears me out in this respect. Wide fields of low-grade pleasure-getting thus reached form the groundwork of æsthetic effects; although cravings and their satisfactions are used as making centres of interest (note, e.g., the use of discords and their resolution in music). In Chap. VI. this is treated more at length.

7. Apart from certain very exceptional eases, contents, if painful, will not become indifferent nor pleasurable if their. intensity continues or increases. On the other hand, if a content be pleasurable, continuity or increase of intensity will result in deerease of the pleasure until it reaches indifference and is replaeed by pain. Pain never fades into pleasure by eontinuance of intensity without intermediate reduetion to indifferenee, and seldom even thus. In a great majority of cases reduction of intensity will reduce pain to indifference, but never into pleasurableness, unless the content disappears (positively or relatively) for a time from conscionsness.

Once in a while we experience slight active pains which without change of content turn into pleasures of low degree without perceptible reduction of the stimulus. "We get used to the pain," we say. Such cases remind us of the "second wind" which athletes tell of, evidently produced by the starting up of nutritive conditions which are in excess of the demand, and which therefore not only build up the wearied nerve, but place it in condition to react in higher degree than the stimulus demands. Many methods in therapeutics aim to break down acute pain by supplying additional nutriment to the affected organ rather than by attempting to reduce the cause of excessive stimulus. Such cases of painreduction without reduction of the intensity, however, form the exception which makes prominent the rule that we must decrease activity if we are to decrease the painfulness of the content presented. The reduction of painfulness by the process of intensity-reduction may bring us to the point of 
indifference, and the reduction of intensity may be such as to involve the disappearance of the content from consciousness, but mere reduction of intensity cannot normally bring about effective aetivity and the attainment of pleasure which goes with it, unless there has been a period of rest-a period of clisappearance of the content involved. ${ }^{1}$ That continuance, or even mere increase, of intensity where we are getting pleasure eventually brings reduction of that pleasure; also that reduction of intensity where we are gaining pleasure reduces the pleasure,-are conclusions involved in our theory, and the commonplace acknowledgment of this is found in the general and unquestioned recognition of the evanescence of all pleasure already referred to. This requires no illustration. $^{2}$

8. Increase of intensity, where a content is indifferent, may at once produce pain, but normally it will at first produce pleasure, which may last but a moment and be searecly traceable, and which in any event will repidly disappear, if the inereased stimelus be continued, until indifference be again reached, when it will begin to be painful, and this pain will rapidly increase.

The last statement covers the ground of Wundt's law,

1 This is in thorough accord with the facts which, as we shall presently see, Professor Sidgwick presents as an objection to Wundt's law, viz. that certain sensations remain disagreeable under reduced intensity until they become indifferent and then vanish.

2 Some apparent exceptions leserve notice here.

It is a fact, as noted by Mr. Gurney, that if we look at a fairly lighted field, and again view it through a blue glass, we will, in the second case, see a less intense blne, but lerive a pleasure from the blueness. This seems to give a case where decrease of stimulus is an immediate cause of pleasure. It is not clear, however, that the pleasure reached is due at all to the particular blueness of some specific spot, but to the blueness as a whole, which by shifting of the eye must produce summationally a higher degree of blue stimulation; but the pleasure here obtained is evidently also complicated by the effects of novelty and by associative resultants, as is also the case where we enjoy a colour more than_a gray containing the colour (Fechner, Vorschule d. Es. ii. 214). 
above referred to, as I interpret it. I think its truth cannot be challenged. As here stated, it appears only as the partial application, in the circumstances most often met with, of a simpler law of wider import. ${ }^{1}$

We shall find, I think, the validity of the law incidentally proven in the points which have been already made. That, in cases where the capacity for pleasure is non-existent or of very low degree, an immediate change from indifference to pain will occur is evident under our theory, and is illustrated under point (3); the normal course, however, is as Wundt states it. That in all cases likely to become subjects of attention there is some capacity for pleasure, we have seen in discussing point (2). That increased intensity of stimulus will ordinarily, therefore, bring the content from indifference into pleasure-plase was shown in discussing point (6). That this pleasure-getting, so far as it is at all possible, will rapidly increase with increased intensity of stimulus, is an implication of our theory, and a fact which I think will not be denied.

2 Professor Sidgwiek, in Methods of Ethics, p. 182, has incidentally denied the validity of Wundt's law, as he understands it, thus : that all disagreeable odours and flavours may be male positively agreeable by diminntion. "I find," says he, "some disagreeable until they become indifferent and then vanish." But Wundt's law, as seen from our standpoint, refers to the inerease of intensity, and means that, if under such increase the stimulus is not too high in degree, in the rise from indifference pleasure will be noted before the advent of pain. Furthermore, our view, as stated above immediately before the deduetive statement of Wundt's law, would show that deerease of a stimulus which was giving pain conld not (except in very exceptional cases of increased nutrition) do anything but produce sensations which would be "disagreeable until they become indifferent and then vanish."

Before leaving this matter, I cannot help calling attention once agaiu to the errors involved in the ordinary way of looking at pleasure-pain phenomena. Professor Sidgwiek's positions would scarcely have been reached, I think, had he not been imbucd with the general notion of modern psychology that "feeling" is a form of mental experience sui generis, involving, perhaps, action in special brain-seats; for how else can he loold it to be an objection to Wundt's law, referred to above, that "pains of shame, disappointed ambition, wounded love, do not appear to be distingnishable from the pleasures of fame, success, reciprocated affection, by any degree 
To increase a pleasure obtained in action in any mental region we always increase that action. But too well do we know that we cannot increase pleasure indefinitely by this process. As we have seen in discussing (7), the increase of pleasure soon reaches a maximum, and then begins to decrease until we reach a state of indifterence. After a period of indifference comes pain, increasing indefinitely till exhanstion brings entire disappearance of the content.

This course, discovered in sensation, appears through all regions of mental activity where the content does not change; a point which must be kept constantly in mind in such introspective examination, for, automatically, we tend to shift our field as soon as pain begins to be felt. Our consciousness reaches out naturally to new contents which do not involve pain, unless there be a continuation of stimulation from without, which compels the continued attention upon the same content. This fact makes it very difficult to trace the change of painful intensity in states not due to external stimuli, which we are able to govern. In emotional life we have a corroborative example in fear, which, when continuous and extreme, ceases in exhaustive inaction, even though the object of fear still be present. The same thing is exemplified even in the higher regions of complex thought. The most reliable corroboration here is found in the morbid continuance of idees fixes, which certainly become painful

of intensity in the impressions or icleas accompanied by the pleasures and pains respectively"? The implication of Wundt's law in this comnection, in my view, would not be that the difference as to pleasure or pain in these regions of various content implies difference of intensity, per se, in relation to some general standard of intensity, but that, if the content does not alter, elanges from normal condition ought to cause the appearance of the content in other pleasure-pain phases than such as are normal. Thus we should look for pleasure in shame, ambition, and love (well known), and for pains in fame, success, and sympathetic attachment (less known, but, I think, traceable). 
enough, and remain so as long as they are able to hold themselves in consciousness. In general, the influence of excessive action is recognised in the painfulness of extreme intellectual effort. We speak of " cracking our brains over some tough problem," comparing thus the distress of the intellectual effort with the pain of extreme pressure.

This law is not without apparent exception. As Horwicz has pointed out (Analysen, iii. 26), there is not always a change from pleasure through the indifference point to pain, although this is the normal course where the stimulus is of a high grade of intensity. This has been explained above at (7).

If the intensity be of low grade (as is frequently noted in the case of warmth mentioned by Horwicz), with the decrease of the pleasure to the indifference point there often comes an increase of capacity through added nutritive supply to the parts affected, so that the indifferent point once being reached, may remain steady; the nutritive supply having become adapted to the demand.

It may be well here to notice further some objections to this law raised by Horwicz. He holds that a very slight stimulus may bring pain, and increase of the stimulus pleasure. His examples, however, are unfortunate. The light touch of tickling truly induces pain, while the more vigorous rubbing will bring pleasure; but we are here evidently dealing with two sources of sensation, as we shall see in Appendix II. With the painful tickling there is brought about an increase of blood-supply to the affected parts, and this may momentarily add to the tickling pain a touch-craving distress. The rubbing brings into activity nerves of touch, thus well nourished, and the pleasure arising evidently comes from organic activities different from those involved in the tickling.

He argues, again, that a weak light brings a veritable "light hunger." Evidently this is pain of quite another source, due in great part to an unused supply of nutriment, which has been brought to the organ by the nutritive activities induced by the weak light stimulation. I think, however, that it is not easy here to separate sensational pain from the pains of obstruction in more complex regions of mentality; according to this view the "light hunger" is really largely due to the obstruction to the working out of many queries suggested by the dimness of perception. 
$\S 12$. Let us now proceed by another method. In an indirect manner we may gain corroboration which approximates to the test of experiment, by examining those means adopted for the avowed purpose of gaining pleasures and avoiding or lessening pains.

All men seek pleasures, and, with most of us, where the seareh does not bring them naturally, we endeavour to produce them artificially. We onght to find, therefore, that the steps taken to procure plecusure are such as will increase the use of surplus stored force.

We have learned in the guidanee of our children to give them unmsual rest before taking them to gatherings where prolonged pleasure-seeking is attempted, and we ourselves tend to take the same course. We have learned too that general excitement reduces our capacity for pleasure-getting in general. The use of well-rested organs is the basis of the pleasure-seeker's universal search for novelty; not absolute newness, but new arrangements of activities which have been customary, but not lately repeated ; restoration of stimuli which for some time past have not aeted upon us. I think it can be shown also-but the task cannot be undertaken here-that the delights obtained in the repartee of wit are in the main explicable as due to the repression of the suggestion of mental fields, well connected with those primarily emphasised, until the former are most fully prepared for attention ; these then, when brought into conscionsness, appear with full flow of pleasure. This principle of artifieial rest is of constant occurrence in the production of asthetie effects-for example, in the principle of contrast; but discussion of such points would lead us too far from our argument, and must be reserved. Another common method of produeing pleasure by artificially increasing the capacity of organs appears in the pleasure-seeker's deliberate excitation of the general action of the nutritive system by 
alcoholic or other means, so that the ordinary stimuli of our habitual environment will produce exceptional reaction.

On the side of hypernormality of stimulation it may be noted that the pleasure-seeker always tends to excesses. Thus he seeks out excitements which involve all his powers of intense attention in certain directions for a limited time, and again between these periods of excessive attention turns to the principle of rest; to small talk, or perhaps to eating sweets - a habit of theatre-goers, which, Aristotle tells us, was common even among the Greeks when they found the action palling upon them. The delight with which the jaded pleasure-seeker turns to puns and sensuous if not malicious story-telling is familiar to all; and this species of delight is explicable, I think, as due to a sudden change of mental activity from channels where effort is required to complete the flow of thought, into others well prepared for activity, and in which a relatively small stimulus produces great proportional effect; or, in other words, in which the amount of energy involved in and transferred from the first montal ficld produces much more than normal stimulation in the seeond ficld. This is the principle of the Ludicrous, of which more later:

We have learned that the man who by overwork has lost all interest in things, all capacity for enjoyment, has exhausted his system as a whole, and needs entire rest if he is to regain this lost interest. We have learned that loss of interest in one special line of activity is to be regained only by working in new lines, to the exclusion of the one in which we have overworked.

It thus appears that we are able to produce pleasures artificially by producing the conditions of pleasure which we have described. How is it in the matter of pains?

It is certainly true that the pleasure-seeker who depends 
upon excesses of stimulation for the attainment of his end finds his pleasure waning and his excess ending in painfulness. The torturer depends upon excessive stimulation to give pain to his victim; and often manages in "refinement of cruelty" to prolong the pain, by intermissions of the excessive stimulation during which, as we have seen above, the paingiving organ is enabled to recuperate slightly, so that rapich deterioration is avoided.

The surgeon, to relieve pain in some region, resorts to excision of the nerve which is producing the abnormal stimulus, or to what he calls counter-irritation, i.e. the production of wide, sometimes painful, irritation of low degree in adjacent parts, which implies exhaustion of the activities in the widely distributed nerve-tracts, hence a general reduction of stimulation in the region productive of the severe pain. It seems to me that not dissimilar is the psychological basis of the elimination of pain, and incidentally of such cures as are effected, by means of hypnotic treatment and by the closely allied methods adopted by the practitioners of "mind-cure," "faith-cure," "Christian science," etc. etc. The procedure may be looked upon as psychological surgery, if we may so speak. Attention away from painful activities, whether produced by command, will, or belief, implies strong activity in physical regions other than those which give the pain, and therefore a reduction of the stimuli to, and activities in, these latter regions, which, if only moderately diseased, may recuperate during these seasons of rest.

Such pains as we have here discnssed are relieved by reduction of the excessive activities involved. Pains of restriction are not caused by hypernormal activity in the directions of control, and hence we do not find them relieved by cessation, but by increase of activity in the directions in which we appreciate the restraint. 
If pains are disadvantageous to the nerve organs involved, we should look for a natural tendency to avoid them.

The systemic pains caused by restriction of activity might be avoided-

1st, By a tendency to increase the activity of the parts involved; which we see in the so-called "spontaneous" activity given out by an over-nourished organ upon the very slightest stimulus.

2nd, By a tendency to the loss of habitual nutriment supply through diversion of this supply in other directions; which we see exemplified in the tendency to atrophy of an unused organ.

The pains of hypernormal activity should be relieved-

1 st, By a tendency to increase the nutrition to the organs involved; which is evident in the quick supply of blood to an organ that is active in any lypernormal degree.

2nd, By a tendency to decrease the activity; which is evidenced by the frittering away of attention under pain.

$\S 13$. I have in Chap. IV. made a criticism against others which my reader is certain to turn against the theory here defended. "Can you convert your propositions," he will ask, "without depending upon the presence of the pleasure and pain themselves for proof of the existence of the conditions which you think determine them?" We, of course, cannot hope to examine every instance, nor to cover all mental fields in detail; no theory pretends to such completeness. Such a criticism as Mill's against Hamilton can indeed only be maintained where, as in the case in point, a great proportion of cases fails of proof. We may hope, however, to obtain sufficient positive evidence to raise a presumption in favour of our theory without serious unexplained oppositions, and this, in my opinion, has already been accomplished. Still we must not hesitate to meet the above query directly. Can we properly maintain that all pleasure is the eoineident of the use of surplus stored foree, and all pain the coincident of conditions where the energy of reaction is less than that whieh shall be expected to result from the stimulus in the organs whose 
action determines the content in each case? The answer, I think, is to be found in what has preceded this.

The correctness of the statement as to pleasure is shown by the acknowledged universality of the law that pleasure (content being unchanged) is always reduced by continuance of hypernormal stimulus. This points to something used up. What it is that is used up is indicated by the acknowledged law that abeyance of a content, i.e. rest, must precede pleasuregetting in connection with the content; rest implying the accumulation of potential energy in the organ involved; corroboration being found also in the fact that decrease in amount of pain-giving stimulus does not bring us back to pleasure conditions in eonnection with the seme content, unless the condition of rest supervenes.

With pain the proof is at first sight less clear, but our thesis is implied in the law that pain always arises where the presence of a hypernormally intense content is continuous, after such pleasure as can be obtained has become reduced to indifference; and, although this law is not as self-evident as the pleasure-laws above noted, I think the exceptions upon which objection may be founded are explicable on the lines laid down in the discussion above. We have further proof in the fact that rest from activity (implying organic repair) is the recognised means of bringing reduction of pain in any special direction ; that increase of a stimulus which is bringing pain increases the pain ; that increasing ineffectiveness is recognised as an accompaniment of continued painful action in an organ.

$\S 14$. Having occupied ourselves so long with physiological conceptions, it will be a relief to the reader, I do not doubt, as it is to myself, to turn again for a moment to psychology proper. Pleasure and pain, I have argued, are qualities one of which must, and either of which may, belong 
to any state of consciousness. We should be able to bring these phenomena into relation with such qualities as must always belong to all consciousness, and thus obtain a definition in purely psychological terms.

In a manner Wundt's law does this with reference to intensity. Let us see whether a clearer statement cannot be made of the laws of pleasure-pain in terms of attention.

Pleasure under our theory, as involving the use of surplus stored force, implies a continuance of activity in the organ of the pleasurable content, and therefore a tendency to continuance of attention upon that content. It implies also an increase of activity in directions connected with the pleasurable content as developments, and this total result may, I think, be called, in the words of Dr. James Ward, "effective attention."

Pain, on the other hand (and here we camnot be said to follow Dr. Ward), implies a tendency to cessation of activity in the organ of the painful content, and therefore the disappearance of that content. The continuing stimulus may indeed force the rise of the content, but there is no spontaneity in this rise. At the same time the lack of efficient outcome of the stimulus in the direction which gives us the pain will determine a transfer of energy to new channels above (so to speak) the channel which leads to the organ which gives pain, a process which the conservative tendencies of nature will emphasise. This means the production of new foci of attention - the frittering away of attention so far as the painful content is concerned.

It may be well to note here that, on the one hand, the spontaneous activity in pleasure implies a diffusion of activities in the lines of the development of the pleasurable content, while, on the other hand, the activity connected with pain implies new activities in lines apart from such content, i.e. the production of collateral activities in both cases. It is 
easy to see that nature may turn these different activities to her own conservative uses in directions which shall look to continuance of the activity which is pleasurable (for the use of surplus stored force must be a saving to the system at large), and to a discontinuance of the painful activity (which is draining the efficiency of the system). These tendencies in the organism, however, will be results gained in the course of development, and not characteristics inherent in the pleasure and pain themselves. Enough examples of these tendencies appear perhaps to warrant the suggestion that "pleasure" may be "a feeling which we seek to bring into consciousness and retain there," and that "pain" may be "a feeling which we seek to get out of consciousness and to keep out"; but I do not think we are warranted by any means in saying-as Mr. Spencer does (Prin. of Psych., i. chap. ix.)that the longer phrases are equivalents of pleasure and pain respectively.

$\S 15$. It will be well now to look back at the theories reviewed in Chap. IV. to note their relation to that here defended.

The theory which connects pain with violation of limit we find correct so far as excessive activity is concerned, and we note evidence that the pains connected with the violation in the direction of sub-normal activity or non-activity will probably be found to be explicable in terms of excess. The related theories which connect pleasure with replenishment, or which make it dependent upon approach to equilibrinm or to normal activity, are based upon facts of pleasurable rest, which we have seen to be secondary and not fundamental. The notion that pleasure is mere absence of pain is denied by our theory; the pleasures so closely connected with contrast being seen to be, not merely negative, but positive states 
connected with effective activities of other contents than those with which the pain was connected. That pain is always due to restriction of activities we find to be true only if we use the word "activity" improperly with two distinct significations: (1) as related to the organ involved in the painfulness, and (2) as related to the organism as a whole; the foundation upon which both rest we find to be the condition in the organ giving the content where the energy of reaction is less than equivalent to the energy of stimulus. That pleasure is always due to action after restriction we find to be not true, although under such conditions the most vivid pleasure will necessarily arise. The Herbartian view appears as a partial truth, in that opposition of presentations must produce pains of activity in wide mental regions, and in that support of presentations implies confluence of stimuli to the increased activity of the organ, which is the coincident of the content that appears pleasurably. The theories which connect pleasure with effectiveness, and pain with non-effectiveness of activity we find to be fundamentally true, although requiring radical restatement; the failures involved in their statement as heretofore made being due to the current misunderstanding of the nature of pleasure-pain, and to a reference of the effectiveness or non-effectiveness to the organism as a whole instead of to the special organ or organs involved in the production of the content of consciousness. The law of "selfconservation" we find to be a secondary law which relates to the distribution of pleasures and pains, and which is dependent upon general laws of the evolution of organismis.

The relation of this theory to evolutionary doctrine is not far to seek.

Upon evolutionary principles it accounts for the connection, in a broad way, between pleasure and pain on the one hand, and activities respectively advantageous and disadvantageous on the other. For those who use surplus stored 
force (i.e. gain pleasure) in connection with activities which are advantegcous, and who find powers curtailed by lack of organic efficiency (i.c. suffer pain) in connection with activities which are disadvantagcous, will evidently prove successful where the struggle for existence is dominant in determining the direction of evolution. It is equally clear, however, that this comnection can only be on very general lines, and will be marked by numerons exceptions such as we find; for pleasure and pain are directly related to the organ giving the pleasurable or painful content, and not to the general activity of the individual of whose mental life this content is a part.

There is evidently a necessary connection between advantage to the nerve organ and pleasure, and between disadvantage to the nerve organ and pain. The use of surplus stored force in pleasure is also apparently indirectly advantageous to the individual in that it tends to conserve the system under strain, and possibly in that it brings about the forcing of direct nerve conduits, and thus renders action definite and effective.

But for all this it is apparent that the connection between pleasure and pain, and advantage and disadvantage, respectively is dircetly with the elemental organ, and only indircetly with the system which makes up the individual. For it is evident that change of relation between the individual and its environment does not necessarily bring any immediate change of the relation of activity to capacity in the individual's special organ; indeed, not until after a long time of readjustment, lasting, perhaps, through many successive generations, can we expect that change of relation to the enviromment will show an effective correspondence in the special organs affected by the change.

Under the theory I defend, the laws of contest and survival teach that the existence of pleasure in certain acts, 
among a large class of people, shows that those acts in the past have not been detrimental, and may not improbably have been directly or indirectly advantageous; but it teaches no more than this. The pleasurableness of a set of acts, if their continuance were detrimental, would result in the stamping out of those individuals thus persisting; but their pleasurableness does not necessarily mean individual advantage, although it does mean past occurrence in people whose course of action has made them survivors; the sets of actions under consideration may have been quite apart from any influence upon survival. Thus, in connection with Darwinian doctrine, the pleasurableness of a mental element tells not necessarily of its individual or racial advantage in the past, but merely of its non-disadvantage; and it tells us nothing whatever of the present general health except what our judgment from the existence in the past may warrant. In fact only those actions or impulses can be looked upon as certainly advantageous to us in the present which have become so habitual as to be indifferent, and which show no tendency to be habitually painful.

$\S 16$. In closing this chapter I think it will be desirable to refer back to certain objections raised in Chap. I. to the sensational theory, which we were not then prepared to discuss, and to attempt to show that our hypothesis is not in disaccord with the observations that have been used as arguments supporting the sensational view, and that it explains with seeming adequacy the facts I have raised in objection to that view.

At the start I must say a word to show that the theory of "specific energies," so far as it is verified, is not in disaccord with the view I support. Sensations are psychoses of limitation-they are due to an emphasis of certain parts of consciousness and an obscuration of certain other parts; and on 
their physical side, so far as we can judge, they are determined by exclusive differentiation in the physical activities coincident with consciousuess,-by the activities of definite parts of the nervous substance or organs. It seems highly probable that all complex fixed contents and also all images simple or complex are also determined by the action of specific organs. But it must not be forgotten that there are also relations between these activities which leave an impress corresponding thereto upon consciousness from moment to moment. The mind acts as a totality, and the relations between its special partial activities must be embodied in consciousness, even though the functioning of no special distinct organ be coincident with the grasp by us of these relations. ${ }^{1}$

How else are we to account for our capacity to see in the drawings of the artist, likenesses to people and to natural objects; for our ability to recognise reproductions, in black and white, of pictures which are but masses of colour; for our power to recall a melody or a complex harmonic sequence when it is played in another key than that in which it was originally heard by us? Intensity, timeness, realness are such psychoses of relation, for instance; and it is in this general category that pleasure and pain, under my theory, are placed.

$\S 17$. Let us now consider the arguments and objections above referred to as they appear in the light of the theory I defend. I shall treat them seriutim with numbers corresponding to those already used in Chap. I. $\$ 4 \mathrm{ff}$.

First, then, is it possible to show that the arguments adduced in favour of the sensational theory do not militate against the hypothesis we defend?

1. That a few pains are very distinet, are "disparate," while it may indicate a likeness to sensation, as is claimed, certainly does not present evidence against the view that we are here exanining; for there appears to be every reason why, under

${ }^{2}$ Cf. Sully, The Human Mind, i. I. 171. 
extreme conditions of excess of activity as related to nourishment, the psychosis of relation should be vivid.

2. Under the physical theory, as I have argued, we should expect to find that organs which are regular in their rhythm of action and are not called upon at intervals to act powerfully would come to be supplied with just enough nutrition to enable them to function properly, and would have little capacity to store or to use surplus stored force, and little ability, therefore, to function pleasurably. For such organs, practically any hypernormal stimulus would produce the conditions of painfulness. This may account for the fact that certain organs appear to be incapable of pleasurable stimulations, although in such cases the lack may be connected with the nature of the stimulus, as above suggested; it certainly accounts, without too great a stretch of the hypothesis, for the common observation that the functioning of certain internal organs scarcely appears in consciousness unless in the painful phase.

3. If it could be shown that an organ, when stimulated with such excess that it resulted in its deterioration, produced its specific sensation and yet no pain in connection with the stimulation, a valid argument would certainly be had against the theory I defend; but, as I have already shown, the evidence is not decisive and the observed facts may be accounted for on other grounds; and when we consider, as I think can be shown, that the preponderance of evidence favours my view, it makes it highly probable that a reinterpretation of the facts will some day be presented.

In my consideration of arguments 4 and 5 in themselves, I have shown how it is possible to explain the observed facts in a manner other than that adopted by those holding the sensational theory, and the reader will readily perceive that the explanation there given is in accord with the theory now before us.

4. The fact that the pain of pricking arises after the sensation of touch, when one operation produces both, is explicable if we suppose that a second set of nerves, viz. those producing the sense differentiation known as pricking or cutting, are brought into action after those of touch, and that they do not appear in pleasurable form under the method of experiment, and, maybe, that they have practically little storage capacity, and are therefore little liable to appear in pleasurable phase at all. Analgesia, in terms of this hypothesis, becomes a very commonplace phenomenon; for it is very frequent in morbid cases, whether produced artificially or by disease, to find one sense obliterated (e.g. that of heat or cold) whilst another is not cut off (e.g. that 
of touch or pressure): the only marked characteristic in this case is this, that the sense which is cut off is not clearly differentiated in conscionsness until it appears under the conditions which make its phase painful.

5. The facts which lead to the conclusion as to there being a separate pain path in the spinal cord are explicable in a manner so similar that repetition of the counter-argument seems unnecessary.

6. The argument based upon the claim of the discovery of specific pain nerves deals with evidence so distinctly in dispute that I do not feel that it needs reply here. I have already shown the direction in which I think it probable the reinterpretation of observations will be made, and if my surmise be correct these observations would not be in opposition to my theory.

7. Is it possible under our theory to explain the distribution of pleasures and pains as we find them? I think it is as simple as under the sensational theory. This matter has been treated fully under $\$ 15$.

8. It is clear from what has been said above that our theory may be stated in terns not incompatible with modern notions of biological genesis. I perhaps do not lay so much stress upon biological argument as others do; this, however, not because I think it mimportant, but because I think it dangerous to rest upon foundations which must be laid so largely upon unverifiable hypotheses. But taking the argument for what it is worth, I think it not too great a strain upon our credibility to surmise that the first general undifferentiated sense, which has now disappeared in its differentiations, may have had attached to it from the very start the capacity for pain under excessive stimulations corresponding to the relation involved in the tendency to discontimance of the coincident neural activities; in the second place, to surmise, as added to this pain capacity, the capacity for pleasure whenever it became of advantage to the organism as a whole that the activities coincident with this general sense should have the capacity of continuance. As the senses became differentiated, those would appear with emphasis of their pleasure capacity where, in the long run, the continuance of the activities involved would be advantageous to the individual, and conversely, mutatis mutandis, as to pain. But evidently the pleasure and pain would be directly connected with the capacity of the organ active in producing the sensation and not directly with the welfare of the individual. An indirect connection on wide lines between pain and pleasure, and disadvantage and advantage respectively, to the individual would, however, 
soon be brought about, because the individuals that took pleasure in and continued disadvantageous actions, and that found pain in and tended to discontinue advantageons actions, would be in time eliminated. The connection would be so indirect, however, that the law could not be expected to be without numerous exceptions, and we should look to find exactly what we do find, viz. those anomalous cases, which have given so much trouble to theorists, where sweets mean death and pains mean health to the individual, they indicating, under our view, actions respectively healthful and harmful to the organs functioning. This hypothesis also makes it easy to understand why, with pleasure-pain so early a development as it must have been, there is no evidence of the later development of consciousness on the two great lines of pain and of pleasure as would seem to be necessitated by any doctrine which makes pleasure and pain the primal sensational elements.

Let us now turn to the objections which I have raised to the sensational view.

9. The bond between pleasure and pain so widely recognised and so inexplicable under the sensational hypothesis becomes natural under the theory here defended; for the two are really parts of a continuum, both being determined by relations of the nutritive conditions to the activity of the organ which is the physical corresponclent of the mental state.

10. Under our theory no special localised organs should be looked for in the brain for pleasure and for pain, for each differentiation of pleasure or pain, except as to degree, implies a change of organ, so to speak. The theory does not meet the demand that we shall tell what special organs are active for pleasure and for pain, becanse under it we are led to hold that, properly speaking, there are none such; or, to put it differently, that there are an indefinite number of such; that each organ which is capable of bringing about by its activities a definite psychosis is in that special case an organ either for pleasure or for pain.

11. This hypothesis accounts most easily for the fact that pleasures and pains are aroused by the widest range of psychic occurrences; that there are sensational, emotional, and intellectual pleasures and pains. It would be most unexpected if it were not so found in experience, when we consider that each sensation, each emotion, each intellectual act implies activity of an organic coincident, in some effective or ineffective relation.

12. That under continuation of stimulus-conditions pleasure habitually fades into pain, is to be expected under my hypo- 
thesis ; for pleasure means the use of surplus stored energy, and the hypernormal stimulus which is bringing about this result, if continued, will surely, in ordinary cases, use up the surplus and then bring about the conditions which give pain. It is a notable corroboration of my theory that the process is not reversed. Pain caused by excess in activity does not go over into pleasure, with. unchanged content, unless there supervenes rest, i.e. opportunity for recuperation and storage in the organ which has been active.

13. That increase of the stimulus which is giving pleasure increases the pleasure for a time, then diminishes it, and then prodnces an increasing pain, is quite in accordance with the notion that something is used up (with pleasure experience) before we can get the organ which is active into the condition in which it becomes capable of giving pain.

14. Under our hypothesis we do not need to look for any special envirommental stimulus-differentiation corresponding with pleasure and pain, as we did urder the sensational view, if the hypothetical pleasure and pain senses are to fall in line with all other sensations; for under our hypothesis pleasure and pain are determined by relations within the organism which are general, and which occur with all differentiations of environmental action upon us.

15. We are not surprised, when we consicler the great variations of mutritive conditions, that a mental element which at one time brings us pleasure on some other day brings us pain, or vice versit, with no change of stimulation. The capacity to bring conscious pleasure or conscions pain after very long intervals is also quite explicable without supposing any such non-activity as would imply atrophy of the organ which finally acts pleasurably or painfully.

That the phenomena of habit are found to be corollaries from the general theory, I have argued at some length above. The action which is painful to-day but not carried too far calls for an unusual supply of nutriment, and this develops a capacity for pleasure-giving at the next moment of stimulation. This pleasure capacity may increase largely by continuous repetition of this process.

The pains which first bring to our notice the existence of inner sensations are accounted for by supposing that these organs, being very regular in their action and not ordinarily called upon to react to unusual stimuli, lose practically the storage capacity; so that a strong stimulus always brings pain, as it also first brings into prominence in conscionsness the psychic elements to which the pain is attached. The theory 
accounts for the fact that the well-rested and vigorous man finds pleasure-getting easy; for with him storage nust be large and the capacity for pleasure-getting full ; and also for the fact that one weakened by excessive activity or illness finds pleasuregetting impossible; his illness or overwork has drained away all his surplus stored force.

16. That localisation should be dim for pleasure-pain is not surprising, since the organs of pleasure and those of pain are so constantly shifting.

17. The difficulty as to representation does not occur under our theory; for no such thing as a representation of a pain or pleasure is supposed, although pleasurable and painful representations are acknowledged and are covered by the general law.

\section{APPENDIX I}

\section{PAINS OF RESTRICTION}

\section{Craving-Impulse-Desire-Disappointment}

In the body of this chapter I have referred the reader to this appendix for evidence in relation to the painfulness of desire and of other states in which repression of activities is involved. It will be advantageous, I think, to analyse these states as far as possible; let us begin with Desire.

The word "desire" is used by psychologists with great variation of connotation. Writers who are acknowledged to be authorities employ it to describe psychoses of varied complexity and of diverse content and relation; often, indeed, making it cover successions of diverse states in one totality.

This difference of usage is of course in itself unfortunate; but more than that, it is especially important to the advance of psychology that an agreement be reached as to the proper meaning to be attached to the word, because of the intimate relation between desire and voluntary action. We cannot hope to see settled the contest which is being waged on this battle-field of modern psychology until the analysis of desire is determined.

It often happens that we gain a better view of an obscure mental state by study of some simple state to which it is evidently related.

The cravings are states thus related to the desires, and it will 
prove of value to us to begin our study in this place with a consicleration of the cravings.

Physiological consideration has taught us that cravings, in most cases, may be produced by the mere deprivation of a stimulus to activity which is usually recurrent. The psychic elements distinguishable in these cravings consist of broad systemic pains, coupled with what is known as a sense of uneasiness, which latter may be supposed to be the psychic counterpart of the tendencies of restricted energy to work itself off in channels adjacent to those which, but for the failure of stimulus, would normally come into action.

That the physiological basis of the cravings and their psychic elements are correctly described above becomes clearer when we consider those special cravings which appear withut unusually recurrent but restricted stimulus; such, for example, as arise with the approach of the age of puberty. In such eases it is apparent that systemic derelopment brings capacity in conbinations of organs which await an unexperienced stimulus. Physically we have here the same conditions of restriction as in the cases first described, and psychically we have the same broad systemic pain and uneasiness.

That desire contains the craving elements in all cases seems to me evident-that is, it contains broad systemic pain and the uneasiness which always goes with it. That it contains more thun this also seems clear to me. Still usage brings the two states very close together at this point. Although I know of no theoretical writer who would use the word "desire" to lescribe the sexual cravings as above described, no less well known an anthor than Herbert Spencer defines desire in terms which could be employed to indicate the more usual form of eravings which, objectively viewed, are traceable to a stimulus that for a time has not appeared in its normal rhythm. In his Principles of Psychology (vol. i. p. 126) he says: "Desires are ideal feelings which arise when the real feelings to which they correspond have not been experienced for some time. They are then liable to be excited by various of the indirect disturb, ances reflected from part to part of the nervous system. They are usually vivid and persistent in moportion to the preicous perioul of rest . . . after a prolonged period during which they continue to arise and almost monopolise conscionsness, they become feeble and finally die away." I think we shall find ample reason below for the rejection of this definition as a description of desire. To cravings, to which his definition applies well, must be adder something more before we obtain the desires. 
That desires and cravings are not very distinctly differentiated by those unaccustomed to introspection is explicalle when we consider that states which often arise as cravings, often also arise as the result of the appearance in the mind of the image of an unrealised object which would, if realised, result in relief of the uneasiness pain; they are then in my view real desires, as will presently appear. Thus the craving of hunger may arise without any thought of food, but it may also arise as the result of seeing others taking a meal. 'That the craving may appear' without the existence of the more complex conditions shows that these latter are not of its essence. Again, desires in a large proportion of cases arise upon the presentation of an object to which the activities which are restricted normally relate, and the same is often true of cravings. But while both desires and cravings are thus frequently initiated by the perception of objects, we shall presently see that desires are not determined by the presentation of those objects, nor are cravings. Hunger may be initiated by the sight of food, but hunger also arises often without antecedent suggestion of edibles. The sexual cravings in their beginnings are clearly not initiated by any antecedent presentation of an objeet. The presentation of an object often produces a clear craving, which is differentiated from a desire by the lack of any idea of an object to be realised, and in refiection is a state distinctly separated from the presentation of the object. With my mind on other things my attention is called to a beautiful horse: I see the horse and feel a craving; - an indefinite painful uneasiness which is separated from the notion of the horse, but is not a desire until to the craving is adcled the notion of the unrealised activities of mounting and riding, which would result in the relief of the pain.

Enough has been sairl, I think, to bring out the distinction between craving and desire, and at the same time to show why the words in common-speech usage oceur not infrequently as interchangeable terms.

A craving then may be defined as the psychosis of puinful systemic obstruction, which we learn by reflection wunld be relicerd ly systemie activities, which are not distinctly motor, for which the system is prepared.

There is another psychosis of painful obstruction which is closely allied with the cravings, but which is differentiated by the fact that reflection teaches us that their relief lies in the direction of co-ordinated motor activities for whieh the proper organs are prepared. 
They are so usually at once conneeted in the mind with the imuge of the motor activities that it requires some introspective discrimination to note the distinction, and we in English have no word which has not the active motor connotation. Triel in German more nearly indicates the simple state. "Blind impulse" seems the best combination of terms to convey our meaning.

A "blind impulse" therefore muy be iefined as the psychosis of painful obstruction of systemis actirities, which we learn by reflection. would be relieved by motor functioning which is stimulated. Of impulse proper we speak below.

Desire appears to me to be a complex which eontains two elements as follows:-

1. The painful psyehosis of non-motor, systemie obstruetion ; of effort by the system to force chamnels for the "pent-up stream of action "(Ward), i.e. to get around the restriction to the realisation, i.e. a craring.

2. The persistent image of the realisation of an unrealised objective idea: which idea we learn by reflection would bring relief of the desire pain if it conld be realised; bnt neither this act of reflection nor its outcome is necessary to the desire.

1. That the psychosis of obstruction of activities is present in desire will probably not be questioned; it is shown by the faet that desires tend to "arise when the real feelings to which they correspond have not been experienced for some time " (to quote Mr. Speneer again), and that in other cases they arise after reeognised restrictions. If this be true the stress of desire onght to be relieved by activities which are represented in connection with them, which is a generally-acknowledged truth ; or by the diversion of the obstrueted energies into new ehamnels - that is, by the rise into absorbing attention of other activities. As Mr. Spencer puts it, "Desires when ungratified become feebler and finally die away."

If this point be granted then under my theory, desire must have always in it an element of pain ; the psychosis of obstruetion must be painful. On this point some authorities are silent: a large proportion of thinkers who have disenssed the subject, however, are agreed in favour of this view; such men, for instance, as Locke, ${ }^{1}$ J. S. Mill, ${ }^{2}$ Wiitz, ${ }^{3}$ Volkmann, ${ }^{4}$ Bain, ${ }^{5}$

1 Itumen Viderstendiny, Book I1. chap. xxi. \$31.

2 James IIIll's Analysis, chap. xxiv., end of note 66. " Lehr. d. Psy., \$ 40.

+ Lehr. d. Psy., xi. \$111. 5 Émotions and Will, chap. viii. $\$ \$ 1,5$. 
Ward, ${ }^{1}$ Bradley ${ }^{2}$ and Sully. ${ }^{3}$ So well recognised is the fact, that it has led to the pessimistic doctrine, as old as Plato, that all desire is a striving away from a present pain.

Professor H. Sidgwick indeed dissents, claiming that he finds desire often nentral or even pleasurable, but I think he uses the term too broadly, to cover the retrospect of a number of successive states; as I have attempted to show in my reply to a criticism by him of my use of the word "desire." 4

2. But, as I have already noted, the pain of restriction is not all of desire; were there nothing more, craving would then not be differentiated from it; to complete the desire there must be added the persistent image of the realisation of an unrealised objective idea. If realised this would bring the clesire to an end and relieve its pain.

The importance of this point is grasped by many of the later German psychologists ; but the Herbartian notion that each rise of an element in consciousness is a striving of a presentation against opposition, has made the conception difficult to hold; has made it hard to draw the line between a desire and the general flow of consciousness, especially in expectation, which, to the Herbartian, would appear to be merely a marked case of the general striving for realisation. ${ }^{5}$

A non-believer in this Herbartian subconscions striving meets with no difficulty in this direction, each successive idea arising through associative stimulation (subjectively speaking). Expectation is an idea which has the qualities of futureness and of realness, and is distinctly differentiated from desire, as I have defined it above.

The realisation in the case of desire may refer to an image only, as when we desire the prosperity of our offspring; the realisation must be for $u s$, but in no sense that it must be a realisation coming to us from the ontside, as Bradley ${ }^{6}$ seems to think needful.

Whether these two elements make up all of desire is a question which may well be deferred for a moment in order to consicler impulse proper, which appears to me to be made up of two elements as follows:-

I Ency. Brit., art. "Psychology."

2 Mind, xlix. p. 17.

3 The Human Mind, xi. p. 199.

4 Mind, N. S. i. pp. 94 fr., $400 \mathrm{ff}$.

${ }^{5}$ Cf. Drobisch, especially Emp. Psy., § 143, quoted by Volkmann; also Volkmann, Lehr. Psy., ii. \$139; Lip'ns, Grund. d. Scclentcbens, p. 610.

6 Mind xlix. p. 21. 
1. The psychosis of painful obstruction of systemic motor' activities, i.e. a blind impulse; and

2. The persistent image of the realisation of a distinctly motor activity; this we judge in reflection would, if realised, bring relief of the obstructive pain.

That impulses always contain the motor idea is not questioned. That they are always painful is not always so clear, but I think Lotze is right when he tells us, "Triebe sind ursprünglich nur Gefühle, mol zwar meistens der Unlust oder doch der Unruhe."

Impmlses to not become emphatic in consciousness except where there is distinct opposition, and in all such cases I think it will be agreed that the measiness is distinctly painful.

If the restriction of impulse be broken down and the instinctive tendencies work themselves out, we have the psychoses which I have called "instinct feelings" (Chap. II. $\$ 1$ ), which, under certain conditions of co-ordination and fixity are called emotions.

We have then,
1. Craving.
2. Desire.
3. Trieb (Blind Impulse).
4. Imprilse.

in which 2 and 4 are more developed states, that is, clearer intellectually, than 1 and 2 .

As motor activities are the last in the physical series which begins with stimulation, we should expect to find "blind impulse" bound to, but most often appearing as subsequent to, craving. This accords with my own introspection. While craving may appear alone it tends to mu into Trieb; on the other hand, Trieb often appears alone, without bringing a craving into conscionsness.

Desire and impulse we should expect to find similarly related. Desire should naturally lead to impulse, and should most often he found bound to it, although we should be able to note cases of desire where impulse seems to be wanting or only very incipient. On the other hand, we should expect to find impulse appearing quite distinct from desire, and not calling desire into being immediately.

Now it seems to me clear that impulse is easily held apart from desire. On the other hand, desire is not ordinarily considered separalile from impulse. Indeed a formidable array of authorities take the position that impulse is of the very essence

1 Grundzüge d. Psy., \$ 102. Cf. also Lip1s, op. cit. p. 439. 
of desire ; for instance, J. S. Mill, ${ }^{1}$ Lewes, ${ }^{2}$ Volkmann, ${ }^{3}$ Horwicz, ${ }^{4}$ Wundt ${ }^{5}$ Höffiding, ${ }^{6}$ Sully. ${ }^{7}$

Still I am convinced that there are cases of desire which have little or nothing of impulse in them : such cases as the "desire to know," the "desire to recollect," for instance. These seem to me to be clear cases of desire ; but no impulse element in the state is appreciable.

It seems proper then to exclude impulse from the essence of desire, but on the other hand we must acknowledge that desire can seldom occur without calling ont impulsive activities.

We here find explanation of another fact of interest, namely, that so many thinkers, and common folk in general, speak of desires as emotional. The explanation in this case seems to be bound up with the fact that emotions are complex impulsive phenomena. As we have just seen, impulses are the most likely outcome of desires, and are therefore most often held together with desire in reflection. If our view be correct, therefore, we should expect to find the desire phase very closely related with the distinct emotions.

There is a tendency among certain thinkers to bring desire and aversion into relations which amount to identification with love and hate respectively, by considering them determined by pleasure in the one case and by pain in the other. ${ }^{8}$ Desire especially is not infrequently practically treated as a love phase, ${ }^{9}$ and is sometimes referred to as a special member of the emotional group. ${ }^{10}$ This identification is impossible if my contention as to the constitution of emotion be granted. The desire states of emotion will be discussed later in another connection, consequently I shall say no more on this point here.

I must later consider certain theories which are in opposition to the views here expressed, but I think the way will be made plainer if before doing so we consider other related pains of restriction.

Disappointments are pains of restriction of marked force. The psychosis of disappointment in my view is made up of

1 J. S. Mill's edition of Janes Mill's Analysis, chap. xxir. footnote 66.

2 Problems, 3rd series, p. 248.

${ }^{4}$ Psy. Anctysen, Vol. III. chap. iv.

3 Lefrouch d. Psy., ii. p. 437.

${ }^{6}$ Outlines of Psy., chap. vi. 2. $e$.

5 Phil. Studicn, VI. iii. p. $373 \mathrm{ff}$.

${ }^{8}$ Cf. Wundt, Phy. Psy., II. chap. xviii.; and Höffling, Outlines of Psy., chap. vi. B. $2 . b$.

${ }^{9}$ Guyau, Prob. de l'Esthétique contemporaine, p. 17 .

${ }^{10}$ Lewes, Prob. of Life and Nind, 3rd series, P1. 248, 357. 
(1) The painful shock of the olstruction canced by the nonrealisation of an expectant idea, that is, of an idea of future timequality, which is developed as real ; and (?) The persistent image of the non-realisation.

If this definition be correct, we should expect to find disappointments complieated with desire, because the persistent idea in desire might or might not have the quality of expectancy.

Desire, whether simple or complicated with impulse, must always have reference to future realisation, ${ }^{1}$ and if the nonrealisation in this futureness be marked, desire wouk be met by the check of disippointment at each movement in the direction of realness in expectancy; this shonld give us a spreeial recognisable state, which we have in what we eall a wish. A wish is close to a desire, but we do not uish unless we know that the impulse is to be thwarted."

If the future non-realisation is not thought as positive, i.e. if the expeetancy is not inhibited as soon as it appear's, and if, when it is inlibited, the desire arises again toward expectancy, only to be again inhibited, we should look for another special, recognisable state, which we have in hope.

If this be a correct analysis of hope, we should find that the shock of effectual non-realisation of the expectant idea would give us true disappointments in connection with it; and in fact we do speak of disappointerl hopes as we do of disappointed expectations; but not of disappointed wishes, nor of disappointed desires, unless we use the world "dlesire" too widely, to descrilie a distinctly expectant state.

Certain other relations seem to corroborate the positions here maintained.

We may desire whet we expect and whet we do not expect.

The muly desire uhut we hope for and uhat we do not hope fur. That is, desire is not dependent upon expectation for its appearance.

On the other hand

We mey envet what we desire or what we do not desire: but, ITe can only hope for what we do desire. The do nut hope for what we do not desire.

It is clear then that expectation is not dependent upon desire for its appearance; lut that hope is dependent upon desire for its arisal.

${ }^{1}$ Cf. Drobische, Emp. Psy., 1. 98, 'fuoted by Tolkmamn; ef. Bradley; Wind, xlix. p. 16.

2 Wundt, Phit. Stuer., VI. iii. 1. 373 ff.; James, Psy., vol. ii. 1. 486. 
This appears to be because the expectation of hope is based upon the desire, which, if not effectually checked, forces expectancy. The power inherent in the forces obstructed in the desire seems to attach itself to the idea of the outcome of the desire, which is thus given a persistency that forces reality upon the futureness and gives us expectancy; so that we are compelled to alternations of belief (hope), or to fixed belief (expectation), in the realness of the future idea. Thus it is that desire may produce hope and also expectation; while hope cannot be induced without desire, although expectation can.

We may obtain a pain quite equivalent to disappointment by the mere breaking off of a current of thonght which circumstances have forced upon us, and which has involved a large and concentrated exertion of force. ${ }^{1}$ A man may compete for a prize, realising that his chances are exceedingly limited, but if he put his soul into his work he will at the end find himself disappointed if he fails, even thongh he knows that in the beginning he did not in the least expect to be the winner.

I have stated above my notion of the analysis of the states of restrictive pain and their relations, in order that my reader may understand, so far as may be, the meaning I attach to the terms when I use them.

These definitions are made not without a knowledge that they are in opposition in particulars to the views, referred to often above, of men whose opinion I consider of the greatest weight. The most important of these oppositions, however, I have not yet touched upon.

I must now consider these with the hope of showing them to be determined by what seems to me to be a too broad, and therefore inaccurate, use of terms.

In very many cases in onr everyday life the appearance in our minds of a sensory object is the signal for the rise of a desire relating to that object. This means of arousal is common to the emotions also, and this fact adds force to the incorrect view that desires are of emotional nature, which view arises, as we have already seen, from the common combination of impulse with desire. But the idea of that object is not, I think, a part of the desire. ${ }^{2}$ The desire proper is for something not realised: in the cases which lead to this view the desire is for inrealised relations to the object of sense; and it seems to me that we

1 Cf. Sully, Human Hind, ii. p. 40.

${ }^{2}$ Cf. Sully, op. cit. ii. p. 196. in opposition. 
may eliminate this latter entirely without cutting away the desire, provided the notion of the realisation of the unrealised relation to this sensory object be retained, together with the restrictive pain of eraving. I see my friends at dimner; this produces the desire (which is a distinct matter) maylue to realise the eating of the food which I am not doing, or to realise the activities of companionship from which I am debarred. But there are cases where the desine arises without such objective suggestion as I have here deseribed. Hunger may bring a desire to eat where no objective notion of food has been presented to the mind. I desire to read, but I camnot hold in my mind with the desire any object which started the desire; although I grant that I judge usually that some object must have stimulated it associationally; still, as it is not present to my mind with the desire it cammot be of its essence.

Finally, the relation of desire to pleasure, searcely referred to thus far, must be considered.

In my view as above stated, beyond its pain, nothing more is necessary to desire than the persistent image of the realisation of an unrealised objective idea. It is claimed by a formidable number of anthorities ${ }^{1}$ that this mrealised objective idea is always an idea of pleasure. James Mill actually went so far as to make "the idea of the pleasurable sensation and the desire of it names for one and the same thing.". John Mill saw the weakness of this extreme position, and since the elder Mill's day statements of this doctrine have been more and more guarded; until now we find the champions of the doctrine far from courageous.

Mr. Sully ${ }^{3}$ does not overlook, as his predecessors in his own tongue have too often done, "that we desire many things, e.g. knowledge, virtue, other's' happiness, without at the moment thinking of the attainment of the objects as pleasure-yielding "; but still he hopes "yet to sare" the general truth of the proposition that what we represent in desire is pleasure-bringing."

These are not the words of a man who feels his position

1 E.g. James $\mathrm{Mill}$ (Analysis, chap. xxiv.); Professor Bain (Senses and Intelleet, chap. iii.); Sidgwick (Method of Lthies, chap. iv.); Martinean (Types of Ethical Theory, ii. 261); L. Stephen (Science of Etties, chap. ii.) ; F. H. Bradley (Mind, xlix.); Waitz (Lchi. d. Psy., § t0); Volkmann (op. cit. ii. p. 397). Lchmann (op. eit. p. 139) in carrying out this doctrine is led to the untenable position that the end of Trieb and instinct movements is the retention of the original pleasure, or the throwing off of the original pain. But it is evident that Trieb and instinct refer to racial effects, and not at all to individual pleasures and pains.

3 Heman Mind, ii. p. $20 t$.

2 Analysis, chap. xxir.

+ Italics mine. 
secure. On the other hand, anthorities are not lacking, especially among the opponents of hedonistie ethies, to combat the doctrine that the idea of a pleasurable end is of the essence of clesire.

It seems to me that the difficulty here is due to a failure to keep apart the desire proper and the mental states which usually, but not nccesscrily, attach themselves to it. $\mathrm{We}$ have already seen how this occurs with reference to desire and impulse. The case here appears to me to be quite similar. ${ }^{1}$ The satisfaction of desire is a pleasurable psychosis, as is all relief from restrietive pain. That pleasure always results if the idea unrealised in desire is realised in its satisfaction is a fact which is soon reeognised, and usually to the desire is quickly added the pleasurable image of the pleasant resultant. Furthermore, pleasurable ideas of pleasure to come are powerful stimuli to all activities, and, when the resultant is restricted, are powerful means of the production of desire; but it cannot be denied, I think, that desires may occur for what is reeognised to be indifferent, or even painful, beyond the pleasure of the mere action after restriction. As Volkmann" says, "We desire originally not that of which we wish the enjoyment, but we cease to desire so soon as we are satisfied; and desire knows well its own pain, but not the pleasure which will arise if it is satisfied."

That the relation to resultant pleasure is not of the essence of desire is, I think, clear from the fact pointed ont by Dr. James Ward ${ }^{3}$ that the strength of desire is not proportional to the intensity of the anticipated pleasure; furthermore, it seems to be necessary, in order to defend the position, to uphold what seems to me to be a false notion, viz. that the "representation" of a pleasurable psychosis must itself always be a pleasure. ${ }^{4}$

A pleasure in fact may, and often does, produce a pleasure in "representation"; this pleasure tends to persist and to realise itself, and when this realisation does not take place we have an obstructive eraving. There is not a corresponding action with painful objects. To express it differently; usually the fact that a thing is recognised as a pleasure in representation acts as

1 As a case in point we may note Professor Bain's remark (Emotions and Will, end of chap. viii.): "When a man loses his enjoyment in hunting he does not continue to desire hunting." This, of course, we must grant, but the fact has been misinterpreted. Corrcetly speaking, we should say, "When a man loses his tendency to hunt he will feel no desire for hunting after rest from or obstruction to the act, and feeling no desire, the action of hunting will give him no pleasure."

2 Op. cit. ii. $\$ 139$; cf. ii. $\$ 143$.

\& Cf. Sully, Human Hind, ii. p. 198.

"Ency. Brit., art. "Psychology." 
the stimulus to love, which, being thwarted, gives us desire in powerful form; and so pain in representation acts as a stimulus to hate, which, being thwarted, gives ns aversion. But as pleasure per se as above noted tends to prodnce desire craving, while pain per se does not, no belief in the object as pleasurable is necessary to desire, although belief in the object as painful is necessary to aversion (Waitz).

On the whole, I think the examples quoted by me from Mr. Sully are sufficient to break down argument in favour of the view under discussion, which latter seems to me to be adequately accounted for by the connections which I have above suggested.

\section{APPENDIX II}

\section{DETAILS OF EVIDENCE}

I wish here to trace with a little more fulness than seemed best in the body of the ehapter the varying algedonic phases in mental states where contents are fixed.

This beeomes more important becanse Alf. Lehmann, in his important Hauptgesetve des menschlichen Gefinhlebens, upholds the doetrines: (A) that each Vorstellung, where the individuality of mind is unchanged, has attached to it a definite pleasure or pain phase which always appears with it whenever it arises in presentation or re-presentation; and (B) that what seem to be changes of phase in connection with one and the same content are really not due to the original content, but to additions of new presentations of different algedonic tone.

He does not hesitate to give many instanees which weigh against his theory (p. I63 ff.), and I fail to find conrincing evidence to prove his position $B$. The experiments upon inerease of temperature (p. 178), which at first sight seem to favour his doctrine, really give us a case in which added complication of content is recognised as the pain takes the place of pleasure. His acknowledgment of a "Schwelle" (p. 174), and of a theoretical neutral point (p. 180), in passing out of pleasure into pain, granting as it does that there is a change of phase as to pleasure withont change of content, argues in favour of the generally accepted view that the pain, where it replaces pleasure, in the cases under consideration, is really attached to the same content.

I shall ask my reader to use great eaution, as I shall try to 
CHAP.

to, to avoid cases where there is a shifting of content with shifting of pleasure-pain phase.

We naturally begin with the relatively simple states called sensations; after that I shall ask the reader to consider the more complex fixed psychoses which we call the emotions.

I shall make no pretence to logical completeness in this review of the sensational and emotional fields, although I shall lead the reader as far as our knowledge seems to warrant us in the distinction of fixed separable contents.

\section{Sensation}

It becomes each day more apparent to the student of nerve physiology that we are only beginning to comprehend the mechanism of the sense organs and of their extensions, so to speak, toward and in the brain, and the reader must not expect to find here definite organic position referred to.

The fact that in two successive cases we appreciate the same sensational content, involves, so far as we can judge, activity of the same organ in the two cases, and this postulate is all that is needed here.

I shall endeavour in each case to note the phases--

1. The pain of reduced activity.

2. Indifference; the practical absence of either pleasure or pain.

3 . The pleasure of active functioning.

4. The pain of active functioning.

5. The pleasure of rest after hypernormal activity. This last, however, is so generally recognised that it would involve mere reiteration to draw attention to it in all cases.

Let us begin with our most clearly defined sensations, i.e. those which are least complicated with resultants in the more complex region of thought.

ToucH.-Touch stimuli which have become habitual and which do not recur normally are distinctly "missed."

We experience the painfulness of itching, which is removed by rubbing of the parts to which the disagreeableness is referred. Itching too is increased by increase of the flow of nutriment to the superficial organs, i.e. by increase of the capacity for action without increased activity in the organ ; inflammatory conditions, warmth, and indirectly even the rubbing which itself at first gives relief, will produce this added capacity and the itching pains.

Indifference appears in our failure to notice the constant touch stimulation produced by our clothing. This common occurrence 
of indifference would lead us to expect that touch pleasures ordinarily would be obtained noticeally only by the summation of activities distributed over wide surfaces. The stroking of furs, or actions which give us considerable pleasure, are determined by the activities of many organs distributed over a considerable cutaneous surface.

The cases where considerable pleasure is obtained from more limited touch stimuli are all to be conneeted with conditions of fulness of nutrition in the parts which are called into activity, and an occasional use only of the pleasure-giving organs.

Hypernormal activity if continuous does bring painfulness. Any rontinuous touching of a surface by some special part of our skin becomes disagreeable very soon. Our clothing does not affect us thus because it does not ordinarily cling; i.e. the surface affected is made to differ with each movement. But where it does cling, it soon becomes intolerable.

The pleasure obtained from touching the hand to a warm soft slin surface becomes after a time disagreeable, unless the position of the hand is changed.

Extreme stimulation of the pressure nerve terminals is recognisably painful, but the sensations under conditions of extreme pressure seem to me to inyolve other elements than those of mere touch: the added elements being probably due to stimulation of subcutaneons nerres-those which are involved under conditions of laceration, pricking and cutting, to which reference has been made above (p. 19 fii.). It has there been argued that in all probability under the conditions open to the experimenter these subcutaneous nerves are always stimulated in painful phase ; where the more moderate stimulations of these subcutineous nerves occur withont lacerations, other superficial terminals seem to be powerfully stimulated, and the coincident sensations of these latter are brought into such prominence as to mask the coincidents of the less vigoronsly active subcutaneous nerves.

Tickling sensations are probably not simple; the tickling brings about spasms which add new mental elements to those directly experienced. It seems scarcely worth while to dwell ou these sensations except to note how enjoyable moderate tickling is (so that children beg to be tickled); and yet on the other hand how very painful it soon becomes under the continuance of the conditions which bring it alsout.

Horwicz ${ }^{1}$ has taken tickling as an example to show, in opposition to Wundt, that very slight stimuli may produce sharp pains; but it 
must be remembered $\left(1^{\circ}\right)$ that the light touch, by acting with wide leverage of the surface hairs upon the superticial nerves, may produce very strong action in the nerves affected; and $\left(2^{\circ}\right)$ that much of the effect of tickling is due to the intensity of spasmodic movements which are connected with it; and $\left(3^{\circ}\right)$ to after aftects of disgust and the like.

HEAT and CoLD nerve terminals have been isolated by Blix, Goldscheider, and Donaldson ; and Lehmann has lately added to our knowledge of their activities.

It appears from his investigations ${ }^{1}$ that certain temperature stimuli which distinctly affect the heat terminals (i.e. that bring sensations of heat) also slightly affect the cold terminals. Therefore there is a range of medium temperatures which affects at the same time both the heat and cold spots.

These facts would lead us to expect ( ${ }^{\circ}$ ) that where large surfaces are involved, normal temperatures would produce practically indifferent, and hence nmmoticed, heat and cold sensations ; $\left(2^{\circ}\right)$ that any sharp departure from the normal in the direction of heat would bring at first pleasure, which would be great if the conditions preceding had involved subnormal stimulation of these heat terminals (e.g. when one approaches a fire after exposure to frosty air) ; but that, if contimed, a condition of warmth painfulness would ensue, compled with a craving pain which would be satisfied by a change of stimulation in the direction of cooling (e.g. when one has been long in a heated atmosphere there is a distinct demand for fresh cooling breezes); $\left(3^{\circ}\right)$ that any sharp departure from the normal in the direction of cold would bring at first pleasure, which would be great if the conditions preceding had involved subnormal stimulation of these cold terminals (t.g. when one steps from a heated room into the cool fresh onter air); but that, if contimned, a condition of cold painfulness would ensue, compled with a craving pain, which would be satistied low a change of stimulation in the direction of warmth (e.g. when one has been long in the cold, heat is appreciably craved).

The examples I have given as I have stated these various conditions, and other's which will readily ocenr to the reader, show, I think, that the facts correspond with our cxpectations.

$\left(4^{\circ}\right)$ The wide distribution of the cold and heat spots would lead us to expect that, as in the case of touch proper, the pleasure capacity of any one spot would be small, and that summation of stimuli would be necessary to bring cold or heat pleasures 
into conscionsness. This agrees with experience. On the other hand, we should look for conditions of heat and cold pain under extreme conditions of stimulation.

Burning pains over limiterl areas are familiar to all, and our psycho-physicists ${ }^{1}$ tell us that they are producible by extreme stimulation of isolated spots: it seems more difficult to obtain cold pains from the stimulation of isolated cold spots (Lehmann suggests that this is beanse the cold reduces the capacity of the nerve for action); the painfulness of tonching extremely cold bodies with limited areas of contact is familiar to all. Acute cold and burning act like cutting, probably affecting the subcutaneous nerves. In reflecting upon this subject, it must not be forgotten that many of the pleasurathle and painful efiects ordinarily comecter in our minds with thermal changes are really due to circulatory alterations.

The Muscular Sexsations.-If any muscle, which we are acenstomed to use frequently, fails of exercise, we feel the pain of eraving. The motionless student working in his study has his attention drawn from his work loy demand for the exercise to which he is accustomed.

Indifference in muscular action, however, is very frequent, as appears from the fact that if we deliberately turn our attention to ordinary musenlar activities we perceive their coineident psychoses without finding them either appreciably painful or pleasurable.

Pleastures here as elsewhere are most notable after rest, and especially after constrained rest, as the walker' well knows. That this pleasure decreases rapidly as the musenlar exercise contimues accords with our law.

The pain of excessive muscular action is so well known as to be typical of pain.

The pleasures of relief after excessive muscular activity deserve mention becanse they are also typical, as in the rest of the tired walker who throws himself upon the ground. The pleasure taken in bathing is, to some extent at least, due to the relief from activity of all supporting muscles.

TASTE.-The activity of the taste organs is as yet little understood. Late experiments seem to show that there are distinct spots upon the gustatory surfaces which serve to produce the activities coineident with particular tastes."

1 Ce. Lelmann, op. cit. 1. 35.

2 Vintsehgar in Hermann's Physiologic, IIl. 1, ii. PI. 157 and 209 ; also Oehwall as mentioned by Snlly (Human Hind, p. 101). The experiments 
The craving for tastes to which we are accustomed is well known: for the bitter of the olive for instance.

The pleasure of gaining the satisfaction of our cravings for these same tastes, and the pains coincident with excessive stimulation of them, are recognisable also.

That all tastes, if makle continuous, become disagreeable has been denied by Herbert Spencer, e.g. in the case of sweets, which he says are always pleasant; but I am fond of sugar, yet appreciate well the disagreeableness of satiety, and know of the case of a friend who actually disliked sweets except in minute amounts. The fact that saleswomen in candy-shops require no especial restraint to keep them from eating the sweets they sell certainly goes against Mr. Spencer's statement; especially as he holds that a pleasure is that which "we seek to bring into consciousness and to retain there."

Complex tastes may be explained thus. A special taste often experienced may require the action of new elements $a^{\times}, b^{\times}, y^{\times}$; now if another substance tasted calls for a different combination as $a^{\times-3}, b^{\times}, y^{\times-5}$, then the organs of $a$ and $y$ will be left in condition fitted to act pleasantly, and if an article requiring the use of $a^{1}, y^{2}$ be presently placed in the mouth, the elements ready to act will be $a^{3}, y^{5}$, and the resulting taste should be pleasant. Certain it is that contrast of taste brings pleasure ; that after "rest" from tasting sugar, e.g., sugars are pleasant.

Siell.-Too little is known of the action of the organs of smell to warrant positive statement as to distinct organic action in any case. However, we may note that longings for certain smells are known, that indifference to ordinary smells is prevalent. The pleasures obtained from certain perfumes are well recognised, as is also the fact that these soon fail to delight and become disagreeable.

That some smells always are known in painful phase indicates that in certain lines we have little pleasure capacity. I remember well once having been aroused from serions thought in a railway carriage by a delicious odour, and the words "What a delightful perfume!" were actually formed in thought. Almost immediately the smell changed to disagreeableness with growing intensity, and there appeared evident the intensely disagreeable smell emitted by a polecat which had been killed by the train.

Sensations of the Alinientary Canal. - Under our theory, as the alimentary canal must be the part of the system

of Vintschgan have been repeated and widened in scope, and his results verified, by Dr. C. L. Dana of New York. 
which has been longest developed in the race, we should expect it to be so fully accommodative to the calls upon it that indifference should be the only phase common, pleasure seldom seen, but pain of over-action always possible.

This is exactly what we find in the lower alimentary canal. The stomach is a later development in the biological history of our race, and should be expected to act with more aceommodation and with less accuracy, so that surplus stored force for unusual activity might be expected to accmmulate and pleasure of action be possible.

Puin of Craving.-Hunger is due to systemic lack of mutrition, as is shown by its alleviation $h y$ the introduction of nutritive enemata into the intestinal canal. The stomach and the rest of the digestive system become accustomed to action at regularly intermittent periods: as these periods reeur we should expect to find an aecumulation of mutrition in these organs which would normally be active, and a consequent restriction of the activities. connected with the supply of this mutrition; this is doubtless the source of hunger; for provision of food to the alimentary system, producing activity, relieves hunger and gives us the pleasure of activity attendant upon the use of surplus stored force. If the pain were one of over-action, we should expect it to continue until disintegrative action set in, which would destroy the capability of action. But if it be a pain caused by failure of normal stimulus to normal action, then if no food be given we should expect at first pain, which would cease after new channels for the blood supply were opened 11 , and the most we should look for would be an atrophic condition after prolonged lack of food; until this happened a power of recuperation being retained. Just such facts we find; Greeley, in his description of the sufferings of his Polar Expedition, says that after a few days the men ceased to suffer hunger pangs, and Lewes gives certain tales which corroborate this statement. ${ }^{1}$

The pains of over-action in the stomach are complicated witl pains of museular distension, but are indeed separate; too lous continued giving of a supply of food produces a tired painfulness and often the reflex of vomiting.

Thirst is also determined by systemic wants; but is

1 Darwin (Ery)ression of Emotion, p. 176) says, "Children, when wanting food, cry out loudly, partly as a call to their parents for" aid and from any great exertion serving as a relief." 1 t is here as with all repressive pains. Excess of surplus storage in one organ may be reduced by calls for energy in nearly related prarts of the system. 
localised in the fauces. It may be reduced by bathing (absorption of water through the skin); and thirst which is due to local canses, e.g. summer heat producing large blood supply to the head, may be relieved by holding water in the mouth as well as by swallowing it.

The extreme thirst felt by cholera patients, and which arises from the great loss of fluids in the system, which is a symptom of the disease, is found to be alleriated by the subcutaneous injection of water raised to a specific gravity approximately equal to that of the blood.

Thirst pain is relieved by drinking, which gives great pleasure. This shows it to be a pain caused by restriction of normal activities. The pain of over-action is not known because the system rejects so easily all surplus fluid.

Respipatory Sensations. - As in the case of the alimentary canal, the organs of respiration require a supply of material to act upon, or their functioning is deranged ; but here the demand is immediate if there be a lack, as the supply is normally constant.

The importance of the work done by the organs in question would lead us to look for an emphatic pain where they conld not function. The constant need of the system for oxygen brings to the lungs an accumulation of blood requiring aeration; if air is not given we soon have the conditions to produce craving pain in the parts supplying the lungs and more or less generally in the whole system. This is the terribly painful condition of asphyxia. Where air becomes rarer the tendency to this pain would appear to be natural, and the apparently opposite effect in the case of those moving gradually into higher altitudes is due partly to general exhilaration of the circulation, and partly to the hypernormal action in the lungs.

Indifference exists where the air supply is normal and the lung action normal: notwithstanding the indifference we can clearly appreciate the action in respiration, it is not unconscious.

As to the pleasurable phase note Bain, who says, "This pleasurable sensation is felt only when we pass from a lower to it higher degree of aeration. We may experience it at any time by holding in the breath for a little and then allowing it full play"; or, in other words, by enforced rest allowing the tissues to accumulate energy, and then by the full action making use of that suplus power we have in store.

The pain of over-action in the lung, apart from mere muscular pain, we should not expect to find emphasised, for it 
is hard to conceive how such over-action could take place; the foreing into the lungs of more oxygen than could be used wonld not cause the organs to be over-active, and other abnormal states would be so immediately complieated by other emplatic activities as to mask the respiratory pains of excess even if they occurred.

When we turn to aural and optical sensations especial care is required to separate the sensation pure and simple from the complieated effects which are produced by and usually woven in with the sensations.

HeAring.-It is very difficult to reach conditions where air vibrations are absent. Still the "silence which can be felt" doubtless gains its effect largely from the oppressive pain due to lack of stimulation of an organ which has been usually aetive. I have noticed this distinetly in passing through a warehonse which was stored with wool, in which I experienced an oppression located in the ear.

Ordinary sounds are evidently practically indifferent: sounds, "go in one ear" and ont the other," as the common saying is, without attracting any attention.

A mere noise of heightened degree after proper rest is highly pleasurable, especially to children and savages ; but for cultivated people eren, this is so where sounds have long been wanting. Harmony and melody, while having their foundation in action of parts of the earr, are really cerebral, and find their explanation elsewhere; but, as Lotze says, ${ }^{1}$ a perfectly clear and well-sustained note does of itself produce an ummistakable feeling of pleasure. On the other hand, the pains produced by excessive noises, by explosions, by the sharp rasping sounds of boilermaking, for instance, and of mere loudness of pure tones, is well recognised. The pleasures of rest obtained after extreme aural stimulation are so typical that they deserve especial mention here.

SIGHT.-Effects produced by total dirkness are largely mixed with other impressions: for a person with normal sight an experience of total lack of ethereal vibrations is hard to conceive of; for some action on the retina must take place, even if not sufficient to give us any definiteness of impression whatever. Still there is a sense of oppression after being long in the dark which is probably partly ocular, as is inclicated by the distinctly ocular delights obtained by the return of light, as for instance

1 Wicrocosmus, Book V. chap. ii. $\$ 1$. 
when we come out of the deep darkness of a mine or tunnel, into a moderately strong light. It is very diffienlt, however, to reach any condition of hypernormal action within the pleasure bounds ; the very numerous accommodative mechanisms of the organ, eyebrow, lash, lid, and the marvellous iris-screen, tending to prevent all hypernormal stimulation. The vast mass of optic effects are practically indifferent. The pain of excessive action, however, is known to any one who suffers with his eyes.

Here again the pleasure of rest is typieal. Rest in darkness after excessive light brings marked pleasure widely diffused throughout the head, the part most nearly connected with the eye action.

\section{The Enotions}

Let us now consider the much less simple states ordinarily ealled the emotions.

That they pass throngh the diverse states of pain and pleasure is often incidentally acknowledged by men of opposed schools of thought. When we undertake a eareful review of the subject, however, not a few difficulties confront us.

As we have seen, the emotions are complex psychoses made up of diverse elements, some of which vary from individual to individual, and in the same individual from day to day. In speaking of them as fixed psychoses, therefore, we can only refer to the relatively unchangeable elements: those which are always present when the state is recognised as an emotion with a special name. We shall be compelled to avoid mention of all fine emotional nuanees, which are what they are because of the relative importance of the variable elements in their formation. Furthermore, except in certain relatively mimportant directions, we are mable to fix the organs eoineidently active with these complex states: we are therefore unable to regulate the conditions of stimulation as we are in the case of the sensations.

We have already seen that the eapacity to experience certain phases of pleasure or of pain in connection with sensations varies with different people, and in certain cases a phase may be all but undiscernible; this variation becomes of more importance with the emotions ; for as pleasure-pain refers to the "welfare" of the nerve tissne, and the emotions refer to the "welfare" of the individual or racial organism, we should expect to find the development of the former overpowered by that of the latter, under the laws of survival; we should look to find practically an entire loss of eapacity for pleasure-gaining with certain emo- 
tions that are detrimental to the ruce, and a corresponding emphasis of pleasure eapacity in connection with those that are advantageons, so that the pain phase will be all but unknown with them.

We are also tronbled by divergent term usage, and by carelessness in attaching to one psyehosis the name of amother which is only by chance often experienced with it.

Considering these difficnlties, I shall not undertake to disenss more than those typical emotions mentioned in Chap. II.

The emotional group, Joy, Sorrow, Dread, Relief may be best considered first.

These, as it has been indicated above, appear to be the coincidents of increase or decrease of general systemic activities; in a very broad sense, therefore, they may be looked upon as different phases of one emotion.

If JoY be the psychic coincident of increase from general. normal to general hypernormal activity, then evidently joy can only be known in the phases of pleasure of activity or pain of aetivity.

Now joy is evidently a typical pleasmable emotion, as we should expect it to be. The pleasures of joy, however, like all other pleasures, are evanescent: they are short-lived; we find ourselves antomatically ceasing from the strong activities which would be painful and disadrantageous in excess. The prineipal pleasure in joy is in its first intensity; the pleasure quickly waning.

That a very intense joy may become painful, and that it may lead to quick exhaustion, seriously affecting the system, is well known.

If SonRow be the psychic eoincident of deerease from a state of general activity in the direction of general subnormal activity, sorrow will evidently be known only in the phase of pain of restraint. The anguish of the first state of grief is doubtless mixed with pains of hypernormal strain; but beyond this, and where grief is of long continuance, the pain is one of repression, as is eridenced by the fact that the remedy for sorrow pains always looks to merease of general activity. We take our sorrowing friend for a walk; we arrange to loring before him novel objects to attract his attention. The first mark of arising activity in weeping is reeognised as a relief and is distinctly pleasurable. It is one of the misfortunes of man's lot that he is incapable of profuse weeping, as a woman is, under conditions of grief.

The pleasure which is called the "luxury of grief" is not 
grief proper. "There is a pleasure," says Aristotle, "in mourning for departed friends under circumstances of distress ancl danger; they are brought as it were before us, exhibiting all those qualities which had formerly excited our kindest affections." I He thus gives the key to the apparent anomaly. The pleasures are not of grief, but are connected with the cause of the grief and with the state of quiet contemplation which grief implies.

If DREAD be the psychic coincident of an enforced repression of general activities, then here, as in the case of sorrow, we should know no phase but that of general painfulness occasioned by restraint, the pain being relieved by activities; and this accords with experience.

ReLIEF from either sorrow or dread must, under our theory, be of necessity a state of pleasure arising from the use of surplus stored force accumulated during the restraint. That relief is always pleasurable will not be denied.

Now let us consider the group of emotions discussed in Chap. II., which involve specific combinations of distinct activities, which may themselves vary in intensity in relation to organic conditions, and which must therefore be expected to give psychoses of varying algedonic phase, viz. Love, Anger, Fear, Surprise.

Love, under my definition, is the psychic coincident of that complex of instinctive reactions which if allowed full derelopment would lead us, in a condition of receptivity, towards the object loved.

What I call love is well known in the condition of craving where there is restraint upon the love, or loss of an object by which love has often been elicited.

Love too is often indifferent, but is best known in its phase of pleasure. Love cravings if satisfied always bring a high degree of pleasure; but the pleasure of love activity may occur without any preceding craving.

That there is a love so intense that it amounts to a pain I think will be agreed: that limited form of love which is induced by an effort of will, under the persuasion that the object of it deserves our love, is very likely to be felt to be onerous.

The pleasure phase of love is, however, on the whole the emphatic phase, and evidently it is one of those cases mentioned above in which developmental laws would naturally lead us to

1 Rhetoric, Book I. chap. ix. 
look for an emphasis of the pleasure phase and an almost total lack of pain emphasis, because a continuance of lovableness among the more highly developed of our race must be of so great importance.

AxGER is the psychic coincident of that complex of instinctive reactions which if allowed full derelopment woukl lead us to proceed toward the object of anger with hostile action.

It is evident that, in a certain stage of development, anger. must have been a most protective reaction (and this stage in the long history of evolution is not so very far away), but that nowadays, among the highly civilised, it must be detrimental and no longer advantageons.

We should expect therefore to find it desired, and pleasurable in the satisfaction of desire, among those of lower development; occasionally among those of a higher class whose animal natme is predominant; and among children, who are in many respects reduplications of their savage ancestors.

The savage or brutal ruffian, and the vigorous boy, find themselves "spoiling for a fight," and make canses of contention with perfectly harmless people just for the satisfaction of fulfilled anger. ${ }^{1}$

But fortunately the day of anger emphasis is past and gone, for most cultivated people, and for them its pleasure phase is satisfied by games in which anger is simulated; by boxing, by the killing of harmless deer, grouse, or fish. With many among us anger is so invariably painful that it is found actually necessary to-day by our ethical writers to argue that there are such states as malevolent pleasures." Anger being painful leads to the avoidance of objects whieh if approached would lead to the anger reaction for our own protection, and thus loathing and contempt give place to wrath.

FEAR in pleasant phase we should not expect to find emphatsised; for evidently such emphasis would induce us to place ourselves too often in danger. Nevertheless, as Mr. Bain says, "a slight fear with speedy relief occurring in times of dulness

1 The Greeks were nearer the are in which anger was advantageous, and among them it was accounted as a well-recognised means of pleasuregretting. Honer says anger is sweeter than loney. Aristotle (Ihetoric, Book I. chap. xi.) tells us "Revenge is pleasant, for it is delightful to obtain that of which the privation is most painful, and men highly injured are tormented with the thirst of vengeance." Plato in the Philebus also speaks of the pleasure of anger.

2 Kames in his Elements of Criticism tells us that resentment is always painful. Cf. Bradley, Mind, xxxi. 
and stolid composure, acts like a stimulant of the nervous system. In the flush of high bodily vigour danger only heightens the interest of action and pursuit."

Schiller tells us "Grösse und Schreckbarkeit können also in gewissen Füllen für sich allein eine Quelle von Vergnügen abgeben."

It seems unreasonable to suggest that the frightened flight of the stag is in the beginning painful, involving as it does activities for which the animal is well prepared.

Aristotle, it will be remembered, claimed that the tragic poet had to procure pleasure from pity and fear.

$\mathrm{T}^{r} \mathrm{e}$ all "occasionally find ourselves desiring to take small risks; the gambler actually desires and finds great pleasure in what would be acutely painful fears in other men, he having encouraged the development of those conditions which make fear pleasure possible." 1

In such cases the thought of the pleasure to be obtained obscures the painfulness of the desire. Not so, however, in the notably painful state of repression of the instinetive tendencies to go away from the disadrantageous, which is known as acersion.

Aversion, the desire phase of fear, is so marked a state that we do not think at first to consider it in any respect as a fear psychosis. Of course it will not contain the major elements of fear panie,-no repressive pain does contain as its emphatic element the repressed psychoses, but the systemic elements which go with the pain as we have already seen. It does, however, contain some of the elements of fear, as its very name implies its expression to be turning away from the object that brings it into conseiousness; and, moreover, it is relieved by the instinctive fear activities.

Turning from this desire phase, Professor Bain tells us "in fictitions terrors . . . the sting of terror" is most effectually extracted." "Some minds can endure a large amount of this element, having that robustness of mind that ean throw off the pain." However, there can be no doult that "a genuine fright is an experience of pure misery." "The state of reaction or relief from terror is eharacteristic as a mode of delight." Mr. Bain thus acknowledges fear as pleasure of activity, as pain of activity, and as pleasure of relief.

1 Qnoted, I believe, from Professor Bain. My uotes here are incomplete. Cf. also Wundt, Phy. Psy., vol. i. p. 528. Here, however, the pieasure is a mixed one. 
One of the principal elements of pleasure connected with the Sublime is donbtless fear in its pleasurable phase. Awe is a less marked phase of the same condition of fear. Fear is most usually occasioned by the unknown, and by the knowledge of power beyond resistance, and these are the two principal characteristies of those objects which bring us the mental state comected with what we call sublimity.

In my own experience the psychosis of the Sublime, upon increasing the strength of the stimulus, may become changed into a veritable fear. I have noted the feeling in all its gradations in passing down into the depths of one of the grand cañons of Colorado.

Surprise is looked upon by some psychologists, e.f. Professor Bain, as a typical case of "neutral excitement" neither pleasurable nor painful, and ordinarily its algedonic quality is close to indifference; but after a monotonous humdrum life, or under conditions of moderate intensity, surprises are eviclently pleasurable. Children play with surprises; the clown's performances which delight such multitudes of adults at the circus, and the transformation scenes of the pantomime, are dependent upon surprises for the delight they give.

That people having experienced this kind of surprise-pleasure can crave it, is evident. St. Paul tells us that the Athenians spent their whole time in looking for novelties. But the pleasures of surprise lose their force rapidly, and soon the complex feeling becomes painful. We at first enjoy the spectacular show, but beyond a certain point our wonder is excited only to disgust us with its painfulness, and to be followed by a strong feeling of relief upon the cessation of the action and the reaching of a state of calm. Note in this comnection the tiresomeness of all artistic products which depend much upon startling effects, and the relief which we feel when we turn to the contemplation of those works which deal with the calmer effects of unity-effects of actual sameness sometimes, and which would often under different circumstances appear tame and monotonous.

Turning to intellectual considerations, we of course are not here called upon to diseuss processes which involve changes of content (which processes are discussed elsewhere), but alterations of conditions of stable contents where the activity of fixed organs under alterable conditions is implied.

Here the stimulus to the arisal of the content is almost completely beyond control, and the difficulty of experimentation, serious with the emotions, becomes overwhelning. 
The difficulty of the situation is increased also by the fact that when pleasure and pain become prominent, these algedonic qualities hold attention to the loss of emphasis of the differential qualities (contents) to which they are attached.

I do not think it worth while to add more on this subject to what has already been said under the headings 1 to 8 , under $\$ 11$, in the body of the chapter. 


\section{CHAP'TER VI}

\section{ALGEDONIC ESTHETICS}

\section{Introductory Summary}

Is the chapters which have preceded this we have seen that resthetics may with propriety be considered as a branch of hedonics; as being dependent directly upon pleasure laws and indirectly therefore upon the laws of pain. Hence

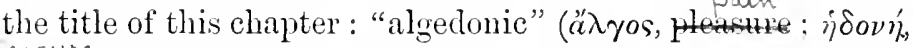
peing being used, as explained in chap. I., to cover the whole ground of pain and pleasure.

We have seen that pleasure excludes both pain and indifference, and we may, therefore, conclude that the laws of resthetics, which we shall find to be of first importance, will be-

I. Negative Esthetic Laws concerned with the exclusion of (A) pain, and of (B) indifference.

A. The cxclusion of Pain. The climination of uyliness (p. 305).

In practice, as we have seen, we have to do with two classes of pains, differentiated by diversity in means of production : $(X)$ the pains of repression, and $(Y)$ the pains of excess. We find it natural to treat each class separately.

$\mathrm{X}$. The acoidence of repressive, obstructive pains (p. 306).- 
Under this principle we are first led to consider the avoidance of shocks, which produce a very large part of the pains of ugliness. We find also that many resthetic conditions which have been defended as fundamental by theorists, but which we do not find satisfactory to us, are really negative principles, not dealing with positive effects but with the elimination of obstructive pains (p. 313 ff.). The necessity of avoiding in a work of art entphasis of elements which involve lack of harmony, uselessness, unfitress, nonconformity with type, untruth, unrest, etc., has led to the adoption of the incorrect views that harmony, or usefulness, or fitness, or conformity to type, or truth, or repose are positive principles which, if made ends in art production, will lead necessarily to rsthetic result. Pains of repression we find (p.307 f.) are not altogether to be eliminated from asthetic work; for, as we have seen in preceding chapters, they are the index of full capacity for pleasure-getting in the lines of the repressed activities; consequently, it is allowable to produce effects which bring them in their train, because we thus guide ourselves to the production of the highest pleasures in the satisfaction of the demands encouraged.

Y. The aroidance of pains of cxcess is natural (p. 319): art methods deal only with fields in which it is possible for us to divert, attention from a stimulus as soon as it begins to tire us. The importance of this avoidance is emphasised by the principle of the "golden mean" which Aristotle thought so clear a guide in asthetics.

The negative laws in general, as involved in the elimination of pain, I have enlarged upon with comparative simplicity in the body of the text (p. 320 ff.), to which I would refer the interested reader.

B. The crclusion of Indifference does not detain us, for it appears that the only means of bringing about this result, 
which is not through pain production, is by means of the excitation to pleasure. We therefore turn without further remark to

II. Positive Estuetic Laws (p. 324), under which heading we trent of the production of relatively permanent pleasure fields.

A. The attainment of pleasure itself gives us a number of important principles. Our previous discussions have shown us-

a. That pleasure may be reached by producing normal action in organs which are unusually well nourished. This we find (p. 325) leads us to emphasise the principle of contrast, which is seen to be most valuable, but not of exclusive importance, for pleasure may also be reached by other means.

$\beta$. It may be reached by artificial mutrition of organs which in the nature of the mental sequence are to be brought into activity. We have here (p. 328) the basis of the use of repression above referred to, and obtain the esthetic principles which Wit and the Lndicrous involve.

$\gamma$. An musually strong stimulus upon a normally efficient organ will also bring pleasure, and this shows us (p. 332) the importance of vividness of impression in the production of resthetic result. We find here also the explanation of the prominence given to the principle of the "unification of the manifold," which we have ahready found to be of far-reaching value, but not ultimate.

B. If our pleasure is to be asthetie, however, it must be relatively permanent; and as pleasures are evanescent, if this relative permanence is to be reached it must be through the production of $(\delta)$ a wide field over which plays $(\eta)$ a shifting focus of attention.

Consideration of $(\delta)$, width of field (p. 335), shows us the importance of summation of stimuli and of brealth of mental 
horizon. It teaches us how wide is the variety of the eluments that it is permissible to nse in order to bring æsthetic result, throngh associative combination, imaginative stimulus, and emotional irradiation. Over this vague field of moderate pleasure-getting must play $(\eta)$ the shifting focus of attention which involves (p. 339) centres of interest. We are able in this connection to account for the emphasis of definiteness in the resthetic theories of such masters as Lotze and Yolkmann.

The necessary shifting of this focus turns us again to certain principles in part or in whole already discussed. The shifting with stability of the mental elements involved brings us again to the principle of rhythm. The shifting with change of mental element gives us the valuable principles of contrast and variety.

It thus appears (p. $343 \mathrm{ff}$.) that the great artist primarily reaches out to the production of a wide non-painful field by the elimination of ugliness. Beyond this, however, he must go, bringing into existence a broad field of moderate pleasuregetting withont permitting the loss of those centres of interest which are supreme for him, and which make his work of art ideal and individual.

\section{Technical Treatment}

$\$ 1$. In earlier chapters I have endearoured to show that the hedonic element is all-important in the consideration of resthetics; a position which I think holds even if my hypothesis as to the differentiation of asthetics from hedonics be rejected. If this position be correct, and if the view which I uphold as to the psychology of pleasure be a true one, it should be possible to deduce certain general laws of resthetic practice from a consideration of the conditions upon which pleasure-getting depends. It should also be possible, in some cases at least, to discover the psychological bases 
upon which have been built the resthetic theories which we have found it necessary to reject, although taught by high authorities. If effort in this direction meet with any degree of success we shall gain not only strong corroboration of the hedonic-resthetic theory, but also an effective argument for the pleasure-pain theory which I have elsewhere defended.

The hedonic-resthetic theory may be succinctly stated as follows:-The beautiful is that in nature or in the activities or the productions of man which produces effects in us that are (relatively) permanently pleasurable in revival. The ugly, on the contrary, is that which produces effects of (relatively) permanent painfulness in revival. If a natural object or the production of the artist is to be effective as an resthetic object, it must bring not only pleasure by its mere presentation, but, more than that, it must result in the production of pleasurable revivals, which will coalesce with that field of pleasurable revival which in reflection we call our resthetic field. The artist must employ all means which lead to the attainment of immediate pleasures so far as these are compatible with the production of pleasures in revival. He may add much in the way of mere presentative pleasure which may or may not bring us pleasurable effect in revival, and all such added pleasure in presentation is a gain to the work as art, provided it neither brings pain in revival nor swamps with resulting indifference the revivals which are pleasurable. He may even go further and add elements which give decided painfulness in the direct presentation produced by the examination of the art work, provided the result in revival is on this account made more permanently pleasurable. He may even use pains of restriction, in either presentation or revival, in moderation, if they are treated as indices of fulness of pleasure to be reached when the restrictions are removed.

Even in the mere examination of art works we must take 
account of revival fields ; for we lose much if we restrict our attention either to the detail or to the mere totality before us. Unless we allow the play of revivals to have full sway our best enjoyment is gone.

While pleasures in primary presentation therefore are important, the pleasures of revival are of pre-eninent moment in resthetic consideration.

To some the separation of the fields of pleasurable "presentation" and revival may seem to involve confusions dangerous for hedonic-æsthetic theory. I think, however, this difficulty disappears entirely if one holds clearly to the implications of the pleasure-pain theory which I defend; for under that theory it matters not what is the content which is pleasurable, whether it be of primary "presentation," or of revival, the conditions of the pleasure production must always be the same. Our task, therefore, amounts simply to a consideration of the means to be adopted to produce a pleasure field of relative permanency.

The theory of pleasure-pain which I defend may, in psychological terms, read as follows:-Given a mental sequence $a-\beta-\gamma$; the content $(\beta)$ is pleasurable (or painful) when it is causal to a resultant $(\gamma)$ of psychic fuhness greater (or less) than that habitually produced by the appearance of the content (a) which is cansal to its own ( $\beta$ 's) appearance.

[If we express this in physiological language we lave: Pleasure is connected with the activity of an oryan when the activity involves a giving ont of surplus stored force-that is, of more stored force than is necessary for its habitual functioning, under the stimnlus received.

Pain is connected with the activity of an organ when that activity involves inherently less outgo than is habitual under the stimulus received.]

Under this theory, in this respect corroborated, I think, 
by the argument of Chaps. IV. and $V$., two points are clear :

1st, Pain is incompatible with pleasure. With a given content, the conditions which involve pain must be absent if the conditions which involve pleasure are present.

2nd, There is a field of non-pleasure, which is also not painful, viz. the so-called field of indifference, which, while theoretically extremely narrow, is practically wide in extent.

It is evident that both of these fields are to be avoided before we can reach pleasure with any given set of contents. The field of pain must be entirely elininated unless its occurrence is useful for pleasure production to follow; that of indifference must be suppressed so far as is necessary to avoid the overwhelming of the pleasurable contents by those which do not interest us.

\section{Part I. Negative Esthetic Laws}

$\$ 2$. It is evident from what I have just said that we may treat as the first principle of resthetics-

The Exclusion of Pain-the Elimination of the

UGLY

In what has preceded we have seen that there are practically two great classes of pains. 1st, the pains produced by repression of activities; and 2 nd, the pains produced by excess of active functioning.

I have already shown, I think, that in all probability the first class must be referred to the second - active functioning apparently being necessary to pain of any lind. As a matter of practical experience, however, we find two means by which we may produce pain, viz. by the repression of activities and by the hypernormal stimulation of activities. 
This fact, which doubtless has prevented the earlier recognition of the common basis of all pains, makes the current distinction between the two classes of pain perfectly legitimate for us who are here concerned with methods of pain production. We may, therefore, properly divide our first principle into two subsidiary ones-A, the avoidance of repressive pains; and $\mathrm{B}$, the prevention of pains of excessive functioning.

\section{A. The Avoidance of Repressive Pains}

$\S 3$. Repressive pains are caused by the failure in consciousness of a content which would normally have appeared. This may happen as follows :-1st, Where contents habitually arise in any rhythmical manner in answer to stimuli, repressive pain will be engendered if the stimuli fail to appear at the usual time. 2nd, Repressive pains will appear if contents arise which would normally act as stimulants to a content $x$, this content $x$ failing to appear. 3rd, Where contents often appear in definite relations of succession, repressive pains will be engendered whenever the usual order of their rise is not fulfilled. 4th, It may be noted that the existence of repressive pains is an indication that the content which fails would appear pleasurably if it appeared at all.

[In terms of my physiological hypothesis, these propositions may be stated as follows:- The inhibition of functioning for which an organ is very fully prepared is the basis of the pains of repression. 1st, Organs which habitually act in any sort of rhythmical manner attain a normal capacity for action at the moment of the habitual rhythmic return of the stimulus. If this stimulus be inhibited we shall have the conditions of repressive pain. 2nd, Again, if by any means the capacity for action of a given organ be brought to a maximum and the stimuli to the nutrition of the organ be continued, unless action of the organ supervenes, we shall have also the conditions of repressive pains. 3rd, Where organs or groups of organs are 
often called into activity in definite relations of succession, the nutritive processes, so far as we can see, must become so connected that the activity of the first element of a series will affect the readiness for activity, i.e. the nutritive condition, of the elements which have ordinarily acted in the successive order, so that as they are stimulated in their order they may be able to react effectively to the stimulus received. If this usual order of stimulation be not fulfilled, we shall have again the conditions of repressive pain. 4th, The existence of the repressive pain is a mark of a condition which will bring the fullest pleasure in case the inhibited activity is not too long delayed.]

1. Those repressive pains included in the first class above mentioned are induced only by the production of abnormal conditions, and in a search for means towards pleasure production, such as resthetics is held to involve, we should expect to find them naturally avoided. No one who desired to produce an resthetic work would think of giving it such form that its appreciation would be dependent upon the holding of one's breath or upon the existence of the mental states which we experience when we hunger or thirst.

2. The second point made above in reference to repressive yains would seem to teach that the artist must in general avoid the stimulation of cravings which cannot be satisfied, the production of desires which are impossible of fulfilment, the suggestion of lines of thoughts which cannot be completed. It is not apparent, at the first glance, that any such canon of practice is recognised by artists or critics. Indeed, on the contrary, many works of art which we all agree to be of the highest order of excellence are distinctly felt to produce these longings of a dull and indefinite sort. When we consider the matter closely, however, we see why no such rule is acknowledged, for it is evident that these pains will be admissible, in a way, provided the observer's thought is thereby turned in new directions of pleasure-getting. It will be admitted, I think, that it cannot be the proper aim of an artist to induce strong cravings - intense desires-fieree passion. It cannot 
CHAP.

be forgotten that as long ago as Aristotle the power of artistic work was felt to lie largely in its capacity to dispel the passions, to purify the objective through the ideal. Those art works which evidently induce lesser unsatisfiable longings, as of love and pity, or which bring desire for what is unattained or at the moment unattainable, gain their power, it would seem, not through the pain so much as by the flow of sympathetic activity which is produced, or by the impulses which are awakened, or by the revival of old-time thoughts which in their wide reaches are ever delightful. It is in reflection that we are most powerfully affected by these works of art. As we, in revival, view the mental state which was induced by their study, we feel the sympathetic delights which give them worth, or we see that they brought to us impulses that we hold to be of highest ethical value, and which it must always give us the deepest satisfaction to feel that we have possessed. With the bitterest pains of repression, we contemplate the portrait of one whom we have loved but lost; and yet, with the pains, are aroused so many trains of memory which tell of joy, that we return again and again to the contemplation. We would not give up the pains, for without them were impossible the renewal of other deep satisfactions.

4. While speaking of these pains of repression which lead to pleasures, we may appropriately bring forward ont of its numerical order the fourth point made above.

If the pain of craving can finally be replaced by the pleasures of its satisfaction, it is apparent that the pains of repression within limits may be encouraged by art workers, for the very sake of the after effects of pleasure to be obtained. The pains of repressed activity indicate, as we have seen, an organic condition of full preparedness, so that if action supervenes it will bring the highest degree of pleasure that can be induced by the organ's activity. These repression pains may, therefore, be taken as the index of pleasure capacity, and we 
may expect them within limits to be used by the artist, because thereby he will gain certainty that the pleasure limits have been attained, and that a full pleasure will accompany the action which is to follow the repressal.

Dependent as such transformations from pain to pleasure are upon the succession of psychic states, we should look for notable practical exemplifications of them in arts which deal especially with phenomena of succession: in music and in literature. In music we have example in the delayed resolntion of a chord which is allowable even to the point of painfulness. In literary work we have example in those everyday complications of plot which delay the consummation longed for, and finally reached. Schiller, speaking of tragedy, tells us that "the highest degree of moral pleasure cannot make itself felt except in conflict. It follows hence that the highest degree of pleasure must always be accompanied by pain." The principle is one of wide import in all branches of resthetics, and here I think we have its basis; for, as we have seen, organic rest is a most important condition of pleasure production. How are we to gain knowledge that we have reached full capacity for organic functioning unless we wait on the systemic pain which comes after the absorption of energy has reached its maximum?

We have here also the psychologic basis of many a metaphysical theory of the relation of the ugly to the beautiful, and of the value of the presentation of ugliness as an element in the beautiful; as instances of which we may note Schlegel's dictum that the principle of modern art can only be found if beauty and the characteristic ugly be indissolubly connected; and Rosenkranz's statement of the Aristotelian notion that the artistic genius finds the highest triumph of his art where he represents the ugly objectified, and beauty all-powerful through triumph over evil. Ethical notions and metaphysical conceptions here lead us away from psy- 
chology proper; and this is not permissible for us in this discussion.

3. The third class of repressive pains, to which we now return, will evidently be of not infrequent occurrence, for they depend upon combinations in varied orders which are easily alterable, and which, on the other hand, are grasped with such difficulty that we cannot expect to find repressive conflicts avoided. We should, therefore, expect to find some recognition of occurrence of these pains and some general attempt at their avoidance in rsthetic theory and practice. It is these pains which make up the very usual form of ugliness which is determined by the combinational effect of many disappointments of expectancy, ${ }^{1}$ each painful, in too small a degree, indeed, to be emphatically presented, but for all that, helping to make up an aggregate of undefinable but emphatic disagreeableness. In one of his interesting and suggestive studies ${ }^{2}$ Schiller tells us that "beauty can tolerate nothing abrupt nor violent." In other words, if an object is to appear beautiful to us it must not bring to us shocks of any kind. The lines - the forms-the colours-the sounds which we find in nature, resultant as they are from the influence of cosmic forces in conjunction with growth, bring to us certain arrangements of stimuli, which, though complex beyond our powers of analysis, must mould our nervous system into preparation for the reception of stimuli in corresponding orders and arrangements; and this in psychological terms means the production of a tendency to the rise of certain special contents in special orders and relations to one another.

If, then, nature presents to us, as she does, with relative infrequency, objects which bring stimuli in relations contrary to those in accord with which our systems have been moulded, we should expect to note just such shocks of repressive pain

1 Cf. Hutcheson.

2 Zerstrente Beobachtungen, p. 86. 
as nature's monsters produce in us, quite apart from the active pains (of aversion or fear, e.g.) which they may superinduce.

In our productive work, it clearly would be indicative of an intelligence far above that which we possess if we did not find ourselves too often bringing about combinations of stimuli which violate the order that nature has impressed upon us.

The reader will understand from the previous chapters how it is possible for a person to gain "an acquired taste" (an acquired pleasure capacity) which will in the end make these unnatural forms not unpleasant and even enjoyable through appreciation of other values than those which are natural.

Illustrations here crowd upon us. All of nature's lines are affected by the power of gravitation. It seems clear to me that the relative grace of the suspension bridge and of the cantilever truss is principally determined by the fact that the catenary curve in the one case presents to us nature's pendent form, while the strutted extensions of the cantilever bring to us other lines than those in accord with which she has educated us. As one's eye follows the lines of the truss, natural organic combinations bring preparation for action in certain directions. But the stimuli to these activities fail when the abrupt and rigid lines break off in directions which nature has never given us; the shocks of repressive pain that result, produce that sense of discomfort which we express by calling the work ugly. One who stands by the brink of Niagara, with its ever-flowing lesson in the curves of gravity, cannot help feeling strongly that the lines of the suspension bridges are in satisfactory harmony with the scene, but that the cantilever bridge makes a blot upon the landscape as unfortunate as the rigid forms of the factories built upon the river's bank. It seems to me that the beauty of the rocket's 
flight is also largely determined by the submission of its movement to the laws of gravity.

The same principle may be recognised in visible forms quite apart from their contour lines. The relations of the parts in the human figure vary in an indefinite number of small ways, but any marked disproportion of parts at once gives us the shock of ugliness. It is comparatively seldom that nature brings these positive shocks, although often the men and women we meet show little of beauty. In the creative representations of man, however, nothing is easier than to produce such misemphasis of relations, and such unnaturalness that ugliness in whole or in part is induced.

Even more delicate are the relations of colours. "Is it not strange," a lover of flowers once said to me, "that nature does not give ugly combinations of flowers when it is so easy for us to combine them in an unsatisfactory manner?" This commonplace observation teaches the doctrine here discussed. Nature, through the influence of the prehistoric past, has been our teacher, and to nature's colourings we must go to learn what combinations to make use of in our work of re-arrangement, and, if we may so speak, of re-creation. If we break away too far from her guidance we have our punishment in the shock of perceived ugliness.

When we turn to sound relations we recognise the disagreeableness of sudden changes from the habitual movements in music, if, for example, some unskilled performer strikes an incorrect note in a known progression, or if the development of a harmony be broken by an erroneous chord.

Here we find ourselves prepared to step away from nature's teachings to the more complex regions of mental effort which depend upon habits artificially formed, if we may so speak, in the process of development. The principle will be recognised as the same, however, whether the pain be caused by breaks away from habitual combinations produced by 
nature's wider and racial, or by more narrow and individual, influences.

The related forms which our race through many generations of experience has learned to feel to be most satisfactory, cannot be lightly disturbed withont producing painful distraction. This we all feel in those lines on which practice enables us to judge with discrimination. The mere novice objects to a Gothic window in what purports to be a "classic" building. The more highly educated student at once revolts against a façade of Corinthian detail massed in Doric proportions or with Ionic intercolumniation; and this is due to the fact that he has learned by observation how these special parts have been best related by the long study of successive generations in the past. The work of one who disregards this racial experience lrings to the expert a shock which for him makes resthetic delight impossible.

So it is with the purist's judgment in all art work. Habit here, as in all of life, dominates us, and perhaps the greatest danger which the critical student has to guard against is that of the artificial creation in himself of petty standards which, when shocked, give a sense of ugliness sufficiently predominant to prevent the appreciation of wider beauties. It is worth noting here that one of the greatest obstacles to resthetic advance is found in this capacity to form artificial standards. We "get used" to forms which are intrinsically bad, and which at one time shocked us; gain such habits of thought in relation to them that they shock us no longer, and thus we are led not only to tolerate what can never show any positive beauty, but even to feel revolt against change produced by the shock which that change induces.

$\S 4$. We are here brought to the consideration of certain negative principles of great importance, which in a number 
of cases we shall find have already been recognised, but erroneously, I think, as positive teachings of the contraries of those principles which should rightly be emphasised. We are all too ready to fall into logical pitfalls connected with incorrect use of complementary opposites. Experience tells us that we must avoid not $x$ if we are to produce a beautiful object; $x$ therefore is fixed upon as the basis of beauty. ${ }^{1}$

It is clear, after what has just been said, that were we to start out from a theoretical basis we should be inclined to hold that our safest course of procedure would be to imitate nature; sifting out her especial beauties, or recombining her elements, so that (relatively) permanent pleasure would result for us. In fact it appears that this is what the great mass of our artists in almost all lines of effort do to-day, and what they always have done; and this observation doubtless led Aristotle to look at imitation as so important a principle of art. It is apparent, however, that it is a means to an end merely, and that it is not possible to make it fundamental for all art, as some of Aristotle's followers, upholding the principle by strained interpretations of the meaning of "imitation," would have us believe he intended to make it. It appears to me that it is a principle of importance rather negatively than positively. It guides us in the direction in which beauty will be found, and far outside of which it cannot be found; but that it gives us a positive basis for the production of rsthetic result, I think untrue, as must be evident to any one who does not exclude architecture from the realm of rsthetics, as Aristotle apparently did.

Other examples of the same illicit procedure and of the consequent misnaming of principles are not wanting, some of which deserve mention.

1 Cf. Hyslop, Elements of Logic, 2nd edit., end of chap. x., for a clear statement of this fallacy. 
Freedom from shocks implies avoidanee of inharmonious relations, and perhaps it is not surprising that the observation of this should have raised Harmony to the dignity of a first principle, notwithstanding that the most cursory examination must show any unprejudiced person that we are fairly enveloped in a world of harmonies, which give us no æsthetic result at all. So again uselessness, unfitness, abnormal departure from type, must be eliminated if painful shocks are to be avoided, and without such avoidance no effect of beauty can be obtained. From this source, it seems to me, have arisen the doctrines of the relation to the rsthetic of Usefulness, ${ }^{1}$ of the importance of Fitness, ${ }^{2}$ of the necessity of Conformity to Type. ${ }^{3}$ No egregious departures from our typical standards, no marked unfitness in the object presented, nor any emphases of qualities which are hurtfully useless, are possible without producing this pain. But it is as far as possible from the truth to hold that departures from normal types within limits are non-resthetic; on the contrary, it is just such departures which add piquancy to much which we admire. It is equally misleading to argue that the nonuseful cannot be beautiful, or, as is more often the case, to overestimate the importance of the recognition of the useful in given resthetic fields. So far as the useful can be considered as a positive principle, it is covered by the principle of the summation of associative pleasures.

An illustration of my contention may be found in that treatment of gracefulness, adopted by Mr. Herbert Spencer, which makes its delights dependent upon adaptation to ends. Grace withont this adaptation is, of course, unattainable, but that is merely a negative description of its field. If his posi-

1 Cf. Buffier, c.g.

2 Sir Joshua Reynolds, e.g.

${ }^{3}$ E.g. Sir C. Bell. Ruskin also counts bcauty of type as a notable category. Cp. Leslie Stephen's Science of Ethics, p. 76. 
tion were correct we should be compelled to grant the quality of gracefulness to a perfectly ordered machine, and to shut out most important elements which have no relation to fitness whatever, e.g. the delight which we gain from those flowing curves which our retentiveness pictures for us in and through movements, the sympathetic pleasures which Schiller has described as dependent upon "beanty of form under the influence of freedom," " without appearance of the strife and conflict which willed actions entail ; and we should be forced to leave out of account many other elements of associative worth.

Perceived nsefulness in like mamer has been made the essential point in architecture. Usefulness truly becomes more important in this than in other arts, not, however, per se, but through the strong emphasis of the painfulness of each useless feature which exists to the detriment of the whole. It is probable that the superior pleasure obtained from ancient works of architecture is in some degree due to the fact that they have lost their capacity to shock through opposition to the immediate needs. The limitations of human capacity are so great that shocks of this kind are forced upon us in every newly constructed building made to serve some distinct purpose, however great be the skill of the designer. To be sure each use may add to the complex pleasures of activities associated with the use, and these associative pleasures will be cut off in disappointment pains, when the lack of this usefulness is noticed; but here again it is the non-æsthetic effect of the non-useful and not the rsthetic effect of the useful which tells, and which forms the basis of the so-called principle.

Mr. Spencer also holds, as Emerson held before him, that the useful tends to become beautiful; but so far as this is true it is not becanse of the usefulness per se; it seems much

1 Armuth und Würde, p. 17. 
more naturally explicable as one of the phenomena of habit; for, as we have seen, in a great class of cases actions which have become habitual gain for themselves pleasure capacities either directly or associatively. Another point made by $\mathrm{Mr}$. Spencer seems to illustrate our contention. Style, he thinks, depends upon the reduction of friction to a minimum in the chosen vehicle. ${ }^{1}$ But surely this is merely a negative principle, a condition preliminary to the use of those satisfactory forms which mark a good style in whatever material the artist works.

Turning in another direction, it appears that the doctrine which makes the expression of truth an essential principle of art has a similar negative basis. Untruth, in all the arts, is a sonrce of great dissatisfaction. This is markedly the case with architectural forms, where better education teaches the observer the natural action of constructional elements, and creates measiness muless there is evidence of their consideration in the building up of the masses. It is natural, therefore, that we find the principle of "truth" constantly reiterated as an especially valuable dictum of architectural rsthetics; but for all that the real principle is the "avoidance of untruth."

Here we may mention the demand for repose in architecture and in the plastic arts in general as another negative principle, founded in this case upon our appreciation of nature's law of gravity. Repose per se will not bring us asthetic joy, but without it, in the cases cited, beanty cannot be reached. The building must be felt as stable, the human figure must "stand upon its feet," or be poised in a position it conld occupy in nature without continued strain; but these con-

${ }^{1}$ Cf. also Guyau, Essais de l'Esth. contemporaine. 
ditions may well be fulfilled without result of resthetic moment.

Let me illustrate this general point once again. Growth is a law of nature. Everywhere around us we see forms which are of marked type indeed, but which present evidences of developing change in non-essentials. Art works which present evidence of such growth gain great power through the sympathetic harmony with nature and with our own developing selves. The evidence of this verisimilitude of life, perhaps unanalysed and not definitely recognised, probably adds much, for example, to the attractiveness of the Gothic cathedral, and emphasises the poetry of the structures of Northern Italy. Musical forms also are especially fertile in producing those living effects. Music which is mechanically produced can never be satisfactory.

But surely it is not in evidence that the expression of growth or of life can be held to be the fundamental in æsthetics, ${ }^{1}$ as some would have us believe. At the most, the effects produced by the representation of these qualities can be but an adjunct to other means of impression. For certain people, however, who become accustomed to look for them, they may be demanded when absent, for the purpose of eliminating a painful need, and may thus become for them necessary to resthetic result: this, however, shows no proof that they are the essential to resthetic effect in general.

The unities which the Greeks made so essential in the development of the drama gain their force negatively, for without such unities distractions must be felt from the line of thought in which the poet would guide his hearer. That this is true is shown by the lessened demand felt for the unities of time and place in the drama of modern times; for, through historical study, the grasp of eras has become as common to-day as that of individual lives; and, with us,

${ }^{1}$ Cf. Guyau, L'At sur p. d. v. Sociologique, p. 75, et al. 
movements from place to place, widely separated, are matters of usual occurrence.

$\S 5$. We now come to the second division of our principle in

\section{B. The Avoidance of Pains of Excessive Functioning ${ }^{1}$}

So important is this avoidance that works of art are in all cases developed on lines in which excesses may be shunnerl with little difficulty. So soon as the work of the artist begins to tire us we must be able to turn away from its consideration. The stimulus given must directly or indirectly be under our control, so that we may grasp the opportunity for enjoyment when, and only when, we are in the mood for the special pleasures involved. ${ }^{2}$ There is no more certain manner of destroying our appreciation of any special art work, that is, of making it non-resthetic for us, than by compelling attention to it when we are weary in the direction of its peculiar stimulus.

As we have seen, a certain class of repressive pains are naturally avoided, and with pains of hypernormal activity nature aids us also very materially, for we tend automatically to prevent excess by the shifting of attention. Concentration and permanence of attention upon one subject are certain to become speedily painful; indeed, because of the reflex effort towards avoidance, they are, strictly speaking, normally impossible, except by means of a cultivated habit, and then only through the artifice of "looking around the subject," so to speak-of allowing the various details to be viewed in the mental focus without letting go the primal theme which is

1 These pains, as we have seen in the preceding discussions, are caused by stimulation to activities for which an organ is not prepared.

${ }^{2}$ Cf. Sully, Possibility of a Science of .Esthetics; Fechner, Vor.d. LEs.s. vol. ii. p. 55. 
held in associative trains. As avoidance of pains of this type is comparatively easy and almost automatic, it is natural to find that theoretic consideration has dealt less with them than with those repressive pains, not naturally avoided, which are the result of unexpectedly-encountered pitfalls, only to be missed by much prevision. That excesses must be shunned is taken for granted. This is the principle involved in Aristotle's emphasis of the necessity of adopting a mean between extremes.

$\S 6$. Taking the realm of pain as a whole, we may state our principle as that of "the avoidance of the ugly," as we have done at the opening of this section. It is by this process that the artist gains the broad background which he must win before he can realise his ideal of beauty. His results must give many a pleasurable element, and, as we shall presently see, some special points of intense interest, but he cannot hope to make the wide mental field which his work arouses altogether pleasurable; the most that he can hope for is that it shall be devoid of elements of possible painfulness.

The importance of the principle will be acknowledged when it is considered that special interest in the work of art as at first presented may very easily blind one to many elements in the work. If these latter are displeasing they will become effective to cast the work out of the realm of resthetics as soon as the intenser interests pall upon us.

All men naturally follow out this maxim, and it is mainly through accumulation of such eliminations of ugliness that our standards of artistic excellence have been reached. On general lines the bad has been sifted out or allowed to fall into the background as time has passed, and the noble and beautiful has been left unaltered because it has been felt too satisfactory to require change.

The possibility of making these eliminations is curtailed 
by everything which tends to emphasise fixity. The rules of the schools, valuable as aids to the student, always carry with them the danger of repression of "the elimination of ugliness." Note how the rules of counterpoint stood in opposition to the development of music; how the establishment of the "orders" in Roman architecture struck the life out of the Greek architectural development; how the dictionary thwarts the natural development of euphony in language.

Most of us are wont thoughtlessly to look back at the architectural forms of Greece as the creation of her golden age. But it is clear to the student that those splendid achievements embody the thought of many generations, and even of diverse races, rather than that of a special era of a few generations' continuance. Generation after generation had felt the same needs in their worship, had built and rebuilt temples as their inferior materials and workmanship, or the more actively destructive forces of nature, compelled. Each new work had made it possible to eliminate some form which had been displeasing in the last effort, to alter some unsatisfactory surface, to change some deficient shadow depth. In the final results we see the record of untold endeavour towards the attainment of beauty, mainly successful because time and experiment have effected the complete elimination of the ugly. The growth of Gothic forms, of which we have better knowledge, tells the same story of experiment and partial failure; of renewed effort with avoidance of the elements which made the last work unsatisfactory; until we reach the glory of the best Gothic, less perfeet than the Greek indeed, as it expressed the demand of a race impelled by less unity of feeling, and as its growth was forced within the relatively short period of perhaps a thousand years.

Too great difficulty of applying eliminative experiment 
may indeed be looked upon as a bar to development. The Egyptians, to whom the expression of permanence seems to have given the greatest satisfaction, built in such ponderous material and so durably that change of form for them was a matter of far greater difficulty than with the Greeks, whose materials were far less permanent and much more easily worked. This difference doubtless accounts largely for the fact that we find Greece in a relatively short time gaining possession of such a flower of architectural art as had failed to spring from the stem that had grown for long ages in the climes of Northern Africa. It is no little comfort to us in these restless times to see how few of our buildings are constructed to last in the future. If, with our changing needs, we have little ability to develop an architectural art, at least our descendants will not fear to sweep the greater part of our work from the face of the earth.

We see the main principle enunciated, again, in our own times and in our own homes. Comparatively few of us can fill our homes with objects which remain for us, or for our friends, permanently beantiful. We may be able to have a gem here or there, but that is all. Still we may avoid "shocks," and in that avoidance lies much of the power of a cultivated mind in architect or householder. To this is surely due the beauty which grows into the homes of those whose culture is handed down with the building that passes from one generation of refined people to another. The inhabitants learn to brush away the "shocks." The inharmonious lines and forms are covered; the harmonious lines and forms are retained; gradually and unwittingly they mould their surroundings to relations which do not clash; and in such an environment the smallest beanties tell.

In looking over other art fields, where the medium of expression has been in less permanent material, it is difficult to realise how much work has been done which has been 
east aside becanse of inferior worth, has been allowed to deteriorate, and thus has been lost. It were much more difficult did we not realise that our race is in the main not far removed from those that time has swept away before us, and did we not see this process of production and elimination going on around us to-day. Practically a vast proportion of the pictures preserved in the great galleries of Europe have been eliminated from the resthetic. WVe go to these vast treasuries to study a few pieces of work; all the others are passed by as if they did not exist. If we conld reproduce the sudden barbaric intrusions of the past, it is easy to see that the few precions gems which time has tanght us to value supremely would be hurried off to places of safety, while all else might readily be eliminated by vandal destruction or neglect.

It is evident, of course, that the attainment of an nupainful background in itself will not suffice to bring about asthetic result. Not only must the artist avoid pain in indifference, bnt before gaining the pleasure field he must move beyond this field of indifference. This brings us to our second division (p. 305), which, however, we may pass over lightly, for indifference may be avoided only in the directions of pain and pleasure. Pain, as we have seen, is also to be avoided by the artist. The attaimment of pleasure is, therefore, the only means by which we can step away from indifference in a direction that will be not uncsthetic, and we are at once brought to the consideration of the positive field of resthetics, to which we now turn. 


\section{Part II. Positive Esthetic Laws}

$\S 7$. The problem before us here is to discover the means necessary to the production of a pleasure ficld which shall be relatively permanent. It will be convenient in our discussion to treat separately (1st) the production of pleasure itself, before considering (2nd) the means used to the attainment of permaneney of pleasure field.

I. In what has preceded this we have seen that all pleasure is dependent upon the rise into consciousness of contents which are coincidents of action in well-prepared organs; i.e. that pleasure occurs whenever the stimulus affecting an organ occasions the use of surplus stored foree. From this theory we may make the following deductions: Pleasure arises-

A. When there appears in consciousness a content which has before appeared but which has been lately absent, because no stimulus to its production has arisen.

B. When a content appears after inhibition of its normal appearance.

C. When a content appears with unusual vividness after normal absence from consciousness.

[In physiological terms these propositions may be stated as follows :-Storage of force is attained by rest from activity. The preparation to act efficiently involves time; recuperative processes are in the main less rapid than are those involved when action takes place in answer to a stimulus from without. All organs, however, have surplus power which is not brought into activity under normal conditions, but which may be brought into use under hypernormal stimulus with only normal nutritive conditions. It appears, therefore, that the use of stored force may be reached-

A. By the stimulation of organs, which having been long rested have gained great potential efficiency, so that a stimulus, 
normal or very little above the normal, will bring fully into action their surplus stored energy.

B. By the artificial nutrition of organs which are to be ealled into aetion.

C. By a deeicled hypernormality of activity for a short time after merely normal rest.]

It is, of course, evident that these methods of pleasure production may be used coincidentally, but it is desirable for us here to treat them in isolation.

The pleasures of rest after labour, or relief from pain, as we have ahready seen, although really to be considered as a sub-class under the pleasures of activity, are in practice separable from them, because they are reached in practice by distinct methods. Unquestionably use is made of them in the arts which deal with phenomena of succession. No slight pleasure is it that we obtain in music by the introduction of a calm restful movement following upon a train of intense and vigorous passages calling for our active attention. But on the whole these pleasures do not form an element of marked importance in resthetic work, especially because they are so dependent upon the existence of, and are inseparably connected with, anterior pains. We may pass on, therefore, without further examination in this direction.

A. The first point made above gives us the widely recognised asthetic principle of contrast. Contrast in any region of mental effect involves the presence of contents which have not been in consciousness in the late past.

[This involves the action of organs which have not been functioning lately. Gradations in sense eflect or in thought transitions are mental movements which imply the gradual coming into action of the organs which are successively the centres of activity. Contrast eliminates all gradations; it involves the action of organs, which through mere rest have become well prepared for activity, and which, therefore, prockuce pleasurable activity when stimulated.] 
That contrast per se is always pleasurable may not be granted by some who recall disagreeable "contrasts" of colour for instance $;^{1}$ the apparent exceptions, however, are in part explicable as dne to connected association with vague painful contents, but in most cases are really not to be called contrasts at all in the sense of my definition, for they cannot be shown to be shiftings to entirely new contents.

That contrast is an important æsthetic principle is recognised by all; indeed, it is not infrequently over-valned, e.g. by Mr. Herbert Spencer, who calls it an essential requisite to all beanty. But our theory would teach that contrasts are not resthetic essentials, because pleasure can be reached without contrast by mere increase of vividness. Still it must be granted that the principle is of the widest application, and a most available one for the guidance of the artist. Very strong contrasts, however, must be used with the greatest caution ; they give powerful effects, but are rapidly exhaustive, and, therefore, must in general be avoided. To this we refer later under the consideration of permanency.

I an not able to follow Fechner and other thinkers of authority in holding that there is a law of contrast for pleasure and pain per se apart from the contents to which the algedonic qualities are attached.

Fechner ${ }^{2}$ states such a "principle" and makes it of importance. He expresses it thus: "Pleasure experiences bring more pleasure the more they come in contrast with experiences of pain or less pleasure; a corresponding position being true for pains."

This "principle" might have a strong foundation if our experience told us that our greatest pleasures were always those that follow pain, or our greatest pains invariably those

1 Cf. Rood, Modern. Chromatics, especially chapters on contrast and colour combinations.

2 Vorschule a. Estheties, ii. p. 232. 
that follow pleasure. But this is not in accord with experience. The agony of angina pectoris may strike a man who is in the indifferent state of sleep unconscionsness. The joypleasure of meeting an unlooked-for acquaintance may come to one who is thoroughly indifferent, and so far as I can see there is no ground whatever for a statement that the angina pectoris would have given keener anguish had the patient been enjoying himself when it arose, nor for a statement that the joy would have been a higher dolight had the previous psychosis been one of toothache.

It is true that some, and indeed a large proportion, of our vivid pleasures follow craving pains, and also that the pleasures of relief from pain are very marked, and that many pains follow excessive pleasures; but the most that we can properly hold, it seems to me, is that in some cases the algedonic sequence appects to alter the algedonic resultant.

What ground indeed have I to say that the pain I am now experiencing would have been greater had it been preceeded by a pleasure, as it was not?

If I can legitimately make such a statement, it must be that I can hold in revival a past state of this kind of pain which did follow pleasure, and can compare it in intensity with the present state of pain that has not followed pleasure; and who would dare to say that he could make such a delicate introspective comparison? For, to claim such ability, we have to assume either that we have a fixed standard apart from thenselves by which to measure pleasures or pains-a position which I do not think would be seriously defended -or that the revived pleasure or pain retains its intensity sufficiently for purposes of comparison, which I think also an indefensible position.

The most that can be claimed, it appears to me, is that by reviving a painful presentation free from a preeeding 
pleasure, and then reviving it as following a pleasurable presentation, we find the pain increasing in intensity. But if we turn to introspection I do not think the law is obviously true. I am not able to convince myself, for instance, that the "representation" of the taste of quinine when I have just had sugar in my mouth is more painful than the "representation" of the same taste of quinine without the sugar taste preceding it. On the whole, I think the represented badness of the taste in the first case is somewhat lessened by the represented remaining sweetness.

How then can we account for the fact that the "principle" is defended? Possibly because of the unnoticed identification of pleasure and pain with sensations, which do contrast as we have seen. More probably because of the common identification of pleasure and pain with emotion, for it is certain that the emotional reaction that follows pain experience is a psychosis that contrasts with that which follows pleasure experience, as the psychic elements of hate and fear (aversion) are in contrast with those of love; and it is true, as would be expected, that the emotional reaction following pain occurring after that following pleasure is more emphatic than it would have been had there been no emotional reaction from pleasure preceding it; and similarly (mutatis mutandis) of pleasure following pain.

In truth, I think, upon careful examination, all the facts presented by Fechner and others in support of the law of algedonic contrast will be found to resolve themselves into cases of the contrast of certain contents to which the algedonic phases are attached, or to which they give rise.

B. The pleasurable appearance of contents after inhibition of their normal occurrence has been already incidentally discussed in considering the repression of activities, and we need give no space here, therefore, to this means of the attainment of a full pleasure field. The principle before us 
becomes important, however, in another direction. If there arise, by suggestion from the expressions of another, trains of thought which are normally connected with other secondary trains, but if by skilful management the arousal of these secondary trains be prevented, then we have a condition of artificial inhibition which will result in pleasure-getting whenever the secondary trains are allowed to appear.

[In physiological language this may be spoken of as artificiul. nutrition of organs which are to be called into action; for the normal connection between the primary and secondary trains implies connections between the stimuli which bring nutrition to the organs involved in the presentation of the two trains. The temporary inhibition of the secondary trains, therefore, implies a gain of nutrition in the organs of the secondary trains without the use of the energy accumulated.]

Such it seems to me is the process in the delicate play of wit.

In what is usually called the "ludicrous" we use this means, although much of the effect in such cases is dependent upon sudden transitions, in the lines of ordinary association, from mental processes which involve effort to more habitual processes where the same energy will produce greater effects, i.e. hypernormal stimulation.

It is not desirable to argue this point here at length, for such argument would carry us too far from our line of thought. While other sources of pleasure-getting are made use of in various ways together with the action above described, I think it can be shown that this is the characteristic movement in what is usually called the ludicrous, and that it serves well to harmonise the oppositions of the many thinkers who have attempted analysis of this mental state. Those cases of the ludicrous which seem to involve little except surprise are explicable on the ground that the surprise in- 
volves attention and expectation of important outcome. When the unimportance of the object or action is perceived, the relaxation of attention results in the same powerful overflow into the channels of ordinary activity. The easy and marked "step from the sublime to the ridiculous" is also thus explicable, as is also the enjoyment we receive when we see a dignified person suddenly take up the actions characteristic of purposeless childhood: as when a man's hat is suddenly carried away by the wind.

It cannot be claimed that all such transitions as are above described are ludicrous, for thought trains of discovery and invention are not infrequently of this nature, and to them surely the word ludicrous cannot be applied. Introspection seems to tell me, however, that the psychoses in the two cases are very closely allied. We have a tendency under such circumstances to laugh, or at least to smile, under the pleasurable excitement, and we occasionally speak of the resultant as a "happy thought." I am inclined to think that the difference, at first one of degree rather than of kind, has become marked because the more emphatic and fuller state produced in us by what we term the "ludicrous" has become indissolubly connected with what Kant describes as "the sudden transformation of a tense expectation into nothing."

Wit and the ludicrous are seldom separated in practice. The wit, properly speaking, plays around his subject, avoiding the more usual ontcome of the train of his thought, but leading that of his hearer close to this normal resultant, until, when it may be supposed that all the organs connected with the normal outcome are fully prepared for action, he turns the thought train in the direction which is effective for pleasure. The stimulation of the wellnourished organs, which is thus involved, is followed by 
the burst of pleasure-giving activity which irradiates the system and expands its surplus energy in the pleasurable exereise of laughter." Pumning and plays upon words give delight in the same way, and also the delicious verbal misunderstundings of children. My little daughter having asked what was meant by Anglo-Saxon, and having been told that the word indicated a mixed race descended from Angles and Saxons, she answered, "Well, I suppose I shall understand it some day. I have not come to Saxons yet in my geometry, but I have studied about angles." She obtained no delight in the saying. For the listeners, however, the sound angle had brought about readiness for activity in the organs of many trains of thought connected with geometrical forms; but the added term Saxon had kept the attention eompletely in other directions; when the thought was turned to the geometrical trains, however, by her naïve remark, the well-prepared organs responded with pleasurable content.

The wit and he who deals with the ludicrous, however, tread on dangerous ground. The elown perehance may not cause laughter, but may disappoint us so painfully that irritation results. Apart from the danger that the witticism may cut too deep, there is the danger that the repressed activity may force itself upon the attention of the hearer before it is designed to appear. In this case the course of thought which is intended to lead up to the latter beeomes obstructive, and the result is wearisome; this is exemplified, for instance, in the "flatness" of old jokes. Further, there is the danger that the play around the subject may develop' trains of so mueh interest that the ehange of thought will

1 The exereises of laughter are pleasurable in such cases becanse they involve the action of rested organs. The more serious aspect of things from which we turn to the perception of the ludicrous involves partial if not total quiescence in all those organs which are notably active when we langh. Laughter is not always pleasurable, as all know who attempt to force it. 
produce a shock powerful and painful enough to overbalance the pleasure led up to. We all realise how dangerous it is to treat lightly subjects which may be of sacred interest to others.

Our third minor division relates to-

C. Pleasures which accompany vividness of presentation.

[In physiological terms these pleasures may be described as due to hypernormal activity of a normally efficient organ.]

Vividness of impression is a well-recognised means of producing æesthetic result in its cruder forms. Barbaric art shows this distinctly, and the art of the masses, even in our day, makes use of the same means. Vivid colouring and contrasts, startling forms and combinations, vivacious rhythms, loudness of sound as in martial music, all are common tools of the popular artist. But we here tread on ground dangerous to permanency ; for hypernormal activity, as we have seen, is the basis of pain as well as of pleasure, and pleasure which is determined by this alone must be of a very ephemeral character. So in the higher art this crude means of producing æsthetic effect is not prominent.

In a more delicate form, however, we do find it of service to higher art in the stimulation by varied means of the same activities at the same time. The principle here involved is that of "harmony" or "the unification of the manifold," which is widely recognised as of the highest importance in æsthetics.

[In hedonic language it may be stated thus: Two or more elements act simultaneonsly as stimuli to the activity of some new element, the resulting psychosis being one in which the original elements stand in the background, the focus of the field consisting of this new element which, being stimulated from more than one source, appears in a pleasurable condition of hypernormality.] 
If this principle were not over-emphasised by high authorities $^{1}$ it would be unnecessary perhaps to call attention to the fact that, although wicle in its bearings, it camnot be universal as the cause of all beauty. Fechner, who certainly makes as much of the "unity of the manifold" as is legitimate, acknowledges this; see p. 42 of his Vorschule, where he mentions several instances to which it is not possible to give this explanation. We are evidently surrounded by appearances of unity in manifoldness that do not impress us with sufficient pleasurableness to give the objects producing them the quality of beauty, the slight pleasure which they give being overwhelmed. On the other hand, many beautiful objects appeal to us in which we can trace no distinct element of this unification. Fsthetic effect, indeed, as we shall see, implies more than the vague gentle pleasure which the unity of the manifold, as it usually appears, can produce.

The principle of duplication of stimulations, of which the unity of the manifold is a special instance, is, however, a most important one for resthetics. As Mr. Sully says : " 'To wake up to a resemblance between two things hitherto kept apart in the mind is always an agreeable experience"; and again," "the feeling of satisfaction which accompanies the full reinstatement of the idea or idea-complex arises from the identification of this with the partially-developed representation that has been present throughout the process."

Throughout the whole field of the "ligher" æesthetics, i.c. of that which deals with the delights arising from the more delicate play of mood and thought, this means of pleasure production is most important.

1 Cf. e.g. Lotze, Hicrocosmus, Book VIII. chap. v., "as we derive asthetic satisfaetion only from a plurality which may be apprehended as a clearly discerned unity," etc.

2 Human Mind, ii. p. 128.

3 Ibid., i. 1. 347. 
I think it must be granted that the mass of æsthetic pleasures is reached by slightly vivid presentations in varied directions, but, as we have so often noted, it is vividness also which leads to pain.

[If hypernormal activity be continued after the surplus force stored up in an organ has been exhausted, pain results; hence if this unusual activity be continued for any great length of time, we will have the conditions productive of pain.]

It becomes necessary then for us to consider the means to be adopted to bring about permanency of pleasure field, and this brings us to the second division proposed in the beginning of this part.

$\S 8$. Our problem here is to define the conditions which make possible the attainment of relative permanence of pleasure.

We have already seen (1) that absence of a content from consciousness for an unusual time suffices to make it pleasurable when it appears; also (2) that vividness of impression is an important source of pleasure-getting; but (3) that the avoidance of continuity of vivid presentation of any one set of contents is a necessity if pain is to be avoiderl.

[In physiological terms: Rest from action before action in a given organ is one of the conditions to pleasure-getting from the content which appears with such activity, or else hypernormality of action in the organ ; but the avoidance of continuity of hypernormal action in any one set of organs is also a necessity if pleasure be sought; for such continuity uses up all surplus energy and leads directly to the physiological conditions which involve pain production.]

If, then, a permanent pleasure field is to be reached, a 
focus is important in our field of conscionsness (see 2 above), but it must shift from element to element (see :3 above), and this shifting involves new means of pleasuregetting (see 1 above). In general, therefore, we may say that the conditions of pleasure permanence are the shifting of a focus in consciousness over a wide pleasure field. Let us consider each of these divisions more fully, in reverse order.

\$. WidTh of Field.-Pleasure in any one direction being essentially ephemeral, the only means by which we are able to insure permanency of pleasure is by having open before us wide opportunities to change the content of our thought. As we have already seen, it is first of all essential that the fulness of our complex mental states should be non-painful: it then becomes important to see that many elements of the complex are capable of developing pleasure. This is important not only because we are thus enabled to shift the focus of attention with little risk of painfulness, but especially because a multiplicity of simultaneous effects thus becomes possible. Lotze, as he views his consciousness, tells us that the resthetic effect "is notably (but not exclusively) bound to simultaneousness and multiplicity of impression." It is thus that the artist groups together as large a number of means of pleasurable stimulation as he can combine without conflict. He endeavours to use at the same time arts of ear and of sight, and those which depict more directly the activities of men. The difficulty of such wide combination, however, is very great, and he more often deals with narrower fields; but always does he use every device which may draw into the field of suggestion all associative factors which are not inharmonious, and which may add one more to the pleasures given. He does not disclain any element, however likely to pall, if he is able to leave our thought free to turn 
elsewhere as soon as the pleasurable effect is gone. The suggestion of sense pleasures he uses, but avoids the actual sense stimulus under conditions that may lead to excess or bring painful results in revival. $\mathrm{He}$ aims to bring into play the imagination which carries one on from height to height in pleasure-giving flight. It is this direction of effort which leads Lessing to call for an incompletion of detail in the artist's work that the imagination may have room in which to work its expansive effects. We look thus for a fulness of non-fulfilment of exact detail; for an avoidance of strictness of realism-for type portrayal. The artist, moreover, aims to stir up those vague regions of psychic life, the content of which we can scarcely grasp -the regions usually termed "emotional." He produces in his observer an resthetic horizon which Guyau has wrongly interpreted as the essential characteristic of rsthetic pleasure : that "irradiation" which seems to have a centre in some sense impression, but which works effects in all mental regions connected with it-effects of so small intensity, of such rapidly-shifting content, that there is little of it but the vagueness of an aurora. The artist cannot undervalue even the effects of admiration of his own skill, for though the pleasure gained thus is for a few, and perhaps only for his fellow-workers, for them it is not a small pleasure-giving element, and if his work holds the admirer by this means but a moment longer, so much the more is his work effective.

Breadth of field without the emphasis of foci implies a widely divided attention which is important. The recognition of the existence of a field in the percipient lacking in definiteness of attention has indeed not infrequently led to over-emphasis of the receptive state-of the passive conditions-for art effect; too little account being taken of the reactive elements involved. These latter, however, do in 
fact make up a large part of the resthetic complex, as our later estheticians, Sully, Guyan, and others, do not fail to recognise distinctly. Guyau, in fuct, in his zeal to force the recognition of his riew, makes himself appear, some will doubtless think, to take an extreme view on the other side: to over-emphasise the active element. ${ }^{1}$ Any work of art which tends to raise a marked attention in one line necessarily excludes pleasurable psychoses in other limes, in that it lowers the effect of these other presentations or revivals as components of conscionsness at the time. A work of art which can so balance its elements that the observer is kept in a state of nicely divided and still of constantly shifting pleasurable attention, will produce the most widespread, the most voluminous, even though not the most vivid, pleasure.

The power of music is often clearly aided by its indefiniteness-its "dreaminess" as we call it, and it seems to me that the great strength of the masters of music has lain in their ability to widen the field of pleasure by the means under discussion. In such a complex art as the opera the difficulty of reaching this balance is very great. An operatic composer of inferior power will not be able to prevent a frequent diversion of attention with consequent loss of fulness. Now one finds oneself watehing the stage effects to the exclusion of the music, and again listening to the music with closed eyes, with no thought of the action. In the impression obtained from the best work, Wagner's for instance, I find myself on the other hand very often lost in the totality: all particulars seem to be forgotten in the general effect; the stage actions are not separately emphatic: the suggestion to note distinetly the "motifs" is an intrusion. The crudeness in respect to finer play of thought and emotion

1 C'f. Grant Allen's Physiological .Esthetics, 10. 37 ; and Guyau's Problemes de l' Esthétique contemporaine. 
which the plot itself in his operas shows is probably a necessary element of their power. The strong development of "plot interest" would doubtless act as a detriment' to the totality.

It is perhaps in part the unconscious recognition of this principle of diffusion of attention which leads to the popular opinion that the critical spirit is fatal to resthetic receptivity, and in one sense this is true; although I am free to confess to the belief that what is lost in width of field by the concentration of the critical view is largely gained in the region of intellectual play. To the critic who knows well his subject this actually prevents his satiety, overcomes the danger of distaste for work with which he must be over-familiar: communication of his thought to others less well equipped, however, is very likely to mar their pleasure. ${ }^{1}$

But width of field has its dangers too, for it makes easy the shifting of one's thought upon lines of pain-giving. An example of this has already been given in another connection, where I called attention to the fact that the tone of voice, or anything which indicates the animus of the describer or critic, will frequently change an resthetic into a non-æsthetic object for the listener, and vice versal.

Esthetics, althongh largely a matter of the complex summation of vague pleasures, needs more than this. To perfection of art there must be a decided centre of interest flitting more or less lightly over this vaguer field. To the consideration of this point we now turn.

1 As Lelmann well says (op. eit. p. 198) : Kenner, die die geschiclitliche Entwickelung der Kunst verfolgen, können oft grosses Gefallen an sehr unvollkommen Kunstwerken finden, indem sie nämlich den grossen Fortschritt in Betracht ziehen, den solche Arbeiten in Gegensatz zu früheren, noch unvollkommneren zeigen können; wogegen Nichtkenner, denen die geschichtliche Entwickelung unbekannt ist, dieselben nur mit den vollkommneren Werken der Gegenwart vergleichen und sie deshalb ungünstig beurteilen. 
$\S 10$. The Shefting Foces. - In Amiol's Jommal, $233 \mathrm{rd}$ May 186:3, we read: "All that is diffused and indistinct without form or sex or accent is antagonistic to beanty, for the mind's first need is light; light means order, ancl order means, in the first place, the distinction of the parts-in the second, their regular action. Beauty is based on reason." Although we have seen that exclusively rationalistic views of resthetics are not tenable, we cannot help agreeing that an object which presents no virile interests but merely a field of moderate pleasures soon cloys: it becomes "sweet," as they say in the studio: It was probably the recognition of this fact that led Lotze to the theory that beauty requires the grasp of the ideal through some definite object, and Volkmann to separate the art field from the field of resthetics on the ground that the former strikes a definite chord above the merely hedonic field of resthetics. For Volkmann this definiteness, which most emphatically takes its object out of its environment, is the direction in which the art of the ancients showed its highest superiority. ${ }^{1}$ But if art work must impress us by its force of attention, its centres of interest, these points of intenser activity are points of danger: all pleasures are ephemeral, the more so as they are vivid, and the shifting of these centres of interest is of as great importance as their existence. I think we shall find this recognised in certain general principles.

First, we may look to find means adopted to retain pleasure in one spctial direction by arranging to shift attention away from the special field before pain or complete indifference occurs, and back again at the moment when

1 Lelerbuch a. Psychologie, vol. ii. p. 357. Cf. also Herbart's notion that beauty is a matter of the relation of the presented thoughts, and has nothing to do with such characteristics as loveliness, yathos, laughableness, which are mixed with beauty in order to give an element of interest. 
pleasurable recurrence of the content is again possible. This brings before us again the great principle of Rhythm (see Chap. V. §5).

[Because processes of nutrition are relatively regular, the times required for complete recovery after full use remain approximately equal in the same set of organs, and it thus happens that we learn to act at recurrent regular intervals, being thus enabled to hold to a special subject-matter for a long time, not only without fatigue, but, if the rhythm be properly timed, with marked pleasure.]

Accurate rhythms are most notable in music and poetry, but what may be termed inaccurate rhythms are the very ordinary tools of the artist in other lines also. The power of order, in architecture, for example, and the value of symmetries $^{1}$ generally, depend largely upon such rhythms. Instances will be recalled by the reader in all the arts without special example.

Passing to the consideration of the shifting of attention beyond the same field, from field to field, we obtain the wellrecognised canon of Variety. Monotony of stimulations gives us first indifference and then the positive pains of fatigue. If the content of consciousness be constantly changed, however, the chances of pleasure gain are greatly increased; if a unity be recognised in the variety, on the principles already discussed, we have an added pleasure to that gained by the shifting of the centre of interest. Variety, however, like all the means of pleasure stimulation, is likely to be carried too far. Variety of pleasurable exhaustive stimulation will eventually aggravate the trouble we attempt to correct

1 Symmetries also may be held to prodnce effect through the hypernormal stimulus involved in the recognition of the unity of the manifold. It may be well here to remark that the search for symmetry in theoretical form which has led many a metaphysician astray has probably had its basis in the asthetic demand of lis nature. 
through variety, by making painful exery activity in our field. An example of this we may all recall in the craving for total rest experienced after a visit to some great exlibition where competitors vie with each other to attract attention to their wares by varied devices looking to pleasuregiving. We often find people remarking that they enjoy an art work (especially is this true in architectural criticism) because it is simple. The distracting elements in the varied objects which they have examined in the hope of gaining pleasurable effects have disappeared, and have left a quiet delight not far removed from the so-called pleasures of rest.

Contrasts, already discussed, also gain their effects through change of region of stimulation. Where notable, however, they depend upon vividness (hypernormality of action) for their results, and must be used with care lest they act exhanstively.

The mechanism of this may not improbably le something like this. If attention be turned in one direction for a time, automatically the systemic activities tend to bring nourishment especially to those organs which are active, and those not active become well prepared indeed (from such nutrition as is not called for elsewhere), but only through failure of stimulation and notwithstanding the calling off of the nourishment supply in other directions. When those second-element organs which have been inactive are stimulated in contrust they answer with pleasure, and their action tends to withdraw the nutritive supplies from the set of organs which had given the first elements of the contrast, so that these first-element organs get less than their normal nutriment; and if we stimulate them again in turning back to the first element, we find a set of organs in some degree prepared, to be sure, but less well prepared for activity than they were in the first instance.

The same thing may be said of those vivid elements of novelty which give the value to what we call the pictmesque. We cannot use these means to gain resthetic result unless we 
are able to turn ourselves away from their stimulation as soon as we begin to be weary. Hence, we must avoid the use of the picturesque in our homes, and must deal most carefully with strong contrasts in the decoration of rooms in which we wish to live, or in buildings which we are compelled to view constantly.

On the whole, it appears that the safest means of producing lasting resthetic results will be reached if we choose that succession of contents, each of which is naturally led up to by those which have preceded.

[In physiological language: we will gain our result best if we choose such successive impressions as will stimulate organs that have been best and fully prepared for action by the associative nutrition (if I may so speak) connected with the previously . stimulated activities.]

From this we may argue to a wide resthetic law, which may perhaps be called the prineiple of the satisfaction of cipectaneies-a legitimate description of the means of gaining resthetic result here tonched upon, as all such movements of thought appear in retrospect to be expectation phases which are fulfilled.' That this canon, however, although of wide application, is not a universal one for cesthetics, is apparent when we consider that our normal, indifferent, scarcely conscious life is largely made up of these fulfilments of expectation, not recognised as such, to be sure, unless their legitimacy is questioned in one way or another, and unrecognised because the ordinary reaction is immediate, and thus not involving any marked transformation of surplus potential into actual energy, i.e. not involving pleasure.

1 Cf. Bergman, Ucber dus Schöne, p. 132, where the value of arousing expectation and allowing its satisfaction is discussed and carried out to the explanation of the delight obtained in curves, etc. The same argument suffices to explain the pleasures reached by the contemplation of muances of all kinds. 
$\S 1$. In general it appears, then, that the great artist is one who is able to make use of the principles above enmmerated. Having avoided pains, having created his wide field of non-pain, he produces a wide summation of pleasurable contents. Further, he so arranges the shifting of attention that as one impression fails in pleasure-giving, another equally enjoyable appears, through natural connection, to supply the place of that pleasure which is farling away. Moreover, by compelling a judicions recurrence of a special interest, he marks a unity of the manifold, which unity gives to his work its distinctive character.

I have already named the great works of Wagner in illustration of the poise of attention; but Wagner's power goes beyond this: wherever we break away from width of effect and allow our attention to concentrate upon details, we there find a gem of melody, a delicious progression, a rich. ness of harmony, or a masterful bit of orchestration; and if we turn from the music we are still thrilled with emotion or impressed by some profundity of thought. But withal, these details are not allowed to efface the value of the special marked development of the work. Shakespeare's wonderful drama, to take another example, shows us great width of interest, yet always some figures of specicel interest, from one to the other of which our attention is artfully shifted without loss of that background of delight which is felt apart from the specially forceful impressions. His genius manifests itself further in the ability to preserve a proper balance, so that using wealth of subordinate elements, no one of them is allowed to rise to sufficiently great importance to mar the greneral movement of the drama, or to detract from the import-. ance of the character whose action is to thrill our souls. The great painter treats his subject in like manner; he gives us a wide, vague, pleasurable background in impression or associ- 
ative revival trains; a wide field of more marked pleasures over which the centre of interest shifts-without loss of the prominence of the central "motif" to which especially he would compel our recurrence.

$\$ 12$. In closing, I think it desirable to take a retrospective view once more. It has been shown in this chapter, I think, that the principles of practical asthetics are in harmony with the hedonic resthetic theory which I defend; and more than that, in accordance with the theory of pleasure-pain which I have elsewhere explained. The sketch of resthetic principles which we have been considering, incomplete and inadequate though it may appear, has thus at least served to accumulate evidence in corroboration of that pleasure-pain theory. Nor can this be counted as a small gain; for a theory which on its physical side must be expressed in terms of necessarily vague physiology, and which is difficult to put to the test of experiment, must gain its acceptance, if it is to gain it at all, by cumulative evidence such as I have here given; for if it be claimed that the evidence presented is not crucial, at least it must be acknowledged that the value of the theory is vonched for in no inconsiderable degree by the fact that in pushing it to its conclusions serious oppositions have not been developed.

Again, I wish to say, however, that I consider the physiological theory of less moment than the purely psychological. It has become clear, it seems to me, at all events that the physical basis of pleasure and of pain is determined by relations of a very general character which may belong to any organic activity, and that pleasure and pain must therefore be treated, psychologically, as qualities of a very general nature which may under proper conditions belong to any content. This appears also from purely psychological evidence. It is evident, therefore, that they are not to be looked upon as 
the outcome of any special and peculiar mentality, that they are not suigeneris among psychic phenomena, that they are grasped mentally very much as other qualities of a general character are grasped. We recognise that a content has pleasure-pain quality, then, much as we recognise that a content has intensity; in one and the same general manner all qualities in our psychic stream gain recognition. 


\section{CHAPTER VII}

\section{GENERAL SUMMARY AND RESULTS}

In the first chapter of this book we undertook to determine the place which must be given to pleasure and pain in a psychological classification, and we concluded that they must be looked upon as general qualities, one of which must, and (given the proper conditions) either of which may, belong to any fixed element of consciousness.

This led us in Chap. II. to examine into the nature of the emotions, which we had found to be often falsely identified with pleasure-pain phenomena, and we concluded that they are the psychic coincidents of relatively fixed co-ordinated instinctive activities arising upon the appearance of definite objects; and that in their nature they are necessarily composed of elements which are likely to be highly pleasurable or painful. We thus found what seemed to be the true relationship between the emotions and pleasure-pain.

In the course of this examination our attention was called to a lack of symmetry which appeared in our emotional scheme, unless we assumed the existence of an impulse within us leading to the working out of an instinct to act blindly to produce results which have power to attract others to us. Upon examination we concluded that this impulse might be identified with the art impulse. This 
view was corroborated in Chap. III., where we examined the field of resthetics from a psychological standpoint, and came to the conclusion that there was a preponderance of evidence favouring the treatment of iesthetics as a branch of hedonics or the science of pleasure. The principal obstacle to the acceptance of such a view appeared in the fact that whilst not all pleasures are called resthetic, yet no satisfactory differentiation of asthetic pleasures from pleasures in general had been discovered. We came to the conchusion, however, that a satisfactory basis for the difference between the two was to be found in the fact that isthetic pleasures are relatively permanent in revival, while pleasures which are nonresthetic are really at the moment of judgment only pleasures in name, or, in other words, are states of mind which were in truth pleasurable and asthetic in presentation when experienced, but which are not pleasurable in revival; the pleasure name nevertheless still elinging to the psychosis in its nonpleasurable revival.

In Chaps. IV. and V. we turned our attention to the inquiries which have been made from time to time to determine the nature of the physical relations upon which pleasure-pain phenomena depend. We there conchded that we were warranted in judging that pleasure and pain are determined by the efficiency and inefficiency respectively of the organs active in coincidence with the pleasurable or painful mental elements; that efficiency and inefficiency are functions of the relation between activity and nutrition; pleasure being dependent upon the use of surplus stored force and pain upon conditions under which the outcome of the organ's activity is less than should be expected in consideration of the energy involved in the stimulus. We found many corroborations of this view, which, whatever its valne prove to be, in its turn we found to be in line with the important position maintained in Chap. I., namely, that pleasure and pain are general 
qualities, one of which must, and either of which may, belong to any conscious element.

In Chap. VI. we turned again to the subject of rsthetics, considering what principles our theory would lead us to expect to find recognised by esthetic students, and what methods of practice by artists. We found here again a large amount of corroboration.

Cumulative evidence has thus presented itself in favom of our theories from many directions and in many forms.

Before bringing this volume to a close it seems desirable, if not necessary, to say a few words concerning the relations of the hypotheses above discussed to the psychological sciences most clearly connected with pleasure and pain.

I have already said all that seems needful concerning resthetics, which we have seen to be fundamentally related to algedonic doctrine.

Our theory as it relates to pedagogies gives us some inportant corollaries.

Pleasure, as we have seen, implies capacity to act effectively in the direction in which pleasure is gained. When a student finds delight in his work, therefore, we have a direct indication that he is likely to make favourable progress in the special direction of the pleasurable study. On the other hand, desire with its restrictive pain is indicative of full preparation for the desired activity, and is therefore an equally clear guide for the teacher who would learn the direction in which success for his pupil is most probable.

Painfulness in the accomplishment of a given task, which is shown by the aversion immediately connected with the pain, is not only indicative of ineffectiveness of effort, but is a mark of positive loss to the energy of the system as a whole. 
It appears that although exereise in a given mental region, up to and a little beyond the line of painful effort, is of importance for progress and for the growth of effective character, in the main the teacher's effort should be to produce desire in the direction of studies in whieh it is advantageous for the pupil to engage, and to look for pleasure in such studies as the most certain mark that attaimment is being effected.

The relation of Ethies to pleasure-pain doctrine has always been considered close.

Ethics being a science which treats of voluntary activities, must necessarily have close relations to algedonic doetrine, under a theory like ours, which expresses the litws of pleasure-pain in terns of activity.

It would be presumptuous to attempt here, where full argument would be impraticable, any adequate diseussion of ethical doetrine; but I think it not impertinent to inclicate briefly the direction in which the theory above defended seens to me to lead the ethical student.

Pleasure under our theory implies an activity which tends to persist, and pain an activity which tends to cease: the How of ideas is therefore necessarily altered by the presenee of pleasure or of pain in commection with the elements involved; the alterations of pleasure-pain phase and of intensity being determined by the same conditions that influence the prominence of the several elements in conscionsness. The pleasurable idea, in so far as it tends to persist, is obstructive to ideas that would oppose its persistence; the painful idea, however, tends to give place with little resistance to any other element of consciousness that may be called up.

We find ourselves, therefore, at once thrust into the thick of the battle between hedonistic and non-hedonistie systems. 
CHAP.

of ethics; for if the pleasurable ideas are the persistent ones we surely cannot be surprised at the hedonist's claim that pleasure is the end that we do and should have in view in our voluntary life. Let us examine into this a little more closely.

Willed action is the ontcome of a conflict of impulsive ideas. This conflict implies repression of opposed impulses, and therefore a state of systemic pain.

The resolution of a conflict implies the breaking into activity of one of the opposed elements, which will act pleasurably, as all action after repression is pleasant; on the other hand, it also implies the chance of an increase of the pain from the opposed elements, now positively prevented from developing. Habit apart, however, the pleasure in connection with the wimning element must overbalance the repressive pain of its opposed ideas, and this largely because the pleasurable persistent idea through its intensity will take possession of the field. Hence it may be laid down as a rule that the will act per se is pleasurable. It is natural, therefore, that in anticipation the ontcome of a state of conflict in will, should (in most cases) be looked forward to as a pleasure; and if there were no other eonsiderations it would be true to say $1^{\circ}$, that the most effective element will win; and $2^{\circ}$, that of the two possible will-pleasures which could result from the conflict, the greater will be attained.

But other considerations do enter. The first alteration of this rule that attracts attention is due to the effect of habit, which makes the appearance of certain resultants easier than the appearance of others, apart from the inherent effectiveness of the winning element. In such cases the more powerful impulsive idea (A) may be obstructed by a less powerful one (B), which holds the road, so to speak. The outcome then will be a will-pleasure $(\beta)$ which we must acknowledge to be less than would have been the will-pleasure $(a)$ which would 
have resulted had the more powerful element (A) won; and on the other hand, the immediate pain of opposition connected with (A) will be sharper than would have accrued if the less strong but habitually occurring element (B) had been obstructed; although in such a case the fact that habit had led to the formation of nutritive and active associations would not improbably result in a more persistent pain of obstruction if the habitual line of movement had been overcome.

A second alteration of the rule above discussed is due to the fact that the most natural outcome of the impulse conflict is at times overborne by an influence from the ego, from the field of inattention; this is of the very essence of many emphatic cases of voluntary action. We act, as Professor James ${ }^{1}$ says, in what we distinctly appreciate to be the line of greater resistance. That is, some influence from the field of inattention appears which forces the activity in the direction in which the will outcome is least pleasurable, and in which at the same time the maximum of obstructive pain is brought about by repression of the more powerful of the conflicting activities.

It thus appears that, ordinarily, action takes place in the direction of the greatest desire (away from the fullest craving pain), but that this action is disturbed by habit relations, and more especially by influences from the field of inattention; in which cases we often act in the direction of the lesser desire (away from the lesser craving pain).

From what has gone before it appears that pleasurable presentations will produce revivals which may be indifferent or painful, but which, on the whole, will tend to be pleasurable; for the fact that the "presentation" as a whole has been pleasurable carries with it the probability that the elements which were in the "presentation," and.which are repeated in the "revival," will also be pleasurable. 
It appears therefore, further, that the "representation" of a will-act will usually be pleasant as its "presentation" was; at all events, that it will seldom be painful, although it may often be practically indifferent. That it usually leans towards pleasure is sufficient ground for the not uncommon view that the end in all voluntary action is our notion of the pleasure to result therefrom.

This brings us at once to the crucial questiou of hedonistic ethics, namely, whether the attainment of pleasure (inclusive of pain avoidance) is a practical end for human conduct.

Unless historical retrospect and developmental theory ring a note altogether false, the ethical impulses relate to racial efficiency. The individual impulses to immediate reaction upon environmental conditions being held in abeyance, the ethical impulses which relate to racial values gain force enough to rise superior to the impulses relating exclusively to inclividual welfare.

Judged from such a standpoint, it is not difficult to show that egoistic hedonism presents no grounds whatever for acceptance. It seems to me clear, as shown above, that, as a matter of fact, we do not always act towards the greatest pleasure; and, furthermore, if, contrary to this fact, we endeavour to make this personal pleasure our end, we fail to fulfil the ethical demand that race efficiency shall be subserved. For it has been seen that pleasure is indicative of vigour in the organ of the pleasurable content, but not necessarily of vigour in the individual. Much less, therefore, can an individual's momentary pleasure be indicative of tendeucies to racial vigour.

But egoistic hedonism finds nowadays few advocates; so without further remark we may tum to the consideration of the relation to our question of altruistic hedonism, which, under the name of utilitarianism, has many adherents among ethical teachers. 
Of a limited altruistic hedonism which would always prefer another's pleasure to one's own we do not here speak, for it is apparent that another's pleasure is in no respect a better indication of racial effectiveness than one's own gratification.

The altruistic hedonism which we call utilitarianism places the pleasure of the race as the end. In so far as this utilitarianism recognises the racial element in ethical promptings, it is, of course, in the right.

From our standpoint the doctrine that we should act to the greatest happiness of the greatest number is valid only in case racial pleasure-getting is agreed to be equivalent to racial effectiveness; which equivalence, although not true in particulars, as we have seen, tends to become true in a general way in the long rum. This equivalence of racial pleasuregetting and effectiveness is implied in much of modern ethical writing, as appears clear when one notes that the utilitarian descriptions of such virtues as temperance and courage are not commonly stated in terms of pleasure, as is the case with most of the virtues, but are stated in terms of racial persistency.

When we consider, then, that the old formula of utilitarianism must be stated anew, so that the end of action would be made "the highest effectiveness of the largest number," we at once perceive its weakness as a practical guide. For no intelligent man would be willing to take as his guide in action the effectiveness of the average man as he knows him-a notion which becomes more distasteful as we consider that Darwinian cloctrine has broken down the boundary between the rational and irrational, and has indefinitely extended our racial brotherhood.

Nor would developmental theory allow that such an end of action would tend to the advance of our race. What developmental theory demands is the encouragement of the most effective groups and the discouragement of the less effective groups. This forces us, incleed, to undertake the 
CHAP.

determination of the basis of racial effectiveness, which is a problem of very great difficulty, but one that appears to me to be far less troublesome than the problem which the hedonistic utilitarian undertakes to solve, viz. that of determining, rationally, what is the average of happiness.

From a purely hedonistic standpoint it might be held that our ethical aim should, incleed, be the subordination of temporary to permanent impulses, but to the end that our memory of past intentions may show our acts to have accorded with these permanent impulses. If we do not so act, the memory of these acts will show an opposition of impulse to the impulse most persistent at the time of the memory and a pain due to this opposition.

But from the evolutionary point of view the avoidance of this revival-pain is not the important point: the existence and strengthening of the permanent impulse itself is the important point; as it is the impulse to activity, and not the avoidance of the pain, which leads to the racially effective resultant.

Under the postulates of survival the tendency which is important to ethics is the tendency to work towards far-off ends; and those ends will survive which, when attained, are effective to living. It is the persistence of these ends that is important, not the prevision of pleasure to be gained nor of pain to be avoided.

It appears to me, then, that, all things considered, the notion must be abandoned that pleasure-getting in any sense can be made serviceable as an ethical end. Beyond this conclusion it would be improper to go in an unethical study.

It may be worth while, however, to call attention to a few points in reference to the ethical relations of Desire.

From what has gone before it would appear that the object 
of desire is not directly related to the production of the painfulness of restriction, which latter is determined by elements apart from those active in defining the object-a fact which seems to argue against the notion that the conscions spring of action lies in the attempt to free oneself from the restrictive pains involved with the contemplation of the desired object. Further, it appear's that the satisfaction of desire is not the only means of overthrowing desire-pain, but that persistent encouragement of activity, in not too closely related regions, will lead to a loss of capacity in the organs formerly in active use, and a loss of the craving which that capacity carried with it.

We are now prepared, I think, to consider briefly the relation between Esthetics and Ethics.

The Good, using the word in its broadest sense, is that which gives us pleasure. Everything that is good is pleasurable, and everything pleasurable is good. Hedonics, the science of pleasure, deals with goods in this wide sense; resthetics being that branch of hedonics which treats of the relatively permanently pleasurable in. revival.

In ethics the word "good" is used in a narrow sense, being made to relate to a special kind of good, viz. the good in action.

Good conduct is that kind of conduct in ourselves or others which accords with our standard of most permanently effective impulses in revival. We approve an act because it accords with our impulse-balance in revival; that is, becanse it does not clash with the relatively permanent impulse in revival. This moral act may be "indifferent," hence is not per se cesthetic. When we "highly approve" we are gaining pleasure in reviral, and so far are gaining an element of an resthetic psychosis.

We disapprove an act because it does not accord with our 
impulse-balance in revival; that is, because it does clash with the relatively permanent impulse in revival. The immoral (for us) act is therefore always painful, and hence always unæsthetic-ugly.

The good in action, while never per se unæsthetic, may be connected so closely with painful associations as to give a totality too painful to allow it to be grouped in the resthetic field. The "beanty of holiness" is hence only occasionally marked, when it is emphatic or when we restrict our thoughts to it apart from all its surroundings. Character may be resthetic, and special acts resthetically sublime; but, on the other hand, a right action may be landed although at the same time it is recognised as distinctly non-resthetic, e.g. when a man enter's a loathsome environment to save a life or a soul.

I cannot say the final word in this work without calling attention to the application of the theories here defended to that which is of deepest interest to all mankind, viz. the problem of pain. As we approach the subject it presents itself to us in the form of the question, "Can we as rational beings wish to eliminate pain from our consciousness?"

If we consiler the fundamental nature of pain from the standpoint of the theories above defended, it appears that pain is caused by clemant upon an organ to which it is incapable of reacting on account of its (the organ's) own weakness. If the possibility of pain were eliminated it wonld be because no demand conlu be made npon the organ greater than that to which it was fully qualifiel to react. This would imply stability of conditions in the organ's environment, which would in turn necessarily imply psychic indifference, and which wonld cut off all but a purely "vegetative life."

If the enviromment of the organ be variable, incapacity for 
pain implies incapacity to react to stimuli more energetic than the normal ones; which in turn means destruction of the organ as soon as its excitation to activity passes above the norm.

Furthemore, the elimination of pain implies loss of all pleasure capacity : for from our previous discussions it would appear that the pleasure capacity of an organ is determined by its use of surplus stored energy; that the storage of this surplus energy in our complex organism is determined by the continuation of nutritive assimilation after the call for activity in the organ has ceased; and that only through hypernormal demand, which in the first instance implies pain, can this continuation of nutritive assimilation take place. The eapacity for pleasure-getting therefore seems to imply the anterior existence of pain : the individual, through ancestral influences, may find capacities for pleasure which have not implied previous pain in himself; still this eapacity must be supposed to be traceable to original painful hypernormal demands upon the organisms from which his lifehabits are inherited.

Theoretically, therefore, it appears that the elimination of pain would imply the elinination of pleasure also, and the destruction of psychic life; that is, the reduction of conscionsness to pure indifference, which, accurately speaking, is no consciousness at all.

Let us turn from simple theory to the conditions of complicated individual life.

Our pains of excessive stimulation are indieative of inability in certain organs to react to special stimuli; are warnings of incapacity and danger. As individuals, we surely camnot wish away these indices of elemental strain which induce reactions that guide the individual away from the conditions acting destructively upon parts of the organism.

Pains of restriction, on the other hand, although probably 
traceable in their essence to hypernormal activities, are for the individual practically a distinct class. They are caused by obstructions of habitual functioning. They are therefore dependent upon previous co-ordinated activities, and we cannot wish their possibility out of life without wishing either to see the stream of consciousness displaced by simple and disconnected psychic moments, or else reduced to the unchanging conditions of psychic death.

Pain of restriction implies an attempt by the systen to break down opposition to habitual functioning. In many instances we can see dimly that these pains are warnings for our everyday life, or are indicative of racial dangers, as in the case of inherited disease.

Of all these pains of restrictions the hardest to submit to are those that come to us with what appears to be unreasonable fortuitousness; such burdens, e.g., as are produced by the loss of dearly beloved companions. These appear to me to turn our minds to the thonght of a broader than racial brotherhood, of which we are individual members, pointing out that we individuals are elements of an organic life fuller and higher than our own; that, as the elements of our individuality call to us as individuals to satisfy their cravings, so we individuals, as elements in the wider life, cry out for deliverance from these ills that crush us to earth. And we are able to hope that we do not cry in vain, for as the elemental pain guides us as individuals to more fitting lives, so must our individual struggles in agony guide the fuller, wider life to a more perfect adaptation to its conditions of development.

Lotze beantifully says, with reference to the material complications of social life, "We can choose only the one or the other-either the simple, monotonous harmony of an uneventful life according to nature, or the full articulated melody of civilisation gradually unfolding through many a discord." 1

1 Microcosmes, Book VI. chan. is. 
So we may hold, in a still broader spirit, that we must choose either the relatively uneventful life of individuality or gladly accept the pains that are necessarily bound up with the gain of a place as elements in the larger life which, through many a discord, is still, surely, gradually unfolding into a full articulated melody of which we elemental individuals can know little or nothing.

Surely we cannot wish even these bitterest of restrictive pains out of our lives; for, were they eliminated, it would mean that the wider entity was giving an answer of unchangeableness to the altering conditions which should influ. ence its life: our loss of pain would be due to death of the higher entity. Otherwise the loss of these pains would imply our own exclusion from elemental partnership in the higher progress of the wider entity. 



\section{INDEX}

Absolutiss in retheties, 116, 156, 161

Addison, 132

Esthetics, definition, 112, 152

negative laws, 305

positive laws, 324

and definiteness, 147

and ethics, 139, 160, 355

and herlonics, $122 \mathrm{f}$.

and imagination, 132

and morality, 132

Esthetic stanclards, $117 f, 154 \pi$.

Algedonic, term usage, 9

Algetonic asthetics, $299 f$.

Algedonic contrast, 176

Algedonic permanency, 232

Algedonic representation, 151

Algedonics and labit, 179

Alimentary sensations, 288

Alison, 120, 129

Allen, G., 120, 135, 143, 206, 33 7

Amiel, 339

Analgesia, 19 f\%., 268

Anger, $77,79,295$

Antagonisn between art and science, xi. $f$.

Anticipation, 235

Aristotle, 80, 87, 115, 131, 134, 173, $174,182,192,258,293,295,308$, 320

Arnold, Ml., 146

Art, definition, 112

Art impulse, 100

Association, 141

Attention, 212, 236, 262

Aversion, 235

BAIN $, 9,11,37,39,78,88,94,135$, $183 f f ., 197,206,229,297,275$, $281 f ., 296$
Baldwin, 154

Bamugarten, 120, 144

Begg, 118

Bell, 315

Bentham, 138

Bergman, 117, 129, 131, 132, 34는

Berkeley, 165

Blencke, 126, 132

Blim impulse, 275

Blix, 21,286

Bosinuluet, 136

Bonillier, 8, 34, 197

Bradley, 59, 189, 276, 279, 281

Brealth of esthetic impression, $1: 0$

Browning, E. B., 248

Brumo, 177

Butfier, 315

Burke, 115, 120, 144

Butler, 193

Cattele, 12

Cherrenl, xir.

Chrysippus, 131

Classitication of pleasure and pain, Ch, I

psychological in general. 5

Clifford, 184

Cold, 286

Colonrs, 312

Conformity to type, 315

Content, usage of worl, 5

Contour lines, 312

Contrast, $176,325,341$

Courmont, 25

Cousin, 131, 144

Cravings, 233, 272, $7,274,307$

Criticism and artistic productivit!. xr.

DANA, C. L., $28 s$ 
Darwin, xv., 67, 71, 72, 74, 75, 76, $78,80,81,92,95,147,230,289$

Delabarre, 231

Delbœuf, $8,10,59,173$

Descartes, 189

Desire, 234, 275

and its object, 280

and pleasure, 281

Despair, 234

Dewey, 3S, 54

Diderot, 130

Disappointment, 235,278

Tivine types, 144

Donaldson, 286

Doubt, 235

Dread, 70, 74, 294

Drobische, 276

Dumont, $8,12,188$

EFFICIENCY and pleasure, 194, 198

Emerson, 147, 316

Emotion, Ch. II., 83

Emotions, expressions of, 85

Ernotions, not pleasure and pain, 90, $94 f$.

Emotional, use of term, 60

Emotionalism in resthetics, $120,129,160$

Empedocles, 88

Epicurus, 123

Ethics and resthetics, 355

Ethical hedonism, 352

Etlical results, 349

Evolution and pleasure-pain, 263, 269

Excitement, 237

Expectation, 235, 2ז9

Expression of emotions, 85

Expression of pleasure and pain, 91

Expressiveness as an esthetic criterion, 136

FEAR, 7\%, 79

of deatl, 34

Fechner, 10, 52, 123, 135, 138, 140, 157. $179,187,253,319,326,333$

"Feeling," 6

Féré, St

Fitness, 315

Floating pains, 16

Formalism in astlietics, 122, 160

Fonillée, 183

GEF̈̈HL,

Gilman, B. I., 126, 179

Goethe, xv.

Goldscheider, 18, 21, 286

Good, 355

Grace, 315

Gravitation curves, 311
Growth, 318

Gurney, 175, 231, 241, 253

Guyau, xvii., 136, 140, 144, 278, 318, 336,337

HABIT relations to pleasure and pain, $179,225 \mathrm{f}$.

Hamilton, 130, 131

Harmony, 121, 332

Hearing, 291

Heat, 296

Hedonics, separation from asthetics, $12 \%, 148 . f f$.

Hegel, 144

Helmholtz, 143, 200

Hemsterhuis, 130

Herbart, 58, 115, 178, 339

Hesitancy, 235

Hobbes, 183

Hodgson, S., $7,50,60$

Höffding, $68,95,183,27 \mathrm{~S}$

Hogarth, 115, 135

Hope, 235, 279

Horwicz, 36, 78, 136, 140, 173, 176, $189,206,240,256,278,285$

Hume, 123, 177

Hunger, 289

Hutcheson, 119, 310

Hyslop, 314

Imagination, xiii., 132

" Imitation impulse," 99

Imitation of nature, 314

Immediacy of æsthetic impression, 140 , 161

Impulse, 69,276

Indifference, $56 f f$., 208, 244

Inefficiency and pain, 194, 197

Instinct, CI. II., $67 \mathrm{f}$.

"Instinct feelings," 69

Intellectualism in æesthetics, 120, 130, 159

JAMES, IV., $7,11,60,72,73,76,78$, $84,85,88,91,236,279,351$

Joy, $70,71,293$

KAMES, 135,138

Kant, 103, 1]6, 120, 122, 124, 125 . $127,130,132 f ., 144,189$

Kirschmann, 12

LADD, 21, 130, 137, 148

Lange, $75,80,84$

Lehmann, 18, 19, 21, 25, 41, 54, S5, S8, $92,96,207,281,283,286$, 257,338

Leibnitz, 121, 177, 183 
Iessing, 336

Lévêque, 131

Lewes, 11, 249, 278, 289

Lipps, Th., 20, 21, 41, 50, 53, 135, 189 , $193,201,276,277$

Locke, 46, 47, 177,275

Lotze, 53, 117, 128, 147, 189, 195, $199,206,277,291,333,335$, 339

Love, 77,294

of life, 34

Ludicrous, 147, 258, 329

MaxtegazzA, 20, 34, 92, 24S

Martineau, 78, 79, IS6, 281

Mill, James, 56, 120, 129, 281

J. S., 7, 31, 94, 138, 146, 183, $275,278,281$

Morgan, Lloyd, 21, 67

Mosso, 75

Muscular sensations, 287

IIyers, 20

Nahlowsky, 189

Nentral excitement, 237

Nichols, H., 15, 18, 22, 24, 29

Novelty, 237

" Nutritive momentum," :10

\section{OEHWALL, 287}

PAIN and inefficiency, 194, 197

floating, 16

of excess, 172

of restriction, $17 \%, 195 \mathrm{f} ., 213 \mathrm{f}$. 233, 306

problem of, 356

Passivity, 135, 161

Paulhan, 83, 185

Pedagogical results, $34 \mathrm{~s}$

Permanency of pleasure and pain, 2:2

Picturesque, 342

Plato, 116, 173, 176, 295

Play, 103

"Play impulse," 103

Pleasure and efficieney, 19.1, 198

Pleasure and pain, and brain locus, 270

and evolutionary doctrine, 263,269

and intensity, 26, 44, 48

and health, $182 f$.

classed as emotions, 12

classed as sensations, 10, $15.7 f$.

classification of, Ch. I.

general qualities of all mental states, 45

not emotions, 32,90

not fundamental elements, 36 not mental states sui generis, 38

not sensations, 15, $23, \ddot{f}$.

organs of, $25.7 ., 47 f f ., 268 f$.

physical basis of, Ch. IV., $172, f$. $201, \pi .$, Ch. V., $221 f$.

relation to intellect, 13,35

relation to will, 13

revival and representation of, 29,53

subjectivity of, 41

Pleasure as ethical end, 352

l'leasures, higher and lower, $137 \mathrm{f}$., 161

of exercise, IS2, 191

of relief, 176

of rest, $195 f ., 209 f$.

Pleasure-prain and sensation, $284 f$. paths in sinal cord. 269

use of term, 9

Pleasure permanence, $149 . / \%$., 162

Positive asthetic laws, 324

Problem of pain, 356

Psychoses of limitation, 5

QUALITIEs of relation, $26 \%$

Ratioxalis in asthetics, 121, 159

Réiıl, I30

Relief, $70,76,294$

Reprose, 317

Representation of pleasure and pain, 29,53

Respiratory sensations, 290

Reynolis, 315

Phythm, 23I, 340

Romanes, 68

liood, xiv., 326

Rosenkranz, 309

Puskin, 131, 135, 144, 146

SATISFACTION, 235

of cravings, 308

of expectancies, 3.2

Schelling, 144

Schitf, 20

Schiller, 103, 140, 309, 310, 316

Schlegel, 309

Schleiermacher, 116,136

Schopenhauer, 177

Sichuelle, 10

Seripture, 7,52

Sensation and pleasure-pain, $28 . \mathrm{f}$.

Sensualism in athetics, 119, 128, 159

Shaftesbury, 119, 131

Shifting focus, 339

sidgwick, H., 185, 208, 246, 251, 253, $254,276,28 \mathrm{I}$

Sight, 291

Simplicity, 341 
Smell, 288

Smith, Adam, 135

Socrates, 146,174

Sorrow, $70,72,293$

Specific energies, 266

Spencer, 6, 11, 35, 37, 56, $59 f_{.,} 103 f_{\text {., }}$, $135,174,227,241,248,263$, $273,275,288,315 f ., 326$

Spinoza, 189

Stephen, L., 59, 79, 176, 281, 315

Stewart, 130,135

Stumpf, 6, 236

Style, 317

Subjectivity and pleasure-pain, 41

Sublime, 147, 297

Sully, xiii., 39, 58, 98, 125, 140, 236, $237,276,278,280,281,282$, $319,333,336^{\circ}$

Surprise, 77, 81, 237, 297

Symmetry, 340

Taine, 10,157

Taste, 287

Thirst, 290

Tickling, 285

Touch, 284

Trieb, 68, 275

Truth, 317

Tyndall, xiii.

Type portrayal 336

UGLY, 309

Unity, 237

of manifold, 121, 332

Usefulness, $134,160,315$

Utilitarianism, 353

VARIETY, 340

Véron, 136

da Vinci, xv.

Vintschgan, 287

Vividlness, 332

Volkmann, $7,41,68,178,195,275$, $278,281,282,339$

Von Hartmann, 120, 124, 131, 132, $134,140,155,246$

WAGNER, 100, 337, 343

Waitz, 7, 275, 281, 283

Ward, J., 6, 9, 10, 38, 41, 47, 51, 59, $138,188,236,240,262,276$, 282

Wilth of field in resthetics, 335

Wish, 279

Wit, 330

Wundt, $7,8,16,20,21,37,42,86$, $157,179,189,193,241,253$, 278,279

ZIEgLer, 37

Zöllner, 207

THE END

Printed by' R. \& R. C1AkK, Edinburgh. 




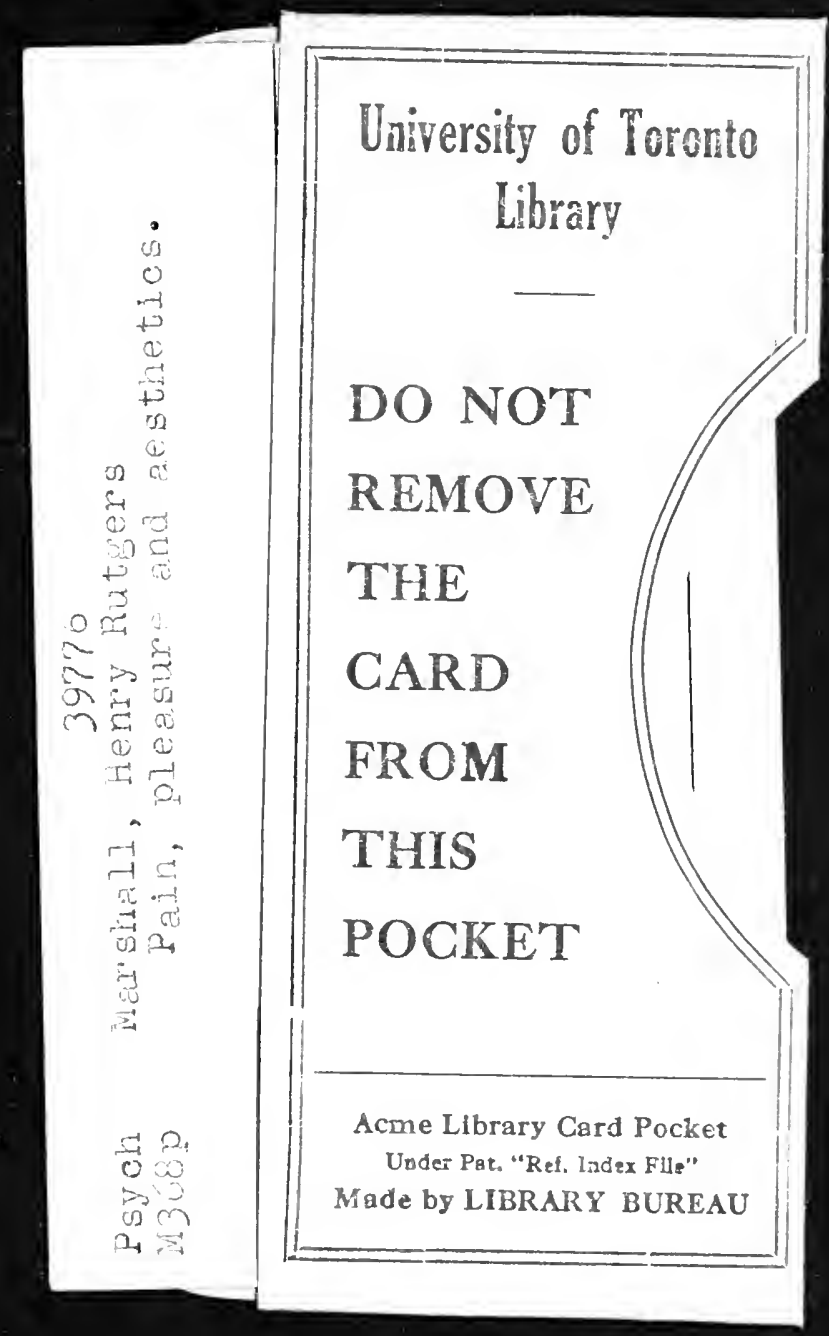




\section{$*$}

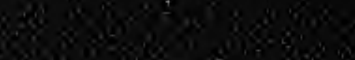

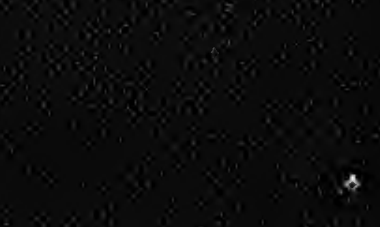

